FLÁVIO EDUARDO DA CRUZ

PRODUÇÃO DE HIDROGÊNIO EM REFINARIAS DE PETRÓLEO: AVALIAÇÃO EXERGÉTICA E CUSTO DE PRODUÇÃO 
FLÁVIO EDUARDO DA CRUZ

\title{
PRODUÇÃO DE HIDROGÊNIO EM REFINARIAS DE PETRÓLEO: AVALIAÇÃO EXERGÉTICA E CUSTO DE PRODUÇÃO
}

\author{
Dissertação apresentada à Escola \\ Politécnica da Universidade de São \\ Paulo para obtenção do título de \\ Mestre em Engenharia Mecânica
}

São Paulo 
Este exemplar foi revisado e alterado em relação à versão original, sob responsabilidade única do autor e com a anuência de seu orientador.

São Paulo, de maio de 2010.

Assinatura do autor

Assinatura do orientador

FICHA CATALOGRÁFICA

Cruz, Flávio Eduardo da

Produção de hidrogênio em refinarias de petróleo: avaliação exergética e custo de produção / F.E. da Cruz. -- ed.rev. -- São Paulo, 2010.

$164 \mathrm{p}$.

Dissertação (Mestrado) - Escola Politécnica da Universidade de São Paulo. Departamento de Engenharia Mecânica.

1. Hidrogênio 2. Refinarias 3. Termodinâmica 4. Custo industrial 5. Avaliação de processos I. Universidade de São Paulo. Escola Politécnica. Departamento de Engenharia Mecânica II. t. 


\section{PRODUÇÃO DE HIDROGÊNIO EM REFINARIAS DE} PETRÓLEO: AVALIAÇÃO EXERGÉTICA E CUSTO DE PRODUÇÃO

Dissertação apresentada à Escola Politécnica da Universidade de São Paulo para obtenção do título de Mestre em Engenharia Mecânica

Área de Concentração:

Energia e Fluidos

Orientador:

Prof. Dr. Silvio de Oliveira Jr. 
Dedico este trabalho às pessoas que amo 


\section{AGRADECIMENTOS}

Ao Prof. Dr. Silvio de Oliveira Jr. pela orientação, motivação e entusiasmo demonstrado ao longo deste período de trabalho. Agradeço também pela confiança em mim depositada, mesmo nos momentos mais difíceis da elaboração deste trabalho.

Agradeço à minha mãe Piedade da Conceição Pina pela educação, carinho e por me ensinar valores que só se aprende em família. Ao meu pai Antonio Sérgio da Cruz e aos meus irmãos Antônio Sérgio da Cruz Filho e Renata da Conceição Cruz pelo apoio, incentivo e suporte.

À minha futura esposa Rita Menezes pelo amor, compreensão, carinho e demonstrações de apoio incondicional à conclusão de mais esta etapa em minha vida.

À Promon Engenharia pelo apoio institucional e a seus profissionais, em especial aos Eng. Moises Falco, Eng. Franco Ferraro e Eng. Sergio Lunardi que se demonstraram grandes incentivadores desde o início da realização deste trabalho, além de toda contribuição técnica oferecida.

Ao colega Luiz Felipe Pellegrini e demais amigos do laboratório pelos batepapos esclarecedores a respeito de exergia e termoeconomia e pela ajuda nos momentos de dúvida e indecisão.

Aos meus amigos, pelos momentos de descontração e apoio. 


\section{RESUMO}

O hidrogênio molecular $\left(\mathrm{H}_{2}\right)$ é um gás muito útil nas indústrias químicas e petroquímicas por conta de sua facilidade de reação com outros elementos químicos. Nas refinarias é o principal insumo no processo de remoção do enxofre de diversos combustíveis como a gasolina e óleo diesel, tendo sua demanda aumentada por conta de novas legislações ambientalmente mais restritivas. O hidrogênio é normalmente encontrado na natureza associado a outros elementos químicos, como a água ou os hidrocarbonetos, sendo necessária a aplicação de processos específicos para sua obtenção. Considerada a rota mais econômica para a produção de hidrogênio, o processo de reforma a vapor do gás natural é avaliado pela aplicação da metodologia de análise exergética e termoeconômica, a fim de determinar a eficiência exergética do processo e o custo de produção do hidrogênio. Este custo de produção é muito sensível ao custo do gás natural, fato que pode prejudicar a competitividade desta rota de produção e, consequentemente, abrir a possibilidade de investir na produção de hidrogênio através de tecnologias alternativas. A unidade de geração de hidrogênio estudada está presente em uma das refinarias da Petrobras e sua produção destina-se à remoção do enxofre presente no óleo diesel. Uma planta síntese do processo foi elaborada e as eficiências exergéticas dos componentes foram determinadas. Em seguida, foi realizada uma análise econômica para determinar o custo de construção, operação e manutenção da planta. Com base nos resultados obtidos, aplicou-se a metodologia de análise termoeconômica para determinar o custo de produção de hidrogênio. Dois tipos de custo foram determinados, o custo atual (ou atualizado) de produção, que indica o custo corrente (2010) do produto, e o custo nivelado, que leva em consideração a produção total prevista ao longo vida útil da planta. Para um custo de gás natural igual a 9,11 US\$/GJ, o custo de produção do hidrogênio em base exergética foi igual a 17,36 US\$/GJ $(2.093,13$ US $\$ / t)$ para o valor atual e 25,35 US\$/GJ (3.056,97 US\$/t) para o valor nivelado. Por fim, estes valores são comparados com outros custos de produção de hidrogênio presentes na literatura.

Palavras-cheve: Hidrogênio. Refinaria. Termoeconomia. Exergia. Custo de produção. 


\section{ABSTRACT}

Pure hydrogen $\left(\mathrm{H}_{2}\right)$ is an useful gas in chemical and petrochemical industries because it reacts easily with several other elements. On refineries, hydrogen is used to sequestrate sulphur from diesel and gasoline. Emission restrictions regard to fossil fuels are rising the world hydrogen demands. In spite of its abundance, hydrogen is normally found associated with other chemical species like water or hidrocarbons like methane or butane. Some especific processes are required to obtain pure hydrogen. Considered the most economic production route, the natural gas reforming process is analyzed by exergetic and thermoeconomic methods in order to determine the efficiencies and the hydrogen production cost. The hydrogen production cost is very sensitive to the cost of natural gas, which has suffered constant increases due to rising demand. This fact opens the possibility of using technologies that were previously considered economically unviable. The hydrogen unit studied was constructed in one of the Petrobras refineries, and the hydrogen produced is for the removal of sulfur in diesel oil. Based on project documents exergetic efficiencies of each component were determined. After that, an economic analysis was conducted in order to determine the construction, operation and maintenance costs of the whole plant. Two types of cost were determined, the actual cost production, which indicates the current cost product (2010), and the levelized cost, which takes into account the total production over life of the plant. Considering a natural gas cost equal to 9.11 US $\$ / G J$, it was obtained an actual hydrogen production cost of 17.36 US $\$ / G J$ $(2,093.13$ US $\$ / t)$ and a levelized cost of 25.35 US $\$ / G J(3,056.97 \$ / t)$. These values were compared with some hydrogen production costs presents on scientific papers and related references.

Keywords: Hydrogen. Refinery. Thermoeconomy. Exergy. Cost Evaluation 


\section{LISTA DE FIGURAS}

Figura 3.1: Graf Zeppelin sobrevoando a baía da Guanabara em 1930 (WIKIPEDIA, 2009)

Figura 3.2: Consumo de hidrogênio por uso final em 2003 (\%) (ARGONNE NATIONAL LABORATORY, 2009)

Figura 3.3: Cadeia do hidrogênio aplicada ao setor de transportes (adaptado de ENERGY INFORMATION ADMINISTRATION, 2009)

Figura 3.4: Origem da produção de hidrogênio no mercado mundial em 2003 (\%) (NATIONAL HYDROGEN ASSOCIATION, 2009).

Figura 4.1: Limites de enxofre no diesel ao redor do mundo (retirado de MOVIMENTO NOSSA SÃO PAULO, 2009)

Figura 5.1: Planta síntese do processo de reforma do gás natural. 28

Figura 5.2: Foto de um sistema de PSA (retirado de UOP LLC, 2009) 32

Figura 5.3: Esquema lógico de um sistema de PSA (adaptado de MAHLER AGS, 2009) 33

Figura 8.1: Aplicação da metodologia de custo nivelado na comparação entre tecnologias diferentes de geração elétrica (AEO, 2010).

Figura 9.1: Volume de controle para o balanço de custos do P-01 98

Figura 9.2: Bifurcação do fluxo do "ponto 37" para alimentação dos MX-02 e MX-03 100

Figura 9.3: Volume de controle para o balanço de custos do P-03 101 
Figura 9.4: Volume de controle para o balanço de custos do P-04 e sistema de distribuição do fluxo de água desmineralizada (ponto 60). 102

Figura 9.5: Volume de controle para o balanço de custos do P-05 103

Figura 9.6: Volume de controle para o balanço de custos do P-07 104

Figura 9.7: Volume de controle para o balanço do sistema de tratamento de condensado do processo. 104

Figura 9.8: Volume de controle para o balanço do sistema de estocagem e controle de vapor 107

Figura 9.9: Bifurcação do fluxo do "ponto 41" para alim. do P-01 e exportação de vapor. 108

Figura 9.10: Volume de controle para o balanço de custos do forno reformador 109 


\section{LISTA DE TABELAS}

Tabela 3.1 - Aplicações do hidrogênio na indústria 8

Tabela 3.2 - Processos presentes no hidrotratamento de derivados do petróleo

Tabela 4.1- Fases do programa de controle de emissões veiculares Proconve (INSTITUTO ESTADUAL DO AMBIENTE, 2009)......24

Tabela 7.1- Valores obtidos na análise exergética por ponto do processo ....50

Tabela 7.2- Valores obtidos na análise exergética por ponto de entrada e saída do processo

Tabela 7.3- Taxa de exergia destruída em cada componente 52

Tabela 7.4- Eficiências exergéticas de cada componente e na planta como um todo. .56

Tabela 7.5 - Taxa de exergia destruída em cada componente para a planta de menor capacidade $\left(550.000 \mathrm{Nm}^{3} / \mathrm{dia}\right)$ (CRUZ; OLIVEIRA JR., 2008).

Tabela 7.6 - Eficiências Exergéticas para a planta de menor capacidade $\left(550.000 \mathrm{Nm}^{3} /\right.$ dia) (CRUZ; OLIVEIRA JR., 2008).

Tabela 8.1- Custos do empreendimento estudado - Definição do escopo .61

Tabela 8.2 - Custos dos equipamentos da UGH. .63

Tabela 8.3 - Custo total por item declarado no escopo de custos. 65

Tabela 8.4 - Avaliação da incerteza da estimativa de custos. 67

Tabela 8.5 - Índice de construção para refinarias Nelson-Farrar (FARRAR, 2009) .69 
Tabela 8.6 - Amortização do investimento pelo sistema de amortização constante

Tabela 8.7 - Amortização do investimento pelo sistema de pagamentos constantes.

Tabela 8.8 - Custos de operação e manutenção considerados para a planta.

Tabela 8.9 - Resumo dos parâmetros da análise econômica. 84

Tabela 8.10 - Custo total de produção de hidrogênio por ano de vida útil da planta.

Tabela 8.11 - Custo de matéria prima: valor atual e valor total. 88

Tabela 8.12 - Custo nivelado anual de produção de hidrogênio - Somatória das parcelas de amortização do investimento e operação e manutenção.

Tabela 8.13 - Custo total de construção da planta distribuído pelos equipamentos.

Tabela 8.14 - Custo atualizado (const. e oper.) por equipamento, por ano. ..92

Tabela 8.15 - Custo nivelado (const. e oper.) por equipamento, por ano. .....93

Tabela 8.16 - Custo atualizado (const. e oper.) por equipamento, por hora. .94

Tabela 8.17 - Custo nivelado (const. e oper.) por equipamento, por hora. ....95

Tabela 9.1 - Custo exergético atualizado total por fluxo da planta estudada. 115

Tabela 9.2 - Custo exergético total por produto principal (atualizado). 116

Tabela 9.3 - Custo exergético nivelado total por fluxo da planta estudada..117

Tabela 9.4 - Custo exergético total por produto principal (nivelados). 118 
Tabela 9.5 - Custo horário dos produtos e insumos da planta (atualizado). 119

Tabela 9.6 - Custo horário dos produtos e insumos da planta (nivelado)...119

Tabela 9.7 - Custo anual de produção da UGH estudada. Relação dos custos de constução, operação e manutenção com o custo anual total. 120

Tabela 9.8 - Avaliação da incerteza sobre o custo anual de produção da UGH

Tabela 9.9 - Custo dos produtos da unidade de geração de hidrogênio de $550.000 \mathrm{Nm}^{3} /$ dia (CRUZ; OLIVEIRA JR., 2008). 122

Tabela 9.10 - Custo atualizado dos produtos da unidade de geração de hidrogênio de $1.200 .000 \mathrm{Nm}^{3} / \mathrm{dia}$. 123

Tabela 9.11 - Custo dos produtos da UGH de $550.000 \mathrm{Nm}^{3} / \mathrm{dia}$ (CRUZ; OLIVEIRA JR., 2008) corrigidos pela inflação acumulada entre 2003 e 2009. 123

Tabela 9.12 - Custo dos produtos da UGH estudada $\left(1.200 .000 \mathrm{Nm}^{3} / \mathrm{dia}\right)$ considerando o valor do gás natural igual a 2,97 US\$/GJ......125 


\section{LISTA DE ABREVIATURAS E SIGLAS}

AEO: $\quad$ American Energy Outlook (EUA)

ANEEL: $\quad$ Agência Nacional de Energia Elétrica

ANP: $\quad$ Agência Nacional do Petróleo

BNDES: Banco Nacional de Desenvolvimento Econômico e Social

Conama: Conselho Nacional do Meio Ambiente

Conpet: $\quad$ Programa Nacional de Racionalização do Uso dos Derivados do Petróleo e do Gás Natural

CEPCl: $\quad$ Chemical Engineering Plant Cost Index (EUA)

EPA: $\quad$ Environmental Protection Agency (EUA)

GEE: $\quad$ Gases de efeito estufa

GLP: $\quad$ Gas liquefeito de petróleo

HDT: $\quad$ Unidade de Hidrotratamento de Diesel

IPCC: $\quad$ Intergovernmental Panel on Climate Change - ONU

MME: $\quad$ Ministério de Minas e Energia

MMSCFPD: Millions square cubic feet per day (Milhões de pés-quadrados padrão por dia)

NFI: $\quad$ Nelson-Farrar Index (Índice Nelson-Farrar)

Proconve: Programa de controle da poluição do ar por veículos automotores

PCl: $\quad$ Poder calorífico inferior

PSA: $\quad$ Pressure Swing Adsorption (sistema de adsorsão por diferença de pressão)

SAC: $\quad$ Sistema de amortização constante

TJLP: $\quad$ Taxa de juros de longo prazo

UGH: $\quad$ Unidade de Geração de Hidrogênio

URAA: Unidade de Retificação de Águas Ácidas 


\section{LISTA DE SÍMBOLOS}

$\dot{n}_{\text {i: }} \quad$ Vazão Molar (kmol/s);

$y$ : $\quad$ Fração Molar;

$R$ : $\quad$ Constante universal dos gases $(\mathrm{kJ} / \mathrm{kmol} . \mathrm{K})$;

$h_{i}$ : Entalpia específica de um produto, mistura de gases ou insumo $(\mathrm{kJ} / \mathrm{kg})$ ou $(\mathrm{kJ} / \mathrm{kmol})$;

$s_{i}$ : $\quad$ Entropia específica de um produto, mistura de gases ou insumo $(\mathrm{kJ} / \mathrm{kg} . \mathrm{K})$ ou (kJ/kmol.K);

$h_{0}$ : Entalpia específica de um produto, mistura de gases ou insumo no estado de referência termodinâmico $(\mathrm{kJ} / \mathrm{kg})$ ou $(\mathrm{kJ} / \mathrm{kmol})$;

$s_{0}$ : $\quad$ Entropia específica de um produto, mistura de gases ou insumo no estado de referência termodinâmico ( $\mathrm{kJ} / \mathrm{kg} . \mathrm{K})$ ou $(\mathrm{kJ} / \mathrm{kmol} . \mathrm{K})$;

$T_{0}$ : $\quad$ Temperatura do ambiente idealizado $(\mathrm{K})$;

$T: \quad$ Temperatura no ponto de interesse $(\mathrm{K})$;

$\dot{B}$ : $\quad$ Fluxo de exergia $(\mathrm{kW})$;

$\dot{B}_{p h}: \quad$ Fluxo de exergia física(kW);

$\dot{B}_{c h}: \quad$ Fluxo de exergia química(kW);

$\dot{B}_{k}$ : $\quad$ Fluxo de exergia cinética $(\mathrm{kW})$;

$\dot{B}_{p}: \quad$ Fluxo de exergia potencial $(\mathrm{kW})$;

Б: $\quad$ Exergia específica molar $(\mathrm{kJ} / \mathrm{kmol})$

$\dot{B}_{i}$ : $\quad$ Fluxo de exergia em um determinado ponto do sistema (kW);

$\varepsilon_{i}$ : $\quad$ Eficiência exergética de um determinado sistema ou componente;

Q: $\quad$ Taxa de transferência de calor $(\mathrm{kW})$;

Z: $\quad$ Fluxo de custos de equipamentos (US $\$ / s)$ ou (US $\$ / h)$;

$\dot{C}_{\text {i }}$ : $\quad$ Custo por unidade de tempo de um insumo ou produto (US $\$ / \mathrm{s}$ ) ou (US $\$ / \mathrm{h}$ );

$S_{\text {gerado }}$ Taxa de entropia gerada em determinado processo/sistema $(\mathrm{kJ} / \mathrm{kmol} . \mathrm{K})$;

$\dot{B}_{\text {destruida }}$ Taxa de exergia destruída $(\mathrm{kW})$;

$c_{i}$ : $\quad$ Custo em base exergética de um insumo ou produto (US $\left.\$ / G J\right)$;

$W_{i}$ : Trabalho realizado/consumido em determinado componente do sistema $(\mathrm{kW})$;

MM: Massa molecular $(\mathrm{kg} / \mathrm{kmol})$;

$\psi_{i}$ : Exergia química padrão de cada substância $(\mathrm{kJ} / \mathrm{kmol})$; 
$\alpha: \quad$ Coeficiente estequiométrico de determinado elemento na reação;

$\beta$ : $\quad$ Coeficiente estequiométrico de determinado elemento na reação;

$\gamma$ : Coeficiente estequiométrico de determinado elemento na reação;

$f_{a}: \quad$ Fator de amortização;

i: $\quad$ Taxa de juros;

n: $\quad$ Prazo de amortização;

FRC: Fator de recuperação de capital. 


\section{SUMÁRIO}

AGRADECIMENTOS ......................................................................

RESUMO

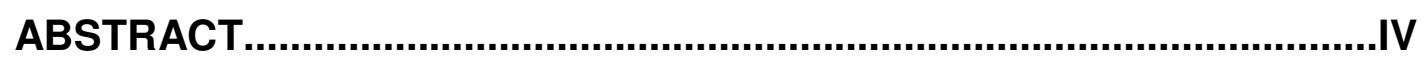

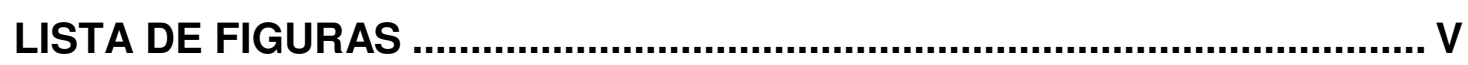

LISTA DE TABELAS........................................................................... VII

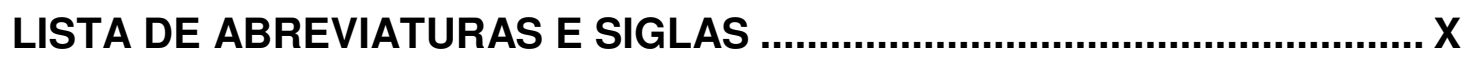

LISTA DE SÍMBOLOS ....................................................................... XI

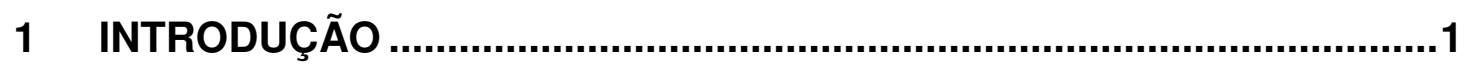

1.1 CONTEXTO GERAL E RELEVÂNCIA …………………..................................... 1

1.2 DIVISÃO DOS CAPÍTULOS ..................................................................................

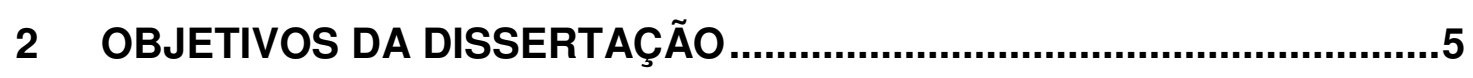

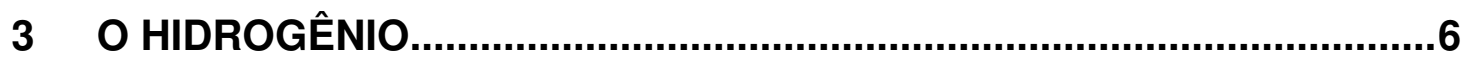

3.1 BREVE HISTÓRICO E PERSPECTIVAS FUTURAS............................................... 6

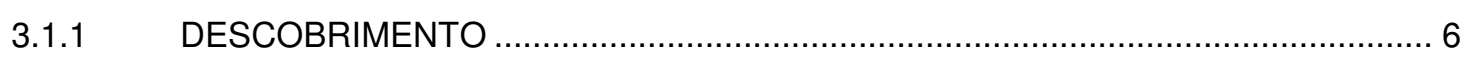

3.1.2 PRIMEIRAS APLICAÇÕES …………………………………………….... 7

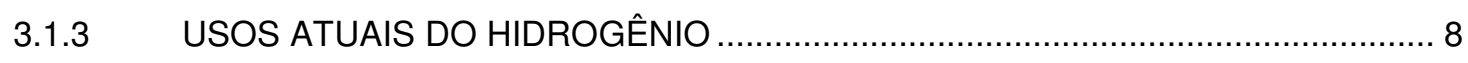

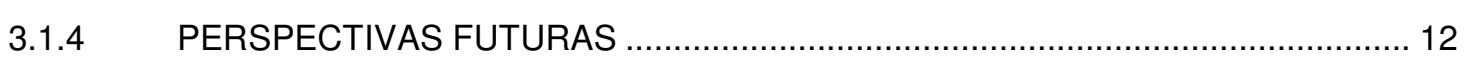

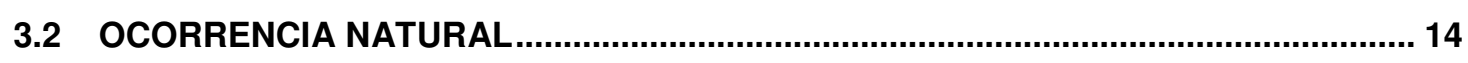

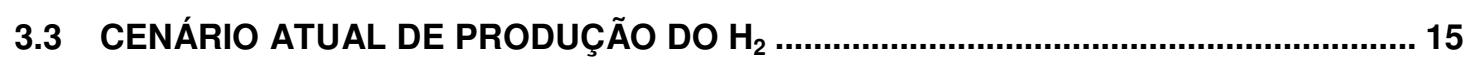

3.4 PROCESSOS PRODUTIVOS ......................................................................... 17

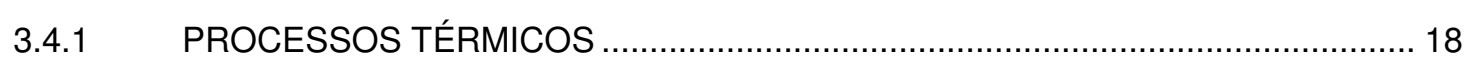




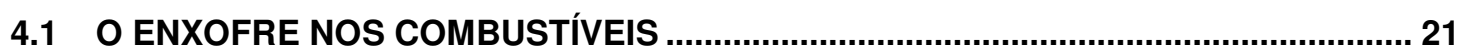

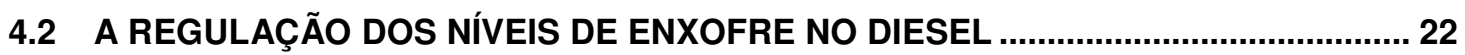

4.2.1 O BRASIL E O CENÁRIO MUNDIAL …......................................................... 22

4.2.2 O PROCONVE E AS RESOLUÇÕES CONAMA ................................................ 23

4.2.3 A REMOÇÃO DO ENXOFRE DO DIESEL E O CONSUMO DE $\mathrm{H}_{2}$ NO REFINO DE PETRÓLEO

5 PLANTA SÍNTESE E DESCRIÇÃO DO PROCESSO DE REFORMA ...27

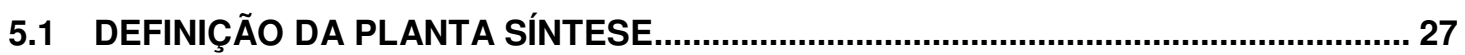

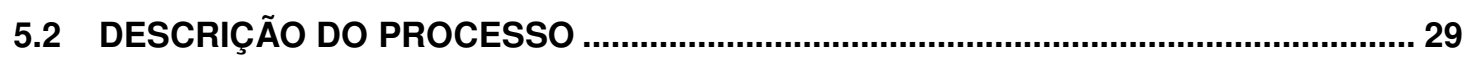

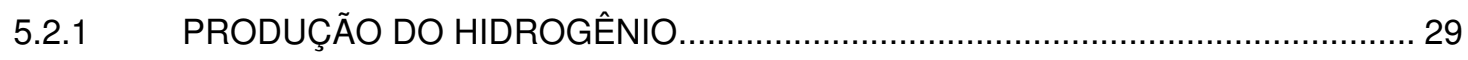

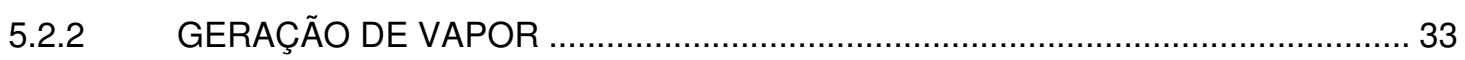

5.2.3 ALIMENTAÇÃO DOS QUEIMADORES DO FORNO REFORMADOR.................. 34

5.2.4 TRATAMENTO DO CONDENSADO DO PROCESSO ........................................ 35

6 ANÁLISE EXERGÉTICA E TERMOECONÔMICA ................................36

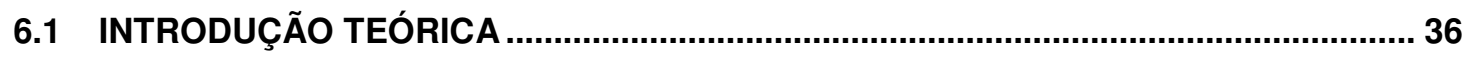

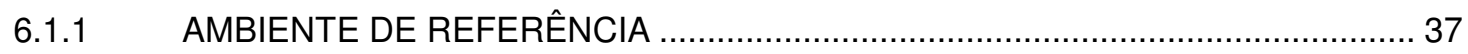

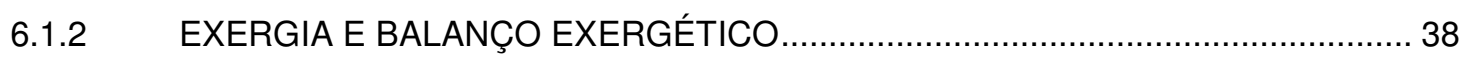

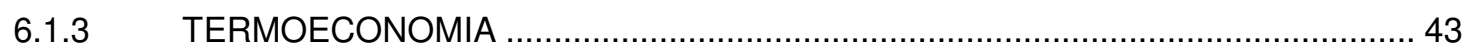

6.1.4 METODOLOGIAS DE CUSTEIO EM BASE EXERGÉTICA …............................. 46

6.2 BASES E PREMISSAS DA ANÁLISE REALIZADA

7 ANÁLISE EXERGÉtICA DA UNIDADE DE GERAÇÃO DE HIDROGÊNIO.......................................................................49

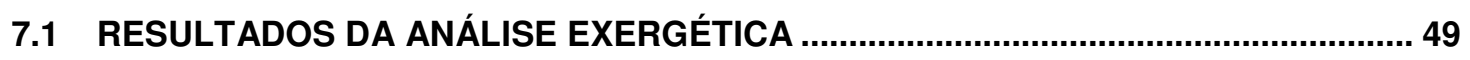

7.2 DISCUSSÃO DOS RESULTADOS OBTIDOS NA ANÁLISE EXERGÉTICA DA PLANTA DE GERAÇÃO DE HIDROGÊNIO.......................................... 57

8 ANÁLISE ECONÔMICA DA UNIDADE DE GERAÇÃO DE HIDROGÊNIO..................................................................60

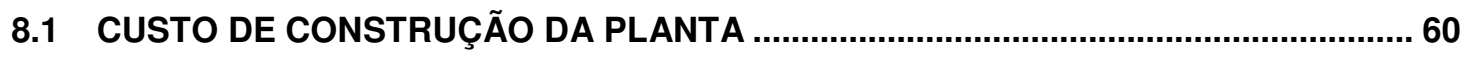




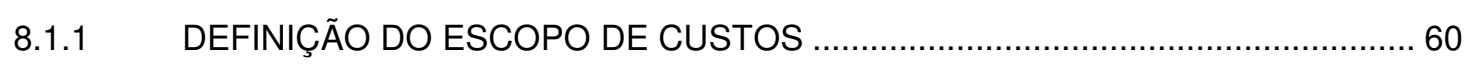

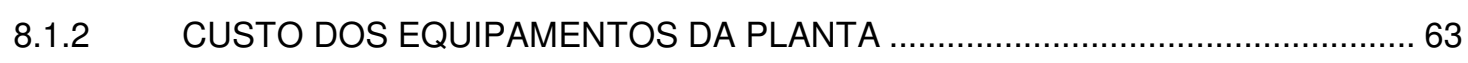

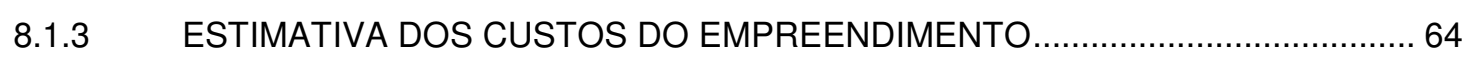

8.1.4 DETERMINAÇÃO DE DESVIOS E DISCUSSÃO DOS RESULTADOS.................. 66

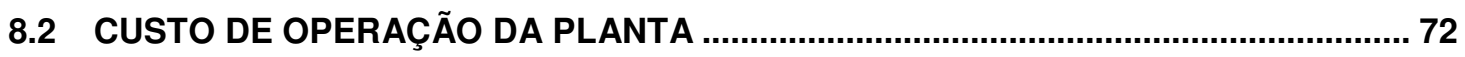

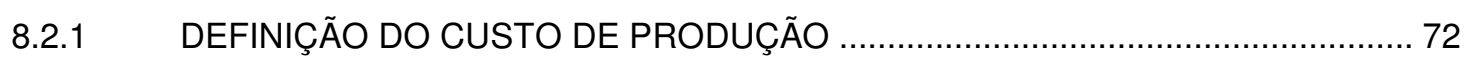

8.2.2 DEFINIÇÃO DAS VARIÁVEIS ECONÔMICAS …............................................... 73

8.2.3 PROCESSO DE AMORTIZAÇÃO DO CAPITAL INVESTIDO …............................ 76

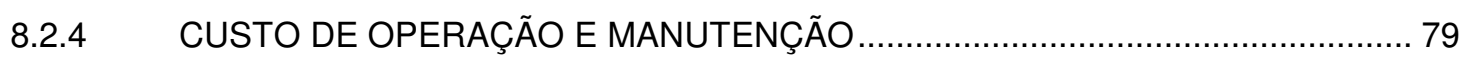

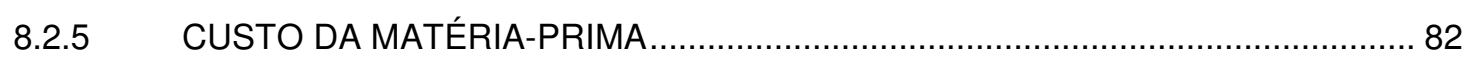

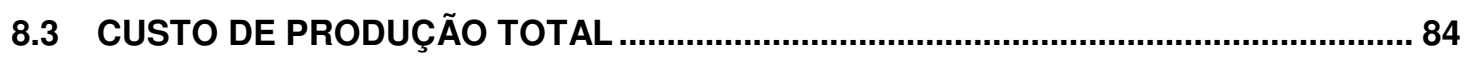

8.4 REDEFINIÇÃO DOS CUSTOS DOS EQUIPAMENTOS DA PLANTA ......................... 90

9 ANÁlise TERMOECONÔMICA DA UNIDADE DE GERAÇÃo DE HIDROGÊNIO.......................................................................96

9.1 BALANÇO DE CUSTO EXERGÉTICO DOS EQUIPAMENTOS DA PLANTA ............. 97

9.1.1 DESCRIÇÃO DAS PREMISSAS ADOTADAS NA APLICAÇÃO DOS MÉTODOS DE PARTIÇÃO.................................................................................. 97

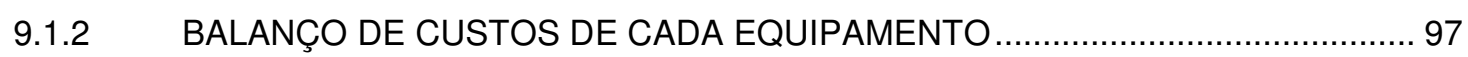

9.1.3 CONSOLIDAÇÃO DAS EQUAÇÕES APRESENTADAS ................................... 110

9.1.4 REPRESENTAÇÃO DO SISTEMA LINEAR NA FORMA MATRICIAL ................. 113

9.2 DETERMINAÇÃO DOS CUSTOS DE CADA FLUXO DA UNIDADE DE GERAÇÃO DE HIDROGÊNIO ............................................................................... 115

9.2.1 DETERMINAÇÃO DOS CUSTOS DE PRODUÇÃO ATUAIS ............................... 115

9.2.2 DETERMINAÇÃO DOS CUSTOS DE PRODUÇÃO NIVELADOS ....................... 116

9.3 DISCUSSÃO DOS RESULTADOS OBTIDOS NA ANÁLISE TERMOECONÔMICA DA

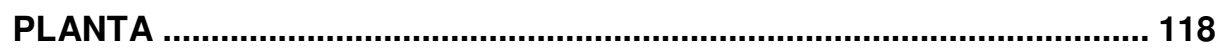

9.3.1 VERIFICAÇÃO DE CONSISTÊNCIA DOS RESULTADOS ................................ 118

9.3.2 DISCUSSÃO SOBRE AS INCERTEZAS DOS RESULTADOS

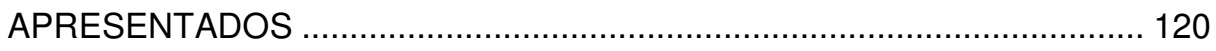

9.3.3 COMPARAÇÃO DOS RESULTADOS COM OUTROS PRESENTES NA

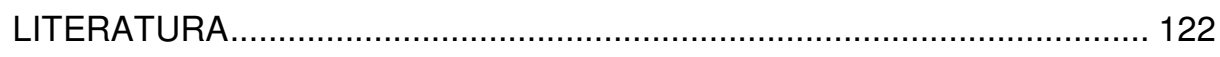

10 CONCLUSÕES.......................................................................128 


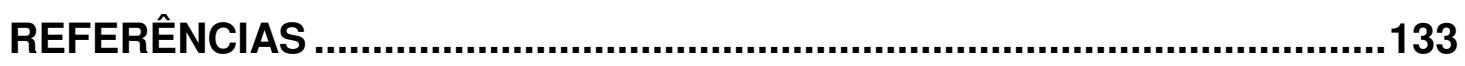

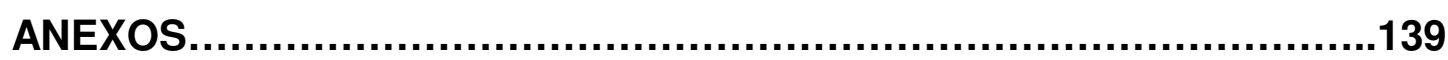




\section{INTRODUÇÃO}

\subsection{CONTEXTO GERAL E RELEVÂNCIA}

Ao longo de sua existência na Terra o homem vem mostrando sua capacidade de adaptação e transformação. Tal capacidade se apresenta na forma única com a qual os seres humanos se relacionam com o meio-ambiente, modificando-o de acordo com suas necessidades de conforto, mobilidade, prestígio, poder, conhecimento e sobretudo conforme suas necessidades de sobrevivência.

Atualmente, a maioria dos países do mundo tem seu modelo socioeconômico baseado no consumo de bens e serviços. Como resultado, as ações do homem sobre o meio ambiente e o uso dos recursos naturais vem se intensificando, causando impactos nos ciclos naturais de formação e de recomposição desses elementos.

Em fevereiro de 2007 foi divulgado pelo IPCC, órgão das Nações Unidas responsável pelo estudo das mudanças climáticas, que as atividades antropogênicas são, com $90 \%$ de certeza, as responsáveis pelo aquecimento global e pelas mudanças climáticas ocorridas ao longo dos últimos anos.

Com o crescente foco da opinião pública sobre o assunto, medidas de caráter mitigatório vêm sendo tomadas por governos e por entidades privadas no sentido de reduzir os impactos gerados pelas atividades humanas nas mais diversas áreas: produção, transporte, energia, etc.

As ações de governo podem ser de incentivo, reduzindo a incidência de impostos sobre produtos ambientalmente mais eficazes, ou de fomento, financiando a produção de energia por fontes renováveis, por exemplo. Outras ações podem ser de caráter social, incentivando redes de pequenos produtores, ou ainda de caráter regulatório, limitando o uso de determinadas matérias primas ou restringindo os níveis de emissão de determinados poluentes.

Um caso recente envolvendo medidas de caráter regulatório, protagonizada pela Agencia Nacional do Petróleo, Gás Natural e Biocombustíveis (ANP), foi a 
edição da resolução ANP 32/2007 (BRASIL, 2007), que reduziu drasticamente os níveis permitidos de enxofre no diesel produzido no Brasil.

A tecnologia mais empregada na remoção de enxofre do diesel utiliza o hidrogênio como elemento de captura do enxofre. Para atender a essa nova regulação muitas refinarias estão ampliando sua produção de hidrogênio visando garantir a disponibilidade deste elemento e 0 atendimento à nova regulação.

O hidrogênio raramente é encontrado na natureza em sua forma molecular $\left(\mathrm{H}_{2}\right)$, sendo normalmente encontrado associado a outros elementos como a água, hidrocarbonetos, ácidos e alcoóis. O processamento industrial de algum destes elementos torna-se necessário para obter o hidrogênio puro. Os processos mais utilizados em escala industrial são a eletrólise da água e a reforma do metano.

Além da demanda atual do hidrogênio, novas perspectivas se abrem para a utilização deste elemento como energético. Pesquisadores de diversos países acreditam que o hidrogênio terá um papel de destaque num cenário de escassez de petróleo. Em seu artigo, Neef (2009) faz referência a este cenário e cita o hidrogênio como um aliado na diversificação da matriz energética e na conseqüente redução da dependência do petróleo:

A batalha por petróleo está a pleno vapor. Nenhum país do mundo importa
e consome tanto petróleo como os Estados Unidos. A dependência da
Europa Ocidental sobre o petróleo importado está aumentando. As
economias emergentes China e Îndia demandam cada vez mais novas
fontes de energia e importam mais e mais petróleo. [...] O mundo teme as
mudanças climáticas. Lutar contra essas mudanças tornou-se prioridade
máxima nos países ricos. Os países em desenvolvimento reconhecem o
problema como uma ameaça, enquanto os países pobres têm prioridades
diferentes. Mas ninguém desenvolveu uma abordagem completa
localizando as dificuldades das mudanças climáticas. [...] Pode o hidrogênio
contribuir para balancear a matriz energética e aliviar a dependência na
energia importada? Assim como a eletricidade e o calor, o hidrogênio pode
ser produzido a partir de uma variedade de energias primárias.
Conseqüentemente, se for possível desenvolver uma forma rentável e
ambientalmente amigável de produzir hidrogênio a partir de fontes fósseis,
renováveis ou até nucleares, isso já seria um passo adiante. (NEEF, 2009,
p.327)

Diante deste cenário de aumento de demanda e de novas perspectivas de uso o estudo detalhado da produção do hidrogênio torna-se extremamente relevante. A comparação entre rotas de produção diferentes, otimização energética da produção, estudos de viabilidade econômica e a obtenção criteriosa do custo real de produção do hidrogênio são, certamente, temas de grande interesse para a 
sociedade na medida em que se buscam alternativas para reduzir os impactos ambientais através da utilização criteriosa deste elemento químico.

Dentro deste contexto, este trabalho pretende determinar de maneira racional qual o custo efetivo de produção do hidrogênio em uma refinaria utilizando para isso uma metodologia baseada nos conceitos de análise exergética e termoeconomia.

\subsection{DIVISÃO DOS CAPÍTULOS}

Segue abaixo um breve descritivo dos capítulos presentes nesta dissertação:

Capítulo 1: Apresenta o tema abordado descrevendo suscintamente o contexto e a relevância do estudo da produção de hidrogênio.

Capítulo 2: Aponta claramente os objetivos da presente dissertação.

Capítulo 3: Discute a respeito da importância do hidrogênio. Apresenta um breve histórico, a utilização atual e as perspectivas futuras de utilização deste elemento químico. Descreve também os processos produtivos disponíveis e trás uma visão geral da produção atual de hidrogênio no mundo.

Capítulo 4: Trás um enfoque mais profundo sobre o contexto e a relevância do tema. Relaciona a utilização do hidrogênio com a remoção do enxofre no óleo diesel e discute a perspectiva de aumento da demanda causada por restrições na legislação ambiental.

Capítulo 5: Mostra a planta síntese e descreve o processo de produção do hidrogênio em uma UGH (unidade de geração de hidrogênio).

Capítulo 6: Introduz os conceitos de análise exergética e termoeconômica. Apresenta as bases teóricas utilizadas no desenvolvimento da metodologia empregada na avaliação da produção do hidrogênio. 
Capítulo 7: Apresenta os resultados da análise exergética da unidade de geração de hidrogênio. Neste capítulo são determinadas as exergias de cada um dos fluxos da planta, bem como a eficiência exergética de cada um dos equipamentos utilizados no processo, bem como a eficiência exergética global.

Capítulo 8: Determina os dados econômicos da planta: custo de implantação, construção, compra de equipamentos, custos previstos de operação e manutenção, entre outros. Expõe as hipóteses e premissas utilizadas na obtenção destes dados.

Capítulo 9: Aplica a metodologia de análise termoeconômica apresentada no capítulo 5, em conjunto com os dados obtidos ao longo dos capítulos 7 e 8 para determinar os custos dos produtos da planta.

Capítulo 10: Apresenta as conclusões e considerações finais deste trabalho.

Anexo I: Apresenta o código fonte do modelo computacional desenvolvido para avaliar o sistema estudado. 


\section{OBJETIVOS DA DISSERTAÇÃO}

Este trabalho tem como objetivo determinar a eficiência dos processos de conversão de energia e o custo de produção do hidrogênio em uma refinaria utilizando a metodologia de análise exergética e termoeconômica.

A unidade de geração de hidrogênio (UGH) estudada utiliza o processo de reforma a vapor do gás natural, considerado por muitos como sendo a rota de produção mais econômica dentre os processos de produção de hidrogênio atuais e, reconhecidamente, o processo de produção mais aplicado dentro das refinarias.

A planta em questão, objeto deste estudo, é responsável por produzir $1.200 .000 \mathrm{Nm}^{3} /$ dia de hidrogênio com $99,9 \%$ de pureza (apenas $0,01 \%$ do fluxo não corresponde ao elemento $\mathrm{H}_{2}$ ) que por sua vez será utilizado na redução do enxofre presente no óleo diesel produzido na refinaria.

Este trabalho se propõe a utilizar a metodologia de análise termoeconômica para determinar dois tipos distintos de custo de produção do hidrogênio, chamados de custos atuais (ou atualizados) e custos nivelados.

O custo atual considera apenas os valores relativos ao ano corrente da análise (2010), sendo um bom parâmetro para formação de preços, por exemplo. O custo nivelado considera toda a produção e todos os custos ocorridos (ou que venham a ocorrer) ao longo do ciclo de vida da planta. Como poderá ser visto ao longo deste trabalho, a determinação do custo pode facilitar a comparação entre tecnologias distintas.

Adicionalmente, serão propostas alternativas que permitam aumentar o rendimento exergético global do processo nos locais onde houver potencias não desprezíveis de aproveitamento, com o intuito de reduzir o custo de produção do hidrogênio.

Por fim, a avaliação executada procura deixar um espaço para que trabalhos futuros comparem o custo de produção do hidrogênio obtido pelo processo de reforma com outros processos tecnológicos, inclusive utilizando outros elementos como insumo básico. 


\section{O HIDROGÊNIO}

O hidrogênio é o mais leve dos elementos químicos, possuindo apenas um único próton, um elétron e nenhum nêutron em sua forma estável mais comum, também conhecido como prótio. Em compostos iônicos pode ter uma carga positiva (se tornando um cátion) ou uma carga negativa (se tornando o ânion conhecido como hidreto). Também pode formar outros isótopos, como o deutério, com apenas um nêutron, e o trítio, com dois nêutrons.

\subsection{BREVE HISTÓRICO E PERSPECTIVAS FUTURAS}

\subsubsection{Descobrimento}

Alguns cientistas já haviam produzido hidrogênio antes mesmo dele ser reconhecido como um elemento químico. Registros escritos em 1671 indicam que Robert Boyle produziu hidrogênio enquanto fazia experimentos com ferro e ácidos. Ainda assim, o hidrogênio só foi caracterizado e reconhecido pela primeira vez como um elemento distinto por Henry Cavendish, em 1766.

Nos anos seguintes Cavendish se dedicou ao estudo de sua descoberta, inicialmente batizada de "ar inflamável". Em 1781 ele provou que o gás produzia água quando queimado. Em 1783 o experimento de Cavendish foi reproduzido por Pierre Simon Laplace e Antoine Lavoisier. Este último deu ao elemento químico o nome de hidrogênio, sintetizando na união das palavras gregas "hidro" (água) e "genes" (gerar) o resultado daquele experimento. 


\subsubsection{Primeiras aplicações}

Dentre suas aplicações iniciais do hidrogênio destacam-se a lâmpada de Döbereiner e a utilização no setor de transporte aéreo.

A lâmpada de Döbereiner foi inventada pelo químico alemão Johann Wolfgang Döbereiner em 1823. Esta lâmpada foi produzida até cerca de 1880. Seu funcionamento baseava-se na reação entre o zinco e o ácido sulfúrico, que produzia gás hidrogênio. Uma válvula regulava a saída de hidrogênio que era queimado, iluminando o ambiente. A ignição utilizava platina como catalizador da queima.

No setor de transporte aéreo o hidrogênio teve ampla utilização como gás de levantamento de balões. A invenção do primeiro dirigível decolado com este gás, em 1852, proporcionou a primeira maneira confiável de viagem aérea.

No início do século XX, o conde alemão Ferdinand von Zeppelin promoveu a idéia de usar o hidrogênio em dirigíveis rígidos (mais tarde chamados de Zeppelins), o primeiro dos quais teve seu vôo inaugural em 1900. Vôos programados regularmente começaram em 1910 e com o surgimento da Primeira Guerra Mundial em agosto de 1914, dirigíveis levantados por hidrogênio foram usados como plataformas de observação e ataque durante a guerra (WIKIPEDIA, 2009).

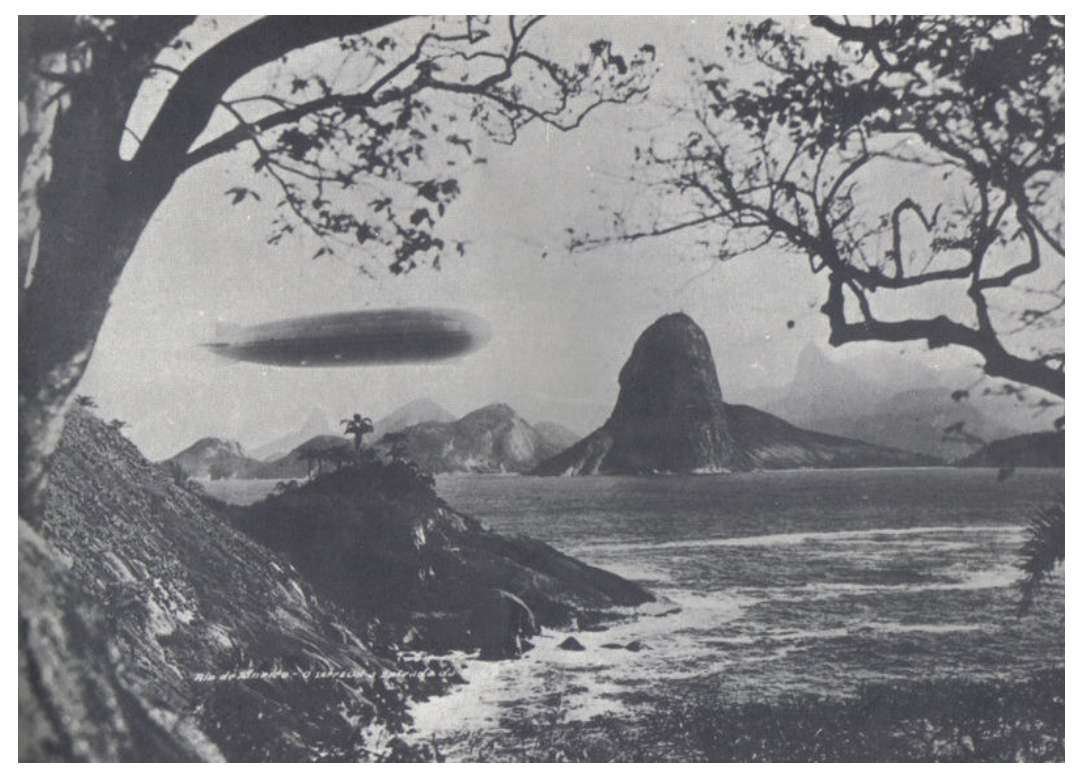

Figura 3.1: Graf Zeppelin sobrevoando a baía da Guanabara em 1930 (WIKIPEDIA, 2009)

A primeira travessia transatlântica sem escalas foi realizada pelo dirigível britânico R34 em 1919. Com o lançamento do Graf Zeppelin nos anos 20 foi 
instituído um serviço regular de transporte de passageiros entre a Frankfurt na Alemanha e a cidade do Rio de Janeiro no Brasil. Esta rota funcionou até meados dos anos 30 sem nenhum acidente (WIKIPEDIA, 2009).

A era do hidrogênio no setor de transporte aéreo foi encerrada com acidente do dirigível Hindenburg, que foi destruído em pleno vôo sobre New Jersey no dia 6 de maio de 1937. Além deste acidente, a concorrência com aviões mais robustos, rápidos e confiáveis contribuiu fortemente para o desaparecimento dos dirigíveis (WIKIPEDIA, 2009).

\subsubsection{Usos atuais do hidrogênio}

Atualmente o hidrogênio tem um papel importante na indústria, sendo aplicado em diversos segmentos como insumo químico ou como energético. As aplicações mais comuns do hidrogênio estão indicadas na tabela 3.1.

Tabela 3.1 - Aplicações do hidrogênio na indústria

\begin{tabular}{|c|c|}
\hline Segmento & Aplicação \\
\hline Refino de Petróleo & Remoção de enxofre de combustíveis (dessulfurização) e hidrocraqueamento \\
\hline Processos Químicos & Fabricação de amônia, metanol, cloro e soda cáustica \\
\hline Indústria Farmaceutica & Fabricação de Sorbitol, utizado em cosméticos, vitaminas, sulfactantes \\
\hline Indústria Alimentícia & Utilizado na hidrogenação de óleos e no aumento da saturação de gorduras \\
\hline Processos Metalúrgicos & \begin{tabular}{c} 
Agente redutor de minérios metálicos \\
\hline Indústria Eletrônica
\end{tabular} \\
\hline Geração de Energia & $\begin{array}{r}\text { Utilizado no processo de fabricação de semicondutores } \\
\text { Utilizado como fonte de energia térmica em queimadores ou } \\
\text { como insumo de células a combustivel }\end{array}$ \\
\hline
\end{tabular}

Além das aplicações já citadas, o hidrogênio também está associado a algumas demandas de pequenos nichos como a fabricação de combustível aeroespacial, aplicações criogênicas e processos de soldagem.

Apesar da variedade de aplicações possíveis, cerca de 99\% da produção mundial de hidrogênio é utilizada pelas indústrias química e petroquímica (U.S. 
DEPARTMENT OF ENERGY, 2009). Isso se deve principalmente à escala de consumo destes dois setores quando comparados com os demais. A intensidade do consumo destes setores é tão grande que a maior parte das instalações de produção de hidrogênio está localizada em refinarias e pólos petroquímicos, o que assegura o fornecimento deste insumo aos processos e reduz os riscos de quebra da produção.

A produção e recuperação de hidrogênio são essenciais no processo de refino do petróleo. Os processos de hidrogenação (utilizam $\circ \mathrm{H}_{2}$ como insumo principal) são responsáveis pela conversão de hidrocarbonetos pesados em frações mais leves (craqueamento) e pela remoção de elementos tóxicos dos combustíveis.

Uma vez que a demanda por gasolina e diesel é maior que a do óleo combustível, o aumento da produtividade destes elementos em detrimento da produção de óleos pesados é extremamente positivo do ponto de vista econômico e determinante na lucratividade da indústria petrolífera.

Existem fundamentalmente quatro processos básicos que possibilitam a conversão de hidrocarbonetos pesados (DOCEKAL, 1986), em sua maioria compostos por óleo lubrificante e gasóleo pesado provenientes da destilação fracionada do petróleo cru, em frações mais leves:

- Craqueamento catalítico;

- Hidrocraqueamento;

- Viscorredução;

- Coqueamento retardado.

As duas primeiras tecnologias citadas consomem grandes quantidades de hidrogênio. No hidrocraqueamento o hidrogênio é consumido diretamente pelo processo enquanto no craqueamento catalítico o consumo de hidrogênio é relacionado à necessidade de dessufurização da matéria-prima que alimenta o processo.

Ao longo do processo de refino do petróleo, a remoção de contaminantes como o enxofre e seus compostos acontece em grande parte das ramificações existentes. Dependendo do uso a qual o produto se destina, os efluentes dos vários processos de craqueamento podem necessitar de tratamento para garantir que os níveis de contaminantes estejam dentro dos parâmetros exigidos pela legislação vigente. O processo que se destina a purificar os efluentes é conhecido por hidrotratamento, onde o hidrogênio é o insumo. 
O processo de hidrotratamento é utilizado para estabilizar hidrocarbonetos leves, como o diesel, a gasolina ou o querosene. Os processos que compõe o hidrotratamento dos derivados de petróleo estão indicados na tabela 3.2.

Tabela 3.2 - Processos presentes no hidrotratamento de derivados do petróleo

\begin{tabular}{|c|c|}
\hline Processo & Descrição \\
\hline Dessulfurização (HDS) & Hidrogenação de compostos sulfurados, como mercaptans e sulfetos \\
\hline Desnitrogenação (HDN) & Hidrogenação de compostos nitrogenados, como pirróis e piridinas \\
\hline Desoxigenação (HDO) & Hidrogenação de compostos oxigenados, como fenóis \\
\hline Desalogenação & Hidrogenação de compostos halogenados, como cloretos \\
\hline
\end{tabular}

O processo de hidrotatamento consome hidrogênio de alta pureza, uma vez que não é desejável a contaminação do produto durante o tratamento. Esta demanda de $\mathrm{H}_{2}$ é garantida por unidades de geração de hidrogênio (UGH) instaladas dentro das refinarias. Outro grande produtor hidrogênio dentro de uma refinaria é a unidade de reforma catalítica de nafta, onde o hidrogênio é produzido como subproduto. No entanto este hidrogênio possui uma pureza menor e seu consumo é direcionado principalmente para as unidades de hidrocraqueamento.

Ao lado das petrolíferas, a indústria química também se mostra como um grande consumidor de hidrogênio. A maior parte do hidrogênio consumido pela indústria química é utilizado para a fabricação de amônia, a qual tem $85 \%$ de sua produção destinada a fabricação de fertilizantes (ARGONNE NATIONAL LABORATORY, 2009). A amônia normalmente é processada em alguns produtos específicos antes de ser utilizada como fertilizantes. Estes produtos incluem uréia, nitratos de amônia, sulfatos de amônia e fosfatos de amônia. Além da aplicação em fertilizantes, a amônia também é utilizada na fabricação de produtos de limpeza, explosivos, nylon e alguns outros polímeros.

Os maiores produtores mundiais de amônia são a China, Rússia, Índia e Estados Unidos, sendo que a produção destes países correspondeu a $54 \%$ da produção mundial em 2007 (DIAS; FERNANDES, 2006). A produção brasileira de amônia ficou em torno de 1\% em 2007, o que resulta em uma grande dependência na importação deste insumo para consumo interno, especialmente para um país onde grande parte da economia é baseada na produção de commodities agrícolas. 
Uma parte relativamente menor da produção mundial de hidrogênio é consumida na fabricação de metanol, que por sua vez é utilizado na fabricação de diversos produtos como plásticos, tintas, explosivos, solventes ou convertido em formaldeido.

Dados de 2003 (ARGONNE NATIONAL LABORATORY, 2009) mostram o consumo relativo de hidrogênio de acordo com sua aplicação final. Como o crescimento econômico mundial nos últimos anos impactou de maneira semelhante o consumo de alimentos e de energéticos, imagina-se que este cenário não tenha sofrido grandes alterações. No entanto, Michael Ball e Martin Wietschel (2009) afirmam que a fabricação de amônia consome aproximadamente $50 \%$ do hidrogênio produzido enquanto o processamento de petróleo consome pouco menos de $40 \%$ da produção de $\mathrm{H}_{2}$.

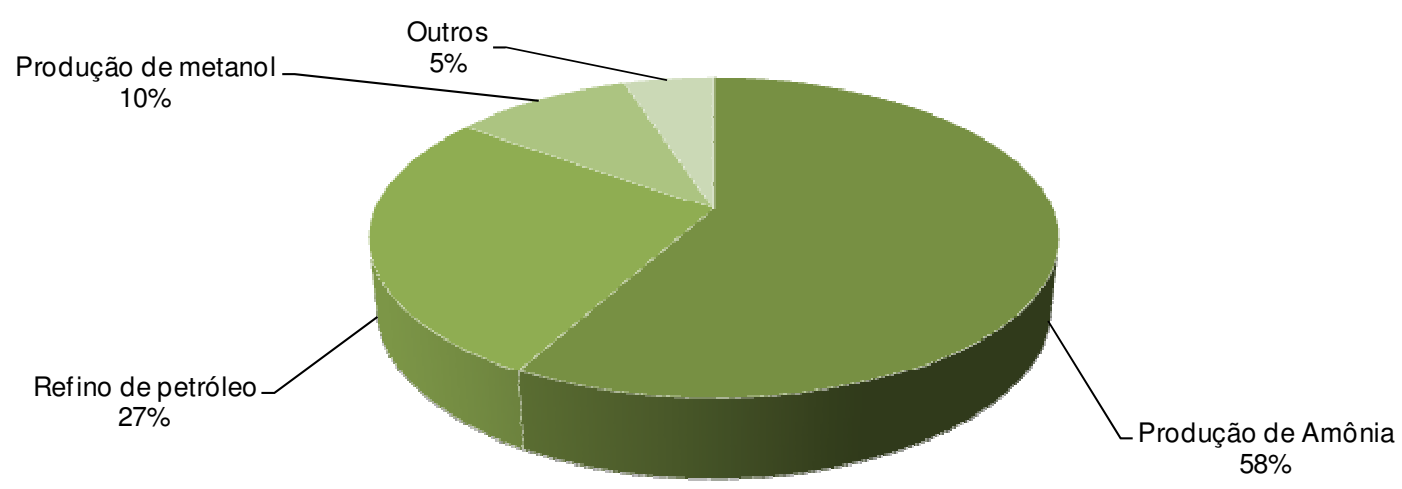

Figura 3.2: Consumo de hidrogênio por uso final em 2003 (\%) (ARGONNE NATIONAL LABORATORY, 2009)

À primeira vista parece que estes dados não são compatíveis com o crescimento apresentado por cada um destes segmentos, uma vez que a produção de amônia teve um crescimento de cerca de $20 \%$ nos últimos cinco anos enquanto a produção de derivados de petróleo cresceu apenas $10 \%$ no mesmo período.

Esta informação a princípio desvincula o aumento do consumo de hidrogênio nas refinarias ao aumento da produção de combustíveis. Sendo assim este aumento de consumo de $\mathrm{H}_{2}$ nas refinarias certamente está ligado à processos adequação dos níveis de enxofre e outros contaminantes presentes nos combustíveis, conseqüência 
de políticas regulatórias recentes que, em todo o mundo, estão obrigando os produtores a fornecer combustíveis com baixos teores de enxofre.

\subsubsection{Perspectivas futuras}

Dentre as perspectivas futuras de uso do hidrogênio a mais promissora está relacionada à sua utilização em células a combustível. O desenvolvimento dessa tecnologia associada à sua viabilização econômica possibilitaria sua utilização em automóveis, ônibus, barcos, geradores e outros equipamentos sem a emissão de gases de efeito estufa (GEE). É a chamada economia do hidrogênio.

O uso do hidrogênio como vetor energético e a formação de um sistema energético baseado em hidrogênio não são idéias recentes. Até a década de 1960 muitos países utilizavam hidrogênio como fonte de energia em cidades (iluminação pública) e casas (aquecimento, preparo de alimentos, iluminação). A idéia da ampla utilização do hidrogênio na base energética dos sistemas econômicos foi formulada durante a crise do petróleo, na década de 1970 (BALL; WIETSCHEL, 2009). No entanto a idéia foi descontinuada ao final da crise.

Com as projeções catastróficas relacionadas ao aquecimento global e o grande salto tecnológicos das células a combustível a idéia da economia do hidrogênio ressurgiu com bastante força. A geração de energia a partir do hidrogênio, com o aprimoramento das células a combustível, ultrapassou a possibilidade de aplicação em sistemas estacionários e criou a perspectiva da utilização do energético no setor de transportes.

Para que o hidrogênio seja utilizado de maneira satisfatória no setor de transportes (figura 3.3), além da evolução das células a combustível uma série de outras barreiras devem ser superadas. Desafios ligados à redução da emissão de $\mathrm{CO}_{2}$ na produção (com a perspectiva do uso da tecnologia de seqüestro de carbono), transporte e armazenamento do hidrogênio ainda não estão completamente resolvidas. 

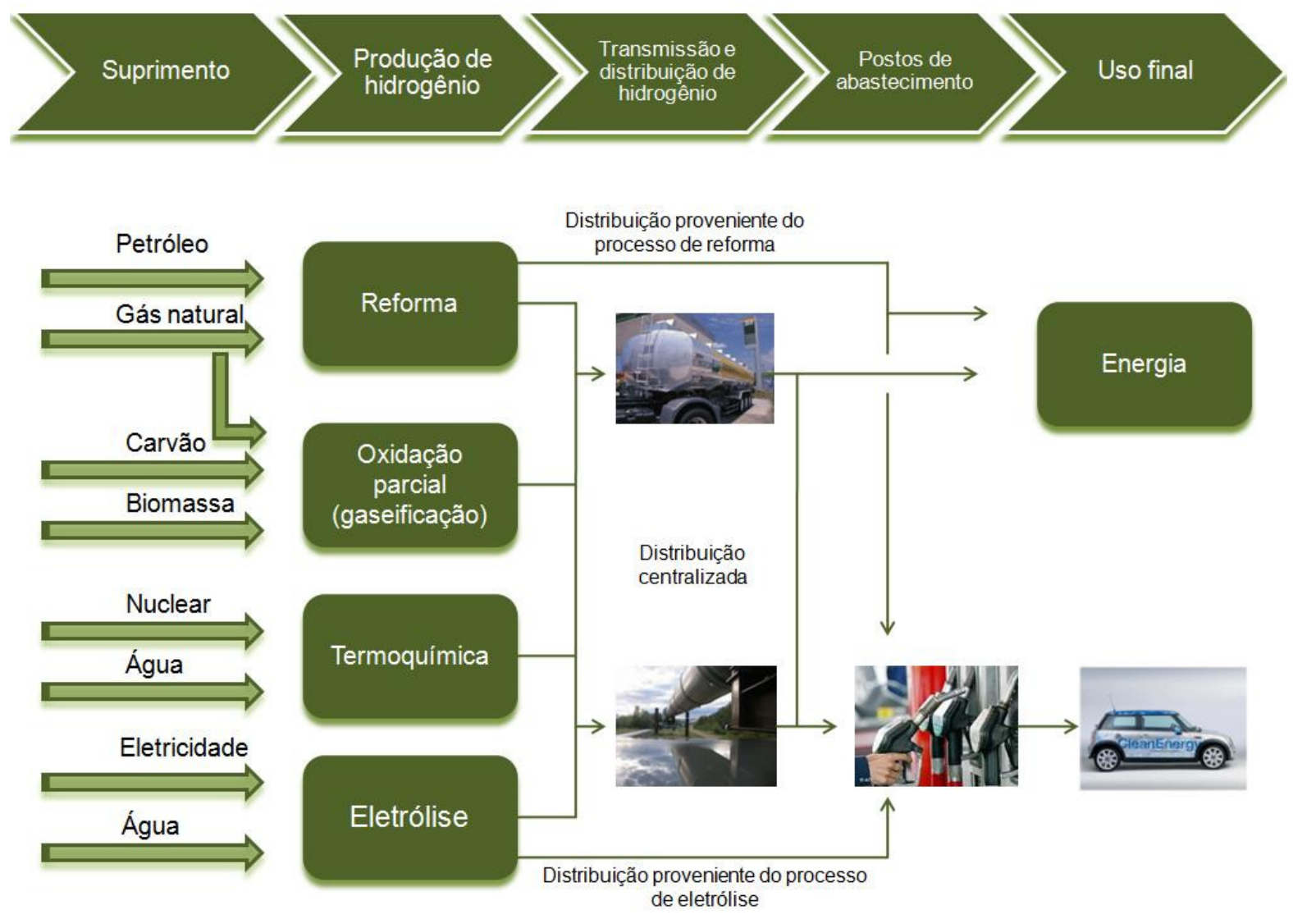

Figura 3.3: Cadeia do hidrogênio aplicada ao setor de transportes (adaptado de ENERGY INFORMATION ADMINISTRATION, 2009)

Apesar das dificuldades existentes, o processo evolutivo para a construção deste novo modelo já se iniciou. Universidades e centros de pesquisa ao redor do mundo vêm trabalhando na resolução de problemas relativos ao tema. Grandes montadoras de automóveis já dispõem de protótipos que utilizam o hidrogênio como combustível. Empresas petrolíferas ao redor do mundo buscam se adaptar a este novo cenário e diversificam seu portfólio. Como exemplo pode-se citar a antiga British Petroleum (atual BP), uma das maiores petrolíferas do mundo, que passou a ser uma empresa de energia ao reconhecer a necessidade de participar do mercado de hidrogênio, ainda que este mercado seja apenas uma aposta promissora.

Os investimentos públicos no setor vêm se intensificando ao longo da última década para construir a infra-estrutura necessária para a distribuição do hidrogênio ao consumidor final, ainda que a maioria das ações tenha um caráter experimental. Alguns países da União Européia possuem programas relativos ao desenvolvimento do hidrogênio como combustível veicular há mais de 10 anos. Os países que mais 
investem no desenvolvimento desta tecnologia na Europa são a Holanda, França e Alemanha.

Mais recentemente, o governo norte americano vem gradativamente aumentando seus investimentos relativos ao uso do hidrogênio como vetor energético. O orçamento total do departamento de energia norte americano (DOE) na área de pesquisa e implantação de infra-estrutura relacionada ao hidrogênio para o ano de 2009 é de 200 milhões de dólares. Estima-se que num período de quatro anos este valor seja em torno de um bilhão de dólares (U.S. DEPARTMENT OF ENERGY , 2009).

Do ponto de vista ambiental, os efeitos benéficos da utilização do hidrogênio como energético de uso geral estão intimamente ligados às emissões produzidas durante sua produção, uma vez que hoje a maior parte do hidrogênio é obtida a partir de combustíveis fósseis e geram grandes quantidades de gás carbônico.

O argumento climático-ambiental por si só não justifica o uso maciço de hidrogênio e nem os grandes investimentos em pesquisa e infra-estrutura. É importante salientar que o hidrogênio é uma fonte de energia secundária, assim como a eletricidade. Portanto, para que o uso do hidrogênio tenha uma vantagem ambiental sobre o uso da eletricidade é necessário contabilizar as emissões durante a produção destes elementos.

\subsection{OCORRENCIA NATURAL}

O hidrogênio é o elemento químico mais abundante do Universo, compondo $75 \%$ da matéria normal em massa e mais de $90 \%$ em número de átomos. Este elemento é encontrado em grande abundância em estrelas e planetas gigantes de gás. O hidrogênio tem um papel importante no fornecimento de energia para as estrelas através de fusão nuclear.

Pelo universo, o hidrogênio é geralmente encontrado nos estados atômico e plasma, cujas propriedades são bem diferentes do hidrogênio molecular. Como plasma, o elétron e o próton de hidrogênio não são ligados, resultando em uma condutividade elétrica muito alta e alta emissividade (produzindo a luz do Sol e outras estrelas). 
Nas condições normais de temperatura e pressão, o hidrogênio apresenta-se normalmente em sua forma molecular, formando um gás diatômico $\left(\mathrm{H}_{2}\right)$. Este gás é inodoro, incolor, inflamável, insípido, não-metálico e insolúvel em água.

O hidrogênio molecular é relativamente raro na atmosfera da Terra, sendo produzido de forma natural apenas por algumas bactérias ou algas. Portanto para obtê-lo em escala industrial se faz necessário algum processo químico para separálo de outros elementos como hidrocarbonetos, ácidos ou água por exemplo.

\subsection{CENÁRIO ATUAL DE PRODUÇÃO DO $\mathrm{H}_{2}$}

O hidrogênio pode ser obtido a partir do processamento de dois tipos principais de matéria-prima: combustíveis fósseis ou água. Dentre os combustíveis fósseis, o mais utilizado atualmente é o gás natural (Figura 3.4).

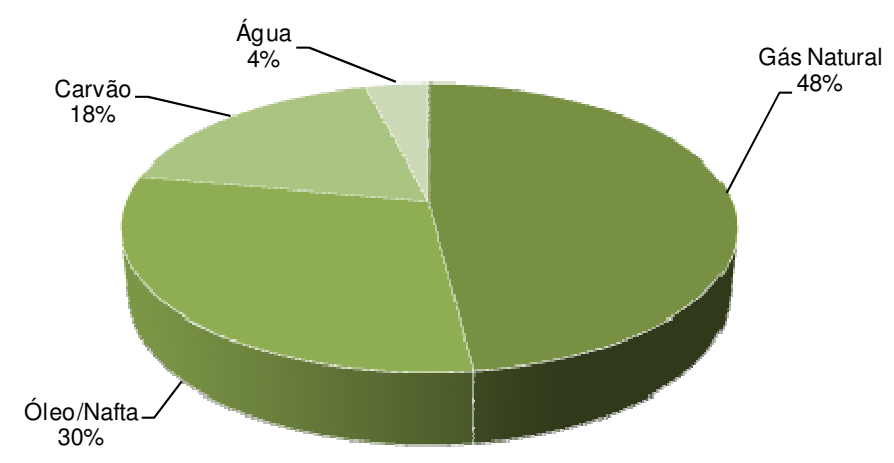

Figura 3.4: Origem da produção de hidrogênio no mercado mundial em 2003 (\%) (NATIONAL HYDROGEN ASSOCIATION, 2009)

Dados relativos ao ano de 2006 indicam que não houve grandes alterações na distribuição apresentada acima (SRI CONSULTING, 2009), sendo que a produção de hidrogênio a partir do gás natural aumentou um ponto percentual enquanto a produção decorrente da reforma catalítica da nafta e do óleo pesado foi reduzida em um ponto percentual. Além disso, Michael Ball e Martin Wietschel (2009) afirmam que aproximadamente metade do hidrogênio produzido no mundo é feito a partir do gás natural enquanto um terço é fabricado a partir de frações de 
petróleo, mostrando quer as proporções apresentadas na figura 3.4 não se alteraram muito.

A produção mundial de hidrogênio não é formalmente monitorada. Existe uma dificuldade no levantamento dos dados de produção de $\mathrm{H}_{2}$ uma vez que este elemento pode ser produzido de maneira intencional ou como subproduto de outros processos. O hidrogênio produzido intencionalmente pode ser mais facilmente monitorado uma vez que este elemento é diretamente aplicado aos processos nos quais serve de insumo. No entanto, a produção não-intencional é significativa, especialmente no processo de fabricação dos aços.

No processo de fabricação de aços, minério de ferro e coque são aquecidos no alto-forno para formarem o ferro gusa, que servirá de matéria-prima principal do aço. Antes de ir ao alto-forno, o coque é tratado nas coquerias. O gás resultante do processo de preparação do coque, também conhecido como gás de coqueria, é um gás com alto poder calorífico e extremamente energético. Possui em sua composição entre 54\% e 59\% de hidrogênio molecular $\left(\mathrm{H}_{2}\right)$ (ZHANG ET AL., 2008), podendo ser considerado como um fluxo de hidrogênio de baixa pureza. Este gás é utilizado essencialmente como combustível, seja em processos internos à aciaria ou quando exportado.

Dados de 2003 (ARGONNE NATIONAL LABORATORY, 2009) indicavam que a produção intencional de hidrogênio daquele ano foi de 41 milhões de toneladas de hidrogênio, o que equivale a 456 bilhões de $\mathrm{Nm}^{3}$ (normais metros cúbicos). Neste mesmo ano, estima-se que a produção total de hidrogênio (soma da produção intencional e não-intencional) foi de aproximadamente 50 milhões de toneladas (556 bilhões de $\mathrm{Nm}^{3}$ ).

Infelizmente existe uma escassez de dados mais atuais relativos à produção de hidrogênio. No entanto é possível traçar projeções a partir dos dados relativos aos produtos que utilizam o hidrogênio de forma intensa em seus processos produtivos, principalmente a produção de amônia e de derivados de petróleo, bem como os dados de produção de aços, um ator importante que tem o hidrogênio como subproduto de seus processos.

O crescimento econômico mundial nos últimos anos causou um forte aumento na demanda de alimentos, energia e metais, gerando impactos não só nos preços de fertilizantes, combustíveis e aço, mas também nos investimentos relacionados ao aumento da produção destes elementos. 
A produção de destilados leves ou médios, como gasolina, diesel e querosene, cresceu $18,35 \%$ nos últimos 10 anos (1998-2008), sendo que no período entre 2003 a 2008 o crescimento acumulado foi de 9,05\% (BP, 2009). No mesmo período a produção mundial de amônia cresceu em torno de $20 \%$ (INDEX MUNDI, 2009) e a produção de aço teve um aumento de $43 \%$ (WORLD COAL INSTITUTE, 2009), impulsionado pelo crescimento da China.

Levando-se em conta que cerca de $85 \%$ da produção intencional de hidrogênio é destinada à fabricação de amônia e ao refino de petróleo, e que a produção não-intencional de hidrogênio era em torno 9 milhões de toneladas em 2003 é possível projetar que a produção anual de hidrogênio em 2008 tenha sido de aproximadamente 60 milhões de toneladas (677 bilhões de $\mathrm{Nm}^{3}$ ).

Ball e Wietschel (2009) citam que a produção anual de hidrogênio no mundo é de aproximada de 700 bilhões de $\mathrm{Nm}^{3}$, o que indica uma coerência nos valores projetados.

\subsection{PROCESSOS PRODUTIVOS}

Embora a matéria-prima para obtenção do hidrogênio se resuma essencialmente a dois tipos de substância (água ou combustíveis fósseis), existe uma grande variedade de tecnologias associadas à produção deste elemento. Essas tecnologias se apresentam em diferentes estágios de desenvolvimento e proporcionam escalas diferentes de produção.

Os processos para produção do hidrogênio podem ser classificados em três segmentos distintos: processos térmicos, processos eletrolíticos e processos fotolíticos. O primeiro segmento é o mais representativo na indústria, enquanto os demais possuem um alto custo operacional ou ainda se encontram em fase experimental. Cada processo apresenta suas próprias vantagens e desvantagens com respeito ao investimento inicial, eficiência, balanço de emissões na produção e consumo (life-cycle) e progressos tecnológicos. 


\subsubsection{Processos térmicos}

\subsubsection{Reforma de hidrocarbonetos leves}

A reforma de hidrocarbonetos é o processo mais utilizado na produção de hidrogênio em larga escala. Neste processo, uma mistura de vapor d'água e hidrocarbonetos reagem a altas temperaturas na presença de um catalisador, formando uma mistura de dióxido de carbono e hidrogênio. A reação que exemplifica de forma simplificada o que acontece neste processo pode ser vista abaixo:

$$
\mathrm{CH}_{4}+2 \mathrm{H}_{2} \mathrm{O} \rightarrow 2 \mathrm{CO}_{2}+4 \mathrm{H}_{2}
$$

O hidrocarboneto mais utilizado no processo de reforma é o gás natural, formado essencialmente de gás metano (cerca de $90 \%$ em volume). Esta característica é muito positiva diante da amplitude da rede de distribuição deste gás, facilitando a implantação de fábricas com este processo e reduzindo o risco de falta de matéria prima.

Esta tecnologia permite uma grande variação na escala de produção, sendo utilizada em pequenas centrais ou grandes plantas de produção. As grandes plantas são localizadas nas proximidades dos grandes consumidores de hidrogênio, como refinarias, plantas de produção de amônia ou metanol, estando normalmente instaladas fisicamente no mesmo complexo industrial com o objetivo principal de reduzir os custos de armazenamento e transporte do gás.

Além da energia requerida para gerar o vapor utilizado no processo existe a necessidade de aquecimento da mistura uma vez que esta reação é extremamente endotérmica. Sendo assim o processo consome um segundo combustível, uma fração do hidrocarboneto utilizado na alimentação ou resíduos energéticos provenientes do sistema de purga. Segundo Lutz et al. (2003) esta última opção é freqüentemente utilizada para recuperar a energia do fluxo que, de outra forma, seria descartada. 


\subsubsection{Oxidação parcial de hidrocarbonetos}

Oxidação parcial de um fluxo rico em hidrogênio, como o gás natural, carvão, coque de petróleo, ou biomassa, é outra forma possível de produção de hidrogênio. O processo é similar ao processo de reforma, no entanto utiliza oxigênio no lugar do vapor:

$$
2 \mathrm{CH}_{4}+\mathrm{O}_{2} \rightarrow 2 \mathrm{CO}+4 \mathrm{H}_{2}
$$

Ao se comparar a reação química acima com a reação do processo de reforma a vapor percebe-se que o processo de oxidação parcial produz menos hidrogênio a partir da mesma quantidade de matéria-prima.

O uso de combustíveis sólidos também é possível através da gaseificação. Neste processo se produz um gás sintético (syngas) que pode ser utilizado diretamente na obteção do hidrogênio.

Alguns estudos recentes avaliam a possibilidade da instalação de plantas de gaseificação em refinarias, acopladas a turbinas de Ciclo Combinado, com o objetivo de gerar energia elétrica e produzir $\mathrm{H}_{2}$ para tratamento de combustíveis (SZKLO; CASTELO BRANCO ; GOMES, 2007). Esta hipótese considera a experiência que a petrolífera Shell vem acumulando desde 1998, ano em que entrou em operação, na Holanda, a refinaria "Pernis". Esta refinaria foi a primeira a utilizar em escala industrial o processo de gaseificação para produção do hidrogênio, desenvolvido pela própria Shell, chamado "Shell Gasification Hydrogen Plant".

Neste processo, a gaseificação é realizada a uma temperatura de $1350{ }^{\circ} \mathrm{C}$ e a 65 bar de pressão (ZUIDEVELD, 1998). O produto da gaseificação é o gás de síntese (syngas), que é basicamente formado por monóxido de carbono e hidrogênio. Os produtos efluentes do gaseificador são resfriados até a temperatura de $400{ }^{\circ} \mathrm{C}$, sendo este calor utilizado para produzir vapor saturado a 95 bar de pressão em caldeiras e economizadores. (ZUIDEVELD, 1998).

O hidrogênio é obtido com o processamento do gás de síntese na unidade de shift, onde o monóxido de carbono é combinado com o vapor produzido formando dióxido de carbono e hidrogênio, aumentando a quantidade de hidrogênio presente no fluxo. Como será visto no capítulo 5 , o processo de shitf realizado sobre o gás de 
síntese proveniente do gaseificador é bastante similar ao tratamento dado aos efluentes do forno reformador no processo de reforma a vapor do gás natural.

Existe a necessidade de suprimento de oxigênio para o processo, que deve ser fornecido a uma pressão de 70 bar e $99,5 \%$ de pureza (ZUIDEVELD, 1998). Consequentemente existe a necessidade da construção de uma unidade de suprimento de ar anexa à planta de gaseificação.

\subsubsection{Eletrólise}

O processo de eletrólise utiliza energia elétrica para dividir moléculas da água em seus componentes básicos (hidrogênio e oxigênio). Este método de produção é o mais limpo ambientalmente (não contabilizando as emissões causadas na geração elétrica), no entanto só é recomendado no uso industrial quando se tem a necessidade de obter hidrogênio com $100 \%$ de pureza, pois seu custo de operação é consideravelmente mais alto que dos demais processos.

\subsubsection{Outros}

Tecnologias avançadas para a produção de hidrogênio estão sendo exploradas por pesquisadores ao redor do mundo. Essas tecnologias utilizam a fissão nuclear, a fotossíntese, fermentação, gás de aterro e reforma de resíduos urbanos. No entanto, a probabilidade de sucesso tecnológico e econômico destas tecnologias avançadas não está garantida. 


\section{ASPECTOS AMBIENTAIS E POLÍTICAS REGULATÓRIAS}

\subsection{O ENXOFRE NOS COMBUSTÍVEIS}

As emissões atmosféricas causadas pela utilização de combustíveis fósseis trazem graves conseqüências ao meio-ambiente. Além da questão relativa aos gases de efeito estufa (GEE), principais responsáveis pelo processo de aquecimento global, existem questões relativas ao impacto na saúde pública, principalmente nas cidades.

Dentre os elementos poluentes provenientes da queima dos combustíveis, alguns recebem atenção especial dos diversos setores da sociedade por apresentarem altos níveis de periculosidade ou toxicidade. Um destes elementos certamente é o enxofre.

A presença de enxofre nos combustíveis causa a formação de dióxido de enxofre $\left(\mathrm{SO}_{2}\right)$ durante a combustão, o qual dependendo da concentração e do tempo de exposição pode causar problemas respiratórios e agravar problemas cardiovasculares, além de ser irritante para a mucosa dos olhos. Nas plantas este gás pode provocar alterações em seus processos metabólicos, tais como redução da taxa de crescimento e da produção de oxigênio por fotossíntese, além de favorecer o aparecimento de necroses e de aumentar a sensibilidade a parasitas e ao gelo em países com inverno rigoroso.

Em contato com o oxigênio presente no ar, o dióxido de enxofre pode se transformar em trióxido de enxofre $\left(\mathrm{SO}_{3}\right)$, que por sua vez pode se transformar em ácido sulfúrico $\left(\mathrm{H}_{2} \mathrm{SO}_{4}\right)$ ao reagir com a umidade. Este processo é o responsável pela formação da chuva ácida que pode atingir plantações, aumentar o nível de acidez de solos e rios (alterações no pH) e acelerar a degradação de estruturas como edifícios ou pontes.

Devido a este potencial destrutivo, houve um movimento mundial nos últimos 20 anos no sentido de reduzir os níveis de enxofre presentes nos combustíveis e aumentar a eficiência dos motores à combustão. $\mathrm{O}$ óleo diesel foi 0 combustível escolhido como vetor destas alterações, isto porque motores movidos à 
diesel consomem grandes quantidades de combustível, possuem níveis maiores de emissão e podem ser controlados, auditados ou substituídos mais facilmente que os motores à gasolina, uma vez que são utilizados em menor quantidade.

\subsection{A REGULAÇÃO DOS NÍVEIS DE ENXOFRE NO DIESEL}

\subsubsection{O Brasil e o cenário mundial}

Nos últimos anos as restrições ao nível de enxofre presente nos combustíveis, em especial no óleo diesel, aumentaram significativamente em todo o mundo. Segundo o Programa Nacional de Racionalização do Uso dos derivados do Petróleo e do Gás Natural (Conpet) do Ministério de Minas e Energia (MME) (COMPET, 2009) o nível de enxofre presente no óleo diesel no início da década de 1990 era de 13 mil partes por milhão (ppm). Este valor foi reduzido ao longo dos anos, sendo que atualmente o índice máximo de enxofre no diesel brasileiro está estabelecido em 500ppm nas regiões metropolitanas e 2000ppm no interior.

Diversos países são mais restritivos aos níveis de enxofre no diesel, em especial os países da união européia e nos Estados Unidos (fig.4.1). Na Europa a regulação "Euro IV" que especifica um nível máximo de 50ppm de enxofre no diesel está em vigor deste 2005. Uma nova regulação chamada "Euro V", que restringirá o nível de enxofre para 10ppm, entrará em vigor até o final de 2009.

Nos Estados Unidos, a Agência de Proteção do Meio Ambiente (EPA Environmental Protection Agency) regulamentou em 2006 que o nível máximo de enxofre no diesel seria de $15 \mathrm{ppm}$ para aplicações gerais, como transporte de cargas ou passageiros. Trens, navios e aplicações estacionárias tiveram limites maiores, de até 500ppm, no entanto devem migrar para o diesel com 15ppm até o final de 2012. 


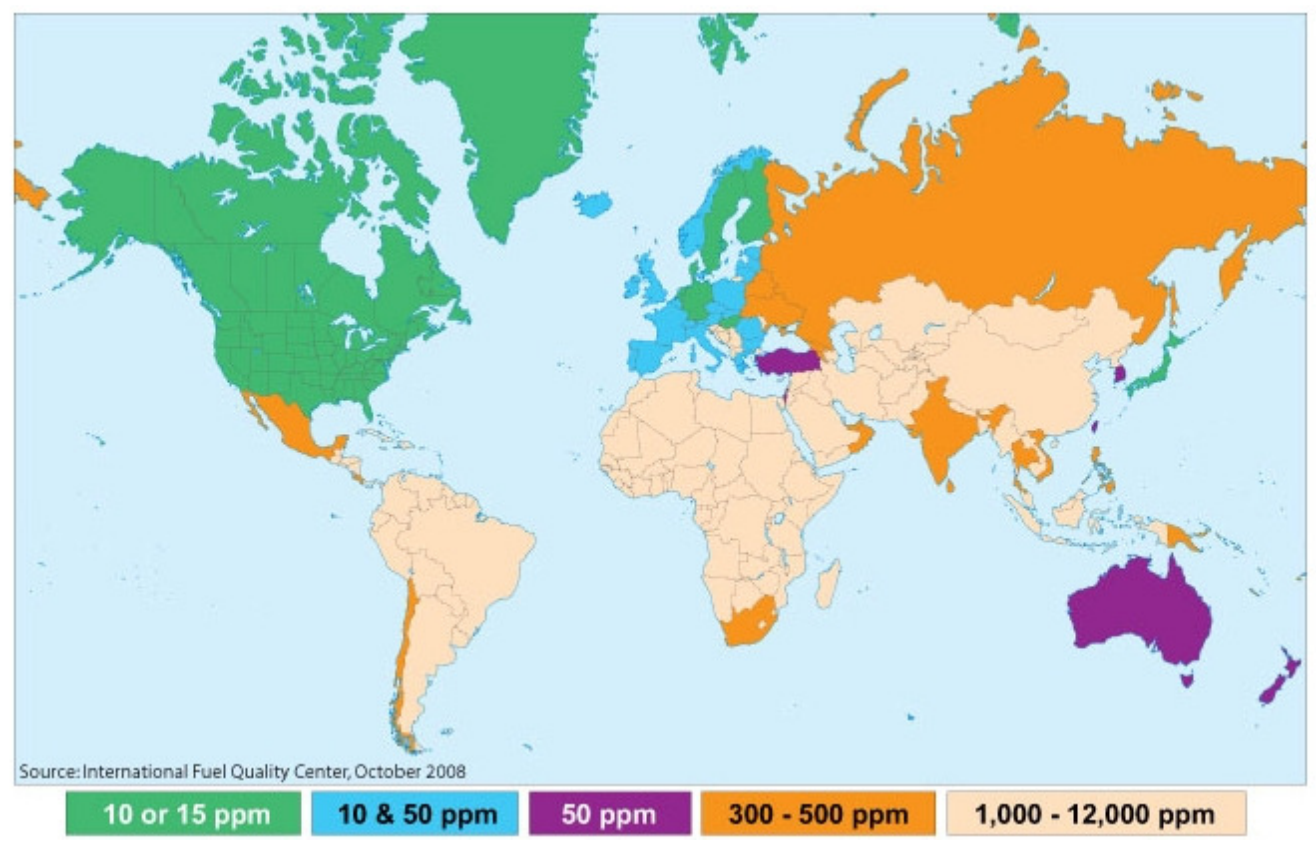

Figura 4.1: Limites de enxofre no diesel ao redor do mundo (retirado de MOVIMENTO NOSSA SÃO PAULO, 2009)

O limite de enxofre no diesel brasileiro é consideravelmente mais alto que os apresentados nos países desenvolvidos. Além dos problemas inerentes à aplicação destes limites, ligados principalmente a questões de saúde pública e danos ambientais, a falta de uma regulação mais restritiva alinhada aos limites existentes no primeiro mundo impõe uma barreira importante para as exportações do diesel produzido no mercado nacional.

\subsubsection{O Proconve e as resoluções Conama}

O Conselho Nacional do Meio Ambiente (Conama) implantou em 1986 o Proconve - Programa de Controle de Emissões Veiculares, com o objetivo de reduzir as emissões provenientes dos veículos automotores no território nacional (CETESB, 2009). Este programa foi um dos responsáveis por tornar o catalizador obrigatório na fabricação de automóveis.

O Proconve possui duas categorias, uma direcionada aos veículos leves ou de passeio (categoria "L") e outra direcionada aos veículos pesados (categoria "P"). 
O processo de implantação do Proconve foi dividido em seis fases, sendo que as restrições nas emissões aumentam a cada fase (tab.4.1).

Tabela 4.1- Fases do programa de controle de emissões veiculares - Proconve (INSTITUTO ESTADUAL DO AMBIENTE, 2009)

\begin{tabular}{|c|c|c|c|c|}
\hline \multicolumn{5}{|c|}{ LIMITES DO PROCONVE PARA VEÍCULOS DIESEL (g/kWh) } \\
\hline FASE & CO & HC & NOx & MP \\
\hline P-1 & $14,00^{*}$ & $3,50^{*}$ & $18,00^{*}$ & $\mathrm{xx}^{*}$ \\
\hline P-2 & 11,2 & 2,45 & 14,4 & $0,60^{*}$ \\
\hline P-3 & 4,9 & 1,23 & 9 & 0,4 \\
\hline P-4 & 4 & 1,1 & 7 & 0,15 \\
\hline P-5 & 2,1 & 0,66 & 5 & 0,1 \\
\hline P-6 & 1,5 & 0,46 & 3,5 & 0,02 \\
\hline
\end{tabular}

*Emissão Gasosa ( fase I ) e MP ( fase II ) não foram exigidos legalmente.

Os fabricantes de automóveis, já em 1990, estavam produzindo motores com níveis de emissão menores que os requeridos para 1993, ano em que teve início o controle de emissão para veículos deste tipo com a introdução das fases um (P-1) e dois (P-2). Nesse período, os limites para emissão gasosa (fase 1) e material particulado (fase 2) não foram exigidos legalmente. Para atender aos limites da fase três (P-3), vigente a partir de 1994, foram desenvolvidos novos modelos de motores com o objetivo de reduzir o consumo de combustível, aumentar da potência e reduzir as emissões gasosas de óxidos de nitrogênio $\left(\mathrm{NO}_{\mathrm{x}}\right)$ por meio da adoção de intercooler e motores turbo. Em 1998, entrou em vigor a fase quatro (P-4), restringindo ainda mais os limites estabelecidos na fase três.

Foi durante a implantação da etapa P-4 que os produtores de diesel do país reduziram os níveis de enxofre aos atuais 500ppm e 2000ppm para atender às regiões metropolitanas e ao interior, respectivamente.

Em 2002 o Conama publicou a resolução 315/2002 (MINISTÉRIO DO MEIO AMBIENTE, 2009) que regulamentava as novas etapas do Proconve (etapas P-5 e P-6). Em sua maior parte, este documento impõe restrições à emissão de poluentes em motores do ciclo Otto e Diesel, caracterizando ensaios e aplicando regras voltadas em grande parte para a indústria automobilística. No entanto o 
documento cita em seu artigo 18, parágrafo 2, que "Os combustíveis comerciais deverão possuir características adequadas e compatíveis com as tecnologias a serem adotadas e estarem disponíveis nas datas previstas nesta Resolução" (MINISTÉRIO DO MEIO AMBIENTE, 2009). Sendo assim, apesar desta resolução não especificar claramente os níveis de enxofre no diesel ela amarra o combustível às emissões permitidas nos motores à combustão.

Além da resolução 315 do Conama não indicar os níveis de enxofre no diesel, os produtores de combustíveis discutiram a validade jurídica desta norma, uma vez que regulamentação sobre a composição dos combustíveis é competência única e exclusiva da Agência Nacional do Petróleo (ANP).

Apesar da discussão sobre o assunto, a fase P-5 do Proconve teve início em janeiro de 2006 sem grandes problemas, uma vez que o desenvolvimento da tecnologia aplicada aos veículos novos permitia a utilização de diesel com até 500ppm sem que os limites de emissão impostos fossem ultrapassados. Entretanto, a indústria automobilística divulgou que para o atendimento da fase P-6 do programa, previsto para janeiro de 2009, o óleo diesel não deveria ter mais do que 50ppm de enxofre.

Esta discussão se encerrou em 2007, quando a Agência Nacional do Petróleo publicou a Resolução ANP n³2 de 16 de outubro de 2007 (BRASIL, 2009), regulamentando os níveis máximos de enxofre e indicando prazos para que os produtores cumprissem a medida. Este prazo seria compatível com o início da fase P-6 do Proconve.

A produção brasileira de óleo diesel não está preparada para fornecer este tipo de combustível, sendo que a Petrobras, empresa que detém o monopólio da produção de diesel no Brasil, se comprometeu a importar diesel com 50ppm de enxofre (também conhecido como diesel S-50). Esta medida atingiria apenas os veículos produzidos a partir de janeiro de 2009, uma vez que, segundo a empresa, o restante da frota não se beneficiaria com a substituição do combustível por não ter tecnologia compatível com o produto.

Todo ano entram em circulação cerca de 120 mil novos caminhões, o que pressiona as importações do diesel S-50. A Petrobras, por sua vez, indica que o investimento na modernização de suas 14 refinarias é da ordem de 6,5 bilhões de dólares, investimento este voltado principalmente para construção de unidades de 
hidrodessulfurização de diesel (HDT) e unidades de geração de hidrogênio (UGH), o que permitira atender à demanda do diesel S-50 sem necessidade de importação.

Além dos investimentos atuais, novos montantes devem ser investidos na redução dos níveis de enxofre no diesel, uma vez que o Conama aprovou no final de 2008 uma nova resolução limitando o enxofre presente no diesel em 10ppm, introduzindo uma nova fase no Proconve (P-7). Esta nova fase entraria em vigor a partir de 2012.

\subsubsection{A remoção do enxofre do diesel e o consumo de $\mathrm{H}_{2}$ no refino de petróleo}

A combinação dos efeitos externos, como as novas legislações na Europa e nos Estados Unidos, com fatores internos, como as novas regulamentações dos níveis de enxofre no diesel brasileiro, aumentaram a demanda pelos processos de hidrotratamento. Muitas refinarias ao redor do mundo estão modernizando suas unidades de hidrotratamento ou construindo novas unidades.

O montante de hidrogênio requerido para operar estas unidades aumenta em proporções ainda maiores. Durante o tratamento, cada átomo de enxofre removido consome dois átomos de hidrogênio, resultando na formação de $\mathrm{H}_{2} \mathrm{~S}$ e, após novo tratamento, em vapor dágua e sulfeto de zinco (ZnS).

Diante deste cenário, o balanço de hidrogênio dentro das refinarias passou a ser crucial para na produção de combustíveis, sendo que no curto prazo existe a necessidade de construir unidades de produção de $\mathrm{H}_{2}$ para manter este balanço, enquanto estudos de novos processos, matérias primas, produtividade e análise econômica da produção do hidrogênio passam a ter enorme importância a médio e longo prazo. 


\section{PLANTA SÍNTESE E DESCRIÇÃO DO PROCESSO DE REFORMA}

\subsection{DEFINIÇÃO DA PLANTA SÍNTESE}

O projeto de uma UGH possui uma complexidade bastante elevada do ponto de vista de engenharia, sendo necessária a utilização de equipamentos de grande capacidade, tubulações de material especial e estruturas civis robustas. Além disso, uma série de processos paralelos são necessários para que a planta tenha a performance esperada. Deste ponto de vista, o sistema de utilidades, combate a incêndios, instrumentação e controle são tão importantes para o bom funcionamento da unidade quanto o forno reformador ou os reatores, por exemplo.

Entretanto, a consideração destes processos secundários na análise da planta provavelmente não traria resultados muito diferentes dos que seriam obtidos com uma análise feita apenas sobre os elementos principais. Contudo, é necessário rigor e critério na definição do processo principal que será objeto da análise, uma vez que a exclusão de elementos importantes pode comprometer o resultado final.

Para a definição da planta síntese do processo de reforma do gás natural foram utilizados dois critérios principais. Primeiro foram destacados os equipamentos que tinham ação direta sobre os fluxos de insumos e produtos, sendo essenciais ao processo produtivo. Após isso foi utilizado o critério da semelhança, onde equipamentos com a mesma função e condições de operação semelhante foram agrupados em um único equipamento equivalente. A presença deste tipo de situação é muito comum em refinarias e outras unidades industriais, onde trocadores de calor se apresentam em baterias por exemplo.

O desenvolvimento da planta síntese do processo de reforma foi realizado com base na aplicação dos critérios acima citados sobre uma refinaria real pertencente à Petrobras, que teve parte de seu projeto de modernização sob responsabilidade da Promon Engenharia. Assim, as informações retiradas dos documentos de projeto asseguram uma boa síntese da planta real (fig.5.1). 


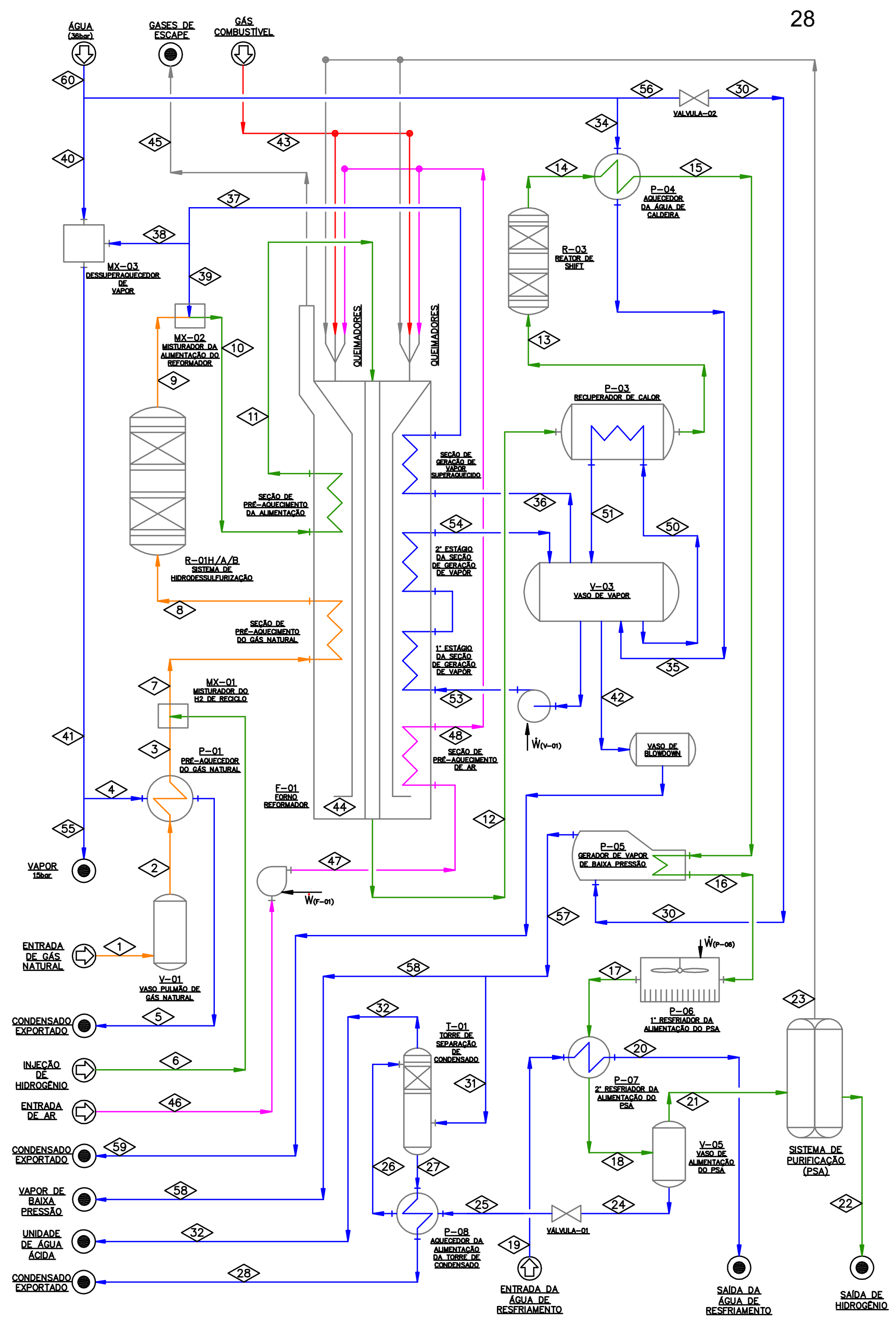

Figura 5.1: Planta síntese do processo de reforma do gás natural 


\subsection{DESCRIÇÃO DO PROCESSO}

A UGH que será descrita neste capítulo foi projetada para produzir 1.200.000 Nm³/dia de hidrogênio com 99,9\% de pureza. Este hidrogênio terá sua produção inteiramente destinada ao processo de hidrodessulfurização do diesel.

O processo será dividido em quatro partes principais com o objetivo de facilitar a compreensão sobre as funções de cada equipamento, bem como as reações químicas nas etapas correspondentes.

\subsubsection{Produção do hidrogênio}

O gás natural entra no processo (ponto 1) e flui para um vaso pulmão (V-01) que tem como objetivo principal evitar grandes oscilações na alimentação do processo. Ao deixar o vaso pulmão (ponto 2), o gás natural é pré-aquecido (P-01) e após isso (ponto 3) recebe uma pequena adição de hidrogênio molecular (MX-01), importante elemento para promover a dessulfurização do gás natural nas etapas posteriores.

Após isso (ponto 7), a mistura é aquecida em uma das seções de convecção do forno reformador (F-01), com o intuito de recuperar a energia proveniente deste equipamento. Na seqüência, o efluente aquecido (ponto 8) é direcionado ao sistema de hidrodessulfurização, composto por três reatores em série $(R-01 H, R-01 A$ e R-01B), onde ocorre a remoção de mercaptanas (RSH).

Mercaptanas são compostos orgânicos de formula RSH contendo um átomo de enxofre e um de hidrogênio (MOGIANA, 2009). A letra "R" significa a presença de um radical orgânico $\left(\mathrm{CH}_{3}\right.$ ou $\mathrm{C}_{2} \mathrm{H}_{5}$, por exemplo). O RSH é um elemento muito comum no gás natural e o processo de remoção se inicia no reator de hidrodessufurização $\mathrm{R}-01 \mathrm{H}$, com a reação entre o $\mathrm{RSH}$ e $\circ \mathrm{H}_{2}$ adicionado, que, sobre a presença de catalizadores formam $\mathrm{H}_{2} \mathrm{~S}$ e hidrocarbonetos diversos (eq.5.1):

$\mathrm{RSH}+\mathrm{H}_{2} \leftrightarrow \mathrm{RH}+\mathrm{H}_{2} \mathrm{~S}$ 
O passo seguinte consiste na remoção completa do enxofre através a reação entre $0 \mathrm{H}_{2} \mathrm{~S}$ produzido e o óxido de zinco $(\mathrm{ZnO})$ presente em um leito fixo no interior dos reatores de dessulfurização R-01A e R-01B (eq.5.2), formando vapor $\left(\mathrm{H}_{2} \mathrm{O}\right)$ e sulfeto de zinco (ZnS), também conhecido como esfalerita, que permanece fixado ao leito de reação.

$\mathrm{H}_{2} \mathrm{~S}+\mathrm{ZnO} \leftrightarrow \mathrm{H}_{2} \mathrm{O}+\mathrm{ZnS}$

Nos reatores R-01A e R-01B, a esfarelita produzida é absorvida pelos catalizadores presentes no leito do reator.

Após o processo de remoção do enxofre (ponto 9), o efluente é misturado ao vapor superaquecido (ponto 39) proveniente do processo de geração de vapor (item 5.2.2.2) no misturador de carga do reformador (MX-02), formando o gás de alimentação do forno reformador (ponto 10). Este gás é aquecido em outra seção de aquecimento convectivo do forno reformador.

$\mathrm{Na}$ saída da seção de aquecimento (ponto 11) o efluente é finalmente direcionado para o forno reformador (F-01) onde ocorre a principal reação do processo.

No forno reformador, a água presente no vapor reage com os hidrocarbonetos leves provenientes do gás natural, formando monóxido de carbono (CO), dióxido de carbono $\left(\mathrm{CO}_{2}\right)$ e hidrogênio $\left(\mathrm{H}_{2}\right)$. Esta reação acontece na presença de catalisadores existentes nos tubos internos ao forno. Além disso, a reação é fortemente endotérmica sendo necessária a adição de uma grande quantidade de energia na forma de calor, energia esta proveniente dos queimadores presentes no forno (item 5.2.2.3). Este processo conta com uma quantia considerável de vapor em excesso, a fim de garantir uma maior eficiência na reação (eq.5.3 e eq.5.4).

$\alpha \mathrm{C}_{n} \mathrm{H}_{2 \mathrm{~m}}+\beta \mathrm{H}_{2} \mathrm{O} \rightarrow[(\mathrm{m}+\mathrm{n}) \alpha+\gamma] \mathrm{H}_{2}+(\mathrm{m} \alpha-\gamma) \mathrm{CO}+\gamma \mathrm{CO}_{2}+(\beta-\mathrm{m} \alpha-\gamma) \mathrm{H}_{2} \mathrm{O}$

onde:

$0 \leq \gamma \leq 1$ 
O efluente do forno reformador (ponto 12) deixa o equipamento a uma alta temperatura (em torno de $800^{\circ} \mathrm{C}$ ) e é direcionado para um recuperador de calor (P-03), onde o calor é utilizado para produção de vapor, seguindo para o reator de aumento (shift) (R-03). Neste equipamento, ocorre outra importante reação do processo, chamada de reação de shift (aumento), onde o monóxido de carbono (CO) e o vapor d'água presentes nos efluentes reagem entre si na presença de um catalisador, formando dióxido de carbono $\left(\mathrm{CO}_{2}\right)$ e hidrogênio $\left(\mathrm{H}_{2}\right)$. Esta etapa aumenta significativamente a produção de hidrogênio e por conseqüência eleva a eficiência global do processo (eq.5.5).

$(\mathrm{m} \alpha-\gamma) \mathrm{CO}+(\beta-\mathrm{m} \alpha-\gamma) \mathrm{H}_{2} \mathrm{O} \rightarrow(\mathrm{m} \alpha-\gamma) \mathrm{H}_{2}+(\mathrm{m} \alpha-\gamma) \mathrm{CO}_{2}+(\beta-2 \mathrm{~m} \alpha) \mathrm{H}_{2} \mathrm{O}$

O efluente proveniente do reator de shift (ponto 14) deve ser resfriado a fim de separar os gases obtidos no processo do vapor d'água residual através da condensação deste vapor. Sendo assim, o gás reformado passa pelo aquecedor de água de caldeira (P-04), segue (ponto 15) para o gerador de vapor de baixa pressão (P-05), em seguida (ponto 16) se encaminha para o primeiro resfriador da alimentação da PSA (sistema de purificação), composto de uma bateria de resfriadores a ar (air coolers)(P-06), de onde é enviado para o segundo resfriador da alimentação do sistema de purificação (ponto 17), composto de um trocador de calor convencional (P-07), chegando finalmente (ponto 18) ao vaso de alimentação da PSA (V-05).

No vaso de alimentação da PSA ocorre a separação do condensado (ponto 24), formado pelo resfriamento da corrente proveniente do reformador, dos demais gases presentes neste fluxo (ponto 21), fluxo este composto de essencialmente de hidrogênio, dióxido de carbono, monóxido de carbono e hidrocarbonetos gasosos residuais. $O$ tratamento do condensado será detalhado mais adiante (item 5.2.2.4).

A corrente de gases citada acima é então direcionada para o sistema de purificação, designado pelo nome de seu equipamento principal, a PSA (Pressure Swing Adsorbtion). Este sistema é composto por uma série de adsorvedores conectados entre si (fig.5.2) onde o hidrogênio é separado dos demais gases. 


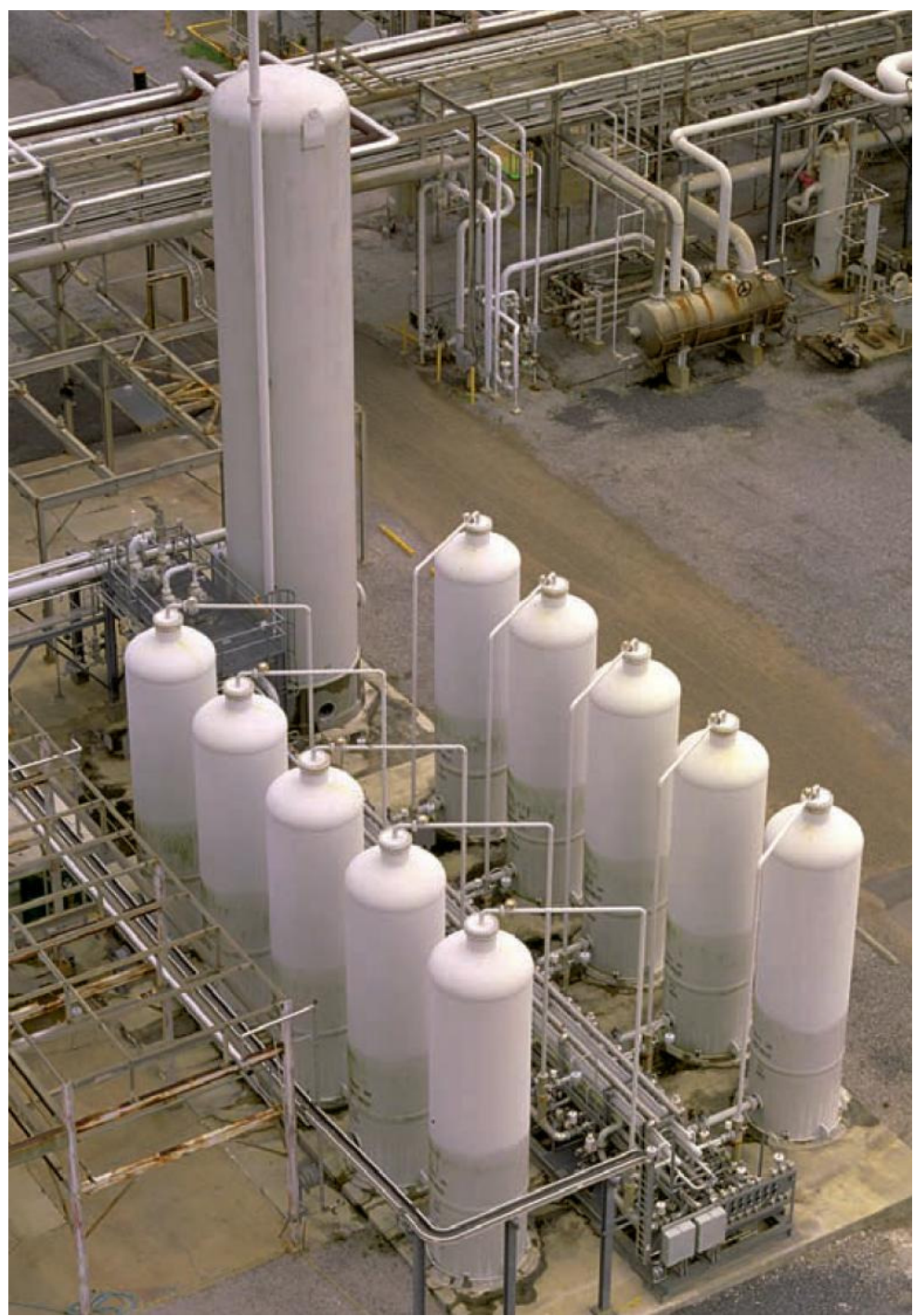

Figura 5.2: Foto de um sistema de PSA (retirado de UOP LLC, 2009)

O processo de funcionamento da PSA é baseado na diferença de pressão entre os diversos vasos que compõe o equipamento e é extremamente dependente das pressões de entrada da alimentação (ponto 21), saída do hidrogênio (ponto 22) e do gás de purga (ponto 23). Trata-se de um processo por batelada, não contínuo, composto por cinco fases em cada um dos vasos. Entretanto os ciclos são rápidos e a quantidade de vasos presentes permite a análise deste equipamento considerando um processo contínuo. Um desenho esquemático deste sistema é apresentado na figura a seguir (fig.5.3). 


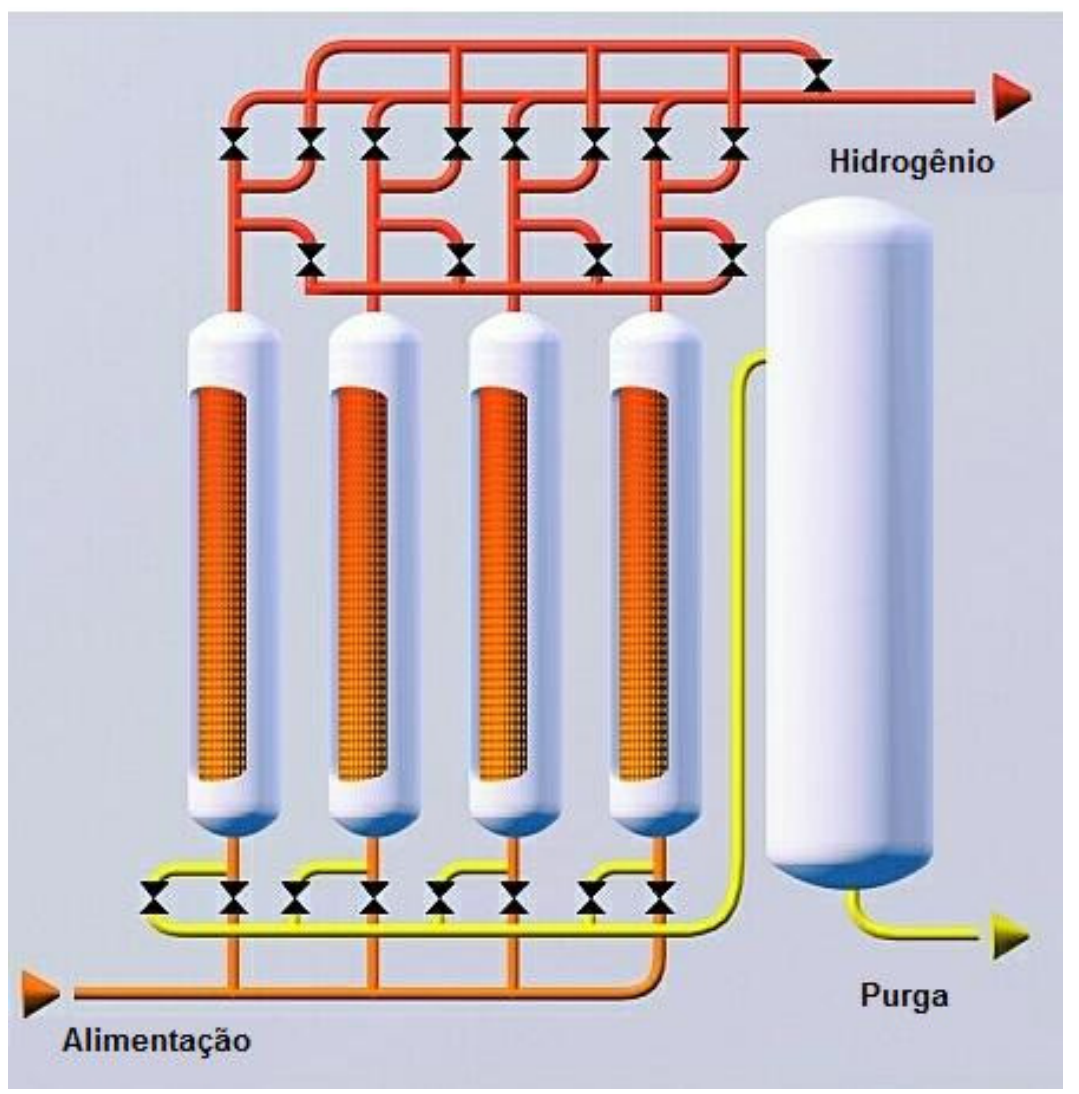

Figura 5.3: Esquema lógico de um sistema de PSA (adaptado de MAHLER AGS, 2009)

Após a purificação, o hidrogênio com 99,9\% de pureza é obtido e enviado aos processos nos quais serve de insumo (ponto 22), sendo que uma parte deste fluxo é destinada ao processo de dessulfurização da própria UGH (ponto 6).

\subsubsection{Geração de vapor}

Conforme descrito no item anterior, vapor d'água é um elemento essencial no processo de reforma do gás natural para obtenção de hidrogênio. A unidade de geração de hidrogênio utiliza as fontes térmicas ao longo do processamento do fluxo principal para obter vapor.

Água a alta pressão é fornecida à unidade de geração de hidrogênio (ponto 60), sendo direcionada (ponto 40) para o dessuperaquecedor de vapor (MX-03), para o gerador de vapor de baixa pressão (P-05), passando pela válvula-02 (pontos 56 e 30), e para o aquecedor de água de caldeira (P-04). 
A água aquecida neste último trocador de calor (P-04) segue para (ponto 35) o vaso de vapor (V-03), principal equipamento do sistema de vapor. A partir deste vaso, o vapor é gerado aproveitando-se os rejeitos térmicos do processo principal. Uma corrente flui através de circulação natural (pontos 50 e 51) para o primeiro recuperador de calor a jusante do forno reformador (P-03). Outra corrente é aquecida em duas seções de convecção no forno reformador, fluindo através de circulação forçada (pontos 53 e 54).

Vapor saturado é enviado a outra seção de convecção do forno reformador (ponto 36), onde é superaquecido (ponto 37). Parte do vapor superaquecido é enviada ao processo principal (ponto 39), onde será misturada ao gás natural livre de enxofre e formar o gás de alimentação do reformador. A outra parte (ponto 38) é enviada ao dessuperaquecedor (MX-03), onde após resfriado o vapor é exportado para o ramal de média pressão da refinaria (ponto 55). Parte do vapor proveniente do dessuperaquecedor (ponto 4) é utilizado no pré-aquecedor de carga (P-01), tendo seu condensado recolhido para o ramal de condensado da refinaria.

$\mathrm{O}$ balanço de massa no interior do vaso de vapor (V-03) é garantido pela saída de purga (ponto 42), direcionada ao vaso de rejeitos (blowdown). Este fluxo é rejeitado para o respectivo ramal de condensado da refinaria (ponto 59).

O vapor produzido (ponto 57) no gerador de vapor de baixa pressão (P-05) é dividido em duas partes. Uma dessas partes (ponto 31) é utilizada no processo de tratamento do condensado proveniente do reformador (item 5.2.2.4), enquanto a outra parte (ponto 58) é exportada para fora da unidade, juntando-se ao sistema de vapor de baixa pressão da refinaria.

\subsubsection{Alimentação dos queimadores do forno reformador}

O processo de alimentação dos queimadores presentes no forno reformador é bastante simples. Parte do combustível utilizado é proveniente da purga do sistema de PSA (ponto 23), uma vez que este gás contém alguns elementos combustíveis como hidrogênio e hidrocarbonetos residuais. O gás de purga é complementado com gás de refinaria (ponto 43), um tipo de gás combustível com poder calorífico 
próximo ao do gás natural (mas de diferente composição), proveniente dos processos de refino do petróleo. Este último corresponde a aproximadamente 10\% do gás utilizado nos queimadores.

$O$ ar utilizado na queima é retirado diretamente do meio ambiente (ponto 46), sendo pré-aquecido em uma das seções de convecção do forno reformador (pontos 47 e 48) e então levado até os queimadores, onde ocorre a combustão.

Os gases desta combustão são conduzidos através das seções de convecção do forno reformador, onde sua energia é aproveitada no aquecimento de diversos fluxos do processo, conforme comentado ao longo desta explanação. Após seu aproveitamento, estes gases são finalmente rejeitados ao meio ambiente (ponto 45).

\subsubsection{Tratamento do condensado do processo}

O condensado removido no vaso de alimentação da PSA (V-05) contém contaminantes gerados no forno reformador e no reator de shift. Dentre estes contaminantes pode-se destacar a amônia, o metanol, e outros elementos dissolvidos no condensado como monóxidos e dióxidos de carbono, hidrogênio, nitrogênio e metano.

Este condensado sofre uma redução de pressão na válvula-01 (pontos 24 e 25) sendo aquecido até o ponto de saturação antes de entrar na torre de separação de condensado (T-01), sendo alimentada pelo topo do equipamento (ponto 26).

Vapor (ponto 31), proveniente do gerador de vapor de baixa pressão (P-05), entra pela parte inferior do equipamento, criando um contra fluxo e removendo os elementos contaminantes pela parte superior do equipamento (ponto 32), enquanto o condensado acumulado na parte inferior da torre encontra-se livre de contaminantes e pode ser enviado para o sistema de coleta de condensado da refinaria (ponto 28), não sem antes ser resfriado ( $\mathrm{P}-08)$ e pré-aquecer o fluxo de alimentação da torre.

Os contaminantes removidos (ponto 32) são enviados para uma unidade de tratamento específica para este tipo de efluente, chamada de unidade retificadora de águas ácidas (URAA). 


\section{ANÁLISE EXERGÉTICA E TERMOECONÔMICA}

\subsection{INTRODUÇÃO TEÓRICA}

A Termodinâmica clássica fornece os conceitos de energia, transferência de calor e trabalho, balanço de energia, entropia, balanço de entropia, bem como formulas matemáticas para calcular as propriedades termodinâmicas no equilíbrio. A aplicação da Segunda Lei da Termodinâmica pode complementar os resultados obtidos em um balanço de energia, permitindo calcular tanto o valor termodinâmico real de um fluxo energético como o valor das ineficiências e perdas existentes em um processo ou sistema (TSATSARONIS, 1993).

A qualidade de uma determinada forma de energia pode ser vista como a capacidade de causar mudanças. A capacidade de se obter algum efeito desejado (aquecer um quarto, comprimir um gás, etc.) com $100 \mathrm{~J}$ de energia elétrica é maior do que com 100J de calor disponível a uma temperatura de $1000 \mathrm{~K}$, e ainda maior que esta mesma quantidade de energia disponível a $400 \mathrm{~K}$, considerando que a temperatura do ambiente seja de 300K. (KOTAS, 1985).

O conceito de exergia utiliza as idéias expressas nos parágrafos acima para qualificar os processos de transferência de energia. A qualidade destes processos está diretamente relacionada à capacidade de realizar trabalho.

Uma oportunidade de realizar trabalho existe toda vez que dois sistemas em estados diferentes são conectados. Este trabalho pode ser realizado até que os dois sistemas entrem em equilíbrio. Sendo assim, pode-se definir exergia como o trabalho obitido quando uma quantidade de matéria é levada ao estado de equilíbrio termodinâmico com o ambiente através de um processo reversível, envolvendo interações apenas com os componentes do ambiente específico mencionado anteriormente (SZARGUT; MORRIS; STEWARD, 1988).

Tsatsaronis (1993) diz em seu estudo que apesar do conceito de exergia ser frequentemente considerado um método recente de análise de sistemas energéticos, os primeiros fundamentos foram introduzidos no final do século XIX, suscedendo a formulação matemática da Segunda Lei da Termodinâmica. Gouy e 
Stodola, no final do mesmo século, apresentaram o desenvolvimento as idéias básicas iniciais, no entanto estes trabalhos não tiveram grande repercussão. Ainda segundo Tsatsaronis (1993) o desenvolvimento da análise exergética moderna foi iniciado por F. Bosnjakovic na Europa e J. H. Keenan nos Estados Unidos entre os anos 30 e 60 .

Atualmente a importância da análise exergética é amplamente reconhecida, uma vez que a aplicação dos conceitos de exergia e balanço exergético na análise de processos térmicos permite caracterizar como a exergia é utilizada ou destruída nas diversas etapas do processo, localizando e quantificando as irreversibilidades, o que permite a identificação de potenciais de melhoria energética.

\subsubsection{Ambiente de referência}

Qualquer sistema real está contido dentro de um ambiente específico no qual opera e interage. O conceito de meio ambiente (environment), utilizado no método de avaliação exergética, é extremamente importante uma vez que a definição das propriedades deste sistema afeta o resultado da análise.

Diferentemente do entendimento geral, na análise exergética o meio ambiente é um corpo gigante em perfeito estado de equilíbrio termodinâmico e químico. Sendo assim, este meio ambiente conceitual não possuiu gradientes ou diferenças envolvendo pressão, temperatura, potenciais químicos, energia cinética, energia potencial e, portanto, não existe a possibilidade de produzir trabalho a partir de nenhuma forma de interação entre partes deste meio ambiente (KOTAS, 1985).

Sendo assim, qualquer sistema que contenha um ou mais parâmetros fora dos definidos para o meio ambiente tem a possibilidade de realizar trabalho pela interação com este meio. Portanto, este meio ambiente ideal é uma referência média das propriedades naturais da atmosfera, do mar e da superfície da Terra, dependendo de qual destes ambientes está no entorno do sistema analisado.

$\mathrm{Na}$ análise exergética, o equilíbrio entre um determinado sistema e o meio ambiente de referência se dá em duas etapas, que equivalem à exergia física e à exergia química do sistema. A exergia física equivale à máxima quantidade de trabalho possível de se obter quando um sistema ou fluxo de uma substância passa 
de um estado inicial ao estado de referência restrito, caracterizado pelo equilíbrio térmico e mecânico com o meio ambiente. A exergia química é o trabalho máximo possível de se obter quando um sistema ou fluxo é levado do estado de referência restrito ao estado morto, caracterizado pela existência de equilíbrio térmico, mecânico e químico, interagindo reversivelmente com os componentes do meio ambiente.

A utilização de um estado termodinâmico de referência estático, onde seus parâmetros não sofrem a influência do sistema analisado, é questionável para alguns autores. Segundo Serova e Brodianski (2004) o ambiente definido não se comporta bem em diversos casos, sendo que pode ocorrer mudanças nos parâmetros do meio ambiente, especialmente quando o sistema interage com dois meios diferentes ao mesmo tempo.

Apesar das críticas, a utilização do ambiente de referência conforme proposto é a mais adequada para atingir os objetivos principais da análise exergética, sendo que a variação do meio ambiente só se torna importante em alguns casos específicos.

\subsubsection{Exergia e Balanço Exergético}

A exergia total, assim como a energia, pode ser considerada como a somatória de diversos componentes. Desconsiderando-se os efeitos nucleares, magnéticos, elétricos e de tensão superficial tem-se que o fluxo de exergia total $(\dot{B})$ é o resultado de quatro componentes: exergia física $\left(\dot{B}_{p h}\right)$, exergia química $\left(\dot{B}_{c h}\right)$, exergia cinética $\left(\dot{B}_{k}\right)$ e exergia potencial $\left(\dot{B}_{p}\right)$, conforme mostra a eq.(6.1):

$$
\dot{B_{t o t}}=\dot{B_{p h}}+\dot{B_{c h}}+\dot{B_{k}}+\dot{B_{p}}
$$

Estes termos podem também ser escritos na sua forma específica, dividindose os valores pela vazão mássica do fluxo estudado ou ainda em sua forma molar, introduzindo a propriedade exergia molar $(\bar{b})$ :

$$
\bar{b}=\frac{\dot{B}}{\dot{n}}
$$




\subsubsection{Exergia Física}

Exergia física é a quantidade máxima de trabalho obtido quando uma substância ou fluxo é levado de seu estado inicial para o estado de referência restrito.

Sabe-se que o trabalho é máximo quando um sistema muda de estado através de um processo reversível. Sendo assim é possível exprimir a exergia física conforme mostrado nas eqs. (6.3) e (6.4), sendo esta última a forma específica molar:

$$
\begin{aligned}
& B_{p h}=n_{t o t} \cdot\left[\left(\bar{h}_{1}-\bar{h}_{0}\right)-T_{0} \cdot\left(\bar{s}_{1}-\bar{s}_{0}\right)\right] \\
& \bar{b}_{p h}=\left(\bar{h}_{1}-\bar{h}_{0}\right)-T_{0} \cdot\left(\bar{s}_{1}-\bar{s}_{0}\right)
\end{aligned}
$$

Onde o subscrito "1" indica as propriedades molares do ponto de interesse e o subscrito " 0 " indica as propriedades molares do ambiente idealizado.

\subsubsection{Exergia Química}

Exergia química corresponde à quantidade máxima de trabalho obtida ao levar uma determinada substância do estado de referência restrito para o estado morto por processos reversíveis envolvendo transferência de calor e massa apenas com os elementos que compõe o meio ambiente.

Um sistema atinge o estado de referência restrito quando ocorre o equilíbrio entre a pressão e a temperatura do sistema e do meio ambiente. Ao atingir o estado de referência restrito, a possibilidade de realização de trabalho só não existe caso o sistema apresenta composição química igual ao do meio ambiente.

No entanto, é comum que as substâncias de um determinado sistema apresentem composições diferentes daquelas presentes no ambiente utilizado como 
referência. Tem-se, portanto, um potencial de realização de trabalho (exergia) relativo à diferença de composição entre o sistema e o meio ambiente.

No caso de mistura de gases a concentração dos elementos de um sistema pode ser diferente das concentrações típicas do ambiente idealizado. Neste caso, existe um potencial para realização de trabalho relativo à diferença entre a pressão parcial dos elementos do fluxo e a pressão parcial destes mesmos elementos no meio ambiente utilizado como referência.

Assim, a exergia química pode ser definida como o trabalho teórico mínimo para formar uma quantidade de matéria a partir das substâncias presentes no ambiente idealizado e levar essa quantidade de matéria para o estado ambiente, envolvendo interações apenas com o ambiente de referência. Utilizando a hipótese de que os gases presentes neste trabalho têm o comportamento de gás perfeito, pode-se definir a exergia química de uma mistura de gases perfeitos como mostrado na eqs. (6.5) e (6.6), sendo esta última a forma específica molar:

$$
\begin{aligned}
& \dot{B}_{c h}=\dot{n}_{t o t} \cdot\left[\sum y_{i} \cdot \psi_{i}+\bar{R} \cdot T_{0} \sum y_{i} \ln \left(y_{i}\right)\right] \\
& \bar{b}_{c h}=\sum y_{i} \cdot \psi_{i}+\bar{R} \cdot T_{0} \sum y_{i} \ln \left(y_{i}\right)
\end{aligned}
$$

Onde $0 y_{i}$ é a fração molar de cada componente da mistura e $\psi_{i}$ é a exergia química padrão de cada componente nas condições do ambiente especificado.

\subsubsection{Exergia Cinética e Exergia Potencial}

A exergia cinética e a exergia potencial equivalem, respectivamente, à energia cinética e à energia potencial, pois teoricamente podem ser totalmente convertidas em trabalho.

Neste trabalho, a exergia cinética e a exergia potencial não foram levadas em consideração por não possuírem valores significativos quando comparados com a exergia física e química. Sendo assim a exergia total do fluxo no caso estudado será sempre composta pela soma da exergia física com a exergia química. 


\subsubsection{Balanço Exergético}

O balanço exergético para um volume de controle em regime permanente é dado pela equação abaixo:

$$
\begin{aligned}
& (\dot{n} \cdot \bar{b})_{\text {saída }}-(\dot{n} \cdot \bar{b})_{\text {entrada }}=\sum \dot{Q} \cdot\left(1-\frac{T_{0}}{T}\right)-\sum \dot{W}-T_{0} \dot{S}_{\text {gerado }} \\
& \dot{B}_{\text {saída }}-\dot{B}_{\text {entrada }}=\dot{B}^{Q}-B^{W}-\dot{B}_{\text {destruída }}
\end{aligned}
$$

A variação entre os fluxos de entrada e saída de exergia, ou saldo exergético no volume de controle (lado esquerdo da equação), é o valor máximo de trabalho que poderia ser obtido nesta transformação. Esta quantidade de trabalho é igual a somatória de três componentes (lado direito da equação). O primeiro termo é associado ao calor transferido do ou para o sistema durante o processo e pode ser interpretado como a exergia (ou disponibilidade de realização de trabalho) transferida no processo proveniente da transferência de energia na forma de calor:

$$
\sum \dot{Q} \cdot\left(1-\frac{T_{0}}{T}\right)
$$

Este valor também pode ser interpretado como o trabalho realizado por um motor térmico operando entre $T$ e $T_{0}$, consumindo $Q$ e rejeitando calor para o meio a $\mathrm{T}_{0}$, ou ainda como o trabalho máximo que se pode obter de um fluxo de calor, uma vez que este é corrigido pelo termo de melhor eficiência para este processo (eficiência de Carnot).

O segundo termo é o trabalho útil realizado pelo sistema. Este trabalho não sofre nenhum tipo de correção por fatores de qualquer natureza uma vez que trabalho útil é exergia pura.

O terceiro termo do lado direito da equação contabiliza a exergia destruída devido às irreversibilidades inerentes aos processos de conversão de energia. $A$ exergia destruída ( $\left.\dot{B}_{\text {destruída}}\right)$ é relacionada com a geração de entropia através da equação abaixo:

$$
\dot{B}_{\text {destruída }}=T_{0} \dot{S}_{\text {gerado }}
$$


$\mathrm{Na}$ literatura, a exergia destruída é frequentemente chamada de "disponibilidade destruída", "irreversibilidade" ou ainda "trabalho disponível perdido". A eq.(6.10) é também conhecida como o teorema de Gouy-Stodola (BEJAN; TSATSARONIS; MORAN, 1996).

Interessante notar que, ao contrário da energia, a lei da conservação não pode ser aplicada à exergia, uma vez que esta pode ser destruída pelas irreversibilidades ao longo do processo estudado.

\subsubsection{Eficiência exergética}

A análise exergética utiliza a eficiência exergética como um parâmetro de avaliação de desempenho termodinâmico. Neste trabalho a eficiência exergética foi definida como a razão entre a exergia útil produzida e a exergia consumida no processo:

$$
\varepsilon=\frac{\text { Exergia útil produzida }}{\text { Consumo de Exergia }}
$$

Em alguns equipamentos, onde só há destruição de exergia (processos dissipativos), a eficiência exergética será definida como a razão entre saída e entrada:

$$
\varepsilon=\frac{\sum \text { Exergia de saída }}{\sum \text { Exergia de entrada }}
$$

A eq.(6.12) também será aplicada em equipamentos que não causam outro efeito senão a divisão do fluxo em várias partes ou a unificação de vários fluxos, como por exemplo um vaso de acumulação de vapor com uma entrada e várias saídas, várias entradas e uma única saída, ou ainda várias entradas e várias saídas.

Os equipamentos onde a eq.(6.12) foi utilizada na determinação da eficiência exergética serão explicitados no capítulo 7. 


\subsubsection{Termoeconomia}

A análise termoeconômica pode ser definida como sendo a combinação entre as análises distintas. Uma delas é a análise exergética, responsável por indicar a máxima quantidade de trabalho que pode ser obtida por fluxo da planta e por mensurar as irreversibilidades de cada componente do processo. A outra é a análise econômica, que consiste em mapear os custos envolvidos na construção, operação e manutenção da planta.

O termo "análise exergoeconômica" pode ser utilizado como alternativa ao termo "análise termoeconômica", conforme proposto por Tsatsaronis (1993) para diferenciar a análise realizada utilizando o custo exergético de outras análises que consideram elementos de análise termodinâmica com elementos econômicos, mas com critérios distintos dos apresentados e, eventualmente, também são chamadas da mesma forma.

\subsubsection{Histórico}

A primeira aplicação da exergia como critério de partição de custos foi realizada em 1932 por Joseph Keenan. No entanto, o desenvolvimento da termoeconomia "moderna" teve seu início na década de 60 do século passado, na Alemanha, com os trabalhos de W. Fretzscher, na Polônia com J. Szargut, na antiga União Soviética com V. Brodyansky e nos Estados Unidos com M. Tribus, R. B. Evans, E. F. Obert e R. A. Gaggioli (TSATSARONIS, 1993; SCIUBBA, 2005).

Os trabalhos de A. Valero e co-autores, C. Frangopoulos, G. Tsatsaronis e M. Von Spakovsky (PELLEGRINI, 2009), citados aqui em ordem alfabética sem qualquer relação com importância ou relevância, trazem contribuições mais recentes para o desenvolvimento da termoeconomia. 


\subsubsection{Conceituação teórica}

O custo de um determinado produto é obtido por meio da soma de todos os custos necessários para sua obtenção, conforme mostra de forma simplificada a eq.(6.13):

$$
\text { Custo }_{\text {Produto }}=\text { Custo }_{\text {Matéria-Prima }}+\text { Custo }_{\text {Construção,etc. }}
$$

A figura abaixo (fig.6.1) mostra um volume de controle genérico, onde os produtos são obtidos através da ação de um equipamento ou sistema sobre os insumos.

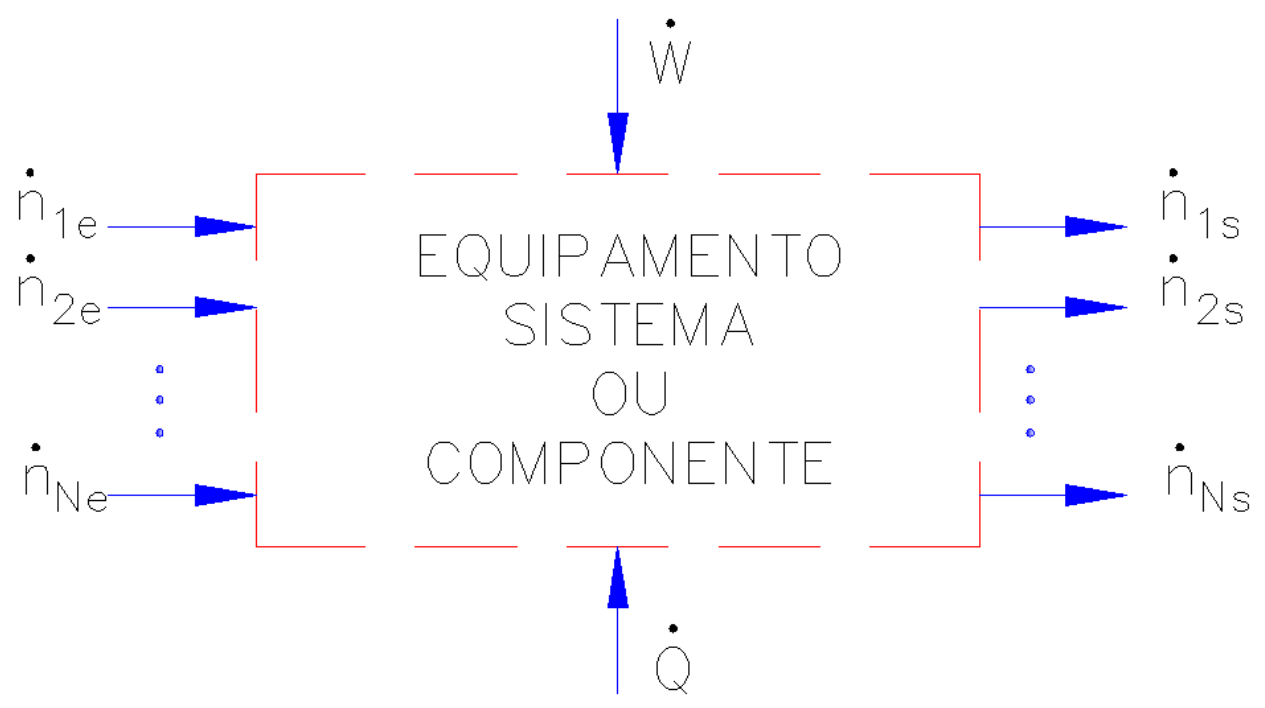

Figura 6.1: Volume de controle genérico

Ao utilizar o conceito de formação de custos apresentado na eq.(6.14) sobre a figura mostrada acima, é possível obter o balanço de custos sobre o equipamento ou sistema em questão:

$$
\sum \dot{\mathrm{C}}_{\text {insumos }}+\dot{\mathrm{C}}_{\text {calor }}+\dot{\mathrm{C}}_{\text {trabalho }}+\dot{\mathrm{Z}}=\sum \dot{\mathrm{C}}_{\text {produtos }}
$$


Assim, o custo dos produtos é igual à soma dos custos entrantes no sistema mais o custo relativo à utilização do equipamento ou sistema (designado pela letra "Ż"). Caso o sistema apresentado, além do produto principal, produzisse calor e trabalho, o custo relativo a estes dois itens estaria do lado direito da eq.(6.14).

$\mathrm{Na}$ termoeconomia, um custo é atribuído a cada fluxo de matéria/energia que entra ou sai do sistema estudado. Este custo, também chamado de custo exergético $\left(c_{1}\right)$, se relaciona com o custo total de determinado fluxo de entrada ou saída $\left(\dot{C}_{\mathrm{i}}\right)$, apresentado na eq.(6.14), através da exergia total presente no respectivo ponto de interesse $\left(\dot{B}_{\mathrm{i}}\right)$. Esta relação é mostrada pela eq.(6.15) abaixo.

$$
c_{i}=\frac{\dot{C}_{i}}{\dot{B}_{i}}
$$

Assim, considerando o subscrito "e" como entrada e "s" como saída do sistema ou equipamento, pode-se descrever o balanço de custos da análise termoeconômica conforme apresentado na eq.(6.16).

$$
\sum\left(c_{e} \dot{B}_{e}\right)_{m}+\dot{Z}=\sum\left(c_{s} \dot{B}_{s}\right)_{n}
$$

Ou ainda, considerando a exergia molar específica de cada fluxo $\left(\bar{\zeta}_{i}\right)$, tem-se a seguinte equação:

$$
\sum\left(c_{e} \dot{n}_{e} \bar{b}_{e}\right)_{m}+\dot{Z}=\sum\left(c_{s} \dot{n}_{s} \bar{b}_{s}\right)_{n}
$$

As eqs. 6.16 e 6.17 foram utilizadas na determinação dos balanços exergéticos da planta estudada. Para obter os demais custos exergéticos utilizou-se uma das metodologias de custeio apresentadas na seção seguinte. 


\subsubsection{Metodologias de custeio em base exergética}

De forma geral, as metodologias para análise termoeconômica podem ser divididas em dois grupos (LAZZARETTO; TSATSARONIS, 2006): métodos de custeio em base exergética e métodos de otimização. O primeiro tem por objetivo calcular os custos médios dos fluxos da planta enquanto o segundo visa calcular os custos marginais dos produtos.

Os métodos de custeio em base exergética (accounting methods) atribuem custos aos produtos e subprodutos do processo e avaliam equipamentos e sistemas. Neste trabalho foram utilizados os métodos da partição apresentados por Gaggioli e Wepfer (1980), onde são definidos dois critérios principais para a partição dos custos de um sistema:

- Critério da igualdade: Determina que todos os produtos do sistema tenham o mesmo custo em base exergética;

- Critério da extração: O custo relativo à variação de exergia do fluxo secundário e à utilização do equipamento é atribuído ao fluxo do produto principal.

Outro critério, chamado de "critério do subproduto", utiliza fatores externos (preços de mercado) para eliminar incógnitas do sistema. Este método não pode ser definido como um método de custeio em base exergética uma vez que não tem ligação direta com a distribuição do custo exergético pelas saídas do sistema. No método do subproduto, define-se uma das incógnitas como sendo o produto principal do processo ou equipamento e, atribuí-se a ele o menor valor de mercado encontrado para este produto. Assim, o custo restante do processo de obtenção do produto principal é atribuído ao subproduto. Este método não será aplicado neste trabalho. 


\subsection{BASES E PREMISSAS DA ANÁLISE REALIZADA}

A análise exergética da planta de reforma de gás natural foi desenvolvida considerando-se os dados de composição real, vazão mássica, pressão e temperatura em cada um dos equipamentos presentes no processo, sendo utilizada a hipótese de regime permanente.

Tal hipótese se baseia no fato das plantas analisadas operarem de forma contínua dentro da refinaria, sendo que paradas breves para manutenção são agendadas normalmente a cada 5 anos.

Os dados de processo foram retirados de documentos utilizados no desenvolvimento do projeto de implantação das unidades, servindo como base para a elaboração de todos os cálculos presentes neste trabalho.

Utilizou-se o aplicativo EES ${ }^{\circledR}$ (KLEIN, 2009) para determinar os valores de entalpia e entropia específicas. Com essas informações, foi possível realizar os balanços de massa, energia e exergia para cada componente, assim como foram determinadas suas respectivas eficiências exergéticas.

As condições de referência utilizadas foram $P_{0}=101,3 \mathrm{kPa}$ e $T_{0}=25^{\circ} \mathrm{C}$ e a composição da atmosfera aquela proposta por Szargut et al. (1988). Essas condições são representativas da região em que está instalada a planta estudada. Além disso, foram desprezadas eventuais transferências de calor entre os volumes de controle analisados e o meio ambiente.

Após um estudo sobre 0 fator de compressibilidade em todos os pontos do sistema verificou-se que este diferia pouco do valor unitário (CRUZ; OLIVEIRA JR., 2008). Essas pequenas variações não induziriam a grandes erros caso os gases estudados fossem modelados como gás perfeito. Sendo assim, a simplificação de considerar os gases estudados se comportando como gases perfeitos será utilizada neste trabalho.

A água foi modelada como substância pura, uma vez que ao longo do processo produtivo ocorrem diversas mudanças de fase e a modelagem deste elemento como gás ideal poderia comprometer os resultados.

Apenas no caso de grandes temperaturas, acima de $400^{\circ} \mathrm{C}$, modelou-se a água como gás ideal pois poderia haver problemas com o limite de aplicação das equações de estado real da água presentes no programa. Esta aproximação 
também não influencia nos resultados obtidos, isso porque as pressões ao longo do processo são relativamente baixas.

Os dados relativos aos valores de equipamentos, custo de engenharia, construção entre outros foram obtidos através de planilhas de custo do projeto, propostas comerciais e entrevistas com profissionais envolvidos na real construção da planta de geração de hidrogênio. Sob este aspecto, apesar da falta de documentos que comprovem a veracidade das informações aqui utilizadas, tem-se uma caracterização de custos muito atual e próxima do que acontece no mercado. 


\section{ANÁLISE EXERGÉTICA DA UNIDADE DE GERAÇÃO DE HIDROGÊNIO}

As premissas estabelecidas no capítulo 6.2 foram para realização da análise exergética da planta de geração de hidrogênio estudada.

O processo de produção de hidrogênio da planta principal está descrito em detalhes no capítulo 5.2. A identificação dos equipamentos e dos pontos de análise condiz com a planta síntese desenvolvida para este caso, apresentada no capítulo 5.1 .

\subsection{RESULTADOS DA ANÁLISE EXERGÉTICA}

Aplicando-se os conceitos e premissas discutidas estabelecidos no capítulo 6, foi possível determinar os fluxos exergéticos de cada ponto do processo principal (tab.7.6). Estes resultados serão muito importantes na realização da análise termoeconômica da unidade de geração de hidrogênio, bem como numa discussão mais aprofundada sobre possíveis melhorias do processo produtivo.

O aplicativo EES $^{\circledR}$ (KLEIN, 2009) foi utilizado para determinar os valores de entalpia e entropia específicas. Os detalhes para determinação destes e de outros valores podem ser encontrados no programa, mostrado na íntegra na seção de anexos deste trabalho.

Com essa informação, foi possível realizar os balanços de massa, energia e exergia para cada componente indicado na planta síntese, assim como foram determinadas suas respectivas eficiências exergéticas.

A tabela 7.1 mostra as principais propriedades dos fluxos em cada ponto da unidade de geração de hidrogênio o resultado da análise exergética em cada ponto. 
Tabela 7.1- Valores obtidos na análise exergética por ponto do processo

\begin{tabular}{|c|c|c|c|c|c|c|}
\hline Ponto & $\begin{array}{c}\text { Vazão molar } \\
\text { (kmol/s) }\end{array}$ & $\begin{array}{c}\text { Temperatura } \\
\left({ }^{\circ} \mathrm{C}\right)\end{array}$ & $\begin{array}{l}\text { Pressão } \\
\text { (bar) }\end{array}$ & $\begin{array}{c}\text { Exergia Física } \\
(\mathrm{kJ} / \mathrm{kmol})\end{array}$ & $\begin{array}{c}\text { Exergia Química } \\
(\mathrm{kJ} / \mathrm{kmol})\end{array}$ & $\begin{array}{c}\text { Exergia Total } \\
(\mathrm{kJ} / \mathrm{kmol})\end{array}$ \\
\hline 1 & 0,228 & 25 & 44,13 & 9355 & 890514 & 899870 \\
\hline 2 & 0,228 & 25 & 36,77 & 8903 & 890514 & 899418 \\
\hline 3 & 0,228 & 190 & 30,69 & 9939 & 890514 & 900453 \\
\hline 4 & 0,04782 & 240 & 14,91 & 16516 & 900 & 17416 \\
\hline 5 & 0,04782 & 200 & 14,61 & 2920 & 900 & 3820 \\
\hline 6 & 0,0114 & 40 & 30,69 & 8466 & 235851 & 244317 \\
\hline 7 & 0,2394 & 185 & 30,69 & 9833 & 858868 & 868700 \\
\hline 8 & 0,2394 & 400 & 29,71 & 15124 & 858868 & 873992 \\
\hline 9 & 0,2394 & 350 & 28,83 & 13483 & 858868 & 872351 \\
\hline 10 & 1,243 & 410 & 28,83 & 20155 & 164933 & 185087 \\
\hline 11 & 1,243 & 510 & 28,34 & 22646 & 164933 & 187579 \\
\hline 12 & 1,644 & 830 & 25,01 & 25626 & 139541 & 165167 \\
\hline 13 & 1,644 & 371 & 24,61 & 14481 & 139541 & 154022 \\
\hline 14 & 1,644 & 410 & 24,12 & 14926 & 138721 & 153647 \\
\hline 15 & 1,644 & 236 & 23,83 & 11769 & 138751 & 150520 \\
\hline 16 & 1,644 & 163 & 23,44 & 8720 & 139174 & 147895 \\
\hline 17 & 1,644 & 65 & 22,95 & 4924 & 140322 & 145246 \\
\hline 18 & 1,644 & 44 & 22,56 & 4785 & 140366 & 145151 \\
\hline 19 & 2,991 & 32 & 3,923 & 11,35 & 900 & 911,3 \\
\hline 20 & 2,991 & 40 & 1,961 & 29,2 & 900 & 929,2 \\
\hline 21 & 1,017 & 40 & 22,56 & 7684 & 226154 & 233839 \\
\hline 22 & 0,6317 & 45 & 18,63 & 7236 & 235845 & 243082 \\
\hline 23 & 0,3866 & 35 & 0,3432 & -2643 & 211658 & 209015 \\
\hline 24 & 0,627 & 40 & 22,56 & 92,53 & 1270 & 1363 \\
\hline 25 & 0,627 & 40 & 4,903 & 47,86 & 1270 & 1318 \\
\hline 26 & 0,627 & 110 & 4,903 & 792 & 1270 & 2062 \\
\hline 27 & 0,6642 & 143,4 & 2,844 & 1431 & 900 & 2331 \\
\hline 28 & 0,6642 & 77 & 2,648 & 309,7 & 900 & 1210 \\
\hline 29 & 0,3461 & 140 & 12,75 & 1370 & 900 & 2270 \\
\hline 30 & 0,3461 & 140 & 4,805 & 1356 & 900 & 2256 \\
\hline 31 & 0,1094 & 158 & 4,805 & 12949 & 900 & 13849 \\
\hline 32 & 0,07239 & 140 & 2,746 & 11173 & 3775 & 14948 \\
\hline 33 & 0,07239 & 139 & 2,059 & 10493 & 3775 & 14268 \\
\hline 34 & 1,459 & 145 & 36,28 & 1520 & 900 & 2420 \\
\hline 35 & 1,459 & 232 & 35,99 & 3982 & 900 & 4882 \\
\hline 36 & 1,415 & 238 & 29,62 & 17456 & 900 & 18356 \\
\hline 37 & 1,415 & 436 & 30,2 & 22496 & 900 & 23396 \\
\hline 38 & 0,4115 & 436 & 30,2 & 22496 & 900 & 23396 \\
\hline 39 & 1,003 & 436 & 30,2 & 22496 & 900 & 23396 \\
\hline 40 & 0,07496 & 145 & 36,28 & 1520 & 900 & 2420 \\
\hline 41 & 0,4864 & 240 & 14,91 & 16516 & 900 & 17416 \\
\hline 42 & 0,04427 & 238 & 31,38 & 4189 & 900 & 5089 \\
\hline 43 & 0,03439 & 30 & 3,138 & 2804 & 934593 & 937397 \\
\hline 44 & 1,746 & 975 & 1,004 & 19822 & 1626 & 21448 \\
\hline 45 & 1,867 & 184 & 1,022 & 1679 & 1434 & 3113 \\
\hline 46 & 1,401 & 26 & 1,002 & $-26,64$ & 104,8 & 78,16 \\
\hline 47 & 1,401 & 26 & 1,002 & $-26,64$ & 104,8 & 78,16 \\
\hline 48 & 1,401 & 191 & 1,002 & 974,8 & 104,8 & 1080 \\
\hline 49 & 0,2401 & 152 & 3,138 & 11928 & 900 & 12828 \\
\hline 50 & 19,67 & 238 & 31,38 & 4189 & 900 & 5089 \\
\hline 51 & 19,67 & 238 & 31,38 & 4780 & 900 & 5680 \\
\hline 52 & 3,466 & 238 & 31,38 & 17497 & 900 & 18397 \\
\hline 53 & 3,466 & 238 & 31,38 & 4189 & 900 & 5089 \\
\hline 54 & 3,466 & 238 & 31,38 & 6436 & 900 & 7336 \\
\hline 55 & 0,4386 & 240 & 14,91 & 16516 & 900 & 17416 \\
\hline 56 & 0,3461 & 145 & 36,28 & 1520 & 900 & 2420 \\
\hline 57 & 0,3461 & 158 & 4,805 & 12949 & 900 & 13849 \\
\hline 58 & 0,2367 & 158 & 4,805 & 12949 & 900 & 13849 \\
\hline 59 & 0,04427 & 100 & 1 & 2656 & 900 & 3556 \\
\hline 60 & 1,88 & 145 & 36,28 & 1520 & 900 & 2420 \\
\hline
\end{tabular}


Para uma melhor visualização dos dados apresentados, a tabela 7.2 apresenta apenas os resultados para os fluxos de entrada e saída da unidade de processo.

Tabela 7.2- Valores obtidos na análise exergética por ponto de entrada e saída do processo

\begin{tabular}{|c|c|c|c|c|c|c|c|c|}
\hline & Ponto & Descrição & $\begin{array}{c}\text { Vazão } \\
\text { molar } \\
\text { (kmol/s) }\end{array}$ & $\begin{array}{c}\text { Temp. } \\
\left({ }^{\circ} \mathrm{C}\right)\end{array}$ & $\begin{array}{c}\text { Pressão } \\
\text { (bar) }\end{array}$ & $\begin{array}{c}\text { Exergia } \\
\text { Física } \\
(\mathrm{kJ} / \mathrm{kmol})\end{array}$ & $\begin{array}{c}\text { Exergia } \\
\text { Química } \\
\text { (kJ/kmol) }\end{array}$ & $\begin{array}{c}\text { Exergia } \\
\text { Total } \\
(\mathrm{kJ} / \mathrm{kmol})\end{array}$ \\
\hline \multirow{9}{*}{ 产 } & 5 & Condensado & 0,048 & 200 & 14,61 & 2.920 & 900 & 3.820 \\
\hline & 20 & Água de resfriamento (saída) & 2,991 & 40 & 1,96 & 29 & 900 & 929 \\
\hline & 22 & Hidrogênio & 0,632 & 45 & 18,63 & 7.236 & 235.845 & 243.082 \\
\hline & 28 & Condensado & 0,664 & 77 & 2,648 & 310 & 900 & 1.210 \\
\hline & 32 & Condensado & 0,072 & 140 & 2,746 & 11.173 & 3.775 & 14.948 \\
\hline & 45 & Gases de chaminé & 1,867 & 184 & 1,022 & 1.679 & 1.434 & 3.113 \\
\hline & 55 & Vapor & 0,439 & 240 & 14,91 & 16.516 & 900 & 17.416 \\
\hline & 58 & Vapor & 0,237 & 158 & 4,81 & 12.949 & 900 & 13.849 \\
\hline & 59 & Condensado & 0,044 & 100 & 1,00 & 2.656 & 900 & 3.556 \\
\hline \multirow{6}{*}{$\begin{array}{l}\text { y. } \\
\text { s. } \\
\sum_{w}^{ \pm}\end{array}$} & 1 & Gás Natural (Processo) & 0,228 & 25 & 44,13 & 9.355 & 890.514 & 899.870 \\
\hline & 6 & Hidrogênio de reciclo & 0,011 & 40 & 30,69 & 8.466 & 235.851 & 244.317 \\
\hline & 19 & Água de resfriamento (entrada) & 2,991 & 32 & 3,92 & 11 & 900 & 911 \\
\hline & 43 & Gás Natural (Queimadores) & 0,034 & 30 & 3,138 & 2.804 & 934.593 & 937.397 \\
\hline & 46 & Ar & 1,401 & 26 & 1,002 & -27 & 105 & 78 \\
\hline & 60 & Água de caldeira & 1,880 & 145 & 36,28 & 1.520 & 900 & 2.420 \\
\hline
\end{tabular}

A partir dos dados apresentados na tabela 7.1, é possível determinar a taxa de exergia destruída em cada componente da planta, bem como a participação percentual de cada componente na taxa de exergia destruída total. Estes resultados estão mostrados na tabela 7.3. 
Tabela 7.3- Taxa de exergia destruída em cada componente

\begin{tabular}{|c|c|c|c|}
\hline $\begin{array}{c}\text { CÓDIGO } \\
\text { DO } \\
\text { EQUIPAMENTO }\end{array}$ & DESCRIÇÃO & $\begin{array}{c}\text { TAXA DE EXERGIA } \\
\text { DESTRUÍDA } \\
(\mathrm{kW})\end{array}$ & (\%) \\
\hline V-01 & VASO PULMÃO & 103 & $0,1 \%$ \\
\hline P-01 & PERMUTADOR DE PRÉ-AQUECIMENTO DA CARGA & 414,1 & $0,6 \%$ \\
\hline MX-01 & MISTURADOR 01 - CONEXÃO ENTRE TUBULAÇÕES & 119,7 & $0,2 \%$ \\
\hline $\mathrm{R}-01 \mathrm{H} / \mathrm{A} / \mathrm{B}$ & SISTEMA DE HIDRODESSULFURIZAÇÃO & 392,7 & $0,5 \%$ \\
\hline MX-02 & MISTURADOR 02 - CONEXÃO ENTRE TUBULAÇÕES & 2261 & $3,2 \%$ \\
\hline $\mathrm{F}-01$ & FORNO REFORMADOR & 50193 & $70,1 \%$ \\
\hline P-03 & RECUPERADOR DE CALOR & 6691 & $9,3 \%$ \\
\hline $\mathrm{R}-02$ & REATOR DE AUMENTO (SHIFT) & 616 & $0,9 \%$ \\
\hline P-04 & AQUECEDOR DE ÁGUA DE CALDEIRA & 1610 & $2,2 \%$ \\
\hline P-05 & GERADOR DE VAPOR DE BAIXA PRESSÃO & 303,1 & $0,4 \%$ \\
\hline P-06 & $1^{\circ}$ RESFRIADOR DA ALIMENTAÇÃO DA PSA & 4353 & $6,1 \%$ \\
\hline P-07 & $2^{\circ}$ RESFRIADOR DA ALIMENTAÇÃO DA PSA & 103,4 & $0,1 \%$ \\
\hline V-05 & VASO DE ALIMENTAÇÃO DA PSA & 12,88 & $0,0 \%$ \\
\hline PSA & SISTEMA DE PURIFICAÇÃO DO H2 - PSA & 3389 & $4,7 \%$ \\
\hline VALVE-01 & VÁLVULA DO SISTEMA DE TRATAMENTO DE CONDENSADO & 28,01 & $0,0 \%$ \\
\hline $\mathrm{P}-08$ & AQUECEDOR DA ALIMENTAÇÃO - TRATAMENTO DE CONDENSADO & 277,9 & $0,4 \%$ \\
\hline T-01 & TORRE DE SEPARAÇÃO DE CONDENSADO & 178,6 & $0,2 \%$ \\
\hline V-03 & VASO DE VAPOR & 437,3 & $0,6 \%$ \\
\hline V-04 & VASO DE REJEITOS (BLOWDOWN) & 67,88 & $0,1 \%$ \\
\hline VALVE-02 & VÁLVULA DO SISTEMA DE GERAÇÃO DE VAPOR & 56,53 & $0,1 \%$ \\
\hline TOTAL & & 71608,1 & $100,0 \%$ \\
\hline
\end{tabular}

Percebe-se que o forno reformador é o grande responsável do ponto de vista da taxa de exergia destruída ao longo do processo de produção do hidrogênio.

As eficiências exergéticas de todos os componentes e da unidade de geração de hidrogênio como um todo foram calculadas pelas eq.7.2 a eq.7.22. Os pontos de referência mostrados são relativos à planta síntese apresentada no capítulo 5 (figura 5.1). Por uma questão de simplicidade, as equações serão apresentadas em função do fluxo de exergia total no ponto de interesse $\left(\dot{B}_{i}\right)$ conforme apresentado na eq.(7.1).

$$
\dot{B}_{i}=\dot{n}_{i} \cdot \bar{b}_{i}
$$

Onde " $\dot{n}_{i}$ " é a vazão molar e " $b_{i}$ " é a exergia específica molar de determinado fluxo da planta. 
Vaso pulmão da alimentação (V-01) ${ }^{1}$ :

$$
\varepsilon_{(V-01)}=\frac{\dot{B}_{2}}{\dot{B}_{1}}
$$

Pré-aquecedor de carga (P-01):

$$
\varepsilon_{(P-01)}=\frac{\dot{B}_{3}-\dot{B}_{2}}{\dot{B}_{4}-\dot{B}_{5}}
$$

Misturador $01(\mathrm{MX}-01)^{1}$ :

$$
\varepsilon_{(M X-01)}=\frac{\dot{B}_{7}}{\dot{B}_{3}+\dot{B}_{6}}
$$

Sistema de Hidrodessulfurização (R-01H, R-01A e R-01B) ${ }^{1}$ :

$$
\mathcal{E}_{(R-01 H / A / B)}=\frac{\dot{B}_{9}}{\dot{B}_{8}}
$$

Misturador $02(\mathrm{MX}-02)^{1}$ :

$$
\varepsilon_{(M X-02)}=\frac{\dot{B}_{10}}{\dot{B}_{9}+\dot{B}_{39}}
$$

Forno reformador (F-01)

$$
\varepsilon_{(F-01)}=\frac{\dot{B}_{8}-\dot{B}_{7}+\dot{B}_{11}-\dot{B}_{10}+\dot{B}_{48}-\dot{B}_{47}+\dot{B}_{12}-\dot{B}_{11}+\dot{B}_{54}-\dot{B}_{53}+\dot{B}_{37}-\dot{B}_{36}}{\dot{B}_{43}+\dot{B}_{23}+\dot{B}_{48}+\dot{W}_{(F-01)}-\dot{B}_{45}}
$$

Recuperador de calor (P-03):

$$
\varepsilon_{(P-03)}=\frac{\dot{B}_{51}-\dot{B}_{50}}{\dot{B}_{12}-\dot{B}_{13}}
$$

Reator de Shift (R-02) ${ }^{1}$ :

$$
\varepsilon_{(R-02)}=\frac{\dot{B}_{14}}{\dot{B}_{13}}
$$

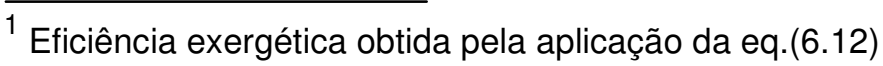


Aquecedor da água de alimentação (P-04):

$$
\varepsilon_{(P-04)}=\frac{\dot{B}_{35}-\dot{B}_{34}}{\dot{B}_{14}-\dot{B}_{15}}
$$

Gerador de vapor de baixa pressão (P-05):

$$
\varepsilon_{(P-05)}=\frac{\dot{B}_{57}-\dot{B}_{30}}{\dot{B}_{15}-\dot{B}_{16}}
$$

Primeiro resfriador da alimentação do sistema da PSA (P-06) ${ }^{1}$ :

$$
\mathcal{E}_{(P-06)}=\frac{\dot{B}_{17}}{\dot{B}_{16}+\dot{W}_{(P-06)}}
$$

Segundo resfriador da alimentação do sistema da PSA (P-07):

$$
\mathcal{E}_{(P-07)}=\frac{\dot{B}_{20}-\dot{B}_{19}}{\dot{B}_{17}-\dot{B}_{18}}
$$

Vaso de alimentação da PSA (V-05) ${ }^{1}$ :

$$
\varepsilon_{(V-05)}=\frac{\dot{B}_{21}+\dot{B}_{24}}{\dot{B}_{18}}
$$

Sistema de purificação (PSA) ${ }^{1}$ :

$$
\varepsilon_{(P S A)}=\frac{\dot{B}_{22}+\dot{B}_{23}}{\dot{B}_{21}}
$$

Válvula 01 (Valve-01) ${ }^{1}$ :

$$
\mathcal{E}_{(\text {Valve-1) }}=\frac{\dot{B}_{25}}{\dot{B}_{24}}
$$

\footnotetext{
${ }^{1}$ Eficiência exergética obtida pela aplicação da eq.(6.12)
} 
Aquecedor da alimentação da torre de tratamento de condensado (P-08):

$$
\varepsilon_{(P-08)}=\frac{\dot{B}_{26}-\dot{B}_{25}}{\dot{B}_{27}-\dot{B}_{28}}
$$

Torre de tratamento de condensado $(\mathrm{T}-01)^{1}$ :

$$
\varepsilon_{(T-01)}=\frac{\dot{B}_{27}-\dot{B}_{32}}{\dot{B}_{26}-\dot{B}_{31}}
$$

Vaso de vapor $(\mathrm{V}-03)^{1}$ :

$$
\varepsilon_{(V-03)}=\frac{\dot{B}_{36}+\dot{B}_{42}+\dot{B}_{50}+\dot{B}_{53}}{\dot{B}_{35}+\dot{B}_{51}+\dot{B}_{54}+\dot{W}_{(V-03)}}
$$

Vaso de Blown Down (V-04) ${ }^{1}$ :

$$
\varepsilon_{(V-04)}=\frac{\dot{B}_{59}}{\dot{B}_{42}}
$$

Válvula $02\left(\right.$ Valve-02) ${ }^{1}$ :

$$
\mathcal{E}_{(\text {Valve-1) }}=\frac{\dot{B}_{30}}{\dot{B}_{56}}
$$

Planta de reforma ${ }^{1}$ :

$$
\varepsilon_{(U G H)}=\frac{\dot{B}_{20}+\dot{B}_{22}+\dot{B}_{28}+\dot{B}_{32}+\dot{B}_{45}+\dot{B}_{55}+\dot{B}_{58}+\dot{B}_{59}}{\dot{B}_{1}+\dot{B}_{6}+\dot{B}_{19}+\dot{B}_{43}+\dot{B}_{46}+\dot{B}_{60}}
$$


Os resultados da determinação da eficiência exergética de cada equipamento podem ser vistos na tabela 7.4. Os resultados mais relevantes desta análise estão indicados com destaque na tabela.

Tabela 7.4- Eficiências exergéticas de cada componente e na planta como um todo

\begin{tabular}{|c|c|c|}
\hline $\begin{array}{c}\text { CÓDIGO } \\
\text { DO } \\
\text { EQUIPAMENTO }\end{array}$ & DESCRIÇÃO & $\begin{array}{l}\text { EFICIÊNCIA } \\
\text { EXERGÉTICA } \\
(\%)\end{array}$ \\
\hline V-01 & VASO PULMÃO & $100,0 \%$ \\
\hline P-01 & PERMUTADOR DE PRÉ-AQUECIMENTO DA CARGA & $36,3 \%$ \\
\hline $\mathrm{MX}-01$ & MISTURADOR 01 - CONEXÃO ENTRE TUBULAÇÕES & $99,9 \%$ \\
\hline $\mathrm{R}-01 \mathrm{H} / \mathrm{A} / \mathrm{B}$ & SISTEMA DE HIDRODESSULFURIZAÇÃO & $99,8 \%$ \\
\hline $\mathrm{MX}-02$ & MISTURADOR 02 - CONEXÃO ENTRE TUBULAÇÕES & $99,0 \%$ \\
\hline F-01 & FORNO REFORMADOR & $54,1 \%$ \\
\hline P-03 & RECUPERADOR DE CALOR & $63,5 \%$ \\
\hline R-02 & REATOR DE AUMENTO (SHIFT) & $99,8 \%$ \\
\hline P-04 & AQUECEDOR DE ÁGUA DE CALDEIRA & $69,9 \%$ \\
\hline P-05 & GERADOR DE VAPOR DE BAIXA PRESSÃO & $93,0 \%$ \\
\hline P-06 & $1^{\circ}$ RESFRIADOR DA ALIMENTAÇÃO DA PSA & $98,2 \%$ \\
\hline P-07 & $2^{\circ}$ RESFRIADOR DA ALIMENTAÇÃO DA PSA & $34,1 \%$ \\
\hline V-05 & VASO DE ALIMENTAÇÃO DA PSA & $100,0 \%$ \\
\hline PSA & SISTEMA DE PURIFICAÇÃO DO H2 - PSA & $98,6 \%$ \\
\hline VALVE-01 & VÁLVULA DO SISTEMA DE TRATAMENTO DE CONDENSADO & $96,7 \%$ \\
\hline P-08 & AQUECEDOR DA ALIMENTAÇÃO - TRATAMENTO DE CONDENSADO & $62,7 \%$ \\
\hline $\mathrm{T}-01$ & TORRE DE SEPARAÇÃO DE CONDENSADO & $93,6 \%$ \\
\hline V-03 & VASO DE VAPOR & $99,7 \%$ \\
\hline V-04 & VASO DE REJEITOS (BLOWDOWN) & $69,9 \%$ \\
\hline VALVE-02 & VÁLVULA DO SISTEMA DE GERAÇÃO DE VAPOR & $93,3 \%$ \\
\hline & PLANTA DE GERAÇÃO DE HIDROGÊNIO & $70,7 \%$ \\
\hline
\end{tabular}

A análise dos resultados para a análise exergética da planta de geração de hidrogênio será realizada na seção seguinte. 


\subsection{DISCUSSÃO DOS RESULTADOS OBTIDOS NA ANÁLISE EXERGÉTICA DA PLANTA DE GERAÇÃO DE HIDROGÊNIO}

Com relação aos resultados obtidos é possível verificar que o responsável pela maior parte das irreversibilidades do processo produtivo é 0 forno reformador (F-01). Conforme os dados presentes na tabela 7.3, este equipamento é o responsável por $70 \%$ de toda a exergia destruída no processo produtivo. Além disso, a eficiência exergética do forno reformador é de apenas $54,1 \%$. Isso significa que pequenos ganhos de eficiência neste equipamento causariam aumentos significativos na eficiência global da planta.

O resultado obtido para o forno reformador é de certa forma justificado pela forte irreversibilidade que ocorre no interior deste equipamento, visto que este é o responsável pela principal reação química ocorrida no processo.

Uma planta similar, de menor capacidade $\left(550.000 \mathrm{Nm}^{3} / \mathrm{dia}\right)$ foi analisada por Cruz e Oliveira Jr. (2008). Os resultados relativos à exergia destruída em cada equipamento $\mathrm{e}$ as respectivas eficiências exergéticas estão mostradas nas tabelas 7.5 e 7.6 respectivamente.

Tabela 7.5 - Taxa de exergia destruída em cada componente para a planta de menor capacidade $\left(550.000 \mathrm{Nm}^{3} / \mathrm{dia}\right)$ (CRUZ; OLIVEIRA JR., 2008).

\begin{tabular}{|l|c|c|}
\hline \multicolumn{1}{|c|}{ Componente } & $\begin{array}{c}\text { Taxa de exergia } \\
\text { destruída (kW) }\end{array}$ & (\%) \\
\hline Compressor de carga & 20,55 & $0,06 \%$ \\
\hline Pré-aquecedor de carga TC-01 & 110,1 & $0,30 \%$ \\
\hline Misturador-01 & 47,07 & $0,13 \%$ \\
\hline Misturador-02 & $1.024,07$ & $2,77 \%$ \\
\hline Trocador TC-02 & $2.885,86$ & $7,82 \%$ \\
\hline Reator de Shift & 197,68 & $0,54 \%$ \\
\hline Trocador TC-02 & 759,27 & $2,06 \%$ \\
\hline Trocador TC-03 & $4.890,60$ & $13,25 \%$ \\
\hline Trocador TC-04 & 410,08 & $1,11 \%$ \\
\hline PSA System & 867,01 & $2,35 \%$ \\
\hline Válvula-01 & 45,17 & $0,12 \%$ \\
\hline Válvula -02 & 35,2 & $0,10 \%$ \\
\hline Válvula -03 & 27,11 & $0,07 \%$ \\
\hline Válvula -04 & 35,27 & $0,10 \%$ \\
\hline Tanque de vapor & 3,62 & $0,01 \%$ \\
\hline Reformador & $25.559,05$ & $69,23 \%$ \\
\hline Total & $36.917,70$ & $100 \%$ \\
\hline
\end{tabular}


Tabela 7.6 - Eficiências Exergéticas para a planta de menor capacidade (550.000 $\left.\mathrm{Nm}^{3} / \mathrm{dia}\right)$ (CRUZ; OLIVEIRA JR., 2008).

\begin{tabular}{|c|c|}
\hline Componente & Eficiência exergética \\
\hline Compressor de carga & $84,95 \%$ \\
\hline Pré-aquecedor de alimentação & $51,85 \%$ \\
\hline Caldeira de recuperação & $63,05 \%$ \\
\hline TC-03 & $73,48 \%$ \\
\hline Reformador & $46,40 \%$ \\
\hline Planta & $\mathbf{6 6 , 6 0 \%}$ \\
\hline
\end{tabular}

Comparando a eficiência exergética obtida para o forno reformador com a eficiência exergética apresentada na tabela 7.6, relativa à planta de menor capacidade, percebe-se que houve uma diferença significativa de eficiência entre os equipamentos, sendo $46,4 \%$ para a planta de menor capacidade e $54,1 \%$ na planta estudada. Esta diferença de eficiência está relacionada diretamente à temperatura de saída dos gases do forno. Na planta de menor capacidade a temperatura dos gases de exaustão é igual a $359^{\circ} \mathrm{C}$, enquanto na planta estudada neste trabalho a temperatura do fluxo de exaustão do forno reformador é de apenas $184^{\circ} \mathrm{C}$.

A diferença expressiva de eficiências do forno reformador obtida na comparação das duas plantas se reflete na eficiência global da planta de geração de hidrogênio estudada. Comparando a eficiência do forno reformador e da planta como um todo, percebe-se que para um aumento teórico de $8 \%$ na eficiência do forno reformador (de $46,1 \%$ para $54,1 \%$ ) tem-se um ganho global de eficiência de 3,5\% no processo de produção (de $66,6 \%$ para $70,1 \%$ ) o que é bastante significativo.

Rostrup-Nielsen (2005) indica que a taxa de consumo teórica mínima requerida no processo de reforma a vapor é de $2,81 \mathrm{Gcal} / 1000 \mathrm{Nm}^{3}$ de $\mathrm{H}_{2}$, quando se inicia o processo com água líquida. Isso equivale a $11,8 \mathrm{GJ} / 1000 \mathrm{Nm}^{3}$. Considerando as entradas de gás natural (pontos 1 e 43 do processo), a exergia total de cada fluxo e suas respectivas vazões molares, conforme indicados na tabela 7.2, obtem-se o valor de 20,48GJ de energia consumida por dia. Para uma planta de $1.200 .000 \mathrm{Nm}^{3} /$ dia, esta razão proposta fica em $17,1 \mathrm{GJ} / 1000 \mathrm{Nm}^{3}$, ou ainda $4,1 \mathrm{Gcal} / 1000 \mathrm{Nm}^{3}$. Isso demonstra o potencial de melhoria do processo estudado, uma vez que o rendimento da planta está 30\% abaixo do valor teórico, segundo a metodologia proposta. 
A utilização de materiais que permitam obter temperaturas mais altas de reação no forno reformador (acima de $1050^{\circ} \mathrm{C}$ ) associadas a uma razão vapor-gás natural adequada, pode permitir a operação de plantas de hidrogênio com uma eficiência de até $3 \mathrm{Gcal} / 1000 \mathrm{Nm}^{3}$ (ROSTRUP-NIELSEN, 2005). Isso significa que parte da ineficiência do processo se deve a fatores construtivos, impossíveis de serem alterados na planta estudada. Ainda assim, parte do ganho de eficiência pode vir de intervenções no processo.

Cruz e Oliveira Jr. (2008) sugeriram aproveitar os gases de saída do forno reformador considerando um trocador adicional, com o custo similar ao de outro trocador da planta, rendimento exergético de 70\%, perda de carga de $10 \%$ entre seções de entrada e saída e temperatura de saída dos gases de chaminé de $120^{\circ} \mathrm{C}$. Este cálculo simplificado resultou em uma redução de $0,82 \%$ no custo de produção de hidrogênio.

O mesmo procedimento não deve ser aplicado neste trabalho, uma vez que os gases de saída do forno reformador estudado não apresentam um grande potencial de aproveitamento térmico devido à sua baixa temperatura $\left(184^{\circ} \mathrm{C}\right)$ em relação à planta de menor capacidade apresentada.

Rostrup-Nielsen (2005) afirma que a redução da relação vapor-gás natural pode trazer ganhos de eficiência ao processo de reforma a vapor. Assim, a baixa eficiência exergética apresentada pelo forno reformador pode ser melhorada com estudos de otimização e com a utilização de materiais que permitam a obtenção de temperaturas mais altas no forno, ou a aplicação de estudos de permitirão o aumento de sua eficiência exergética.

É possível observar que alguns equipamentos do processo têm eficiências menores que a do forno reformador. É o caso do permutador de pré-aquecimento de carga (P-01) e do segundo resfriador da alimentação da PSA (P-07), ambos com eficiência exergética em torno de $35 \%$. A análise de um aumento na eficiência destes dois equipamentos é certamente importante, entretanto, os ganhos para o processo como um todo não serão grandes, visto que esses dois equipamentos somados representam menos que $1 \%$ da exergia destruída no processo. 


\section{ANÁLISE ECONÔMICA DA UNIDADE DE GERAÇÃO DE HIDROGÊNIO}

A análise dos custos envolvidos na construção, operação e manutenção da planta de geração de hidrogênio é essencial para a realização deste trabalho, uma vez que os valores obtidos nesta análise servem de base para as etapas subseqüentes.

Os dados utilizados neste capítulo trazem uma forte relação com a realidade de mercado atual, sendo que os valores apresentados são iguais aos declarados nas propostas comerciais utilizadas na compra dos equipamentos da planta.

Informações complementares foram obtidas em entrevistas com profissionais de comercialização e orçamentação, com grande experiência em projetos do setor de petróleo e gás natural.

\subsection{CUSTO DE CONSTRUÇÃO DA PLANTA}

\subsubsection{Definição do escopo de custos}

Como primeiro passo para a realização da análise econômica foi elaborada uma estimativa dos custos de implantação da planta de geração de hidrogênio.

O custo do um empreendimento deste tipo é fortemente influenciado por uma série de fatores. Um deles é o valor da mão-de-obra direta, que pode variar muito dependendo do país onde o projeto for realizado (produtividade dos operários, encargos trabalhistas, salário, etc.). Outro fator de influência é a sinergia entre unidades produtivas, sendo que a construção de unidades fora de complexos industriais tem um valor mais elevado por não contar com um sistema de utilidades integrado.

Sendo assim, é importante definir minimamente o que está sendo custeado para que a utilização dos dados presentes neste trabalho não seja feita de forma 
imprudente. Além disso, a declaração deste escopo de custos facilita a compreensão a respeito da abrangência do empreendimento. Essa definição pode ser vista na tabela 8.1 .

Tabela 8.1- Custos do empreendimento estudado - Definição do escopo (continua)

\begin{tabular}{|c|c|c|c|}
\hline A & CUSTOS DIRETOS & INCLUSO & NÃO INCLUSO \\
\hline A.1 & COMPRA DE EQUIPAMENTOS & & \\
\hline A.1.1 & CUSTO DE COMPRA DOS EQUIPAMENTOS & $\mathrm{x}$ & \\
\hline A.1.2 & PEÇAS AVULSAS & $\mathrm{x}$ & \\
\hline A.1.3 & FOLGA E SOBRESSALENTES & & $\mathrm{x}$ \\
\hline A.1.4 & FRETE & $\mathrm{x}$ & \\
\hline A.1.5 & IMPOSTOS, SEGURO, TAXAS & & $\mathrm{x}$ \\
\hline A.2 & CONSTRUÇÃO E MONTAGEM & & \\
\hline A.2.1 & MÃO DE OBRA DIRETA & $\mathrm{x}$ & \\
\hline A.2.2 & CONSUMÍVEIS (ELETRODOS, ENERGIA ELÉTRICA, ETC.) & $\mathrm{x}$ & \\
\hline A.3 & INSTRUMENTAÇÃO E CONTROLE & & \\
\hline A.3.1 & INSTRUMENTOS & $\mathrm{x}$ & \\
\hline A.3.2 & INSTALAÇÃO DOS INSTRUMENTOS & $\mathrm{x}$ & \\
\hline A.3.3 & CALIBRAÇÃO & $\mathrm{x}$ & \\
\hline A.3.4 & CABEAMENTO & $\mathrm{x}$ & \\
\hline A.4 & TUBULAÇÕES & & \\
\hline A.4.1 & TUBULAÇÕES DE PROCESSO (AÇO CARBONO, AÇO INOX E AÇO LIGA) & $\mathrm{x}$ & \\
\hline A.4.2 & CONEXÕES, VÁLVULAS, SUPORTES & $\mathrm{x}$ & \\
\hline A.4.3 & ISOLAMENTO E PINTURA & $\mathrm{x}$ & \\
\hline A.5 & EQUIPAMENTOS E MATERIAIS ELÉTRICOS & $\mathrm{x}$ & \\
\hline A.5.1 & GERADORES, RETIFICADORES DE TENSÃO, ESTABILIZADORES, ETC. & $\mathrm{x}$ & \\
\hline A.5.2 & CABOS, FIBRAS OPTICAS, ELETRODUTOS, LAMPADAS, ETC. & $\mathrm{x}$ & \\
\hline A.6 & CIVIL & & \\
\hline A.6.1 & SUB-ESTRUTURAS, BASES, PLATAFORMAS, ACESSOS & $\mathrm{x}$ & \\
\hline A.6.2 & PREDIOS AUXILIARES - OPERAÇÃO (ADM., MANUT., ETC.) & & $\mathrm{x}$ \\
\hline A.6.3 & TERRAPLANAGEM, ARRUAMENTO, ETC. & $x$ & \\
\hline A.6.4 & ESTRUTURAS PERMANENTES - PIPE RACK, PREDIOS DAS UNIDADES, ETC. & $\mathrm{x}$ & \\
\hline A.7 & UTILIDADES E SERVIÇOS & & \\
\hline A.7.1 & |CONSTRUÇÃO DE PLANTA DE UTILIDADES (VAPOR, TRATAMENTO DE EFLUENTES, ETC.) & & $\mathrm{x}$ \\
\hline A.7.2 & UTILIZAÇÃO DOS SERVIÇOS EXISTENTES (VAPOR, AR COMPRIMIDO, ETC.) & $\mathrm{x}$ & \\
\hline A.7.3 & INFRAESTRUTURA ADMINISTRATIVA (MOBILIA, COMPUTADORES, ETC.) & & $\mathrm{x}$ \\
\hline A.7.4 & SISTEMA DE COMBATE A INCENDIOS & $\mathrm{x}$ & \\
\hline A.7.5 & UNIDADES AUXILIARES (MANUTENÇÃO, ESTOCAGEM, ALMOXARIFADO, ETC.) & & $\mathrm{x}$ \\
\hline A.8 & TERRA & & \\
\hline A.8.1 & COMPRA DO TERRENO & & $\mathrm{x}$ \\
\hline A.8.2 & CUSTOS DE PROPRIEDADE (IMPOSTOS, MANUTENÇÃO, ASPECTOS LEGAIS, ETC.) & & $\mathrm{x}$ \\
\hline
\end{tabular}


Tabela 8.1-Custos do empreendimento estudado-Definição do escopo (conclusão)

\begin{tabular}{|c|c|c|c|}
\hline B & CUSTOS INDIRETOS & INCLUSO & NÃO INCLUSO \\
\hline B.1 & ENGENHARIA E SUPERVISÃO & & \\
\hline B.1.1 & MÃO DE OBRA ESPECIALIZADA & $\mathrm{x}$ & \\
\hline B.1.2 & SERVIÇO DE SUPRIMENTOS & $\mathrm{x}$ & \\
\hline B.1.3 & SUPERVISÃO, INSPEÇÃO E DILIGENCIAMENTO & $\mathrm{x}$ & \\
\hline B.1.4 & INFRA ESTRUTURA DE PROJETO (SOFTWARES, MAQUETE ELETRONICA) & $\mathrm{x}$ & \\
\hline B.2 & DESPESAS DE CONSTRUÇÃO & & \\
\hline B.2.1 & CONSTRUÇÃO DE PREDIOS AUXILIARES - CANTEIRO & $\mathrm{x}$ & \\
\hline B.2.2 & MÃO DE OBRA INDIRETA (ADMINISTRAÇÃO, FINANCEIRO, LIMPEZA, ETC.) & $\mathrm{x}$ & \\
\hline B.2.3 & FERRAMENTAS E EQUIPAMENTOS DE CONSTRUÇÃO E MONTAGEM & $\mathrm{x}$ & \\
\hline B.2.4 & ALMOXARIFADO E DESPESAS COM SEGURANÇA & $\mathrm{x}$ & \\
\hline B.2.5 & AMBULATÓRIO MÉDICO & $\mathrm{x}$ & \\
\hline B.2.6 & TESTES DE CAMPO (RAIO-X, LÍQ. PENETRANTE, TESTES HIDROSTÁTICO E PNEUMÁTICO) & $\mathrm{x}$ & \\
\hline B.2.7 & IMPOSTOS, SEGUROS & & $\mathrm{x}$ \\
\hline B.2.7 & ADICIONAIS LEGAIS & $\mathrm{x}$ & \\
\hline B.3 & REMUNERAÇÃO DAS EMPRESAS CONTRATADAS & $\mathbf{x}$ & \\
\hline B.4 & CONTINGÊNCIAS & $\mathbf{x}$ & \\
\hline C & OUTRAS DESPESAS & INCLUSO & NÃO INCLUSO \\
\hline C.1 & CUSTOS DE PARTIDA & & \\
\hline C.1.1 & PRÉ-COMISSIONAMENTO & $\mathrm{x}$ & \\
\hline C.1.2 & COMISSIONAMENTO & $\mathrm{x}$ & \\
\hline C.1.3 & CONDICIONAMENTO & $\mathrm{x}$ & \\
\hline C.1.4 & OPERAÇÃO ASSISTIDA & $\mathrm{x}$ & \\
\hline C.2 & CAPITAL DE GIRO & & $\mathbf{x}$ \\
\hline C.3 & CUSTOS COM LICENCIAMENTO, PESQUISA E DESENVOLVIMENTO & & $\mathbf{x}$ \\
\hline
\end{tabular}

A subdivisão dos itens da tabela acima utiliza a abordagem apresentada por Peters e Timmerhaus (1991), que relacionam custos diretos com as despesas de fabricação, construção e montagem ligadas diretamente na unidade construída, incluindo equipmentos permanentes, mão-de-obra, estruturas civis e materiais entre outros recursos. Por conseqüência, os custos indiretos são aqueles que não têm relação com as intalações permanentes da planta, mas são necessários para que o empreendimento ocorra. No item "Outras Despesas" encontram-se gastos que são feitos após o término da construção da unidade, mas que não podem ser categorizados como despesas de operação uma vez que ocorrem apenas no início do ciclo de vida da planta. 


\subsubsection{Custo dos equipamentos da planta}

Apesar do custo de muitos itens apresentados na tabela 8.1 dependerem de uma série de fatores (em especial do local da instalação) o custo de compra dos equipamentos (item A.1.1) utilizados no setor petroquímico têm seus preços bastante nivelados por conta da concorrência global. Este fato permite que os custos de cada equipamento sejam utilizados em estimativas de custos para plantas similares, desde que se considerem fatores de ajuste adequados (taxas de inflação, aumentos de preços setorizados, etc.).

Tabela 8.2 - Custos dos equipamentos da UGH.

\begin{tabular}{|c|c|c|}
\hline $\begin{array}{c}\text { CÓDIGO } \\
\text { DO } \\
\text { EQUIPAMENTO }\end{array}$ & DESCRIÇÃO & $\begin{array}{c}\text { CUSTO DO } \\
\text { EQUIPAMENTO } \\
\text { (US\$) (SET/07) }\end{array}$ \\
\hline V-01 & VASO PULMÃO & $31.000,00$ \\
\hline P-01 & PERMUTADOR DE PRÉ-AQUECIMENTO DA CARGA & $43.000,00$ \\
\hline $\mathrm{MX}-01$ & MISTURADOR 01 - CONEXÃO ENTRE TUBULAÇÕES & \\
\hline $\mathrm{R}-01(\mathrm{H})$ & REATOR DE HIDRODESSULFURIZAÇÃO & $346.000,00$ \\
\hline $\mathrm{R}-01(\mathrm{~A})$ & REATOR DE DESSULFURIZAÇÃO "A" & $429.000,00$ \\
\hline $\mathrm{R}-01(\mathrm{~B})$ & REATOR DE DESSULFURIZAÇÃO "B" & $429.000,00$ \\
\hline $\mathrm{MX}-02$ & MISTURADOR 02 - CONEXÃO ENTRE TUBULAÇÕES & \\
\hline $\mathrm{F}-01$ & FORNO REFORMADOR & $9.007 .000,00$ \\
\hline P-03 & RECUPERADOR DE CALOR & $2.031 .000,00$ \\
\hline $\mathrm{R}-02$ & REATOR DE AUMENTO (SHIFT) & $429.000,00$ \\
\hline P-04 & AQUECEDOR DE ÁGUA DE CALDEIRA & $702.000,00$ \\
\hline P-05 & GERADOR DE VAPOR DE BAIXA PRESSÃO & $724.000,00$ \\
\hline P-06 & $1^{\circ}$ RESFRIADOR DA ALIMENTAÇÃO DA PSA & $1.517 .000,00$ \\
\hline P-07 & $2^{\circ}$ RESFRIADOR DA ALIMENTAÇÃO DA PSA & $319.000,00$ \\
\hline V-05 & VASO DE ALIMENTAÇÃO DA PSA & $346.000,00$ \\
\hline PSA & SISTEMA DE PURIFICAÇÃO DO H2 - PSA & $2.658 .000,00$ \\
\hline VALVE-01 & VÁLVULA DO SISTEMA DE TRATAMENTO DE CONDENSADO & $6.000,00$ \\
\hline P-08 & AQUECEDOR DA ALIMENTAÇÃO - TRATAMENTO DE CONDENSADO & $157.000,00$ \\
\hline $\mathrm{T}-01$ & TORRE DE SEPARAÇÃO DE CONDENSADO & $440.000,00$ \\
\hline V-03 & VASO DE VAPOR & $1.337 .000,00$ \\
\hline V-04 & VASO DE REJEITOS (BLOWDOWN) & $703.000,00$ \\
\hline \multirow[t]{2}{*}{ VALVE-02 } & VÁLVULA DO SISTEMA DE GERAÇÃO DE VAPOR & $6.000,00$ \\
\hline & TOTAL & $21.660 .000,00$ \\
\hline
\end{tabular}


Para converter em dólar os valores cotados inicialmente em reais, relativos ao fornecimento de itens nacionais, foi utilizada a cotação média do dólar entre início de junho e final de setembro de 2007. Os valores relativos à cotação do dólar neste período foram obtidos em consulta ao histórico cambial disponível no sítio do Banco Central do Brasil na internet (BANCO..., 2010), sendo a conversão adotada neste trabalho conforme mostrado abaixo:

$$
1 U S \$=1,92 R \$
$$

Essa mesma cotação média foi utilizada na estimativa de custos do empreendimento, para conversão dos custos locais, a fim de manter a mesma base monetária ao longo do trabalho.

Cabe ressaltar que esta conversão pode causar distorções em alguns itens estimados caso ocorra uma variação exagerada do dólar frente ao real. Esse efeito pode ser avaliado e ajustado de forma conveniente a partir de considerações adequadas sobre os dado e premissas presentes neste trabalho.

\subsubsection{Estimativa dos custos do empreendimento}

Diversas metodologias podem ser aplicadas para obtenção do custo de implantação de uma unidade industrial. Muitas delas utilizam o custo dos equipamentos como base para determinação dos demais custos envolvidos, sendo aplicado um fator multiplicativo sobre este parâmetro inicial.

Alguns estudos trazem dados importantes para obtenção de estimativas de custo de plantas industriais, mostrando faixas típicas de aplicação para parâmetros como custo com tubulações, materiais elétricos, instalação de equipamentos, custos de partida da planta, contingências e fatores típicos para instalação de equipamentos da indústria química e petroquímica (UPPAL, 1997).

No caso da unidade de geração de hidrogênio apresentada neste trabalho, além dos custos dos equipamentos estavam disponíveis outros dados financeiros utilizados no projeto real. No entanto, estes dados não foram suficientes para caracterizar o custo total de implantação da unidade, sendo que houve a 
necessidade de mesclar dados reais com outros estimados, ou ainda com dados provenientes da experiência de alguns profissionais do setor. Essa análise foi realizada independentemente para cada equipamento, visto que o nível dos dados disponíveis para cada um era bastante diferente.

Os resultados globais obtidos nesta análise estão presentes na tabela 8.3, categorizados sobre os itens apresentados anteriormente na declaração do escopo de custos.

Tabela 8.3 - Custo total por item declarado no escopo de custos.

\begin{tabular}{|c|l|r|}
\hline ITEM & DESCRIÇÃO & $\begin{array}{r}\text { CUSTO } \\
\text { US\$ } \mathbf{( S E T / 2 0 0 7 )}\end{array}$ \\
\hline A & CUSTOS DIRETOS & $\mathbf{6 5 . 4 2 0 . 0 0 0 , 0 0}$ \\
\hline A.1 & COMPRA DE EQUI PAMENTOS & $22.718 .000,00$ \\
\hline A.2 & CONSTRUÇÃO E MONTAGEM & $15.460 .000,00$ \\
\hline A.3 & INSTRUMENTAÇÃO E CONTROLE & $4.330 .000,00$ \\
\hline A.4 & TUBULAÇÕES & $9.292 .000,00$ \\
\hline A.5 & EQUIPAMENTOS E MATERIAIS ELÉTRICOS & $3.470 .000,00$ \\
\hline A.6 & CIVIL & $9.469 .000,00$ \\
\hline A.7 & UTILIDADES E SERVIÇOS & $681.000,00$ \\
\hline A.8 & TERRA & - \\
\hline B & CUSTOS INDIRETOS & $\mathbf{2 3 . 6 0 0 . 0 0 0 , 0 0}$ \\
\hline B.1 & ENGENHARIA E SUPERVISÃO & $4.990 .000,00$ \\
\hline B.2 & DESPESAS DE CONSTRUÇÃO & $5.650 .000,00$ \\
\hline B.3 & REMUNERAÇÃO DA CONTRATADA & $5.960 .000,00$ \\
\hline B.4 & CONTINGÊNCIAS & $7.000 .000,00$ \\
\hline C & OUTRAS DESPESAS & $\mathbf{9 . 1 6 0 . 0 0 0 , 0 0}$ \\
\hline C.1 & CUSTOS DE PARTIDA & $9.160 .000,00$ \\
\hline C.2 & CAPITAL DE GIRO & - \\
\hline C.3 & CUSTOS COM LICENCIAMENTO, PESQUISA E DESENVOLVIMENTO & \\
\hline & CUSTO TOTAL (A + B + C) & $\mathbf{9 8 . 1 8 0 . 0 0 0 , 0 0}$ \\
\hline
\end{tabular}




\subsubsection{Determinação de desvios e discussão dos resultados}

8.1.4.1 Intervalo de incerteza da estimativa de custos

Uma estimativa de custos para unidades como a estudada pode variar desde um detalhamento de custos feitos a partir das especificações e dados de um projeto plenamente desenvolvido até uma avaliação preliminar de valores baseada apenas no porte do projeto. Entre estes dois extremos existe uma série de métodos de estimativa de custos que podem ser aplicadas de acordo com o nível das informações disponíveis.

Peters e Timmerhaus (1991) propõem cinco categorias representativas para estas avaliações com as respectivas incertezas envolvidas:

1. Ordem de grandeza - Estimativa baseada em dados históricos de plantas similares. Incerteza dos resultados maior que $\pm 30 \%$;

2. Estimativa do estudo inicial - Baseado no conhecimento dos itens mais relevantes da planta. Incerteza de $\pm 30 \%$;

3. Estimativa preliminar - Baseada em dados estimados que permitam a obtenção de propostas para orçamentação. Incerteza de $\pm 20 \%$;

4. Estimativa definitiva - Baseada na consolidação da maioria dos dados de projeto, mas antes da emissão de desenhos e especificações. Incerteza de $\pm 10 \%$;

5. Estimativa detalhada - Baseada nos desenhos de engenharia, especificações e levantamentos de campo. Incerteza de $\pm 5 \%$.

Excetuando-se os itens "tubulações" e "compra de equipamentos", os custos apresentados na tabela 8.3 foram obtidos utilizando-se fatores típicos aplicados sobre os custos dos equipamentos da planta, sendo que esta metodologia pode ser categorizada como "estimativa preliminar" (PETERS; TIMMERHAUS, 1991). Isso levaria a uma incerteza de $\pm 20 \%$ nos resultados apresentados para os itens onde este método foi aplicado. 
Para determinar a incerteza da estimativa realizada, foi considerada igual a zero a incerteza dos valores relativos aos itens "tubulações" e "compra de equipamentos", visto que estes elementos foram adquiridos pelos valores apresentados na tabela (não estão sujeitos a erros de estimativa). Sendo assim, utilizando a eq.(8.1) (MEDIDAS...,2009), foi possível determinar a incerteza da estimativa de custos apresentada neste trabalho.

$$
(x \pm \Delta x)+(y \pm \Delta y)=(x+y) \pm(\Delta x+\Delta y)
$$

A tabela 8.4 mostra o percentual de incerteza de cada custo da estimativa e o percentual de incerteza total, relativo à estimativa como um todo.

Tabela 8.4 - Avaliação da incerteza da estimativa de custos.

\begin{tabular}{|c|c|c|c|c|c|c|}
\hline ITEM & DESCRIÇÃO & $\begin{array}{c}\text { CUSTO } \\
\text { US\$ (SET/2007) }\end{array}$ & $\begin{array}{c}\% \\
\text { INCERTEZA }\end{array}$ & $\begin{array}{c}\text { DESVIO } \\
\text { AVALIADO }\end{array}$ & LIMITE SUPERIOR & $\begin{array}{l}\text { LIMITE } \\
\text { INFERIOR }\end{array}$ \\
\hline A & CUSTOS DIRETOS & $65.420 .000,00$ & $\pm 12 \%$ & 7.674.400,00 & 73.094.400,00 & $57.745 .600,00$ \\
\hline A.1 & COMPRA DE EQUIPAMENTOS & $22.718 .000,00$ & $0 \%$ & - & $22.718 .000,00$ & $22.718 .000,00$ \\
\hline A. 2 & CONSTRUÇÃO E MONTAGEM & $15.460 .000,00$ & $\pm 20 \%$ & $3.092 .000,00$ & $18.552 .000,00$ & $12.368 .000,00$ \\
\hline A. 3 & INSTRUMENTAÇÃO E CONTROLE & $4.330 .000,00$ & $0 \%$ & - & $4.330 .000,00$ & $4.330 .000,00$ \\
\hline A. 4 & TUBULAÇÕES & $9.292 .000,00$ & $\pm 20 \%$ & $1.858 .400,00$ & $11.150 .400,00$ & $7.433 .600,00$ \\
\hline A.5 & EQUIPAMENTOS E MAT. ELÉTRICOS & $3.470 .000,00$ & $\pm 20 \%$ & $694.000,00$ & $4.164 .000,00$ & $2.776 .000,00$ \\
\hline A. 6 & CIVIL & $9.469 .000,00$ & $\pm 20 \%$ & $1.893 .800,00$ & $11.362 .800,00$ & $7.575 .200,00$ \\
\hline A.7 & UTILIDADES E SERVIÇOS & $681.000,00$ & $\pm 20 \%$ & $136.200,00$ & $817.200,00$ & $544.800,00$ \\
\hline A.8 & TERRA & - & - & - & - & - \\
\hline B & CUSTOS INDIRETOS & $23.600 .000,00$ & $\pm 20 \%$ & $4.720 .000,00$ & $28.320 .000,00$ & $18.880 .000,00$ \\
\hline B.1 & ENGENHARIA E SUPERVISÃO & $4.990 .000,00$ & $\pm 20 \%$ & $998.000,00$ & $5.988 .000,00$ & $3.992 .000,00$ \\
\hline B. 2 & DESPESAS DE CONSTRUÇÃO & $5.650 .000,00$ & $\pm 20 \%$ & $1.130 .000,00$ & $6.780 .000,00$ & $4.520 .000,00$ \\
\hline B. 3 & REMUNERAÇÃO DA CONTRATADA & $5.960 .000,00$ & $\pm 20 \%$ & $1.192 .000,00$ & $7.152 .000,00$ & $4.768 .000,00$ \\
\hline B. 4 & CONTINGÊNCIAS & $7.000 .000,00$ & $\pm 20 \%$ & $1.400 .000,00$ & $8.400 .000,00$ & $5.600 .000,00$ \\
\hline C & OUTRAS DESPESAS & $9.160 .000,00$ & $\pm 20 \%$ & $1.832 .000,00$ & $10.992 .000,00$ & $7.328 .000,00$ \\
\hline C.1 & CUSTOS DE PARTIDA & $9.160 .000,00$ & $\pm 20 \%$ & $1.832 .000,00$ & $10.992 .000,00$ & $7.328 .000,00$ \\
\hline C.2 & CAPITAL DE GIRO & - & - & - & - & - \\
\hline C.3 & CUSTOS COM LICENCIAMENTO, ETC & - & - & - & - & - \\
\hline & CUSTO TOTAL (A + B + C) & $98.180 .000,00$ & $\pm 14 \%$ & $14.226 .400,00$ & $112.406 .400,00$ & $83.953 .600,00$ \\
\hline
\end{tabular}

Assim, pode-se afirmar que o percentual de incerteza total da estimativa de custos para o empreendimento é de $\pm 14 \%$. 
8.1.4.2 Comparativo entre a estimativa de custos realizada e fontes presentes na literatura

Como parte da discussão acerca dos resultados obtidos na estimativa de custos optou-se por confrontar os valores obtidos com outros encontrados na literatura.

Os valores apresentados foram ajustados por índices de preços específicos, que permitem atualizar de maneira confiável valores numa faixa de aplicação de até cinco anos. Para períodos maiores a confiabilidade dos resultados é distorcida por eventuais ganhos tecnológicos, sejam na construção da planta ou no processo produtivo. Ainda assim, a aplicação destes índices de reajuste é considerada mais adequada que o uso de outro indexador, como a inflação, mesmo para períodos maiores que cinco anos, isso porque eles caracterizam a variação de preços específica de determinado setor da indústria.

É possível encontrar diversos desses índices na literatura, entre eles o Nelson-Farrar Refinery Construction Index (FARRAR, 2009), publicado trimestralmente pelo Oil and Gas Journal, o CEPCI - Chemical Engineering Plant Cost Index (CHEMICAL ENGINEERING MAGAZINE, 2009), publicado também trimestralmente pela revista Chemical Engineering, ou ainda o IHS-CERA Downstream Capital Cost Index (IHS-CERA, 2009), disponibilizado na internet pelo IHS Cambridge Research Associates.

Estes índices são compostos pela variação de preços dos elementos necessários para a construção de uma nova planta (equipamentos, mão-de-obra, etc.). Os pesos de cada item são muito similares entre os índices, sendo que a aplicação de qualquer um deles trará resultados bastante parecidos.

Optou-se, neste trabalho, por utilizar os valores do índice Nelson-Farrar (NFI), criado em 1946, quando seu valor foi estipulado como sendo igual a 100. Os dados para este índice, entre os anos de 1970 e 2009 estão compilados na tabela 8.5 (FARRAR, 2009). 
Tabela 8.5 - Índice de construção para refinarias Nelson-Farrar (FARRAR, 2009).

\begin{tabular}{|c|c|c|c|c|c|c|c|}
\hline ANO & NFI & ANO & NFI & ANO & NFI & ANO & NFI \\
\hline 1970 & 365 & 1980 & 823 & 1990 & 1226 & 2000 & 1543 \\
\hline 1971 & 406 & 1981 & 904 & 1991 & 1253 & 2001 & 1580 \\
\hline 1972 & 439 & 1982 & 977 & 1992 & 1277 & 2002 & 1642 \\
\hline 1973 & 468 & 1983 & 1026 & 1993 & 1311 & 2003 & 1710 \\
\hline 1974 & 523 & 1984 & 1061 & 1994 & 1350 & 2004 & 1834 \\
\hline 1975 & 576 & 1985 & 1074 & 1995 & 1392 & 2005 & 1918 \\
\hline 1976 & 616 & 1986 & 1090 & 1996 & 1419 & 2006 & 2008 \\
\hline 1977 & 653 & 1987 & 1122 & 1997 & 1449 & 2007 & 2107 \\
\hline 1978 & 701 & 1988 & 1165 & 1998 & 1478 & 2008 & 2251 \\
\hline 1979 & 757 & 1989 & 1196 & 1999 & 1497 & 2009 & 2201 \\
\hline
\end{tabular}

O índice NFI (Nelson-Farrar) deve ser aplicado conforme mostra a eq.(8.2):

Custo Presente $=$ Custo Original $\cdot\left(\begin{array}{c}\text { Valor do índice no Presente } \\ \text { Valor do índice no período que o } \\ \text { Custo Original foi obtido }\end{array}\right)$

Alguns artigos e livros trazem informações sobre o montante provável que será investido na construção de unidades produtivas através de análises parametrizadas.

Kaiser e Gary (2009) propõem funções de custo para diversas unidades produtivas que compõem uma refinaria de petróleo, considerando como local de implantação a costa americana do golfo do México. Estas funções consideram exclusivamente a construção de plantas novas, incluindo equipamentos, mão-deobra, materiais, projeto básico, detalhamento de engenharia e outras despesas, assemelhando-se com o escopo da planta estudada. A função de custo específica da unidade de geração de hidrogênio que utiliza o processo de reforma de vapor é dada pela eq.(8.3).

$$
\text { Custo }=3,35 \cdot(\text { Capacidade da planta })^{0,599}
$$


Para esta equação, a capacidade da planta deve ser dada em MMSCFPD (milhões de pés cúbicos padrão por dia) enquanto o custo é obtido em milhões de dólares (ano base 2005).

Para a planta estudada, a capacidade diária de produção é igual a 1.200.000 $\mathrm{Nm}^{3}$, sendo a conversão apresentada na eq.(8.4):

$$
1.200 .000 \frac{\mathrm{Nm}^{3}}{\mathrm{dia}}=44,7909 \mathrm{MMSCFPD}
$$

Com isso, obtem-se um custo da planta de produção de hidrogênio igua a 32,7 milhões de dólares. Aplicando o índice NFI para corrigir a diferênça entre o período de 2005 e 2007 tem-se:

$$
\text { Custo Presente }(2007)=32.700 .000 \cdot\left(\frac{2107}{1918}\right)
$$

O que resulta num custo estimado de 36 milhões de dólares.

Análise similar pode ser feita sobre o dado fornecido por Maples (2000), que indica o investimento aproximado de 60 milhões de dólares no primeiro trimestre de 1991 para construção de uma planta de geração de hidrogênio com capacidade de produção de 100 MMSCFPD.

A eq.(8.6) utiliza o índice NFI proposto para corrigir este dado entre os anos de 1991 e 2007:

$$
\text { Custo Presente }(2007)=60.000 .000 \cdot\left(\frac{2107}{1253}\right)
$$

O que resulta num custo de 101 milhões de dólares.

Para corrigir o valor acima devido à diferença de capacidade entre a planta indicada (100 MMSCFPD) e a planta estudada (44,8 MMSCFPD) será utilizada a abordagem sugerida por Peters e Timmerhaus (1991), mostrada na eq.(8.7):

$$
\text { Custo } A=\text { Custo } B \cdot\left(\frac{\text { Capacidade da unidade } A}{\text { Capacidade da unidade B }}\right)^{x}
$$


Onde o valor de " $x$ " varia entre 0,6 e 0,7 para diversos tipos de unidades produtivas. Para o caso da unidade de geração de hidrogênio, o valor de " $x$ " corresponde a 0,6.

Sendo assim, para uma unidade similar à estudada, tem-se o custo corrigido igual a 62 milhões de dólares.

Ambos os valores apresentados anteriormente, 37 milhões de dólares (Kaiser; Gary, 2009) e 62 milhões de dólares (Maples, 2000), possuem coerência entre si, uma vez que a primeira análise possui uma variação de até $25 \%$ segundo os autores e a segunda análise pode variar em até $40 \%$, devido à aplicação do índice NFI sobre um período grande de tempo associado à estimativa paramétrica. No entanto estes valores se mostram distantes do custo total obtido na estimativa apresentada (98 milhões de dólares aproximadamente), em especial o primeiro deles.

Uma investigação mais acurada pode justificar a grande diferença entre estes números. Segundo Kaiser e Gary (2009) "historicamente a costa americana do golfo tem custos de construção muito favoráveis quando comparados com outros mercados, sejam domésticos (EUA) ou interacionais".

Para se ter uma idéia do impacto desta afirmação, Peter e Timmerhaus (1991) consideravam aceitável uma diferença de 176\% no custo de instalação na costa americana do pacífico (São Francisco, por exemplo) quando comparada com a costa do golfo, para unidades similares com a mesma capacidade. Esta diferença se deve em parte ao clima e seus efeitos no projeto e nas atividades de construção, regulamentos locais, normas, impostos, concentração de fornecedores próximos, farta mão-de-obra especializada e alta produtividade dos trabalhadores.

Ainda segundo Kaiser e Gary (2009), "isto provavelmente é menos verdadeiro hoje em dia [comparativamente ao dado apresentado relativo ao ano de 1991], mas a costa americana do golfo continua muito competitiva". Isso demonstra claramente a grande influência que a locação da unidade que será construída trás aos resultados da estimativa econômica.

Não foram encontrados dados específicos que permitissem comparar a produtividade no Brasil e nos Estados Unidos. Sendo assim não foi possível realizar uma comparação mais justa entre os dados apresentados nesta seção. Contudo, os resultados obtidos na estimativa de custos foram obtidos através de uma metodologia consolidada e com a faixa de incerteza bem definida, sendo uma referência bastante confiável. 


\subsection{CUSTO DE OPERAÇÃO DA PLANTA}

Para dar continuidade à análise econômica é importante considerar toda a vida útil da planta, e não só o investimento inicial relativo à concepção, construção e partida.

Uma análise econômica completa deve considerar fatores como amortização de dívidas, incidência de impostos, custos de operação e manutenção, depreciação de equipamentos, seguros, despesas com administração, vendas, divulgação e propaganda, etc. Estes fatores devem ser compensados no período de operação da planta de geração de hidrogênio estudada.

Nesta seção serão apresentadas, discutidas e definidas as hipóteses utilizadas na análise econômica ao longo do período de operação, a fim de se obter o custo de produção que compense os valores gastos ao longo de todo o ciclo de vida da planta.

\subsubsection{Definição do custo de produção}

A construção da unidade de geração de hidrogênio (UGH) estudada é parte de um amplo projeto de modernização de uma das refinarias da Petrobras. Conforme dito nos capítulos anteriores, o hidrogênio produzido por esta nova unidade será utilizado como insumo no processo de dessulfurização do óleo diesel produzido nesta refinaria. Além do óleo diesel, esta refinaria da Petrobras produz gasolina, querosene de aviação, GLP, asfalto e enxofre.

A fabricação destes produtos depende de um conjunto enorme de equipamentos, agrupados convenientemente em unidades dentro da refinaria, cada qual com uma função específica dentro do processo de produção.

Devido à complexidade dos processos produtivos, a distribuição dos custos gerais de produção entre todas as unidades da refinaria torna-se impraticável, uma vez que a elaboração de critérios que permitam subdividir de forma adequada estes 
custos é algo extremamente trabalhoso e ultrapassa os limites propostos para esta dissertação.

Sendo assim, optou-se neste trabalho por utilizar uma abordagem simplificada de custos de produção, excluíndo-se da análise os elementos que não tenham seu custo ligado diretamente ao produto.

O critério utilizado na abordagem proposta pressupõe que os responsáveis por "carregar" os custos indiretos são os produtos principais da refinaria (produtos finais), e não os produtos intermediários (como o hidrogênio). Portanto, os desembolsos relativos às atividades não-produtivas (impostos, taxas, distribuição dos produtos, custo de vendas, divulgação e propaganda, despesas administrativas, mão de obra indireta, etc.) devem ser considerados apenas no final da cadeia, na formação dos preços dos produtos principais da refinaria.

Com isso, para este trabalho, o custo do hidrogênio apresentado é composto apenas pelos gastos ligados diretamente à produção (construção da unidade, custo de matéria-prima, custos de operação e de manutenção).

\subsubsection{Definição das variáveis econômicas}

8.2.2.1 Inflação e taxa de juros

O parâmetro tempo é fundamental em qualquer análise econômica. O desembolso de um dólar hoje não é economicamente igual ao desembolso de um dólar daqui a um ano, visto que este mesmo dólar poderia permanecer este tempo em alguma aplicação que o reajustaria para compensar a inflação no período ou até para permitir ganhos acima da inflação, dependendo da taxa de juros.

De maneira geral, a inflação ocorre quando se aumenta a disponibilidade de dinheiro e crédito no mercado, sem que ocorra um aumento de mesma proporção na disponibilidade de produtos e serviços. Do mesmo modo, a deflação ocorre quando se reduz a disponibilidade de dinheiro com relação à disponibilidadde de produtos e serviços. 
São diversos os fatores que podem interferir neste mecanismo: taxa de juros, políticas de incentivo, regulamentações, abertura de novos mercados, concorrência, desastres naturais, efeitos de sazonalidade, etc.

Alguns governos, dentre eles o do Brasil, optaram por uma política macroeconômica baseada em um sistema de metas de inflação. No sistema de metas para a inflação, a política monetária tem por prioridade garantir que a inflação se situe dentro do alvo estabelecido.

Desde 1999, o Brasil utiliza o sistema de metas de inflação na sua condução econômica, sendo que de 2005 a 2009 o centro da meta de inflação foi de 4,5\% ao ano. Para os anos de 2010 e 2011 o Banco Central do Brasil divulgou o mesmo percentual de 4,5\% ao ano como centro da meta de inflação (HISTORICO..., 2010).

Assim, será utilizado neste trabalho o percentual de reajuste de $4,5 \%$ para todos os desembolsos ocorridos em datas futuras e que não sejam corrigidos por nenhum outro fator de juros, como os custos de operação e manutenção da planta, ou ainda os custos de matéria-prima.

É com base nas metas de inflação e numa componente de risco de longo prazo que o BNDES, Banco Nacional de Desenvolvimento Econômico e Social, órgão do Governo Federal responsável por grande parte dos financiamentos de longo prazo relacionados com investimentos no setor produtivo, calcula sua taxa de juros de longo prazo (TJLP) (TAXA...,2010).

A TJLP, somada a uma taxa de juros básica (chamada de spread básico), relativa aos encargos administrativos, remunera o capital investido em projetos como a unidade de geração de hidrogênio estudada neste trabalho. Assim, esta taxa de juros se mostra como sendo a melhor referência para reajuste dos valores apresentados na análise econômica.

Atualmente, o valor da TJLP está em $6 \%$ ao ano, sendo que, nos últimos três anos este valor não variou mais do que 0,5\% (TAXA...,2010). A componente chamada de spread básico varia de acordo com as políticas de incentivo do governo. No caso em estudo, será usazado um valor médio arbitrado de $2 \%$ ao ano. Com isso, a taxa de juros efetiva utilizada na análise econômica presente nesta dissertação está apresentada abaixo: 
Desta forma, pode-se considerar que esta taxa de juros corrige os efeitos da inflação prevista para o período e remunera o capital disponibilizado de acordo com as regulamentações típicas em investimentos deste porte feitos no Brasil.

\subsubsection{Tempo de vida da planta}

Pode-se definir o tempo de vida útil da planta como sendo o período estimado de produção da unidade construída, considerando fatores como desgaste dos equipamentos, ou ainda o período no qual se espera que a unidade se torne obsoleta devido ao surgimento de processos produtivos mais competitivos.

O tempo de vida útil a ser considerado na análise influi diretamente no resultado obtido, pois, reduzindo a vida da planta, reduz-se o prazo de retorno sobre ela e consequentemente aumenta-se o retorno médio por período, uma vez que a planta deve "se pagar" mais rapidamente. Aumentando-se a vida útil da planta temse o efeito inverso e o retorno médio por período passa a ser menor. Para investimentos como o estudado, o tempo de vida útil da planta gira em torno de 20 anos, valor este que será utilizado neste trabalho.

\subsubsection{Fator de carga}

O fator de carga é a relação entre a quantidade produzida efetivamente e a capacidade nominal projetada para o sistema. Um sistema pode operar acima do seu limite nominal (sobrecarga), sendo que o fator de carga será maior que um para estes casos. No entanto, quando isso acontece, o sistema sofre um desgaste maior, aumentando os custos de manutenção e reduzindo a vida útil dos equipamentos.

A planta de geração de hidrogênio estudada foi projetada para suportar uma sobrecarga de até $40 \%$ na capacidade nominal, porém para este trabalho foi considerado que o sistema opera à plena carga (capacidade nominal) o que leva a um fator de carga igual a um. 


\subsubsection{Tempo de operação anual}

O serviço dentro de uma refinaria é contínuo, sendo que poucas paradas são previstas durante o ano para manutenção e verificação dos sistemas. Com isso, considerou-se uma média de duas semanas de parada por ano, o que leva a um tempo de operação anual de 8400 horas.

\subsubsection{Processo de amortização do capital investido}

Os recursos financeiros investidos em qualquer empreendimento podem ser amortizados através de processos diferentes. Qualquer um deles garante igual retorno ao credor, que terá seu capital remunerado pela taxa de juros previamente definida.

Do ponto de vista do tomador do empréstimo, duas formas são comumente utilizadas na amortização de dívidas: o sistema de amortização constante e o sistema de pagamentos constantes.

É importante atentar ao fato de que, durante o período de construção da planta, que ocorre entre setembro de 2007 e janeiro de 2010, não existe amortização da dívida ou parcela a ser paga, uma vez que a unidade ainda não está em operação e, consequentemente, ainda não existe geração de recursos decorrentes da produção do hidrogênio.

Assim, independente do sistema de amortização utilizado, durante o período de construção o montante investido foi reajustado pela taxa de juros correspondente, sem que ocorresse qualquer amortização neste valor.

No sistema de amortização constante, também conhecido como SAC, as parcelas são formadas por uma componente fixa, relativa ao montante a ser amortizado no período, e uma parcela variável, relativa à incidência dos juros sobre o saldo residual da dívida. A tabela 8.6 mostra a aplicação deste sistema sobre o custo total da planta, utilizando uma taxa de juros de $8 \%$ ao ano e um prazo de amortização de 20 anos, conforme discutido anteriormente. 
Tabela 8.6 - Amortização do investimento pelo sistema de amortização constante.

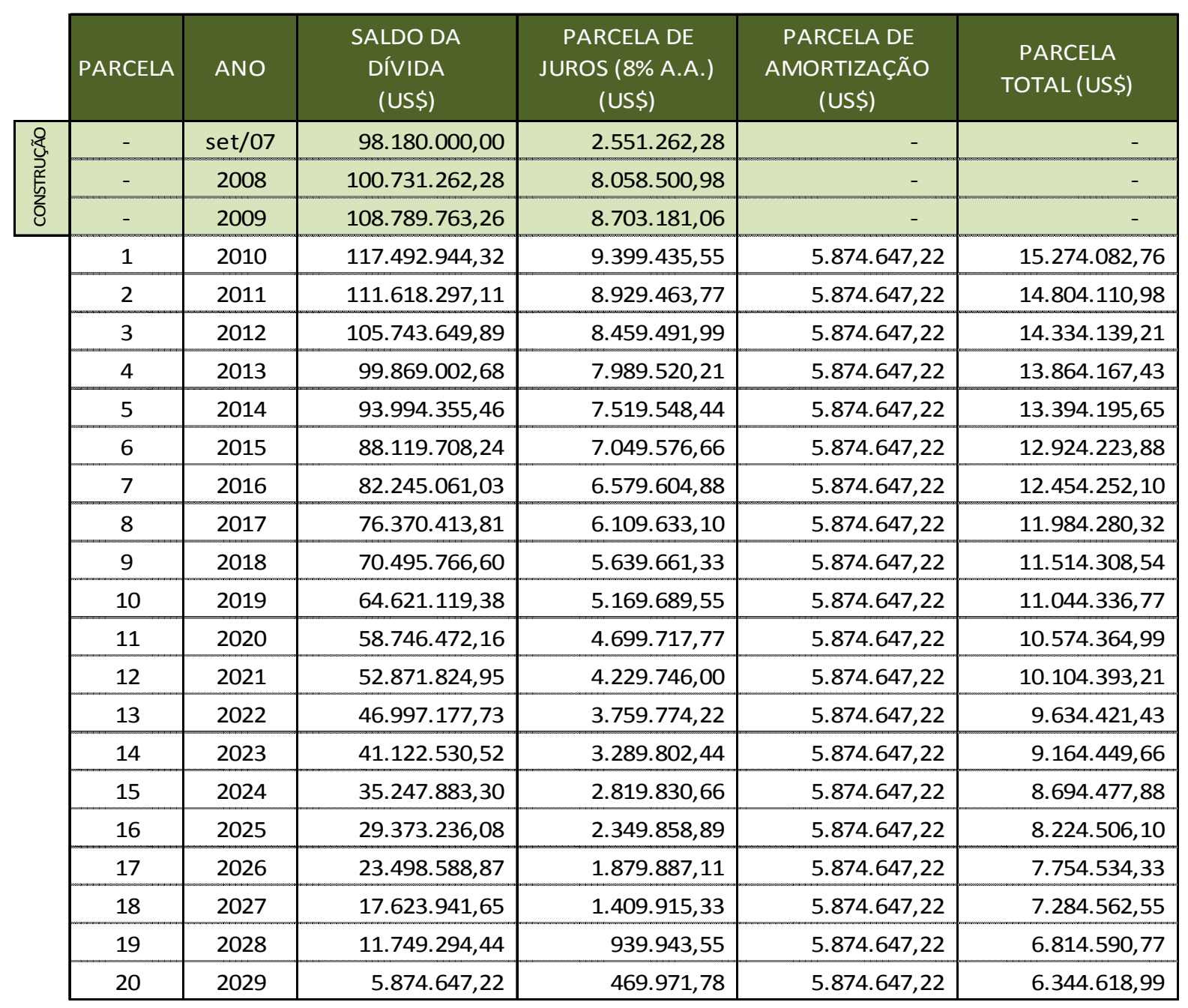

A amortização da dívida se inicia ao final do primeiro período de operação, no caso, no final do ano de 2010. Observa-se que, a partir desta data, o montante a ser amortizado é sempre constante, enquanto a parcela a ser paga em cada período varia consideravelmente ao longo do prazo de amortização.

No sistema de pagamentos constantes a parcela a ser paga é fixa ao longo do período de amortização. Cada parcela contém os encargos relativos à taxa de juros e considera o prazo total. Para este sistema, o chamado fator de amortização $\left(f_{a}\right)$ é dado pela eq.(8.8):

$$
f_{a}=\frac{i}{1-(1+i)^{-n}}
$$

Onde " "é a taxa de juros que incidirá sobre o empréstimo e " $n$ " é o prazo de amortização. A aplicação do fator de amortização sobre o montante total emprestado 
resulta no falor da parcela fixa a ser paga até o final do prazo estabelecido para amortizar a dívida. A tabela 8.7 mostra o resultado da aplicação do fator de amortização sobre o custo total da planta após o período de construção, utilizando uma taxa de juros de $8 \%$ ao ano e considerando um prazo de amortização de 20 anos.

Tabela 8.7 - Amortização do investimento pelo sistema de pagamentos constantes.

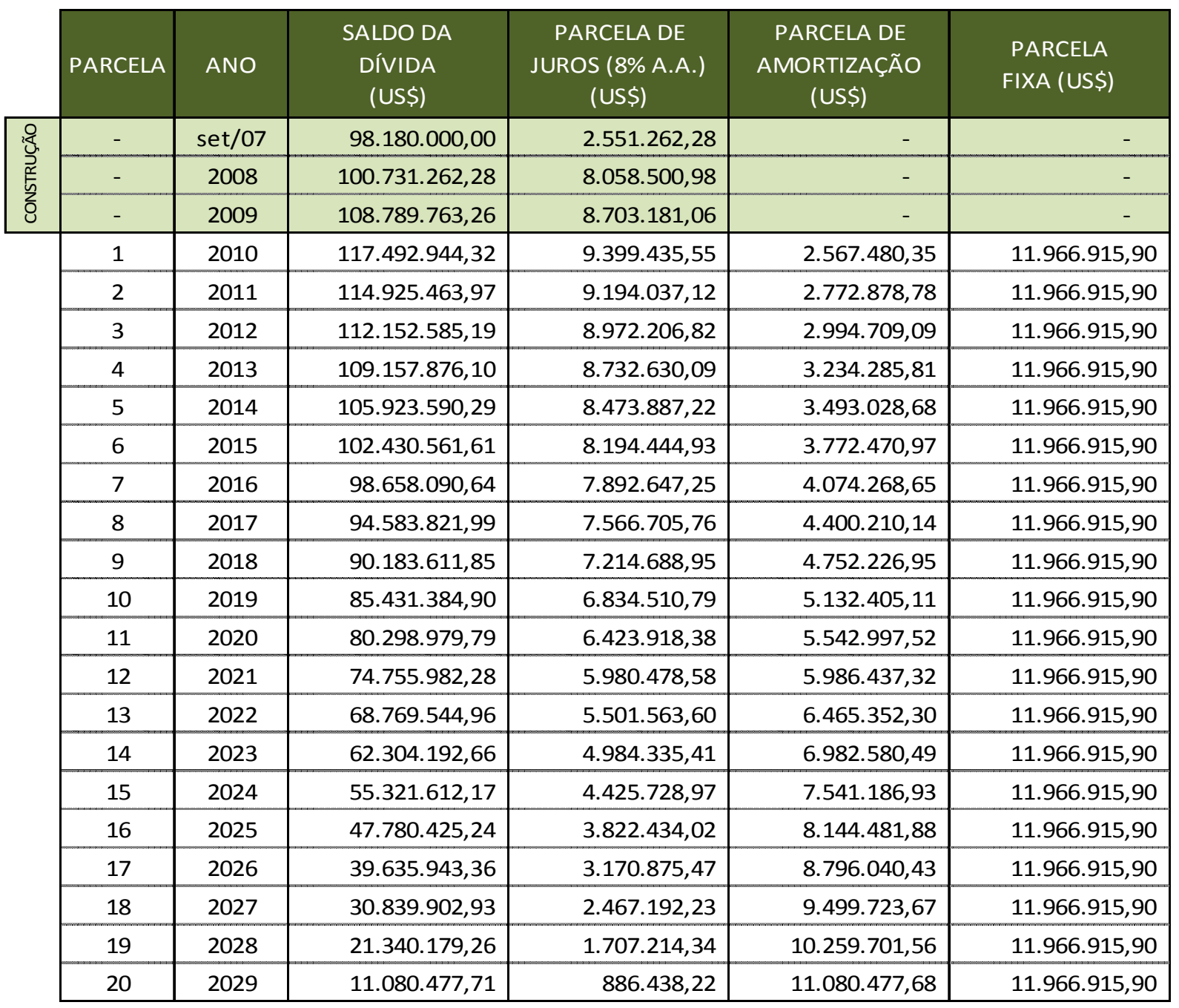

Percebe-se que, ao contrário do sistema SAC, as parcelas são constantes ao longo do tempo enquanto o valor amortizado varia ao longo do período de amortização.

Qualquer um dos métodos apresentados pode ser aplicado para obtenção do custo do hidrogênio desde que na análise se respeite o prazo total de amortização. A comparação dos resultados obtidos utilizando-se cada um dos métodos em um ano específico certamente trará valores muito diferentes. Sendo assim, cabe 
destacar que o valor de custo do hidrogênio que será obtido na análise econômica como um todo não é absoluto e invariável, mas sim é o resultado de um processo específico de custeio que têm suas hipóteses e metodologia previamente definidas.

Por conveniência, optou-se neste trabalho por utilizar o sistema de pagamentos constante como método de amortização do capital investido na unidade de geração de hidrogênio.

\subsubsection{Custo de operação e manutenção}

Para operar a planta de geração de hidrogênio serão utilizados quatro operadores por turno de trabalho. A refinaria tem três turnos de trabalho de oito horas, sendo que o total de pessoas envolvidas com a operação da planta será igual a 12 pessoas.

Contando com um salário médio mensal de $\mathrm{R} \$ 8.000,00$ (encargos inclusos), tem-se um salário anual por operador de $\mathrm{R} \$ 96.000,00$, ou ainda, utilizando a conversão para dólar adotada neste trabalho, obte-se um salário anual de US $\$ 50.000,00$ para cada operador.

Sendo assim, o gasto anual de operação apenas com mão-de-obra chega a US $\$ 600.000,00$.

Os gastos relativos ao uso de energia elétrica para iluminação ou outro fim não-produtivo não serão considerados. No entanto, para se obter uma dimensão mais real do custo do hidrogênio, os gastos com energia elétrica relacionados diretamente às atividades de produção do hidrogênio, em especial o consumo de energia elétrica dos equipamentos da planta, serão considerados nesta análise de custos.

Com isso, para definir o valor da energia elétrica utilizou-se o preço de mercado praticado pela AES-Eletropaulo. Esta tarifa mensal é subdividida em grupos, sendo que para o caso estudado foram consideradas as tarifas do grupo " $A$ ", subgrupo "A3a" (típicamente utilizado na indústria pesada), sendo os valores iguais a 13,97 R $\$ / \mathrm{kW}$ de demanda e 0,1644 $\mathrm{R} \$ / \mathrm{kWh}$ de consumo (ANEEL,2009).

A planta estudada possui quatro equipamentos que consumem energia elétrica de forma intensiva, são eles: 
- Motor elétrico do ventilador da entrada de ar do forno (pertencente ao pacote do Forno Reformador) - Potência de 310 kW;

- Motor elétrico do ventilador da saída dos gases do forno (pertencente ao pacote do Forno Reformador) - Potência de $250 \mathrm{~kW}$;

- Conjunto de motores elétricos do P-06 (Primeiro resfriador da alimentação do sistema da PSA) - Potência de 82 kW;

- Bomba de circulação forçada do V-03 (Vaso de Vapor) - Potência de $45 \mathrm{~kW}$.

Com estes valores definidos, é possível determinar o gasto de energia elétrica anual na produção efetiva de hidrogênio. Assim, utilizando os dados apresentados de tarifas, tempo de operação e conversão de moeda tem-se um gasto de 59.983,69 US $\$$ /ano relativos à demanda e 494.124,75 US\$/ano relativos ao consumo, o que compõe um gasto total de 554.108,44 US\$/ano com energia elétrica.

A definição de um custo equivalente, relativo apenas ao consumo destes equipamentos, é bastante importante para realização da análise termoeconômica. Sendo assim, ao dividir o custo anual total pela potência horária consumida no ano, obtem-se o valor de $9,602 \times 10^{2}$ US $\$ / \mathrm{kWh}$.

Neste trabalho, o custo de energia elétrica será contabilizado apenas durante a análise termoeconômica dos equipamentos da planta, através do custo equivalente mostrado no parágrafo anterior. Isso porque, na análise termoeconômica, deve-se garantir que cada custo seja atribuído sobre o equipamento que, de fato, consome o recurso.

A depreciação dos equipamentos pode ser considerada por dois pontos de vista distintos, um contábil e outro real. A depreciação contábil visa reduzir o valor de máquinas e equipamentos produtivos para compensar o seu tempo de uso e assim reduzir os impostos incidentes sobre este capital. Este tipo de depreciação não será abordado neste trabalho, pois, além de existirem períodos de depreciação distintos para cada item da refinaria (definidos pela legislação tributária), optou-se por não tratar a incidência de impostos no levantamento dos custos de produção do hidrogênio.

A depreciação real dos equipamentos é a perda do seu valor econômico ao longo do tempo, relativa ao desgaste natural decorrente da utilização dos mesmos ou por se tornarem tecnologicamente ultrapassados. A depreciação real só pode ser medida quando ocorre a substituição do equipamento utilizado, sendo que seu valor 
será igual à diferença entre o preço de compra do novo equipamento e o preço de venda de equipamento antigo. Assim, este desembolso ocorrerá apenas se os equipmentos forem substituídos antes do término da vida útil prevista para a planta.

Neste trabalho será considerada a hipótese de que não haverá necessidade de substituição dos equipamentos ao longo da vida útil da planta. Além disso, será considerado que o preço de venda do equipamento ao final da vida útil da planta será igual ao custo de remoção do mesmo. Desta forma não haverá custo ou receita decorrente da substituição ou venta de equipamentos.

Os demais custos de operação e manutenção foram obtidos através de alguns fatores típicos apresentados por Anderson (2009), que, aplicados sobre uma base conveniente, podem ser utilizados para estimar o custo de operação de uma planta petroquímica. Os resultados desta análise estão sumarizados na tabela 8.8.

Tabela 8.8 - Custos de operação e manutenção considerados para a planta (Valores de 2010)

\begin{tabular}{|l|c|r|r|}
\hline \multicolumn{1}{|c|}{ ITEM } & FATOR & \multicolumn{1}{c|}{ BASE (US\$̦) } & \multicolumn{1}{c|}{$\begin{array}{r}\text { TOTAL POR } \\
\text { RUBRICA (US\$̦) }\end{array}$} \\
\hline Mão-de-obra direta & $\mathbf{1}$ & $600.000,00$ & $600.000,00$ \\
\hline Mão-de-obra indireta & $\mathbf{0 , 6}$ & $600.000,00$ & $360.000,00$ \\
\hline Suprimentos & $\mathbf{0 , 3}$ & $600.000,00$ & $180.000,00$ \\
\hline Custos administrativos & $\mathbf{0 , 9}$ & $600.000,00$ & $540.000,00$ \\
\hline Custos de Manutenção & $\mathbf{0 , 0 2}$ & $117.500 .000,00$ & $2.350 .000,00$ \\
\hline Outros custos operacionais & $\mathbf{0 , 0 1}$ & $117.500 .000,00$ & $1.175 .000,00$ \\
\hline CUSTO TOTAL DE OPERAÇÃO E MANUTENÇÃo & & $\mathbf{5 . 2 0 5 . 0 0 0 , 0 0}$ \\
\hline
\end{tabular}

O valor utilizado como base para aplicação dos fatores nos quatro primeiros itens da tabela 8.8 é justamente a expectativa de gasto com mão-de-obra direta na operação, enquanto o valor base utilizado no cálculo dos dois últimos itens da tabela, relativos aos custos de manutenção e a outros custos operacionais, refere-se ao investimento total previsto (US\$98.180.000,00) atualizado pela taxa de juros correspondente até a data de início da operação da planta. 


\subsubsection{Custo da matéria-prima}

As matérias-primas necessárias para a obtenção do hidrogênio pelo processo de reforma são o gás natural e a água. O gás natural, além de servir como insumo no processo, é também utilizado como gás combustível para os queimadores do forno reformador.

Segundo boletim do Ministério de Minas e Energia, o preço do gás natural fornecido pela Petrobras para as distribuidoras na região sudeste do país foi de 9,6154 US\$/MMBTU em novembro de 2009 (BOLETIM..., 2010), o que equivale a $9,1136 \times 10^{-6}$ US $\$ / k J$.

A água, apesar de ser um recurso natural importante, tem seu valor econômico variável, e, muitas vezes, difícil de ser estabelecido. Água sem tratamento pode ser obtida em rios, efluentes ou poços artesianos sem qualquer custo que não seja o de bombeamento e construção de instalações que permitam sua utilização.

A Sabesp (Companhia de Saneamento Básico do Estado de S. Paulo) declara que o custo do serviço de fornecimento de água tratada para consumidores com demanda contratada é de $4,83 \mathrm{R} \$ / \mathrm{m}^{3}$ (COMUNICADO...,2010), o que equivale a 2,52 US $\$ / \mathrm{m}^{3}$, enquanto algumas referências internacionais indicam o custo de 0,05 US $\$ / \mathrm{m}^{3}$ (KRATOCHVIL ET AL., 2009) para água bruta sem tratamento ou ainda $0,07 \mathrm{US} \$ / \mathrm{m}^{3}$ e $1,10 \mathrm{US} \$ / \mathrm{m}^{3}$ para água bruta e água desmineralizada respectivamente (STOLL; LINDE, 2000).

Assim, é possível verificar que apesar de não existirem valores de referência estabelecidos para a água, seu valor econômico varia de acordo com a sua qualidade e com o tipo de tratamento pela qual a água foi submetida.

Para geração do vapor é necessário que a água tenha uma qualidade específica, dentro de padrões que permitam o funcionamento correto da caldeira sem que ocorra incrustrações que afetem no rendimento do equipamento. Para este caso a água deve ser desmineralizada (também chamada de água de caldeira).

Para o caso de trocadores de calor do tipo casco-tubo, a água não necessita de um tratamento tão rigoroso quanto o aplicado à água de caldeira, no entanto o uso de água bruta também deve ser evitado para prevenir o sistema de 
incrustrações. A água para este caso é chamada de água de resfriamento e seus principais tratamentos são filtração e controle de $\mathrm{pH}$.

Diante da dificuldade em estabelecer uma referência específica para o caso estudado, foram utilizados neste trabalho os dados apresentados por Stoll e Linde (2000), corrigidos pela inflação acumulada no período. Sendo assim, o valor definido para água de caldeira (desmineralizada) é igual a $1,71 \mathrm{US} \$ / \mathrm{m}^{3}$ enquanto o valor para a água de resfriamento será de 0,11 US $\$ / \mathrm{m}^{3}$.

Tendo os custos de matéria-prima definidos, é possível utilizar os valores de vazão molar e exergia molar total, apresentados no capítulo 7, para se obter o custo anual de matéria-prima.

O gás natural entra no sistema através do "ponto 1" e do "ponto 43" da planta síntese definida no capítulo 5 (fig.5.1). Assim, o custo anual total relativo a este item foi obtido através da aplicação da eq.(8.9):

$$
\text { Custo }_{G N}=\left(\dot{n}_{1} b_{1}+\dot{n}_{43} b_{43}\right) \cdot \frac{3600 s}{h} \cdot \frac{8400 h}{a n o} \cdot 9,1136 \times 10^{-6} \frac{U S \$}{k J}
$$

O que resulta em um gasto anual de US\$ 65.419.158,86 com o consumo de gás natural para produção do hidrogênio e para alimentação do forno reformador.

A água de caldeira entra no processo pelo "ponto 60". Com isso, é possível utilizar a eq.(8.10) para obter o custo anual total relativo a este item:

$$
\text { Custo }_{\text {H2O cald. }}=\left(\dot{n}_{60} M M_{H 2 O}\right) \cdot \frac{1 m^{3}}{1000 \mathrm{~kg}} \cdot \frac{3600 \mathrm{~s}}{h} \cdot \frac{8400 \mathrm{~h}}{\text { ano }} \cdot 1,71 \frac{U S \$}{\mathrm{~m}^{3}}
$$

Sendo assim, a previsão de gastos com água desmineralizada na produção do hidrogênio é de US\$1.751.524,48 por ano.

De maneira similar, é possível utilizar a eq.(8.11) para obter o custo anual da água de resfriamento que entra no processo pelo "ponto 19":

$$
\text { Custo }_{\mathrm{H} 2 \mathrm{O} \text { resfr. }}=\left(\dot{\mathrm{n}}_{19} \mathrm{MM}_{\mathrm{H} 2 \mathrm{O}}\right) \cdot \frac{1 \mathrm{~m}^{3}}{1000 \mathrm{~kg}} \cdot \frac{3600 \mathrm{~s}}{\mathrm{~h}} \cdot \frac{8400 \mathrm{~h}}{? \mathrm{no}} \cdot 0,11 \frac{\mathrm{US} \$}{\mathrm{~m}^{3}}
$$

Desta forma, o gasto anual com a água de resfriamento que entra no processo é de US\$179.253,94. 
A soma dos valores acima resulta em um custo anual total de matéria-prima de US $\$ 67.349 .937,29$, o que corresponde a pouco mais de $57 \%$ do valor total investido na construção da planta.

Este fato mostra claramente que o aumento da eficiência dos processos termoquímicos utilizados na transformação dessa matéria-prima em hidrogênio é um fator de competitividade importante para as empresas deste setor.

\subsection{CUSTO DE PRODUÇÃO TOTAL}

O custo total de produção contempla os gastos realizados na fase de construção da planta (incluídos no valor de amortização) e os gastos realizados para promover a produção do hidrogênio, chamados de custos de operação.

A tabela 8.9 mostra o resumo dos principais parâmetros utilizados na elaboração da análise econômica.

Tabela 8.9 - Resumo dos parâmetros da análise econômica.

\begin{tabular}{|c|c|c|c|}
\hline & PARÂMETROS & UNIDADE & VALOR \\
\hline \multirow{5}{*}{ 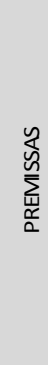 } & INFLAÇÃO PREVISTA NO PERÍODO DE OPERAÇÃO DA PLANTA & AO ANO & $4,50 \%$ \\
\hline & TAXA DE JUROS SOBRE O INVESTIMENTO INICIAL & AO ANO & $8,00 \%$ \\
\hline & VIDA ÚTIL DA PLANTA DE GERAÇÃO DE HIDROGÊNIO & ANOS & 20 \\
\hline & FATOR DE CARGA AO LONGO DA OPERAÇÃO DA PLANTA & - & 1 \\
\hline & TEMPO DE OPERAÇÃO PREVISTO & HORAS/ANO & 8400 \\
\hline \multirow{4}{*}{ 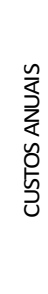 } & PARCELA ANUAL DE AMORTIZAÇÃO & US\$(2010) & $11.966 .915,90$ \\
\hline & CUSTO ANUAL DE OPERAÇÃO E MANUTENÇÃO & US\$(2010) & $5.205 .000,00$ \\
\hline & CUSTO ANUAL DE ENERGIA ELÉTRICA & US\$(2010) & $554.108,44$ \\
\hline & CUSTO ANUAL DE MATERIA-PRIMA & US\$(2010) & $67.349 .937,29$ \\
\hline \multirow{4}{*}{ 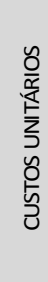 } & CUSTO UNITÁRIO DE ENERGIA ELÉTRICA & US\$(2010)/kWh & $9,602 \mathrm{E}-02$ \\
\hline & CUSTO UNITÁRIO DO GÁS NATURAL & US\$(2010)/kJ & $9,114 \mathrm{E}-06$ \\
\hline & CUSTO UNITÁRIO DA ÁGUA DE CALDEIRA & US\$(2010) $/ \mathrm{m}^{3}$ & 1,71 \\
\hline & CUSTO UNITÁRIO DA ÁGUA DE RESFRIAMENTO & US\$(2010) $/ \mathrm{m}^{3}$ & 0,11 \\
\hline
\end{tabular}


A consideração dos valores apresentados na tabela 8.9 permite quantificar os desembolsos anuais previstos ao longo do tempo de operação da planta de geração de hidrogênio. Estes valores, mostrados na tabela 8.10, consideram a inflação anual prevista sobre o custo de operação, manutenção e matéria-prima.

Tabela 8.10 - Custo total de produção de hidrogênio por ano de vida útil da planta.

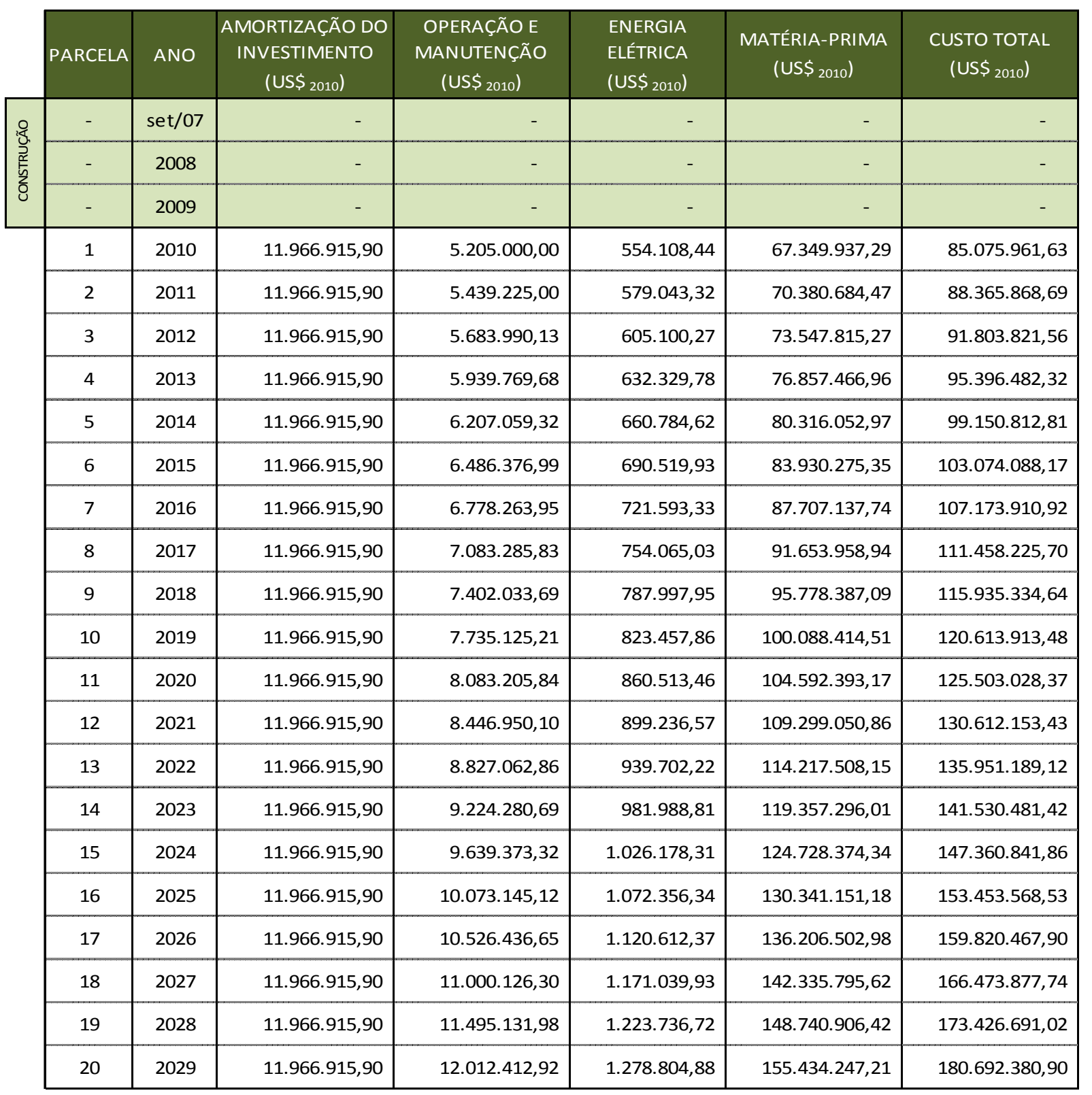

O custo total indicado na tabela 8.10 pode ser considerado como o capital anual necessário para compensar os custos de produção, sendo portanto o retorno financeiro mínimo requerido para que se produza hidrogênio dentro das condições especificadas e com o capital (equipamento, mão-de-obra e matéria-prima) previsto. 
Ainda sobre a tabela 8.10, percebe-se que mesmo utilizando o sistema de pagamentos constantes para amortização do capital investido, o custo anual total (ou retorno mínimo anual total) cresce ao longo do tempo por conta da incidência da inflação sobre os custos operacionais.

Assim como ocorreu na discussão sobre os sistemas de amortização, podese optar por diferentes métodos para definir o custo total de produção. Se a opção for por utilizar os dados conforme apresentados na tabela 8.10, o resultado será um custo de produção do hidrogênio diferente para cada ano de operação da planta.

Como alternativa, pode-se optar por transformar a série crescente referente aos custos de operação em uma série constante, chamada de custo nivelado (levelized cost), o que acarretaria um custo de produção constante ao longo da vida da planta.

À primeira vista, a opção por utilizar o custo nivelado parece fugir um pouco da realidade, pois sugere que o trabalho seja realizado com valores constantes ao longo do tempo (20 anos no caso), o que, de fato, foge da lógica do dia-a-dia onde todos os preços são reajustados com o passar do tempo. Entretanto, a utilização do custo nivelado se torna importante para padronizar os resultados e permitir comparações, uma vez que este valor carrega consigo todas as premissas econômicas utilizadas em sua obtenção.

Para entender o conceito de custo nivelado parte-se da suposição que toda a produção prevista ao longo da vida útil da unidade e todos os custos decorrentes desta produção, sejam de construção ou operação, ocorram simultaneamente logo após o término de sua construção, como mostrado pela eq.(8.12):

$$
\text { custo nivelado }=\frac{\text { Total gasto até } o \text { final da vida útil da planta }}{\text { Quantidade total produzida ao longo da vida útil }}
$$

Com isso, é possível obter um parâmetro de custo que relaciona o montante total investido em determinado empreendimento com a totalidade do que se espera produzir.

A hipótese de que todos os custos e toda a produção ocorram de forma instantânea ao final da construção é, sem dúvida, absurda. Sendo assim, uma hipótese que leve em consideração o tempo de implantação e de produção, utilizando parâmetros econômicos como a taxa de juros e a inflação, deve ser levada em conta na análise. Portanto, para manter o conceito inicial é necessário anualizar 
o numerador e o denominador da eq.(8.12). Dessa forma o custo nivelado permaneceria constante.

A anualização do denominador desta equação é bastante simples, sendo necessário apenas considerar a produção anual da planta. Entretanto, a anualização mostrada na tabela 8.10 resulta em custos nivelados diferentes para cada período verificado, o que não condiz com o conceito apresentado na eq.(8.12), que mostra a existência de um valor constante.

Para anualizar a série mostrada acima, deve-se aplicar a eq.(8.13), chamada de fator de recuperação de capital $(F R C)$, sobre a somatória dos valores presentes de cada pagamento previsto.

$$
F R C=\frac{i(1+i)^{n}}{(1+i)^{n}-1}
$$

Onde "i" é a taxa de juros utilizada e " $n$ " é o número de anos a qual o fator se aplica.

Este tipo de análise é muito comum quando se pretende comparar tecnologias diferentes, com prazos e custos de implantação distintos, mas com o mesmo produto final (AEO, 2010). A figura 8.1 trás um exemplo deste tipo de análise aplicado às novas tecnologias para geração de energia elétrica nos EUA.

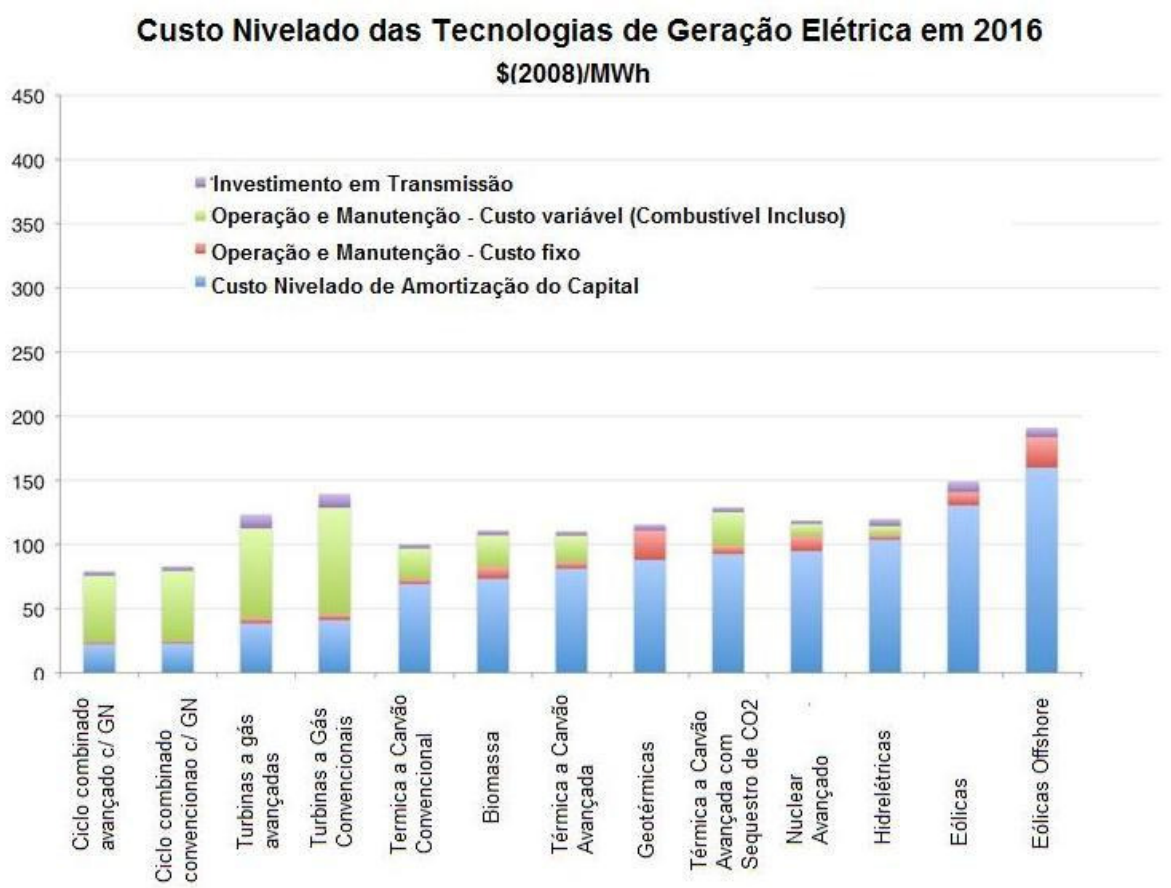

Figura 8.1: Aplicação da metodologia de custo nivelado na comparação entre tecnologias diferentes de geração elétrica (AEO, 2010) 
Para os custos de matéria-prima, a eq.(8.13) foi aplicada sobre a somatória dos valores presentes do respectivo custo unitário apresentado na tabela 8.9, e não sobre o custo anual total. Desta forma, cada custo unitário (nivelado) pode ser atribuído ao respectivo equipamento consumidor do recurso, como requer a análise termoeconômica. O mesmo deve ocorrer com o custo de energia elétrica. A tabela 8.11 mostra os valores atuais de cada um destes recursos e seus respectivos valores nivelados, considerando uma correção de 4,5\% ao ano e um período de operação de 20 anos.

Tabela 8.11 - Custo de matéria prima: valor atual e valor total.

\begin{tabular}{|l|c|c|c|}
\hline \multicolumn{1}{|c|}{ PARÂMETROS } & UNIDADE & $\begin{array}{c}\text { VALOR ATUAL } \\
\text { (ANO: 2010) }\end{array}$ & $\begin{array}{c}\text { VALOR NIVELADO } \\
(\mathrm{i}=4,5 \% ; n=20 \text { anos })\end{array}$ \\
\hline CUSTO UNITÁRIO DE ENERGIA ELÉTRICA & US\$(2010)/kWh & $9,602 \mathrm{E}-02$ & $1,476 \mathrm{E}-01$ \\
\hline CUSTO UNITÁRIO DO GÁS NATURAL & US\$(2010)/kJ & $9,114 \mathrm{E}-06$ & $1,401 \mathrm{E}-05$ \\
\hline CUSTO UNITÁRIO DA ÁGUA DE CALDEIRA & US\$(2010) $/ \mathrm{m}^{3}$ & 1,71 & 2,63 \\
\hline CUSTO UNITÁRIO DA ÁGUA DE RESFRIAMENTO & US\$(2010) $/ \mathrm{m}^{3}$ & 0,11 & 0,17 \\
\hline
\end{tabular}

No intuito de reconhecer a importância de cada uma das abordagens apresentadas e de facilitar a comparação entre os resultados obtidos com outros presentes na literatura, este trabalho se propõe a apresentar os valores obtidos por ambos os métodos de avaliação de custos de produção (atual e nivelado).

O custo atual (ou atualizado) de produção será obtido através da análise do primeiro ano de operação da planta (2010), cujos valores relativos à amortização do investimento, operação e manutenção da planta estão presentes na tabela 8.10. Os custos de energia elétrica de matéria-prima serão utilizados os valores presentes na coluna "Valor Atual (Ano: 2010)" da tabela 8.11.

Para obter 0 resultado relativo ao custo de produção total nivelado serão utilizados os valores presentes na tabela 8.11, coluna "Valor Nivelado ( $\mathrm{i}=4,5 \%$; $\mathrm{n}=20$ anos)", em conjunto com os valores apresentados na tabela 8.12, obtidos na aplicação do fator de recuperação do capital à somatória dos valores presentes de operação e manutenção.

Assim, ao somar o desembolso relativo à parcela de amortização (constante ao longo do tempo) com a parcela de operação e manutenção nivelada, obtem-se 
um custo total constante ao longo do tempo (nivelado), coerente com o conceito apresentado para este tipo de abordagem.

Tabela 8.12 - Custo nivelado anual (2010) de produção de hidrogênio - Somatória das parcelas de amortização do investimento e operação e manutenção.

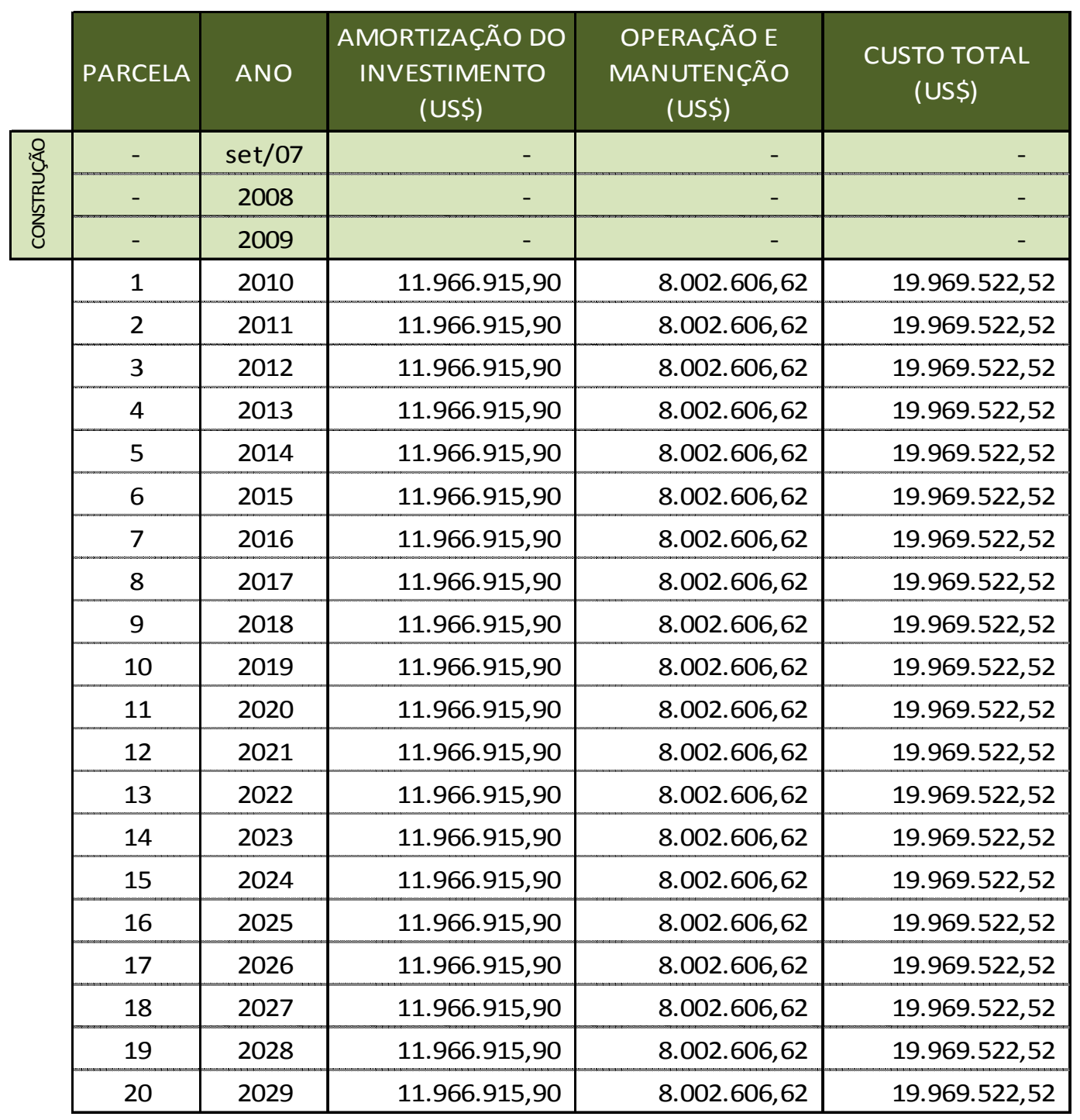

Neste trabalho, portanto, serão obtidos dois custos distintos. Um deles, chamado de "custo atualizado" (ou "custo atual"), procura representar o valor corrente do produto. Este custo contempla exclusivamente os gastos relativos à produção de hidrogênio no ano utilizado como referência para análise (2010). O outro, chamado de "custo nivelado", contém imbutido em seu valor parâmetros como vida útil da planta e taxa de inflação (contempla todo o ciclo de vida da planta). Devido à diferença de conceito entre estes dois valores a utilização deles deve ser feita com cautela, de acordo com sua característica específica. 
O custo atualizado pode ser comparado diretamente com valores de mercado, ou ainda utilizado na formação de preço do produto final, respeitando-se o ano de referência (2010, no caso).

O custo nivelado permite comparar de forma justa os resultados obtidos para a planta estudada com outros provenientes de tecnologias, vida útil, prazos e taxas de juros diferentes e que utilizem a mesma metodologia de obtenção.

\subsection{REDEFINIÇÃO DOS CUSTOS DOS EQUIPAMENTOS DA PLANTA}

Para realizar a análise termoeconômica é necessário compatibilizar os gastos previstos em todas as fases do empreendimento com a metodologia de análise proposta.

$\mathrm{Na}$ análise termoeconômica, os dados de entrada relativos aos custos de produção são de dois tipos:

- Custo em base exergética - custo ligado a um determinado fluxo que entra ou sai de um dos equipamentos do processo.

- Taxa de custo dos equipamentos do processo - custo ligado à utilização do equipamento pelo processo produtivo. Relaciona o custo total de implantação, compra, construção, operação e manutenção pelo tempo de utilização previsto.

Os custos unitários de energia elétrica e de matéria-prima são considerados como sendo do primeiro tipo, enquanto os custos de compra dos equipamentos do processo, mostrados na tabela 8.2, devem ter seus valores redefinidos. Assim, o novo custo dos equipamentos deve considerar não só o valor de compra mas também os gastos relativos à construção, operação e manutenção de cada equipamento específico.

Conforme visto ao longo do capítulo 8.1, diversas hipóteses foram aplicadas aos custos de compra dos equipamentos para estimar o custo de construção da planta. Desta forma, foi obtido o custo implantação total por equipamento, conforme mostra a tabela 8.13 , sendo que os dados apresentados contemplam todos os gastos envolvidos na construção do empreendimento (engenharia, tubulação, 
instrumentação, construção civil, mão-de-obra direta, partida da planta, contingências, etc) embutidos em seu valor. Além disso, estes resultados consideraram a complexidade de implantação de cada equipamento específico, uma vez que cada um tem características diferentes de montagem, requisitos diferentes de estruturas civis e níveis de automação diferenciados, por exemplo.

Tabela 8.13 - Custo total de construção da planta distribuído pelos equipamentos.

\begin{tabular}{|c|c|c|c|}
\hline TAG & DESCRIÇÃO & $\begin{array}{l}\text { ESTIMATIVA DE CUSTO } \\
\text { TOTAL POR } \\
\text { EQUIPAMENTO } \\
\text { (US\$) (SET/07) }\end{array}$ & $\begin{array}{c}\text { PERCENTUAL } \\
\text { RELATIVO ENTRE } \\
\text { OS CUSTOS } \\
\text { (\%) }\end{array}$ \\
\hline V-01 & VASO PULMÃO & $159.182,23$ & $0,16 \%$ \\
\hline $\mathrm{P}-01$ & PERMUTADOR DE PRÉ-AQUECIMENTO DA CARGA & $222.838,09$ & $0,23 \%$ \\
\hline MX-01 & MISTURADOR 01 - CONEXÃO ENTRE TUBULAÇÕES & & \\
\hline $\mathrm{R}-01(\mathrm{H})$ & REATOR DE HIDRODESSULFURIZAÇÃO & $1.825 .401,74$ & $1,86 \%$ \\
\hline $\mathrm{R}-01(\mathrm{~A})$ & REATOR DE DESSULFURIZAÇÃO "A" & $2.263 .646,15$ & $2,31 \%$ \\
\hline $\mathrm{R}-01(\mathrm{~B})$ & REATOR DE DESSULFURIZAÇÃO "B" & $2.263 .646,15$ & $2,31 \%$ \\
\hline MX-02 & MISTURADOR 02 - CONEXÃO ENTRE TUBULAÇÕES & & \\
\hline $\mathrm{F}-01$ & FORNO REFORMADOR & $40.020 .526,05$ & $40,77 \%$ \\
\hline $\mathrm{P}-03$ & RECUPERADOR DE CALOR & $8.449 .087,90$ & $8,61 \%$ \\
\hline $\mathrm{R}-02$ & REATOR DE AUMENTO (SHIFT) & $2.263 .646,15$ & $2,31 \%$ \\
\hline $\mathrm{P}-04$ & AQUECEDOR DE ÁGUA DE CALDEIRA & $3.629 .347,21$ & $3,70 \%$ \\
\hline $\mathrm{P}-05$ & GERADOR DE VAPOR DE BAIXA PRESSÃO & $3.739 .242,65$ & $3,81 \%$ \\
\hline P-06 & $1^{\circ}$ RESFRIADOR DA ALIMENTAÇÃO DA PSA & $7.838 .294,55$ & $7,98 \%$ \\
\hline $\mathrm{P}-07$ & $2^{\circ}$ RESFRIADOR DA ALIMENTAÇÃO DA PSA & $1.649 .760,19$ & $1,68 \%$ \\
\hline V-05 & VASO DE ALIMENTAÇÃO DA PSA & $1.787 .374,38$ & $1,82 \%$ \\
\hline PSA & SISTEMA DE PURIFICAÇÃO DO H2 - PSA & $9.600 .791,58$ & $9,78 \%$ \\
\hline VALVE-01 & VÁLVULA DO SISTEMA DE TRATAMENTO DE CONDENSADO & $22.476,70$ & $0,02 \%$ \\
\hline P-08 & AQUECEDOR DA ALIMENTAÇÃO - TRATAMENTO DE CONDENSADO & $831.793,39$ & $0,85 \%$ \\
\hline $\mathrm{T}-01$ & TORRE DE SEPARAÇÃO DE CONDENSADO & $2.330 .938,16$ & $2,37 \%$ \\
\hline V-03 & VASO DE VAPOR & $5.623 .532,28$ & $5,73 \%$ \\
\hline V-04 & VASO DE REJEITOS (BLOWDOWN) & $3.629 .347,21$ & $3,70 \%$ \\
\hline \multirow[t]{2}{*}{ VALVE-02 } & VÁLVULA DO SISTEMA DE GERAÇÃO DE VAPOR & $22.476,70$ & $0,02 \%$ \\
\hline & TOTAL & 98.173.349,47 & $100,00 \%$ \\
\hline
\end{tabular}


Utilizando a proporção entre os custos apresentados na tabela 8.13, pode-se definir o custo anual (relativos à construção, operação e manutenção) para cada equipamento da planta. Conforme proposto, a análise será feita sobre o custo atualizado (referênte ao primeiro ano de operação da planta), e sobre o custo nivelado. Assim, os custos anuais dos equipamentos para cada um destes casos estão presentes nas tabelas 8.14 e 8.15 respectivamente.

Tabela 8.14 - Custo atualizado (const. e oper.) por equipamento, por ano.

\begin{tabular}{|c|c|c|c|}
\hline TAG & DESCRIÇÃO & $\begin{array}{c}\text { PERCENTUAL } \\
\text { RELATIVO ENTRE } \\
\text { OS CUSTOS } \\
\text { (\%) }\end{array}$ & $\begin{array}{l}\text { CUSTO ATUALIZADO } \\
\text { POR EQUIPAMENTO } \\
\text { (US\$) (2010) }\end{array}$ \\
\hline V-01 & VASO PULMÃO & $0,16 \%$ & $27.843,24$ \\
\hline P-01 & PERMUTADOR DE PRÉ-AQUECIMENTO DA CARGA & $0,23 \%$ & $38.977,55$ \\
\hline MX-01 & MISTURADOR 01 - CONEXÃO ENTRE TUBULAÇÕES & & \\
\hline $\mathrm{R}-01(\mathrm{H})$ & REATOR DE HIDRODESSULFURIZAÇÃO & $1,86 \%$ & $319.288,74$ \\
\hline $\mathrm{R}-01(\mathrm{~A})$ & REATOR DE DESSULFURIZAÇÃO "A" & $2,31 \%$ & $395.943,93$ \\
\hline $\mathrm{R}-01(\mathrm{~B})$ & REATOR DE DESSULFURIZAÇÃO "B" & $2,31 \%$ & $395.943,93$ \\
\hline $\mathrm{MX}-02$ & MISTURADOR 02 - CONEXÃO ENTRE TUBULAÇÕES & & \\
\hline $\mathrm{F}-01$ & FORNO REFORMADOR & $40,77 \%$ & $7.000 .159,53$ \\
\hline P-03 & RECUPERADOR DE CALOR & $8,61 \%$ & $1.477 .865,71$ \\
\hline $\mathrm{R}-02$ & REATOR DE AUMENTO (SHIFT) & $2,31 \%$ & $395.943,93$ \\
\hline P-04 & AQUECEDOR DE ÁGUA DE CALDEIRA & $3,70 \%$ & $634.824,48$ \\
\hline P-05 & GERADOR DE VAPOR DE BAIXA PRESSÃO & $3,81 \%$ & $654.046,75$ \\
\hline P-06 & $1^{\circ}$ RESFRIADOR DA ALIMENTAÇÃO DA PSA & $7,98 \%$ & $1.371 .029,26$ \\
\hline P-07 & $2^{\circ}$ RESFRIADOR DA ALIMENTAÇÃO DA PSA & $1,68 \%$ & $288.566,54$ \\
\hline V-05 & VASO DE ALIMENTAÇÃO DA PSA & $1,82 \%$ & $312.637,21$ \\
\hline PSA & SISTEMA DE PURIFICAÇÃO DO H2 - PSA & $9,78 \%$ & $1.679 .315,07$ \\
\hline VALVE-01 & VÁLVULA DO SISTEMA DE TRATAMENTO DE CONDENSADO & $0,02 \%$ & $3.931,49$ \\
\hline P-08 & AQUECEDOR DA ALIMENTAÇÃO - TRATAMENTO DE CONDENSADO & $0,85 \%$ & $145.492,50$ \\
\hline $\mathrm{T}-01$ & TORRE DE SEPARAÇÃO DE CONDENSADO & $2,37 \%$ & $407.714,25$ \\
\hline $\mathrm{V}-03$ & VASO DE VAPOR & $5,73 \%$ & $983.635,82$ \\
\hline V-04 & VASO DE REJEITOS (BLOWDOWN) & $3,70 \%$ & $634.824,48$ \\
\hline \multirow[t]{2}{*}{ VALVE-02 } & VÁLVULA DO SISTEMA DE GERAÇÃO DE VAPOR & $0,02 \%$ & $3.931,49$ \\
\hline & TOTAL & $100,00 \%$ & 17.171.915,90 \\
\hline
\end{tabular}


Tabela 8.15 - Custo nivelado (const. e oper.) por equipamento, por ano (ref.2010).

\begin{tabular}{|c|c|c|c|}
\hline TAG & DESCRIÇÃO & $\begin{array}{l}\text { PERCENTUAL } \\
\text { RELATIVO ENTRE } \\
\text { OS CUSTOS } \\
(\%)\end{array}$ & $\begin{array}{l}\text { CUSTO NIVELADO } \\
\text { POR EQUIPAMENTO } \\
\text { (US\$/ANO) }\end{array}$ \\
\hline V-01 & VASO PULMÃO & $0,16 \%$ & $32.379,39$ \\
\hline P-01 & PERMUTADOR DE PRÉ-AQUECIMENTO DA CARGA & $0,23 \%$ & $45.327,68$ \\
\hline MX-01 & MISTURADOR 01 - CONEXÃO ENTRE TUBULAÇÕES & - & \\
\hline $\mathrm{R}-01(\mathrm{H})$ & REATOR DE HIDRODESSULFURIZAÇÃO & $1,86 \%$ & $371.306,48$ \\
\hline R-01(A) & REATOR DE DESSULFURIZAÇÃO "A" & $2,31 \%$ & $460.450,14$ \\
\hline R-01(B) & REATOR DE DESSULFURIZAÇÃO "B" & $2,31 \%$ & $460.450,14$ \\
\hline MX-02 & MISTURADOR 02 - CONEXÃO ENTRE TUBULAÇÕES & & \\
\hline $\mathrm{F}-01$ & FORNO REFORMADOR & $40,77 \%$ & $8.140 .608,43$ \\
\hline P-03 & RECUPERADOR DE CALOR & $8,61 \%$ & $1.718 .635,98$ \\
\hline $\mathrm{R}-02$ & REATOR DE AUMENTO (SHIFT) & $2,31 \%$ & $460.450,14$ \\
\hline P-04 & AQUECEDOR DE ÁGUA DE CALDEIRA & $3,70 \%$ & $738.248,53$ \\
\hline P-05 & GERADOR DE VAPOR DE BAIXA PRESSÃO & $3,81 \%$ & $760.602,45$ \\
\hline P-06 & $1^{\circ}$ RESFRIADOR DA ALIMENTAÇÃO DA PSA & $7,98 \%$ & $1.594 .394,00$ \\
\hline P-07 & $2^{\circ}$ RESFRIADOR DA ALIMENTAÇÃO DA PSA & $1,68 \%$ & $335.579,09$ \\
\hline V-05 & VASO DE ALIMENTAÇÃO DA PSA & $1,82 \%$ & 363.571,31 \\
\hline PSA & SISTEMA DE PURIFICAÇÃO DO H2 - PSA & $9,78 \%$ & $1.952 .904,99$ \\
\hline VALVE-01 & VÁLVULA DO SISTEMA DE TRATAMENTO DE CONDENSADO & $0,02 \%$ & $4.572,00$ \\
\hline P-08 & AQUECEDOR DA ALIMENTAÇÃO - TRATAMENTO DE CONDENSADO & $0,85 \%$ & $169.195,78$ \\
\hline $\mathrm{T}-01$ & TORRE DE SEPARAÇÃO DE CONDENSADO & $2,37 \%$ & 474.138,07 \\
\hline $\mathrm{V}-03$ & VASO DE VAPOR & $5,73 \%$ & $1.143 .887,37$ \\
\hline $\mathrm{V}-04$ & VASO DE REJEITOS (BLOWDOWN) & $3,70 \%$ & $738.248,53$ \\
\hline \multirow[t]{2}{*}{ VALVE-02 } & VÁLVULA DO SISTEMA DE GERAÇÃO DE VAPOR & $0,02 \%$ & $4.572,00$ \\
\hline & TOTAL & $100,00 \%$ & 19.969.522,52 \\
\hline
\end{tabular}

Os dados apresentados acima sugerem que os custos de operação e manutenção por equipamento será proporcional ao custo total de implantação de cada um deles. Apesar desta afirmação não ser totalmente verdadeira parece ser razoável imaginar que os equipamentos mais caros têm custos de operação maiores. Sendo assim, na falta de um critério melhor para divisão destes custos, a hipótese apresentada será considerada válida para as análises subseqüentes. 
É possível ainda obter os custos nivelados por hora de cada um dos equipamentos, utilizando para isso os dados de tempo de operação anual, o qual foi estimado em 8400 horas por ano. Os resultados para o custo atualizado e para o custo nivelado estão apresentados nas tabelas 8.16 e 8.17 respectivamente.

Tabela 8.16 - Custo atualizado (const. e oper.) por equipamento, por hora (ref.2010).

\begin{tabular}{|c|c|c|}
\hline TAG & DESCRIÇÃO & $\begin{array}{c}\text { CUSTO ATUALIZADO } \\
\text { POR EQUIPAMENTO } \\
\text { (US\$/HORA) }\end{array}$ \\
\hline V-01 & VASO PULMÃO & 3,31 \\
\hline P-01 & PERMUTADOR DE PRÉ-AQUECIMENTO DA CARGA & 4,64 \\
\hline MX-01 & MISTURADOR 01 - CONEXÃO ENTRE TUBULAÇÕES & - \\
\hline $\mathrm{R}-01(\mathrm{H})$ & REATOR DE HIDRODESSULFURIZAÇÃO & 38,01 \\
\hline $\mathrm{R}-01(\mathrm{~A})$ & REATOR DE DESSULFURIZAÇÃO "A" & 47,14 \\
\hline R-01(B) & REATOR DE DESSULFURIZAÇÃO "B" & 47,14 \\
\hline MX-02 & MISTURADOR 02 - CONEXÃO ENTRE TUBULAÇÕES & - \\
\hline $\mathrm{F}-01$ & FORNO REFORMADOR & 833,35 \\
\hline $\mathrm{P}-03$ & RECUPERADOR DE CALOR & 175,94 \\
\hline $\mathrm{R}-02$ & REATOR DE AUMENTO (SHIFT) & 47,14 \\
\hline $\mathrm{P}-04$ & AQUECEDOR DE ÁGUA DE CALDEIRA & 75,57 \\
\hline $\mathrm{P}-05$ & GERADOR DE VAPOR DE BAIXA PRESSÃO & 77,86 \\
\hline P-06 & $1^{\circ}$ RESFRIADOR DA ALIMENTAÇÃO DA PSA & 163,22 \\
\hline P-07 & $2^{\circ}$ RESFRIADOR DA ALIMENTAÇÃO DA PSA & 34,35 \\
\hline V-05 & VASO DE ALIMENTAÇÃO DA PSA & 37,22 \\
\hline PSA & SISTEMA DE PURIFICAÇÃO DO H2 - PSA & 199,92 \\
\hline VALVE-01 & VÁLVULA DO SISTEMA DE TRATAMENTO DE CONDENSADO & 0,47 \\
\hline $\mathrm{P}-08$ & AQUECEDOR DA ALIMENTAÇÃO - TRATAMENTO DE CONDENSADO & 17,32 \\
\hline $\mathrm{T}-01$ & TORRE DE SEPARAÇÃO DE CONDENSADO & 48,54 \\
\hline V-03 & VASO DE VAPOR & 117,10 \\
\hline V-04 & VASO DE REJEITOS (BLOWDOWN) & 75,57 \\
\hline \multirow[t]{2}{*}{ VALVE-02 } & VÁLVULA DO SISTEMA DE GERAÇÃO DE VAPOR & 0,47 \\
\hline & TOTAL & $2.044,28$ \\
\hline
\end{tabular}


Tabela 8.17 - Custo nivelado (const. e oper.) por equipamento, por hora (ref.2010).

\begin{tabular}{|c|c|c|}
\hline TAG & DESCRIÇÃO & $\begin{array}{l}\text { CUSTO NIVELADO } \\
\text { POR EQUIPAMENTO } \\
\text { (US\$/HORA) }\end{array}$ \\
\hline V-01 & VASO PULMÃO & 3,85 \\
\hline P-01 & PERMUTADOR DE PRÉ-AQUECIMENTO DA CARGA & 5,40 \\
\hline $\mathrm{MX}-01$ & MISTURADOR 01 - CONEXÃO ENTRE TUBULAÇÕES & - \\
\hline $\mathrm{R}-01(\mathrm{H})$ & REATOR DE HIDRODESSULFURIZAÇÃO & 44,20 \\
\hline $\mathrm{R}-01(\mathrm{~A})$ & REATOR DE DESSULFURIZAÇÃO "A" & 54,82 \\
\hline $\mathrm{R}-01(\mathrm{~B})$ & REATOR DE DESSULFURIZAÇÃO "B" & 54,82 \\
\hline MX-02 & MISTURADOR 02 - CONEXÃO ENTRE TUBULAÇÕES & - \\
\hline $\mathrm{F}-01$ & FORNO REFORMADOR & 969,12 \\
\hline P-03 & RECUPERADOR DE CALOR & 204,60 \\
\hline $\mathrm{R}-02$ & REATOR DE AUMENTO (SHIFT) & 54,82 \\
\hline P-04 & AQUECEDOR DE ÁGUA DE CALDEIRA & 87,89 \\
\hline P-05 & GERADOR DE VAPOR DE BAIXA PRESSÃO & 90,55 \\
\hline P-06 & $1^{\circ}$ RESFRIADOR DA ALIMENTAÇÃO DA PSA & 189,81 \\
\hline P-07 & $2^{\circ}$ RESFRIADOR DA ALIMENTAÇÃO DA PSA & 39,95 \\
\hline V-05 & VASO DE ALIMENTAÇÃO DA PSA & 43,28 \\
\hline PSA & SISTEMA DE PURIFICAÇÃO DO H2 - PSA & 232,49 \\
\hline VALVE-01 & VÁLVULA DO SISTEMA DE TRATAMENTO DE CONDENSADO & 0,54 \\
\hline P-08 & AQUECEDOR DA ALIMENTAÇÃO - TRATAMENTO DE CONDENSADO & 20,14 \\
\hline $\mathrm{T}-01$ & TORRE DE SEPARAÇÃO DE CONDENSADO & 56,45 \\
\hline V-03 & VASO DE VAPOR & 136,18 \\
\hline V-04 & VASO DE REJEITOS (BLOWDOWN) & 87,89 \\
\hline VALVE-02 & VÁLVULA DO SISTEMA DE GERAÇÃO DE VAPOR & 0,54 \\
\hline & TOTAL & $2.377,32$ \\
\hline
\end{tabular}

Conforme dito anteriormente, estes resultados, associados aos custos de matéria-prima presentes na tabela 8.11, servirão de base para a elaboração da análise termoeconômica da planta de geração de hidrogênio. Esta análise será apresentada no capítulo 9 deste trabalho. 


\section{ANÁLISE TERMOECONÔMICA DA UNIDADE DE GERAÇÃO DE HIDROGÊNIO}

A análise termoeconômica utiliza conceitos da análise exergética em conjunto com dados econômicos para determinar os custos dos produtos da unidade de geração de hidrogênio estudada. Desta forma, os dados apresentados no capítulo 7, referentes à análise exergética da planta serão utilizados em conjunto com os dados presentes no capítulo 8, relativos à análise econômica, a fim de se obter o custo total de produção do hidrogênio, vapor, e demais produtos da planta.

Para isso os conceitos e formulações apresentados no capítulo 6 serão resgatados e aplicados convenientemente para cada um dos equipamentos e sistemas do processo. Em seguida, serão apresentados o resultado dos custos atuais (ou atualizados) e dos custos nivelados de cada produto da planta, obtidos na aplicação da metodologia.

Estes resultados serão discutidos e comparados com referências da literatura, a fim de verificar a consistência dos valores obtidos. 


\subsection{BALANÇO DE CUSTO EXERGÉTICO DOS EQUIPAMENTOS DA PLANTA}

\subsubsection{Descrição das premissas adotadas na aplicação dos métodos de partição}

Os métodos de partição dos custos exergéticos apresentados por Gaggioli e Wepfer (1980) foram utilizados sempre que se obteve mais de um produto por equipamento ou sistema. Tendo em vista que os principais produtos da planta estudada são o hidrogênio e o vapor d'água, as seguintes premissas serão utilizadas na aplicação dos métodos de partição:

I. O método da igualdade será utilizado sempre que os fluxos de saída de um determinado equipamento estiverem diretamente ligados à produção de hidrogênio e vapor d'água, de forma simultânea.

II. O método da extração será utilizado quando apenas um dos fluxos de saída estiver ligado à produção de hidrogênio ou vapor, sendo que os demais fluxos de saída serão considerados secundários.

III. Todos os rejeitos do processo terão seu custo em base exergética igual a zero.

IV. Fluxos que apresentem mesmo estado termodinâmico (bifurcações) terão os mesmos custos em base exergética.

\subsubsection{Balanço de custos de cada equipamento}

O resultado da aplicação do balanço de custos para cada equipamento da planta, considerando as premissas de aplicação dos métodos de partição, pode ser visto entre as eq.(9.6) e eq.(9.42). Por uma questão de simplicidade, os balanços serão apresentados em função do fluxo de exergia total no ponto de interesse $\left(\dot{B}_{i}\right)$, 
conforme notação apresentada na eq.(6.16). Todos os pontos de interesse relativos aos fluxos mássicos da planta estão indicados na planta síntese do processo (fig.5.1), apresentada no capítulo 5 deste trabalho.

\section{Vaso pulmão de gás natural (V-01):}

$$
c_{1} \cdot \dot{B}_{1}+\dot{Z}_{(V-01)}=c_{2} \cdot \dot{B}_{2}
$$

\section{Pré aquecedor do gás natural (P-01):}

$$
c_{2} \cdot \dot{B}_{2}+c_{4} \cdot \dot{B}_{4}+\dot{Z}_{(P-01)}=c_{3} \cdot \dot{B}_{3}+c_{5} \cdot \dot{B}_{5}
$$

Conforme mostra a figura (9.1), neste equipamento tem-se dois fluxos de produtos, sendo que o fluxo do "ponto 5" pode ser considerado secundário (saída de condensado). Assim, será utilizado o método da extração, conforme premissa adotada para aplicação dos métodos de partição (premissa II). Com isso, pode-se adotar que o custo exergético relativo ao fluxo secundário permanece constante, conforme mostrado na eq. (9.8).

$$
c_{4}=c_{5}
$$

Substituíndo na eq. (9.7):

$$
c_{2} \cdot \dot{B}_{2}+c_{4} \cdot\left(\dot{B}_{4}-\dot{B}_{5}\right)+\dot{Z}_{(P-01)}=c_{3} \cdot \dot{B}_{3}
$$

Sempre que houver uma igualdade entre os custos exergéticos em fluxos distintos, convencionou-se por adotar a notação relativa ao ponto numericamente menor ( $c_{4}$, no caso).

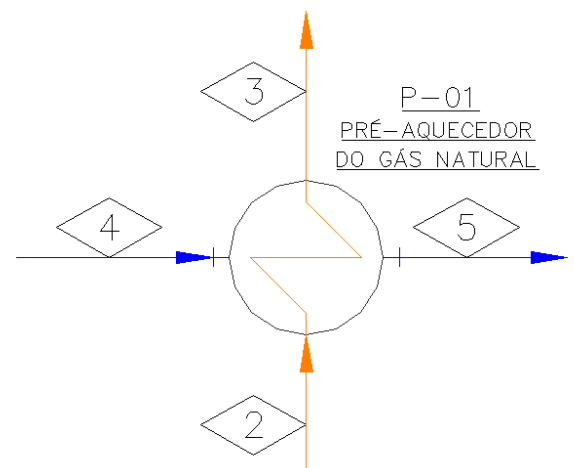

Figura 9.1: Volume de controle para o balanço de custos do P-01 


\section{Misturador do reciclo de $\mathrm{H}_{2}(\mathrm{MX}-01)$ :}

Uma vez que o misturador não é um equipamento, mas sim uma coneção entre tubulações, não existe um custo de equipamento $(\dot{Z})$ associado a este sistema. Assim o balanço de custos resume-se à eq.(9.10) mostrada abaixo:

$$
c_{3} \cdot \dot{B}_{3}+c_{6} \cdot \dot{B}_{6}=c_{7} \cdot \dot{B}_{7}
$$

Neste caso, o custo exergético do fluxo do "ponto 6", referente ao hidrogênio de reciclo, será considerado como sendo igual ao custo de produção do hidrogênio no final do processo (fluxo do "ponto 22"). Assim:

$$
c_{6}=c_{22}
$$

\section{Reatores de dessulfurização (R-01H, R01A e R-01B):}

Este sistema é composto por três reatores, sendo um reator de hidrodessulfurização e outros dois de dessulfurização montados em série. O balanço de custos para este sistema é mostrado pela eq.(9.12):

$$
c_{8} \cdot \dot{B}_{8}+\dot{Z}_{(R-01 H)}+\dot{Z}_{(R-01 A)}+\dot{Z}_{(R-01 B)}=c_{9} \cdot \dot{B}_{9}
$$

\section{Misturador da alimentação do forno reformador (MX-02):}

Conforme explicado anteriormente, não existe um custo de equipamento $(\dot{Z})$ associado a este sistema. Assim o balanço de custos resume-se à eq.(9.13) mostrada abaixo:

$$
c_{9} \cdot \dot{B}_{9}+c_{39} \cdot \dot{B}_{39}=c_{10} \cdot \dot{B}_{10}
$$

O fluxo do "ponto 39" é uma parte do fluxo proveniente de uma bifurcação da tubulação (fig.9.2), alimentada pelo fluxo do "ponto 37". 


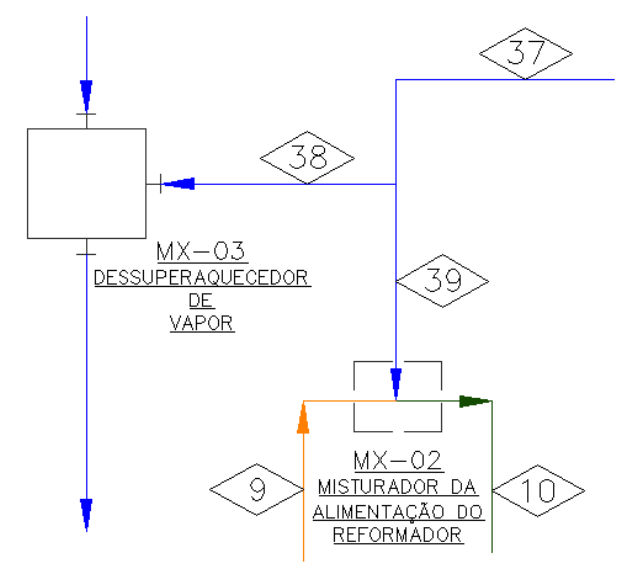

Figura 9.2: Bifurcação do fluxo do "ponto 37" para alimentação dos MX-02 e MX-03

Uma vez que a matéria presente nos três pontos (37, 38 e 39) possue o mesmo estado termodinâmico, torna-se possível aplicar a premissa IV apresentada na seção 9.2.1, sendo que o resultado pode ser visto na eq.(9.14):

$$
c_{37}=c_{38}=c_{39}
$$

Com isso, pelo critério de notação adotado, a eq.(9.13) pode ser reescrita como:

$$
c_{9} \cdot \dot{B}_{9}+c_{37} \cdot \dot{B}_{39}=c_{10} \cdot \dot{B}_{10}
$$

\section{Recuperador de calor (P-03):}

$$
c_{12} \cdot \dot{B}_{12}+c_{50} \cdot \dot{B}_{50}+\dot{Z}_{(P-03)}=c_{13} \cdot \dot{B}_{13}+c_{51} \cdot \dot{B}_{51}
$$

Para este equipamento (fig.9.3) também será utilizado o método da igualdade (premissa I), uma vez que os itens produzidos estão diretamente relacionados com os produtos principais da planta: vapor no "ponto 51" e hidrogênio no "ponto 13". Com isso, pode-se adotar a igualdade entre os custos exergéticos mostrada na eq. (9.17):

$$
c_{13}=c_{51}
$$




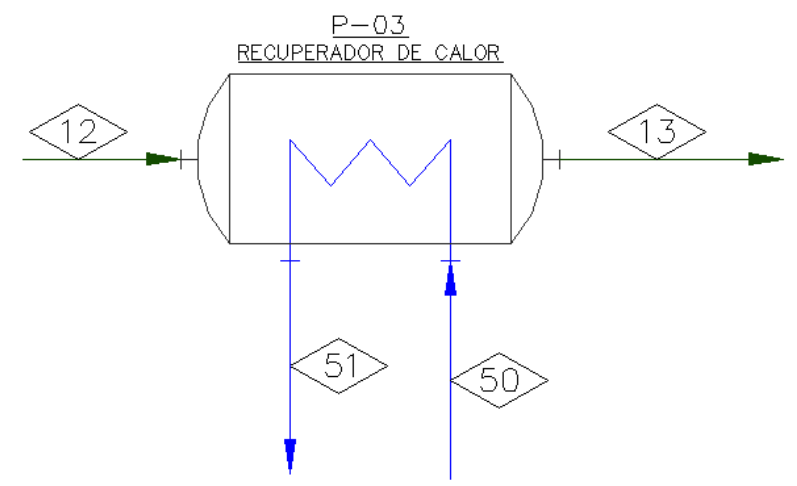

Figura 9.3: Volume de controle para o balanço de custos do P-03

Com isso a eq.(9.16) pode ser reescrita como sendo:

$$
c_{12} \cdot \dot{B}_{12}+c_{50} \cdot \dot{B}_{50}+\dot{Z}_{(P-03)}=c_{13} \cdot\left(\dot{B}_{13}+\dot{B}_{51}\right)
$$

\section{Reator de Shift (R-02):}

$$
c_{13} \cdot \dot{B}_{13}+\dot{Z}_{(R-02)}=c_{14} \cdot \dot{B}_{14}
$$

\section{Aquecedor da áqua de alimentacão (P-04):}

$$
c_{14} \cdot \dot{B}_{14}+c_{34} \cdot \dot{B}_{34}+\dot{Z}_{(P-04)}=c_{15} \cdot \dot{B}_{15}+c_{35} \cdot \dot{B}_{35}
$$

Para o aquecedor de água de alimentação (fig.9.4) também será considerado o método da igualdade, visto que os itens produzidos estão diretamente relacionados com os produtos principais da unidade: vapor no "ponto 35" e hidrogênio no "ponto 15". A igualdade entre os custos exergéticos por conta da aplicação do método de partição está mostrada na eq. (9.21):

$$
c_{15}=c_{35}
$$

A água desmineralizada utilizada no fluxo de entrada do P-04 (ponto 34) é proveniente de um sistema de distribuição (mostrado também na fig.9.4) composto de tubulações apenas, e sua alimentação principal está relacionada ao fluxo do "ponto 60". 


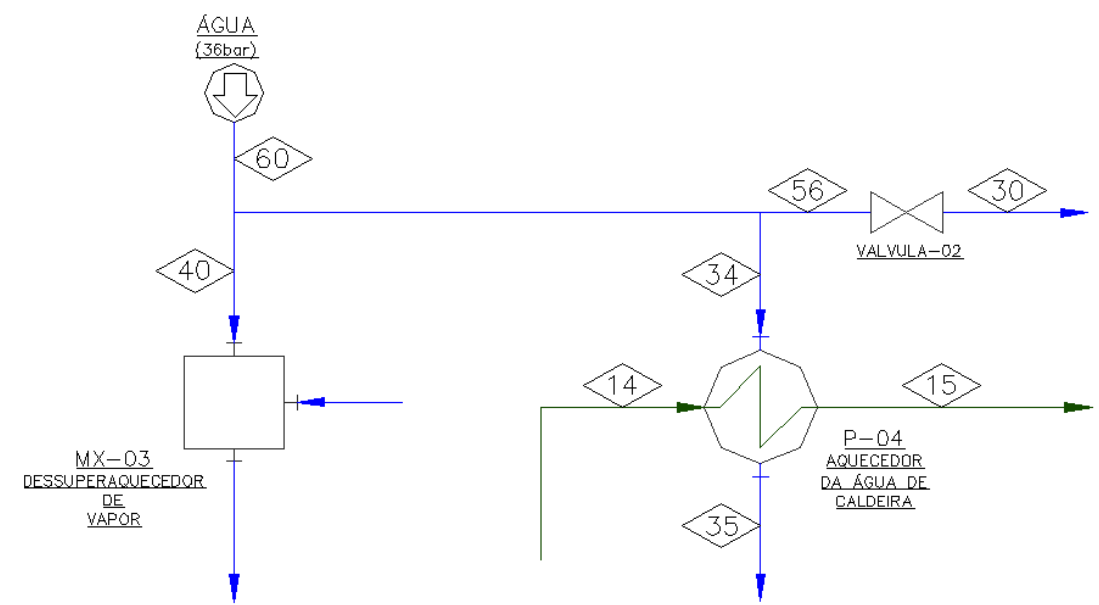

Figura 9.4: Volume de controle para o balanço de custos do P-04 e sistema de distribuição do fluxo de água desmineralizada (ponto 60).

Dessa forma, sabe-se que a matéria presente nos quatro pontos do sistema (34, 40, 56 e 60) tem o mesmo estado termodinâmico, o que torna possível a aplicação premissa IV apresentada anteriormente, formando a igualdade apresentada na eq.(9.22):

$$
c_{34}=c_{40}=c_{56}=c_{60}
$$

\section{Válvula 02 (Valve-02):}

Utilizando a eq.(9.22), o balanço de custos na Válvula 02 pode ser escrito conforme a eq.(9.23) mostrada abaixo:

$$
c_{34} \cdot \dot{B}_{56}+\dot{Z}_{\text {Valve- } 02}=c_{30} \cdot \dot{B}_{30}
$$

\section{Gerador de vapor de baixa pressão (P-05):}

$$
c_{15} \cdot \dot{B}_{15}+c_{30} \cdot \dot{B}_{30}+\dot{Z}_{(P-05)}=c_{16} \cdot \dot{B}_{16}+c_{57} \cdot \dot{B}_{57}
$$

No gerador de vapor de baixa pressão (fig.9.5) foi considerado o método da igualdade para partição dos custos, pelos mesmos motivos apresentados para o equipamento P-03. Neste caso, o fluxo do "ponto 16" está ligado à produção do hidrogênio enquanto o fluxo do "ponto 57" está ligado à produção de vapor. A eq.(9.25) mostra o resultado da aplicação do método:

$$
c_{16}=c_{57}
$$




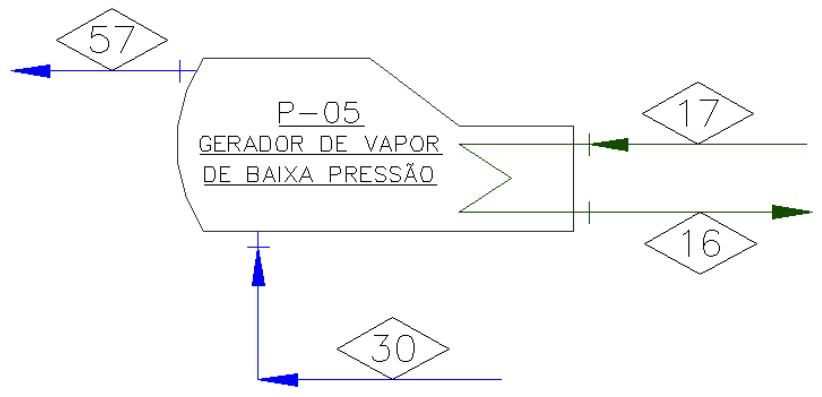

Figura 9.5: Volume de controle para o balanço de custos do P-05

\section{Primeiro resfriador da alimentação da PSA (P-06):}

Este resfriador utiliza uma bateria de ventiladores que forçam a passagem do ar por um conjunto de serpentinas, sendo chamado de "air-cooler" na indústria em geral. Este equipamento é um consumidor de energia elétrica, conforme discutido na seção 8.2.4 do capítulo anterior. $\mathrm{Na}$ eq.(9.26) e equações subseqüentes, o subscrito "e.e" quer dizer "energia elétrica". Assim:

$$
c_{16} \cdot \dot{B}_{16}+c_{e . e .} \cdot \dot{W}_{(P-06)}+\dot{Z}_{(P-06)}=c_{17} \cdot \dot{B}_{17}
$$

\section{Segundo resfriador da alimentacão da PSA (P-07):}

$$
c_{17} \cdot \dot{B}_{17}+c_{19} \cdot \dot{B}_{19}+\dot{Z}_{(P-07)}=c_{20} \cdot \dot{B}_{20}+c_{18} \cdot \dot{B}_{18}
$$

Este trocador de calor utiliza água de resfiramento para reduzir a temperatura do fluxo principal (pontos 17 e 18), conforme mostra a fig.(9.6). O fluxo de saída da água de resfriamento (ponto 20) não é aproveitado diretamente pela planta, sendo necessário um gasto adicional relativo ao seu resfriamento (que acontece em uma torre de resfriamento), bombeamento e uma eventual reposição para que o mesmo volte a ter as condições do fluxo do "ponto 19". Devido a este gasto relativo à recuperação do fluxo no "ponto 20 ", optou-se por considerar este fluxo como rejeito. Aplicando-se a premissa IV, definida na seção 9.2.1, tem-se:

$$
c_{20}=0
$$




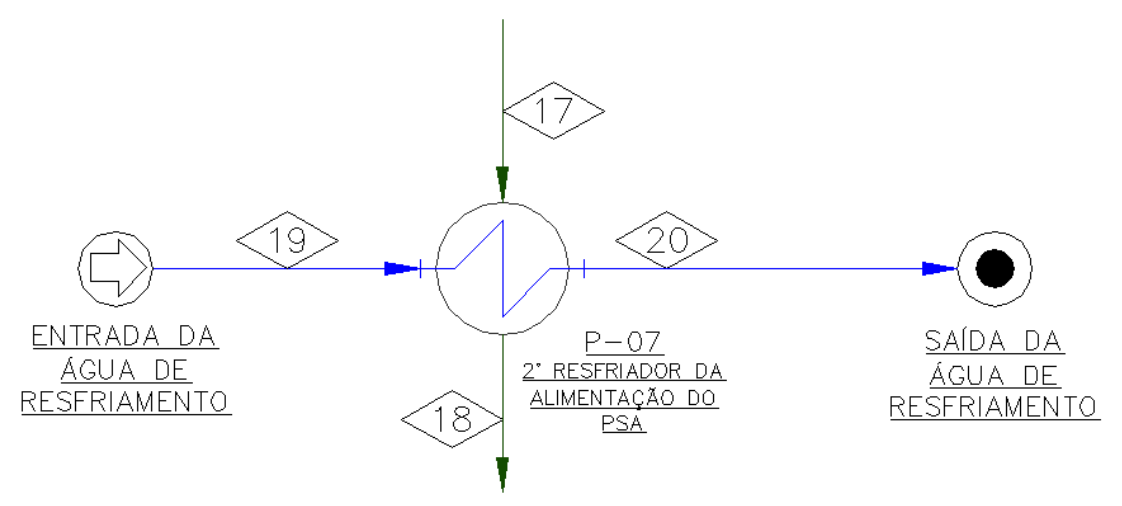

Figura 9.6: Volume de controle para o balanço de custos do P-07

Sistema de tratamento de condensado do processo (V-05, Valve-01, P-08 e T-01):

A água condensada no processo de produção do hidrogênio possui uma série de impurezas (hidrocarbonetos e outros elementos), sendo necessário um conjunto grande de equipamentos para esta água seja tratada, com o objetivo de promover condições mínimas de qualidade que permitam o seu reúso ou descarte na natureza.

Assim, considerou-se que o produto principal, representado pelo fluxo no "ponto 21 ", é o responsável por arcar com os custos relativos ao tratamento deste condensado. O sistema de equipamentos, apresentado na fig.(9.7), foi escolhido de forma a permitir que os custos dos equipamentos envolvidos neste processo de tratamento fossem atribuídos ao fluxo principal.

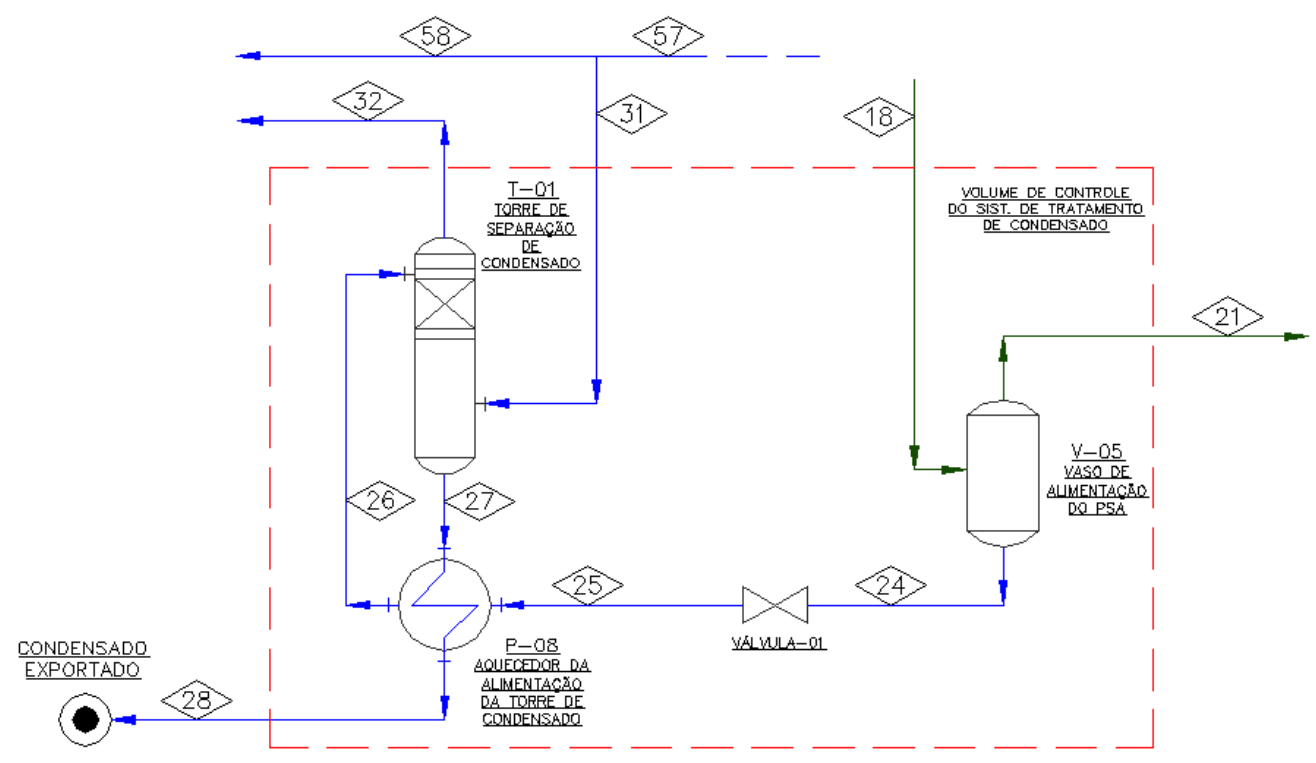

Figura 9.7: Volume de controle para o balanço do sistema de tratamento de condensado do processo 
Os custos exergéticos dos fluxos relativos aos pontos $24,25,26$ e 27 não serão considerados por estarem dentro do volume de controle proposto para o sistema. Assim:

$$
c_{18} \cdot \dot{B}_{18}+c_{31} \cdot \dot{B}_{31}+\dot{Z}_{(V-05)}+\dot{Z}_{(V a v e-01)}+\dot{Z}_{(P-08)}+\dot{Z}_{(T-01)}=c_{21} \cdot \dot{B}_{21}+c_{28} \cdot \dot{B}_{28}+c_{32} \cdot \dot{B}_{32}
$$

O custo exergético relativo ao fluxo do "ponto 32" será considerado como rejeito do processo, tendo valor igual a zero (premissa IV) conforme mostrado na eq.(9.30). Este fluxo, chamado de água ácida, não tem valor comercial e necessita de uma unidade industrial específica que possibilite o seu tratamento.

$$
c_{32}=0
$$

O condensado recuperado no tratamento, relativo ao fluxo do "ponto 28", terá seu custo exergético igualado ao custo exergético do fluxo de água de resfriamento (ponto 19). Esta convenção não segue nenhuma das premissas estabelecidas no início da análise, serve apenas para atribuir um valor ao fluxo que, depois do tratamento, pode ser utilizado pelo processo novamente:

$$
c_{28}=c_{19}
$$

O efluente do "ponto 31" deriva de uma bifurcação na tubulação de saída do vapor de baixa pressão gerado no P-05. Dessa forma, sabe-se que a matéria presente nos pontos 31,57 e 58 possui o mesmo estado termodinâmico, o que torna possível a aplicação da premissa IV apresentada na seção 9.2.1. O resultado da aplicação desta premissa pode ser visto na eq.(9.32):

$$
c_{31}=c_{57}=c_{58}
$$




\section{Sistema de purificação (PSA):}

O sistema de purificação é o responsável por aumentar a pureza do hidrogênio produzido pela planta. Durante seu funcionamento, a PSA separa o hidrogênio de outros elementos presentes no fluxo (hidrocarbonetos em sua maior parte), produzindo assim dois fluxos distintos (pontos 22 e 23).

$$
c_{21} \cdot \dot{B}_{21}+\dot{Z}_{(P S A)}=c_{22} \cdot \dot{B}_{22}+c_{23} \cdot \dot{B}_{23}
$$

O fluxo do "ponto 22" é relativo ao produto principal da planta (hidrogênio com $99,9 \%$ de pureza) enquanto o fluxo do "ponto 23 ", chamado de gás de purga, é aproveitado nos queimadores do forno reformador por ser altamente combustível. Assim, é possível considerar que ambos os produtos que saem da PSA devem ser valorizados. Neste caso, portanto, será aplicado o método da igualdade (premissa I), conforme mostra a eq.(9.34) abaixo:

$$
c_{22}=c_{23}
$$

\section{Sistema de estocagem e controle de vapor (V-03 e V-04):}

O vaso de vapor é o grande repositório de vapor da planta de geração de hidrogênio. Vapor d'água saturado, produzido nos equipamentos do processo, é concentrado neste vaso com o intuito de controlar oscilações de vazão ou paradas súbitas.

Este vaso utiliza uma bomba de circulação para levar líquido saturado presente no seu interior para a seção de convecção do forno reformador, formando mais vapor. Esta bomba é consumidora de energia elétrica, conforme discutido na seção 8.2.4 do capítulo anterior.

O vaso de blowdown é o responsável por controlar o rejeito de água do processo. Desta forma, considerou-se que a análise em conjunto destes dois equipamentos, mostrados na fig.(9.8), seria mais apropriada. 


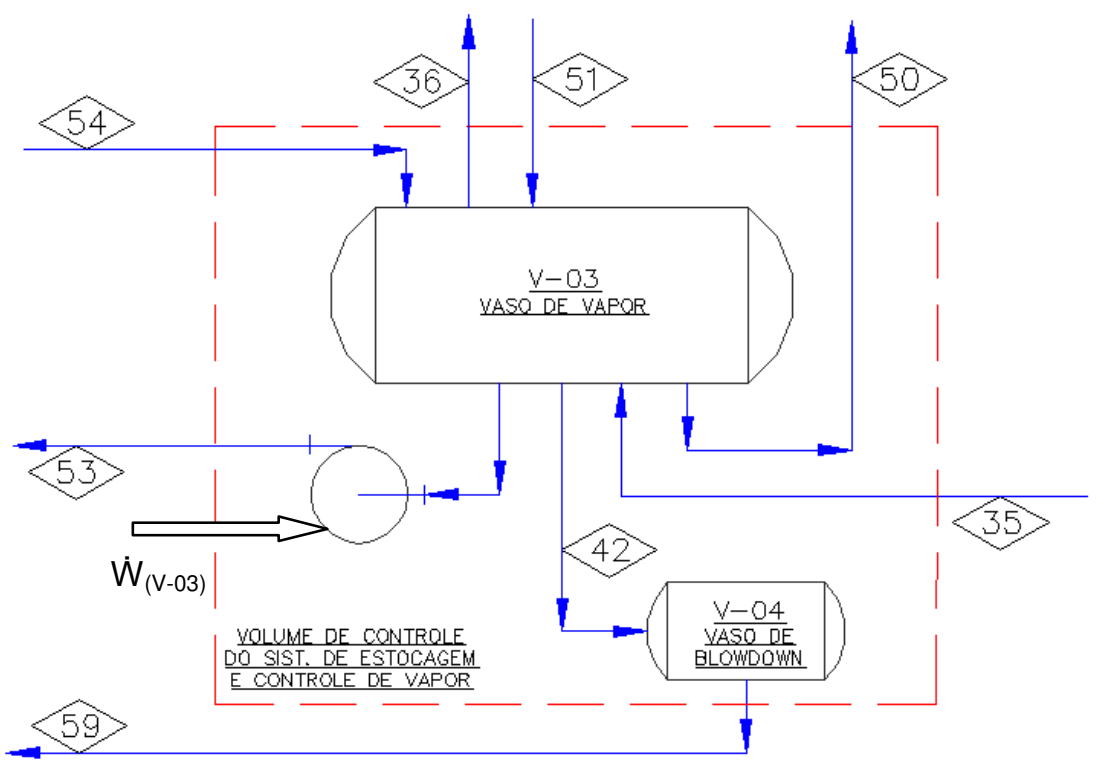

Figura 9.8: Volume de controle para o balanço do sistema de estocagem e controle de vapor

O custo exergético do fluxo relativo ao ponto 42 não será considerado. Assim, para o sistema proposto temos o balanço de custos mostrado na eq.(9.35):

$$
\begin{aligned}
& c_{51} \cdot \dot{B}_{51}+c_{35} \cdot \dot{B}_{35}+c_{54} \cdot \dot{B}_{54}+c_{e . e .} \cdot \dot{W}_{(V-03)}+\dot{Z}_{(V-03)}+\dot{Z}_{(V-04)}= \\
& =c_{36} \cdot \dot{B}_{36}+c_{50} \cdot \dot{B}_{50}+c_{53} \cdot \dot{B}_{53}+c_{59} \cdot \dot{B}_{59}
\end{aligned}
$$

O fluxo efluente do "ponto 59" é uma mistura de líquido-vapor. Sua temperatura e pressão são baixas, sendo igual a $100^{\circ} \mathrm{C}$ e 1 bar respectivamente, 0 que dificulta o aproveitamento deste fluxo no processo. Desta forma, este fluxo será caracterizado como rejeito do processo (premissa III), conforme mostra a eq. (9.36).

$$
c_{59}=0
$$

Os demais fluxos de saída deste sistema estão ligados à produção efetiva do vapor. Assim, o método da igualdade pode ser aplicado a estes fluxos (premissa I), de acordo com a eq.(9.37) abaixo:

$$
c_{36}=c_{50}=c_{53}
$$

\section{Dessuperaquecedor de vapor (MX-03):}

Este dessuperaquecedor é formado por um conjunto simples de tubulações conectadas entre si, desta forma, não foi atribuído um custo de equipamento $(\dot{Z})$ 
associado a este sistema. Com isso, o balanço de custos deste sistema resume-se ao apresentado na eq.(9.38).

$$
c_{40} \cdot \dot{B}_{40}+c_{38} \cdot \dot{B}_{38}=c_{41} \cdot \dot{B}_{41}
$$

O fluxo do "ponto 41" é dividido por uma bifurcação na tubulação (fig.9.9), resultando em um fluxo de vapor que será exportado da planta (ponto 55) e em outro fluxo (ponto 4) que será utilizado no trocador de calor P-01, já descrito anteriormente.

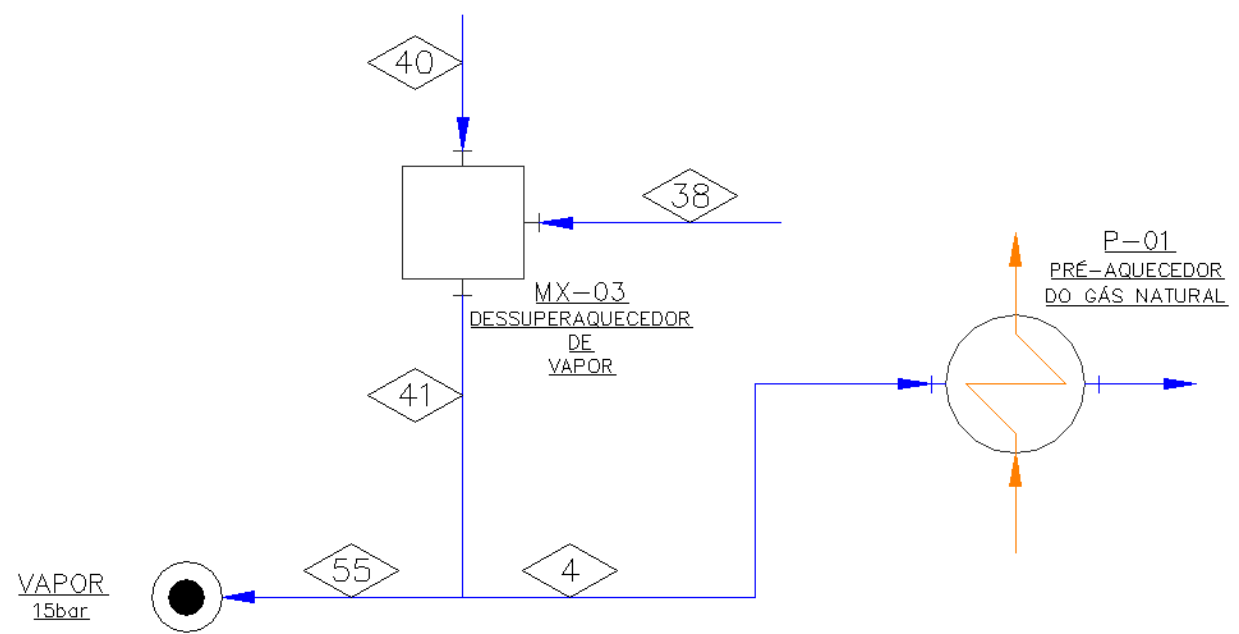

Figura 9.9: Bifurcação do fluxo do "ponto 41" para alim. do P-01 e exportação de vapor

Uma vez que a matéria presente nos três pontos (4, 41 e 55) possui o mesmo estado termodinâmico, torna-se possível indicar a igualdade apresentada na eq.(9.39), decorrente da aplicação da premissa III estabelecida anteriormente:

$$
c_{4}=c_{41}=c_{55}
$$

\section{Forno reformador (F-01):}

O forno reformador é o principal equipamento da unidade de geração de hidrogênio, sendo o responsável simultaneamente pela produção de hidrogênio e pela produção de vapor.

Este equipamento possui dois grandes ventiladores, responsáveis por forçar a entrada de ar para dentro do equipamento e por garantir a saída dos gases de escape pela chaminé. Estes ventiladores são movidos por motores elétricos e seu consumo de energia elétrica foi discutido na seção 8.2.4 do capítulo anterior. A fig.(9.10) apresenta o sistema do forno reformador onde, por conveniência, os 
ventiladores foram agrupados num mesmo equipamento esquemático na seção de entrada.

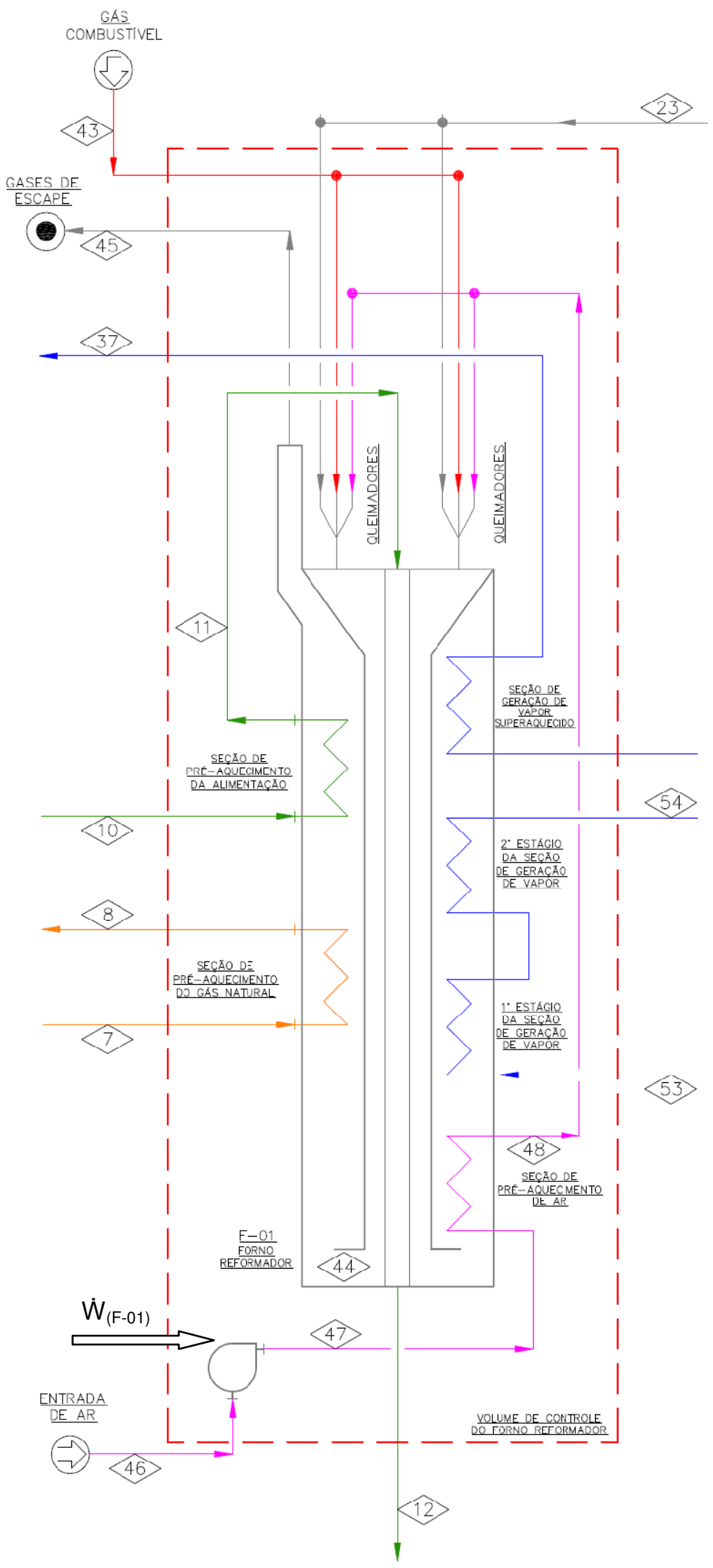

Figura 9.10: Volume de controle para o balanço de custos do forno reformador 
O balanço de custos para o forno reformador pode ser escrito conforme mostrado na eq.(9.40):

$$
\begin{aligned}
& c_{7} \cdot \dot{B}_{7}+c_{10} \cdot \dot{B}_{10}+c_{23} \cdot \dot{B}_{23}+c_{36} \cdot \dot{B}_{36}+c_{43} \cdot \dot{B}_{43}+ \\
& +c_{46} \cdot \dot{B}_{46}+c_{53} \cdot \dot{B}_{53}+c_{e . e} \cdot \dot{W}_{(F-01)}+\dot{Z}_{(F-01)}= \\
& =c_{8} \cdot \dot{B}_{8}+c_{12} \cdot \dot{B}_{12}+c_{37} \cdot \dot{B}_{37}+c_{45} \cdot \dot{B}_{45}+c_{54} \cdot \dot{B}_{54}
\end{aligned}
$$

Os custos exergéticos dos fluxos relativos aos pontos 11, 47 e 48 não serão considerados na análise pois não atravessam a fronteira do sistema.

Considerou-se que os fluxos relativos aos pontos 45 e 46, representando a saída dos gases de exaustão e a captação do ar respectivamente, têm seu custo exergético igual a zero.

$$
c_{45}=c_{46}=0
$$

Todos os fluxos de produto que saem do sistema estão relacionados com os produtos principais da planta (hidrogênio e vapor), tornando válida a aplicação do método da igualdade. Assim:

$$
c_{8}=c_{12}=c_{37}=c_{54}
$$

\subsubsection{Consolidação das equações apresentadas}

Ao considerar as definições de custo exergético apresentadas nas eq.(9.8), eq.(9.11), eq.(9.14), eq.(9.17), eq.(9.21), eq.(9.22), eq.(9.25), eq.(9.28), eq.(9.30), eq.(9.32), eq.(9.34), eq.(9.36), eq.(9.37), eq.(9.39), eq.(9.41) e eq.(9.42), foi possível rearranjar as demais equações apresentadas de forma a isolar a variável independente em cada situação. Estas equações consolidadas já contemplam a aplicação dos critérios de partição e demais premissas elaboradas na abordagem do sistema estudado. 
Mantendo-se o critério de, quando houver igualdade entre custos exergéticos, adota-se a notação relativa ao índice referente ao ponto de menor valor numérico podem ser vistas entre as eq.(9.43) e eq.(9.59) mostradas a seguir.

Vaso pulmão de gás natural (V-01):

$c_{1} \cdot \dot{B}_{1}-c_{2} \cdot \dot{B}_{2}=-\dot{Z}_{(V-01)}$

Pré aquecedor do gás natural (P-01):

$c_{2} \cdot \dot{B}_{2}-c_{3} \cdot \dot{B}_{3}+c_{4} \cdot\left(\dot{B}_{4}-\dot{B}_{5}\right)=-\dot{Z}_{(P-01)}$

Misturador do reciclo de $\mathrm{H}_{2}(\mathrm{MX}-01)$ :

$c_{3} \cdot \dot{B}_{3}+c_{6} \cdot \dot{B}_{6}-c_{7} \cdot \dot{B}_{7}=0$

Reatores de dessulfurização (R-01H, R01A e R-01B):

$c_{8} \cdot \dot{B}_{8}-c_{9} \cdot \dot{B}_{9}=-\left(\dot{Z}_{(R-01 H)}+\dot{Z}_{(R-01 A)}+\dot{Z}_{(R-01 B)}\right)$

Misturador da alimentação do forno reformador (MX-02):

$c_{8} \cdot \dot{B}_{39}+c_{9} \cdot \dot{B}_{9}-c_{10} \cdot \dot{B}_{10}=0$

$\underline{\text { Recuperador de calor (P-03): }}$

$c_{8} \cdot \dot{B}_{12}-c_{13} \cdot\left(\dot{B}_{13}+\dot{B}_{51}\right)+c_{36} \cdot \dot{B}_{50}=-\dot{Z}_{(P-03)}$

Reator de Shift (R-02):

$c_{13} \cdot \dot{B}_{13}-c_{14} \cdot \dot{B}_{14}=-\dot{Z}_{(R-02)}$ 
Aquecedor da água de alimentação (P-04):

$c_{14} \cdot \dot{B}_{14}-c_{15} \cdot\left(\dot{B}_{15}+\dot{B}_{35}\right)+c_{34} \cdot \dot{B}_{34}=-\dot{Z}_{(P-04)}$

Válvula 02 (Valve-02):

$-c_{30} \cdot \dot{B}_{30}+c_{34} \cdot \dot{B}_{56}=-\dot{Z}_{\text {Valve }-02}$

Gerador de vapor de baixa pressão (P-05):

$c_{15} \cdot \dot{B}_{15}-c_{16} \cdot\left(\dot{B}_{16}-\dot{B}_{57}\right)+c_{30} \cdot \dot{B}_{30}=-\dot{Z}_{(P-05)}$

Primeiro resfriador da alimentação da PSA (P-06):

$c_{e . e .} \cdot \dot{W}_{(P-06)}+c_{16} \cdot \dot{B}_{16}-c_{17} \cdot \dot{B}_{17}=-\dot{Z}_{(P-06)}$

Segundo resfriador da alimentação da PSA (P-07):

$c_{17} \cdot \dot{B}_{17}-c_{18} \cdot \dot{B}_{18}+c_{19} \cdot \dot{B}_{19}=-\dot{Z}_{(P-07)}$

Sistema de tratamento de condensado do processo (V-05, Valve-01, P-08 e T-01):

$c_{16} \cdot \dot{B}_{31}+c_{18} \cdot \dot{B}_{18}-c_{19} \cdot \dot{B}_{28}-c_{21} \cdot \dot{B}_{21}=-\left(\dot{Z}_{(V-05)}+\dot{Z}_{(\text {Valve-01) }}+\dot{Z}_{(P-08)}+\dot{Z}_{(T-01)}\right)$

Sistema de purificação (PSA):

$-c_{6}\left(\dot{B}_{22}+\dot{B}_{23}\right)+c_{21} \cdot \dot{B}_{21}=-\dot{Z}_{(P S A)}$ 
Sistema de estocagem e controle de vapor (V-03 e V-04):

$$
\begin{aligned}
& c_{e . e} \cdot \dot{W}_{(V-03)}+c_{8} \cdot \dot{B}_{54}+c_{13} \cdot \dot{B}_{51}+c_{15} \cdot \dot{B}_{35}-c_{36} \cdot\left(\dot{B}_{36}+\dot{B}_{50}+\dot{B}_{53}\right)= \\
& =-\left(\dot{Z}_{(V-03)}+\dot{Z}_{(V-04)}\right)
\end{aligned}
$$

Dessuperaquecedor de vapor (MX-03):

$$
c_{34} \cdot \dot{B}_{40}+c_{8} \cdot \dot{B}_{38}-c_{4} \cdot \dot{B}_{41}=0
$$

\section{Forno reformador (F-01):}

$$
\begin{aligned}
& c_{e . e} \cdot \dot{W}_{(F-01)}+c_{1} \cdot \dot{B}_{43}+c_{6} \cdot \dot{B}_{23}+c_{7} \cdot \dot{B}_{7}+c_{10} \cdot \dot{B}_{10}+ \\
& +c_{36} \cdot\left(\dot{B}_{36}+\dot{B}_{53}\right)-c_{8} \cdot\left(\dot{B}_{8}+\dot{B}_{12}+\dot{B}_{37}+\dot{B}_{54}\right)=-\dot{Z}_{(F-01)}
\end{aligned}
$$

\subsubsection{Representação do sistema linear na forma matricial}

As equações mostradas anteriormente, após o rearranjo proposto, se apresentam como um sistema linear, sendo possível descrever o sistema na forma de matrizes, conforme mostrado na eq.(9.60). A solução deste sistema linear permite obter os custos exergéticos dos pontos do sistema.

$$
[\dot{B}] \cdot[c]=[\dot{Z}]
$$

A fig.(9.11) mostra as matrizes obtidas na consideração de todos os balanços de custo apresentado nas equações consolidadas, enquanto os resultados dos custos exergéticos dos fluxos da planta serão apresentados na seção 9.3. 


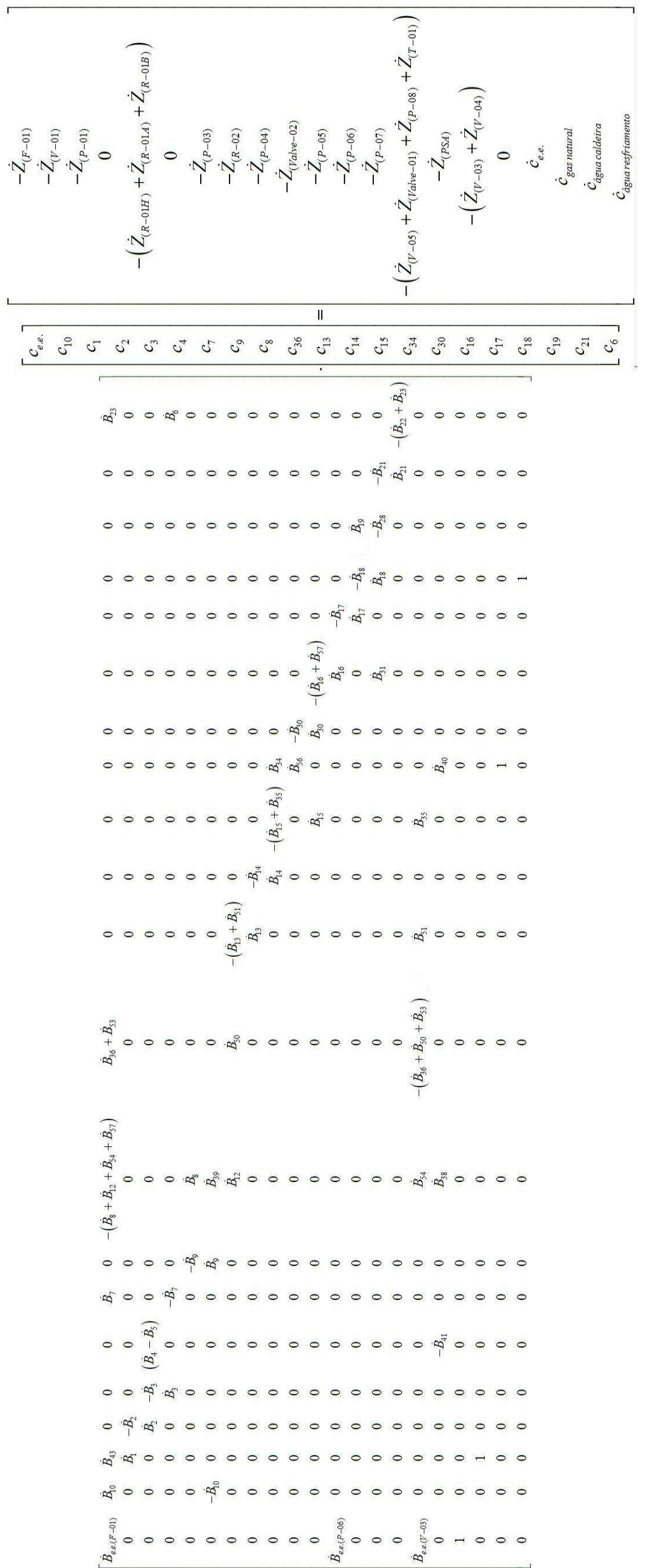




\subsection{DETERMINAÇÃO DOS CUSTOS DE CADA FLUXO DA UNIDADE DE GERAÇÃO DE HIDROGÊNIO}

\subsubsection{Determinação dos custos de produção atuais}

A tabela 9.1 mostra os custos exergéticos obtidos na aplicação dos valores presentes nas tabelas 8.11 e 8.14 do capítulo anterior. Conforme discutido, os valores apresentados representam o custo atual (2010), também chamado de custo atualizado, de produção dos fluxos da planta.

Tabela 9.1 - Custo exergético atualizado (2010) total por fluxo da planta estudada.

\begin{tabular}{|c|c|c|}
\hline $\begin{array}{c}\text { PONTOS } \\
\text { DO SISTEMA }\end{array}$ & $\begin{array}{c}\text { CUSTO EXERGÉTICO } \\
\text { ATUALIZADO } \\
\text { US\$̦/GJ }\end{array}$ & OBSERVAÇÕES \\
\hline$c_{1}$ & 9,11 & $\mathrm{c}_{1}=\mathrm{c}_{43}$ \\
\hline$c_{2}$ & 9,12 & \\
\hline$c_{3}$ & 9,17 & \\
\hline $\mathrm{c}_{4}$ & 17,32 & $c_{4}=c_{5}=c_{41}=c_{55}$ \\
\hline $\mathrm{c}_{6}$ & 17,36 & $c_{6}=c_{22}=c_{23}$ \\
\hline $\mathrm{c}_{7}$ & 9,29 & \\
\hline $\mathrm{C}_{8}$ & 15,08 & $c_{8}=c_{12}=c_{37}=c_{38}=c_{39}=c_{54}$ \\
\hline $\mathrm{C}_{9}$ & 15,29 & \\
\hline $\mathrm{c}_{10}$ & 15,42 & \\
\hline $\mathrm{c}_{13}$ & 15,78 & $c_{13}=c_{51}$ \\
\hline $\mathrm{c}_{14}$ & 15,87 & \\
\hline $\mathrm{c}_{15}$ & 15,94 & $c_{15}=c_{35}$ \\
\hline $\mathrm{c}_{16}$ & 16,03 & $c_{16}=c_{31}=c_{57}=c_{58}$ \\
\hline $\mathrm{c}_{17}$ & 16,53 & \\
\hline $\mathrm{c}_{18}$ & 16,60 & \\
\hline $\mathrm{C}_{19}$ & 2,17 & $c_{19}=c_{28}$ \\
\hline $\mathrm{c}_{21}$ & 16,88 & \\
\hline$c_{30}$ & 8,95 & \\
\hline$c_{34}$ & 8,19 & $c_{34}=c_{40}=c_{56}=c_{60}$ \\
\hline $\mathrm{c}_{36}$ & 16,11 & $c_{36}=c_{50}=c_{53}$ \\
\hline$c_{\text {e.e. }}$ & 46,86 & \\
\hline
\end{tabular}


Com o custo exergético em mãos, é possível utilizar a eq.(9.3), em conjunto com os dados exergéticos de cada ponto obtidos no capítulo 6 , para determinar o custo total de cada um dos fluxos da planta. Para não perder o foco mostrando os custos das etapas intermediárias do processo, optou-se por apresentar na tabela 9.2 apenas os custos dos fluxos que deixam a planta em direção a outras unidades da refinaria ou descartadas ao meio.

Tabela 9.2 - Custo exergético total (2010) por produto principal (atualizado).

\begin{tabular}{|c|c|c|c|c|c|}
\hline & Ponto & Descrição & $\begin{array}{l}\text { Custo } \\
\text { exergético } \\
\text { (US\$/GJ) }\end{array}$ & $\begin{array}{l}\text { Custo horário } \\
\text { (US\$/h) }\end{array}$ & $\begin{array}{l}\text { Custo em base } \\
\text { mássica } \\
\text { (US\$ /t) }\end{array}$ \\
\hline \multirow{5}{*}{$\begin{array}{l}0 \\
5 \\
5 \\
0 \\
0 \\
0\end{array}$} & 22 & Hidrogênio & 17,36 & $9.594,65$ & $2.093,13$ \\
\hline & 28 & Condensado a $77^{\circ} \mathrm{C}$ e $2,5 \mathrm{bar}$ & 2,17 & 6,29 & 0,15 \\
\hline & 58 & Vapor a 5 bar & 16,03 & 189,12 & 12,32 \\
\hline & 5 & Condensado a $200^{\circ} \mathrm{C}$ e 15 bar & 17,32 & 11,39 & 3,67 \\
\hline & 55 & Vapor a 15 bar & 17,32 & 476,19 & 16,74 \\
\hline
\end{tabular}

Os valores obtidos serão analizados criticamente no capítulo referente à discussão e análise dos resultados.

\subsubsection{Determinação dos custos de produção nivelados}

A obtenção dos custos nivelados obedeceu à mesma formulação utilizada para obtenção dos custos de produção atualizados, vista no item anterior. Para isso, foram aplicados os dos valores presentes nas tabelas 8.11 e 8.15 , relativos aos custos nivelados, mostrados do capítulo anterior. A tabela 9.3 mostra os custos exergéticos obtidos quando se utilizou valores nivelados como referência para os cálculos. 
Tabela 9.3 - Custo exergético nivelado (2010) total por fluxo da planta estudada.

\begin{tabular}{|c|c|c|}
\hline $\begin{array}{c}\text { PONTOS } \\
\text { DO SISTEMA }\end{array}$ & $\begin{array}{c}\text { CUSTO EXERGÉTICO } \\
\text { NIVELADO } \\
\text { US\$ /GJ }\end{array}$ & OBSERVAÇÕES \\
\hline $\mathrm{c}_{1}$ & 14,01 & $\mathrm{c}_{1}=\mathrm{c}_{43}$ \\
\hline $\mathrm{c}_{2}$ & 14,02 & \\
\hline$c_{3}$ & 14,10 & \\
\hline $\mathrm{c}_{4}$ & 25,65 & $c_{4}=c_{5}=c_{41}=c_{55}$ \\
\hline $\mathrm{c}_{6}$ & 25,35 & $c_{6}=c_{22}=c_{23}$ \\
\hline$c_{7}$ & 14,26 & \\
\hline $\mathrm{C}_{8}$ & 22,34 & $c_{8}=c_{12}=c_{37}=c_{38}=c_{39}=c_{54}$ \\
\hline $\mathrm{C}_{9}$ & 22,58 & \\
\hline $\mathrm{c}_{10}$ & 22,78 & \\
\hline $\mathrm{c}_{13}$ & 23,27 & $c_{13}=c_{51}$ \\
\hline $\mathrm{c}_{14}$ & 23,38 & \\
\hline $\mathrm{c}_{15}$ & 23,48 & $c_{15}=c_{35}$ \\
\hline $\mathrm{c}_{16}$ & 23,58 & $c_{16}=c_{31}=c_{57}=c_{58}$ \\
\hline $\mathrm{c}_{17}$ & 24,26 & \\
\hline $\mathrm{c}_{18}$ & 24,35 & \\
\hline $\mathrm{c}_{19}$ & 3,34 & $\mathrm{c}_{19}=\mathrm{c}_{28}$ \\
\hline$c_{21}$ & 24,72 & \\
\hline $\mathrm{c}_{30}$ & 13,70 & \\
\hline$c_{34}$ & 12,59 & $c_{34}=c_{40}=c_{56}=c_{60}$ \\
\hline$c_{36}$ & 23,66 & $c_{36}=c_{50}=c_{53}$ \\
\hline$c_{\text {e.e. }}$ & 72,05 & \\
\hline
\end{tabular}

Percebe-se que os custos exergéticos nivelados mostrados na tabela acima são relativamente maiores do que os custos exergéticos mostrados na tabela 9.1, relativos aos valores atuais, referentes ao ano de 2010 apenas.

Assim como no caso anterior, é possível obter os custos totais de produção para as novas entradas de dados, relativas aos custos nivelados de matéria-prima e amortização do investimento. Os resultados obtidos para os produtos principais da planta estão mostrados na tabela 9.4. 
Tabela 9.4 - Custo exergético total (2010) por produto principal (nivelados).

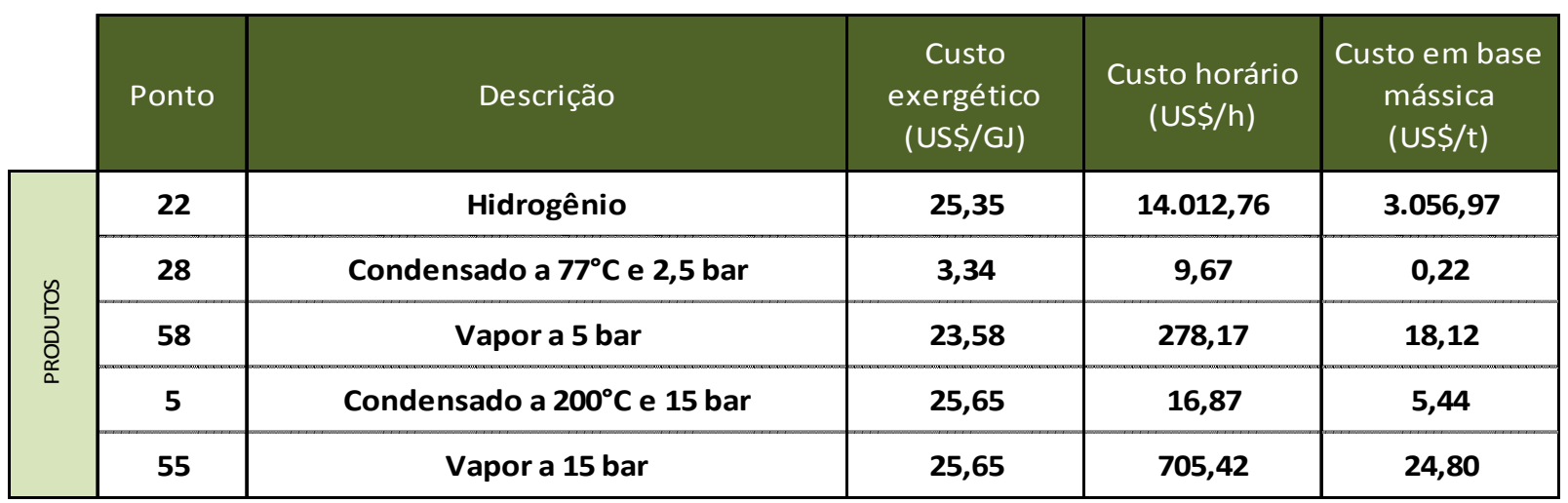

\subsection{DISCUSSÃO DOS RESUltados OBTIDOS NA ANÁLISE TERMOECONÔMICA DA PLANTA}

Este capítulo como um todo se propõe a analisar criticamente os resultados da análise termoeconômica. Para isso, foi realizada uma verificação de consistência dos valores apresentados e, posteriormente, discuscutiu-se a respeito da incerteza do resultado obtido. Por fim, houve a comparação dos resultados obtidos, em especial o custo de produção do hidrogênio, com outros valores presentes na literatura.

\subsubsection{Verificação de consistência dos resultados}

Para validar o equacionamento proposto e os resultados obtidos, é importante mostrar coerência entre os custos de entrada e de saída do processo. Assim, conforme mostra a eq.(6.13), o custo total de produção (saída) deve ser igual à soma de todos os custos de entrada (amortização, operação e manutenção). A tabela 9.5 mostra os custos horários totais (atualizados) referentes às entradas (insumos) e saídas (produtos) da planta de geração de hidrogênio. 
Tabela 9.5 - Custo horário (2010) dos produtos e insumos da planta (atualizado).

\begin{tabular}{|c|c|c|c|}
\hline & Ponto & Descrição & $\begin{array}{l}\text { Custo horário } \\
\text { (US\$̦/h) }\end{array}$ \\
\hline \multirow{5}{*}{$\begin{array}{l}\text { o } \\
5 \\
0 \\
\stackrel{0}{0}\end{array}$} & 22 & Hidrogênio & $9.594,65$ \\
\hline & 28 & Condensado a $77^{\circ} \mathrm{C}$ e 2,5 bar & 6,29 \\
\hline & 58 & Vapor a 5 bar & 189,12 \\
\hline & 5 & Condensado a $200^{\circ} \mathrm{C}$ e 15 bar & 11,39 \\
\hline & 55 & Vapor a 15 bar & 476,19 \\
\hline \multirow{7}{*}{$\begin{array}{l}\text { on } \\
\sum_{\underline{\underline{n}}}^{\underline{\underline{n}}}\end{array}$} & 1 & Gás Natural (Processo) & $6.730,28$ \\
\hline & 60 & Água de caldeira a $145^{\circ} \mathrm{C}$ e 36 bar & 134,13 \\
\hline & 43 & Gás Natural (Queimadores) & $1.057,71$ \\
\hline & 19 & Água de resfriamento a $32^{\circ} \mathrm{Ce} 4$ bar & 21,34 \\
\hline & 6 & Hidrogênio de reciclo & 174,00 \\
\hline & - & Custo de amortização total por hora & $2.044,28$ \\
\hline & - & Custo de energia elétrica total por hora & 115,90 \\
\hline
\end{tabular}

É possível observar que os resultados mostram coerência com o critério de formação do custo de produção, pois, a soma dos valores horários relativos aos insumos é igual à soma dos valores horários dos produtos (10.277,63 US $\$ / h$ ).

O mesmo acontece com os custos nivelados, mostrados na tabela 9.6, onde a soma dos valores horários relativos aos insumos consumidos é igual à soma dos valores horários dos produtos obtidos na planta (15.022,89 US\$/h).

Tabela 9.6 - Custo horário (2010) dos produtos e insumos da planta (nivelado).

\begin{tabular}{|c|c|c|c|}
\hline & Ponto & Descrição & $\begin{array}{c}\text { Custo horário } \\
\text { (US\$/h) }\end{array}$ \\
\hline \multirow{5}{*}{ 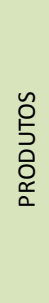 } & 22 & Hidrogênio & $14.012,76$ \\
\hline & 28 & Condensado a $77^{\circ} \mathrm{C}$ e 2,5 bar & 9,67 \\
\hline & 58 & Vapor a 5 bar & 278,17 \\
\hline & 5 & Condensado a $200^{\circ} \mathrm{C}$ e 15 bar & 16,87 \\
\hline & 55 & Vapor a 15 bar & 705,42 \\
\hline \multirow{7}{*}{ 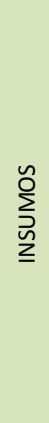 } & 1 & Gás Natural (Processo) & $10.347,95$ \\
\hline & 60 & Água de caldeira a $145^{\circ} \mathrm{C}$ e 36 bar & 206,23 \\
\hline & 43 & Gás Natural (Queimadores) & $1.626,25$ \\
\hline & 19 & Água de resfriamento a $32^{\circ} \mathrm{C}$ e 4 bar & 32,81 \\
\hline & 6 & Hidrogênio de reciclo & 254,12 \\
\hline & - & Custo de amortização total por hora & $2.377,32$ \\
\hline & - & Custo de energia elétrica total por hora & 178,19 \\
\hline
\end{tabular}


Os valores apresentados nas tabelas 9.5 e 9.6 demonstram que 0 modelamento matemático da análise do custo de produção do hidrogênio é consistente.

\subsubsection{Discussão sobre as incertezas dos resultados apresentados}

No capítulo 8 (seção 8.1.4.1) foi realizada uma análise para estimar a incerteza da estimativa dos custos de construção da planta de geração de hidrogênio estudada. Verificou-se que 0 valor da estimativa dos custos de construção da planta tinha uma incerteza de $\pm 14 \%$.

Para verificar a incerteza relativa ao custo total de produção do hidrogênio obtido neste trabalho, é importante verificar as incertezas relativas à fase de operação, bem como determinar a relação entre estes custos comparativamente ao custo total. Esta relação pode ser vista na tabela 9.7.

Tabela 9.7 - Custo anual de produção da UGH estudada. Relação dos custos de constução, operação e manutenção com o custo anual total.

\begin{tabular}{|c|c|c|c|}
\hline & PARÂMETROS & $\begin{array}{c}\text { VALOR } \\
\text { US\$ (2010) }\end{array}$ & $\begin{array}{c}\text { RELAÇÃO COM O } \\
\text { CUSTO TOTAL }\end{array}$ \\
\hline \multirow{5}{*}{ 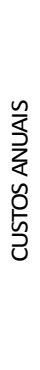 } & PARCELA ANUAL DE AMORTIZAÇÃO & $11.966 .915,90$ & $14,07 \%$ \\
\hline & CUSTO ANUAL DE OPERAÇÃO E MANUTENÇÃO & $5.205 .000,00$ & $6,12 \%$ \\
\hline & CUSTO ANUAL DE ENERGIA ELÉTRICA & $554.108,44$ & $0,65 \%$ \\
\hline & CUSTO ANUAL DE MATERIA-PRIMA & $67.349 .937,29$ & $79,16 \%$ \\
\hline & TOTAL & $85.075 .961,63$ & $100,00 \%$ \\
\hline
\end{tabular}

Os dados apresentados acima mostram o impacto do custo da matéria-prima (custo do gás natural, essencialmente) na produção do hidrogênio. Segundo Rostrup-Nielsen (2005), os custos operacionais da produção do hidrogênio pelo processo de reforma do gás natural representam cerca de dois terços $(66,6 \%)$ do custo total de produção do hidrogênio. 
Com isso, é possível observar que o custo de produção de hidrogênio pelo processo de reforma a vapor é muito sensível ao custo do gás natural utilizado como matéria-prima no processo.

$\mathrm{Na}$ planta estudada, considerou-se o custo unitário do gás natural como sendo igual a 9,114 US\$/GJ (BOLETIM..., 2010). Este é o preço pelo qual a Petrobras repassa o gás natural para as distribuidoras.

Entretanto, é possível observar que existem contratos de fornecimento de gás natural com preços mais baixos, como por exemplo, os valores praticados junto às termelétricas, que pagam 4,08US\$/MMBTU (BOLETIM..., 2010), o que equivale a 3,86 US $\$ / G J$. Este valor é subsidiado pelo governo federal e foi instituído pelo Programa Prioritário de Termelétricas, lançado no ano de 2000 com o objetivo de diversificar a matriz energética brasileira (REGO, 2007).

A consideração do preço do gás natural subsidiado não é aplicável neste trabalho, uma vez que este valor é praticado exclusivamente na geração elétrica. Assim, a opção por considerar o custo do gás natural utilizado na produção do hidrogênio igual ao custo do gás disponibilizado para as distribuidoras de gás parece adequada. Desta forma, o custo de produção do hidrogênio pode ser comparado com plantas que utilizem o custo de mercado do gás natural como principal entrada de custo do sistema, sem subsídios.

Uma vez definidos os valores de referência para o gás natural, não existem incertezas relacionadas à variação deste valor. $\mathrm{O}$ mesmo pode-se dizer dos gastos com energia elétrica.

Sendo assim, pode-se consider os valores apresentados na tabela 9.8 para a avaliação das incertezas presentes nos resultados obtidos.

Tabela 9.8 - Avaliação da incerteza sobre o custo anual (2010) de produção da UGH.

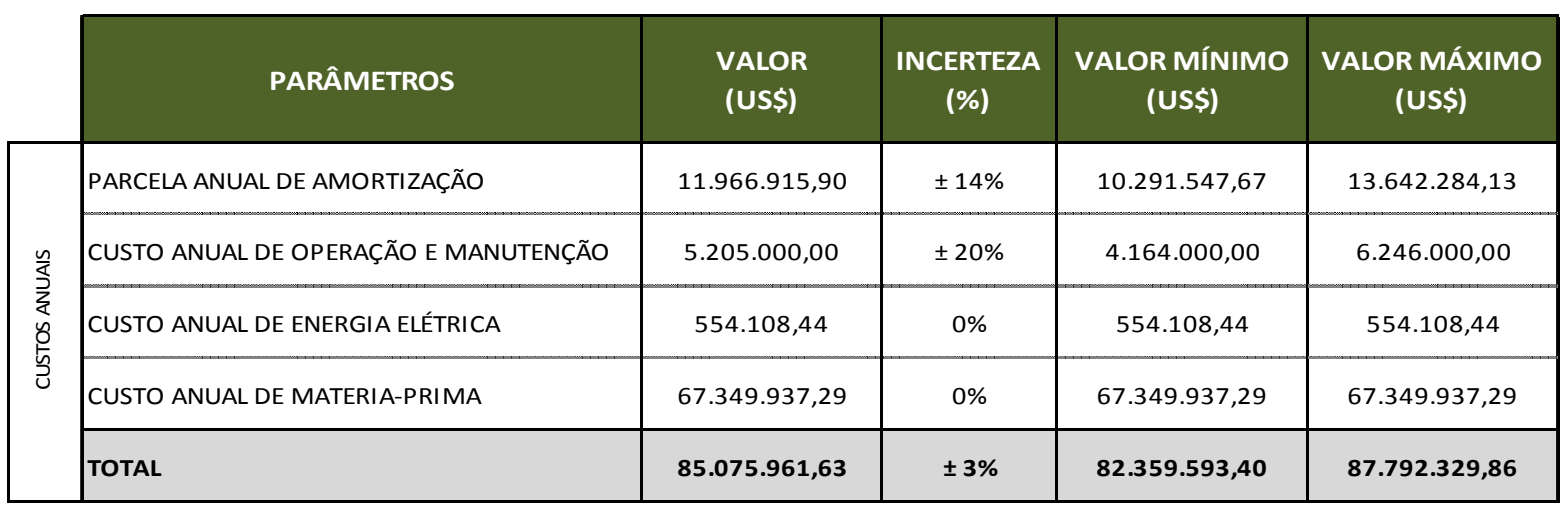


Pode-se afirmar, portanto, que o percentual de incerteza sobre o resultado obtido para os produtos da planta é de $\pm 3 \%$, para o custo de gás natural definido.

\subsubsection{Comparação dos resultados com outros presentes na literatura}

Como parte importante do debate em torno dos resultados obtidos, procurouse nesta seção comparar os custos resultantes da análise realizada, especialmente para o hidrogênio, com dados presentes na literatura.

Cruz e Oliveira Jr. (2008) fizeram uma análise termoeconômica, semelhante à realizada neste trabalho, sobre uma unidade de geração de hidrogênio de menor porte, responsável por produzir $550.000 \mathrm{Nm}^{3} /$ dia. Os custos obtidos para esta análise estão na tabela 9.9 abaixo.

Tabela 9.9 - Custo (2003) dos produtos da unidade de geração de hidrogênio de $550.000 \mathrm{Nm}^{3} / \mathrm{dia}$ (CRUZ; OLIVEIRA JR., 2008).

\begin{tabular}{|c|c|c|c|}
\hline Produtos da Planta & $\begin{array}{c}\text { Custo } \\
\text { exergético } \\
\text { (US\$̦/GJ) }\end{array}$ & $\begin{array}{c}\text { Custo horário } \\
\text { (US\$়/h) }\end{array}$ & $\begin{array}{c}\text { Custo em base } \\
\text { mássica } \\
\text { (US\$̦/t) }\end{array}$ \\
\hline Hidrogênio & 9,75 & $2.463,61$ & $1.185,86$ \\
\hline Vapor superaquecido (3,1 MPa) & 9,75 & 223,19 & 12,39 \\
\hline Água saturada (1,3 MPa) & 9,75 & 1,67 & 1,95 \\
\hline Água líquida da coluna de separação & 9,75 & 7,27 & 0,52 \\
\hline Água comprimida do TC-05 & 9,75 & 27,53 & 0,52 \\
\hline
\end{tabular}

A análise econômica desta planta e os custos dos produtos têm como referência $\mathrm{o}$ ano de 2003. O procedimento adotado para obtenção destes custos considera como nivelados apenas os valores relativos ao investimento inicial, sendo que foi utilizado o custo corrente (2003) de operação e manutenção. 
Sendo assim, a comparação mais adequada entre os dados obtidos neste trabalho (tabela 9.10) e os dados relativos à planta de geração de hidrogênio de menor capacidade se dará sobre os custos atualizados.

Tabela 9.10 - Custo atualizado (2010) dos produtos da unidade de geração de hidrogênio de $1.200 .000 \mathrm{Nm}^{3} /$ dia.

\begin{tabular}{|c|c|c|c|c|c|}
\hline & Ponto & Descrição & $\begin{array}{c}\text { Custo } \\
\text { exergético } \\
\text { (US\$̦/GJ) }\end{array}$ & $\begin{array}{l}\text { Custo horário } \\
\text { (US\$/h) }\end{array}$ & $\begin{array}{l}\text { Custo em base } \\
\text { mássica } \\
\text { (US\$\$/t) }\end{array}$ \\
\hline \multirow{5}{*}{$\begin{array}{l}0 \\
0 \\
5 \\
0 \\
0 \\
\alpha\end{array}$} & 22 & Hidrogênio & 17,36 & $9.594,65$ & $2.093,13$ \\
\hline & 28 & Condensado a $77^{\circ} \mathrm{C}$ e 2,5 bar & 2,17 & 6,29 & 0,15 \\
\hline & 58 & Vapor a 5 bar & 16,03 & 189,12 & 12,32 \\
\hline & 5 & Condensado a $200^{\circ} \mathrm{C}$ e 15 bar & 17,32 & 11,39 & 3,67 \\
\hline & 55 & Vapor a 15 bar & 17,32 & 476,19 & 16,74 \\
\hline
\end{tabular}

Os valores horários apresentados não serão comparados num primeiro momento, pois devem ser ponderados pela produção diária de cada uma das plantas apresentadas para que os custos possam ser comparados entre si.

Antes de compar os resultados, deve-se corrigir os valores apresentados na tabela 9.9 pela inflação acumulada entre 2003 e 2009, que foi de 35,35\% (HISTÓRICO..., 2010). Os valores corrigidos estão na tabela 9.11 abaixo.

Tabela 9.11 - Custo (2010) dos produtos da UGH de $550.000 \mathrm{Nm}^{3} /$ dia (CRUZ; OLIVEIRA JR., 2008) corrigidos pela inflação acumulada entre 2003 e 2009.

\begin{tabular}{|c|c|c|c|}
\hline Produtos da Planta & $\begin{array}{c}\text { Custo } \\
\text { exergético } \\
\text { (US\$\$/G) }\end{array}$ & $\begin{array}{c}\text { Custo horário } \\
\text { (US\$(h) }\end{array}$ & $\begin{array}{c}\text { Custo em base } \\
\text { mássica } \\
\text { (US\$/t) }\end{array}$ \\
\hline Hidrogênio & 13,20 & $3.334,50$ & $1.605,06$ \\
\hline Vapor superaquecido (3,1 MPa) & 13,20 & 302,09 & 16,77 \\
\hline Água saturada (1,3 MPa) & 13,20 & 2,26 & 2,64 \\
\hline Água líquida da coluna de separação & 13,20 & 9,84 & 0,70 \\
\hline Água comprimida do TC-05 & 13,20 & 37,26 & 0,70 \\
\hline
\end{tabular}


Focando a análise apenas nos valores obtidos para o hidrogênio, nota-se que 0 custo obtido neste trabalho, referente à planta com capacidade de $1.200 .000 \mathrm{Nm}^{3} /$ dia, está aproximadamente $30 \%$ maior que o valor obtido para a planta de menor capacidade $\left(550.000 \mathrm{Nm}^{3} / \mathrm{dia}\right)$.

O fato do custo de produção do hidrogênio ser mais elevado na planta de maior capacidade parece não ter muito sentido, visto que, normalmente, o aumento da escala de produção tende a reduzir o custo de um produto.

Um primeiro fator que justifica este comportamento é o critério de partição adotado na planta de menor capacidade. Percebe-se que o método da igualdade foi aplicado para a planta como um todo, o que resulta em um custo exergético igual para todos os produtos da planta. Ao fazer esta consideração, o custo do hidrogênio tende a ser menor, pois parte dos custos de produção é transferida aos produtos secundários da planta, como as saídas de condensado.

Outro ponto a ser discutido é o valor do gás natural utilizado para obtenção do custo de produção do hidrogênio na planta de $550.000 \mathrm{Nm} 3 /$ dia. O valor adotado foi de 2,20US\$/GJ (CRUZ; OLIVEIRA JR., 2008).

Atualizando este valor pela inflação acumulada entre 2003 e 2009, o valor do gás natural utilizado na planta de menor capacidade seria de 2,97 US\$/GJ. Este valor é três vezes menor que o valor utilizado na obtenção do custo de produção do hidrogênio da planta de $1.200 .000 \mathrm{Nm}^{3} /$ dia analisada neste trabalho.

Apenas como parte da verificação, foi calculado o custo de produção do hidrogênio da planta de maior capacidade considerando o valor de 2,97 US\$/GJ para o gás natural, proveniente da discussão feita no parágrafo anterior. Desta forma, torna-se possível avaliar o efeito da escala sobre o custo do hidrogênio sem 0 efeito da diferença nos custos de matéria-prima. A tabela 9.12 mostra os resultados da aplicação do custo do gás natural conforme citado neste parágrafo. 
Tabela 9.12 - Custo dos produtos (2010) da UGH estudada (1.200.000 $\left.\mathrm{Nm}^{3} / \mathrm{dia}\right)$ considerando o valor do gás natural igual a 2,97 US\$/GJ.

\begin{tabular}{|c|c|c|c|c|c|}
\hline & Ponto & Descrição & $\begin{array}{c}\text { Custo } \\
\text { exergético } \\
\text { (US\$/GJ) }\end{array}$ & $\begin{array}{l}\text { Custo horário } \\
\text { (US\$/h) }\end{array}$ & $\begin{array}{l}\text { Custo em base } \\
\text { mássica } \\
\text { (US\$̦/t) }\end{array}$ \\
\hline \multirow{5}{*}{$\begin{array}{l}\text { 口 } \\
5 \\
\text { о } \\
\alpha\end{array}$} & 22 & Hidrogênio & 8,37 & $4.626,84$ & $1.009,37$ \\
\hline & 28 & Condensado a $77^{\circ} \mathrm{C}$ e 2,5 bar & 2,17 & 6,29 & 0,15 \\
\hline & 58 & Vapor a 5 bar & 7,42 & 87,52 & 5,70 \\
\hline & 5 & Condensado a $200^{\circ} \mathrm{C}$ e 15 bar & 7,70 & 5,07 & 1,63 \\
\hline & 55 & Vapor a 15 bar & 7,70 & 211,83 & 7,45 \\
\hline
\end{tabular}

Ao comparar as tabelas 9.11 e 9.12, agora em bases iguais, percebe-se claramente o ganho de escala obtido na planta de maior capacidade, objeto deste trabalho, com relação à planta de menor capacidade, apresentada por Cruz e Oliveira Jr. (2008). Hidrogênio produzido pelo processo de reforma a vapor em uma planta com capacidade de $1.200 .000 \mathrm{Nm}^{3} / \mathrm{dia}$ tem o custo $37 \%$ menor do 0 hidrogênio obtido numa planta similar que utilize a mesma tecnolgia, mas com capacidade de produção de $550.000 \mathrm{Nm}^{3} /$ dia.

Além da comparação apresentada, os resultados obtidos podem ser confrontados com outros encontrados na literatura, que utilizam tecnologias distintas de produção de hidrogênio.

Leybros et al. (2009) investigou alguns processos termoquímicos de produção de hidrogênio, pouco utilizados na indústria mas muito favoráveis em termos ambientais. Dois ciclos específicos foram estudados, o ciclo "iodo-enxofre" e o ciclo de "enxofre-híbrido". A estimativa de custos levou em consideração dados paramétricos de uso comum na indústria francesa. Os custos de produção obtidos para cada um dos ciclos foi de $12 € / \mathrm{kg}$ de $\mathrm{H}_{2}$ e $6,6 € / \mathrm{kg}$ de $\mathrm{H}_{2}$ respectivamente. Isto equivale a aproximadamente US\$16.000,00 por tonelada de $\mathrm{H}_{2}$ produzido pelo do processo termoquímico "iodo-enxofre" e aproximadamente US $\$ 9.000$ por tonelada de hidrogênio produzido pelo processo termoquímico de "enxofre-hibrido", considerando um cambio médio de 1,35 US\$/€.

Percebe-se que estes valores são bastante altos quando comparados com o hidrogênio obtido pelo processo de reforma a vapor. Isso denota que estes 
processos termoquímicos mostrados necessitam de desenvolvimento e pesquisa adicional para serem considerados economicamente competitivos.

A avaliação do custo de produção de hidrogênio (com a captura do $\mathrm{CO}_{2}$ emitido) e eletricidade obtido por uma planta de gaseificação que utiliza carvão como insumo é apresentada por Davison et al.(2009). Esta planta será construída na Holanda. Adicionalmente, os autores indicam a vida útil prevista para esta planta ( 25 anos) e a taxa de juros utilizada ( $5 \%$ ao ano). Entretanto estes valores não são utilizados para obtenção dos custos nivelados (levelized), mas sim para cálculo do retorno de investimento sobre a unidade construída. Neste caso, o custo para produção exclusiva de hidrogênio (sem produção de energia elétrica) com captura de $\mathrm{CO}_{2}$ é de 13,3 €/GJ ou, utilizando a taxa de conversão proposta (1,35 US\$/€), tem-se o valor de produção igual a 17,95 US $\$$ /GJ (valores de 2008).

Os custos apresentados estão em base energética e consideram o poder calorífico inferior do hidrogênio. Uma vez que o $\mathrm{PCl}$ do hidrogênio é igual a 119,965 kJ/g, obtem-se um custo por unidade de massa igual a 2153,37 US\$/t.

O custo do hidrogênio obtido pela planta de gaseificação de carvão é bastante semelhante ao custo obtido na planta de geração de hidrogênio estudada neste trabalho, que utiliza o processo de reforma a vapor do gás natural. Além da semelhança de custos de produção, o $\mathrm{CO}_{2}$ produzido na planta de gaseificação é capturado ao longo do processo de produção, sendo portanto uma vantagem adicional quando se compara os dois resultados.

Cabe ressaltar que não é possível fazer qualquer juízo de valor a respeito destas duas tecnologias sem que se compare o custo de produção nivelado. Além disso, conforme discutido no capítulo 8 , os custos de produção e operação podem variar muito dependendo do local onde a planta será construída. É preciso ter cautela ao comparar uma planta de produção de hidrogênio na Holanda com uma no Brasil.

Alguns trabalhos voltados ao estudo de ampliação de refinarias de petróleo (SZKLO; CASTELO BRANCO ; GOMES, 2007) sugerem a implantação de unidades de gaseificação de coque verde para a produção de hidrogênio em detrimento da construção de novas unidades de geração pelo processo de reforma a vapor do gás natural. Segundo os autores, unidades de gaseificação podem, simultaneamente, atender ao aumento da demanda de $\mathrm{H}_{2}$, reduzir a produção de resíduos sólidos (coque) e produzir energia elétrica. 
Esta primeira análise é um indício de que a utilização de plantas de gaseificação na produção de hidrogênio pode ser economicamente viável, uma vez que o carvão, ou o coque, são energéticos de baixo custo. Além disso o preço do gás natural certamente sofrerá pressões sobre o seu preço atual, decorrentes do aumento da demanda relativa a este energético (em especial no Brasil). 


\section{CONCLUSÕES}

O principal objetivo deste trabalho foi avaliar a eficiência dos processos de conversão de energia e determinar o custo de produção do hidrogênio em uma refinaria utilizando a metodologia de análise exergética e termoeconômica.

A abordagem proposta foi aplicada a uma unidade de geração de hidrogênio real que utiliza o processo de reforma a vapor do gás natural. Sua capacidade de produção é de $1.200 .000 \mathrm{Nm}^{3} /$ dia de hidrogênio com $99,9 \%$ de pureza, que será utilizado para reduzir o enxofre presente no óleo diesel produzido na refinaria.

O contexto e a relevância do tema em questão foram apresentados, indicando o relevante papel que o hidrogênio possui na sociedade atual. Dados relativos a setores da indústria que consomem hidrogênio de forma intensiva foram investigados e analisados, em especial o setor petrolífero e de fertilizantes. Também foi abordada a possibilidade de utilização do hidrogênio como fonte de energia renovável e a perspectiva da criação de uma economia baseada no hidrogênio. Mostrou-se o cenário atual de produção de hidrogênio, bem como as tecnologias de produção em escala. As restrições no teor de enxofre presente nos combustíveis também foram comentadas, em âmbito global e em âmbito nacional. Com isso, percebe-se que a sociedade é, indiretamente, cada vez mais demandante de hidrogênio, o que torna sua produção em larga escala um mercado cada vez mais promissor. Além disso, estudos relacionados com o aumento da eficiência de processos produtivos e com a redução dos custos de produção do hidrogênio serão cada vez mais importantes e valorizados.

Uma planta síntese do processo produtivo foi elaborada com o objetivo de separar os processos secundários do processo principal da planta e assim facilitar a aplicação da metodologia de análise. Desta forma, foi possível avaliar os equipamentos que de fato causam influência direta sobre o processo produtivo, desde a entrada da matéria-prima (gás natural e da água líquida) até a obtenção dos principais produtos do processo (hidrogênio e do vapor d'água). Além disso, com base na planta síntese desenvolvida, foi explicado o processo de reforma a vapor do gás natural em detalhes. 
Os resultados da análise exergética da planta indicam que o forno reformador é o responsável por $70 \%$ das irreversibilidades na produção do hidrogênio pelo processo de reforma. Este resultado é de certa forma justificado pela própria função do equipamento, que é o responsável pela principal reação química (altamente irreversível) ocorrida no processo. Observou-se ainda que este equipamento possui uma eficiência exergética de 54,1\%, considerada bastante reduzida.

Foram comparados os resultados obtidos na análise exergética com os apresentados por Cruz e Oliveira Jr.(2008), relativa a uma planta similar à estudada, mas de menor capacidade. Observou-se uma diferença significativa entre as eficiências do forno reformador, sendo $46,4 \%$ para a planta de menor capacidade e $54,1 \%$ para a planta estudada neste trabalho. Concluiu-se que a diferença entre as eficiências das duas plantas está relacionada à temperatura de saída dos gases do forno, sendo $359^{\circ} \mathrm{C}$ para planta de menor capacidade e de apenas $184^{\circ} \mathrm{C}$ na planta estudada neste trabalho.

A comparação entre as plantas evidencia o impacto do aumento da eficiência do forno reformador na eficiência da planta como um todo $(66,6 \%$ contra $70,1 \%)$.

Ao longo das discussões foi possível concluir que o procedimento proposto por Cruz e Oliveira Jr.(2008) para aumento da eficiência do processo não se mostrou aplicável, uma vez que a temperatura dos gáses de exaustão do forno são relativamente baixas. Além disso, observou-se que a obtenção de aumentos significativos na eficiência global do processo decorrentes da análise de outros equipamentos também não seria possível, uma vez que ganhos decorrentes de melhorias nesses equipamentos têm pouco efeito na eficiência global do processo, 0 que indica que o foco de otimização do processo produtivo deve ser realmente o forno reformador.

Neste sentido, observou-se que a utilização de materiais que possibilitem o aumento da temperatura de reação no forno, associada a uma razão vapor-gás natural adequada pode aumentar a eficiência do processo de reforma (ROSTRUPNIELSEN, 2005). Conclui-se, portanto, que um aumento relevante da eficiência exergética da planta de produção de hidrogênio estudada está ligado à otimização da razão vapor-gás natural na entrada do processo.

O escopo do empreendimento analisado foi definido e os custos dos equipamentos do processo foram utilizados para se estimar o investimento total requerido na construção da planta de geração de hidrogênio. Os resultados da 
estimativa foram comparados com dados da literatura, onde foi possível verificar a grande influência que o local geográfico causa sobre o custo do empreendimento, sendo que o custo de uma unidade similar à estudada seria cerca de $50 \%$ menor caso fosse instalada na costa americana do golfo.

Foram definidos parâmetros econômicos importantes, como taxa de câmbio, taxa de inflação, taxa de juros sobre o valor investido, vida útil da planta, fator de carga, tempo de operação anual e método de amortização do investimento. Com estes parâmetros definidos, optou-se por realizar dois tipos de análise de custos distintos, que resultam em dois custos diferentes, chamados de custo atual (ou atualizado) e custo nivelado. $\mathrm{O}$ "custo atual" procura representar o valor corrente do produto. Este custo contempla exclusivamente os gastos relativos à produção de hidrogênio no ano utilizado como referência para análise (2010). O "custo nivelado" contém parâmetros como vida útil da planta e taxa de inflação em seu valor final (contempla todo o ciclo de vida da planta).

Assim, estes custos têm funções bastante diferentes. O custo atualizado deve ser utilizado para comparação de custos direta com o mercado, enquanto o custo nivelado deve ser utilizado na avaliação de custo de produção em alternativas tecnológicas distintas.

A aplicação do procedimento de análise termoeconômica, que consistiu no balanço de custos de cada equipamento e na consideração dos critérios de partição de custos apresentados na discussão teórica do método, resultou nos custos de produção mostrados nas tabelas 9.2 e 9.4 , para os valores de custo atual e custo nivelado respectivamente. $O$ custo de produção do hidrogênio, foco deste trabalho, foi de 17,36 US $\$$ /GJ $(2.093,13$ US\$/t) para o custo atualizado e de 25,35 US $\$ / G J(3.056,97$ US $\$ /$ t) para o custo nivelado.

Uma análise de sensibilidade foi realizada sobre os valores obtidos, o que resultou numa incerteza de $\pm 3 \%$ sobre o custo dos produtos da planta. Este valor baixo de incerteza nos resultados se deve ao fato do custo anual de amortização do investimento na construção da planta (que tem $\pm 14 \%$ de incerteza) ser bem menor que os custos de operação. Considerando o valor do gás natural como sendo $9,1136 \times 10^{-6}$ US $\$ / \mathrm{kJ}$, o custo de operação anual obtido equivale a $79 \%$ do custo total de produção, conforme mostrado nas tabelas 8.9 e 9.7. Este valor apresenta certa coerência com os apresentados na literatura, segundo o qual os 
custos de produção do hidrogênio pelo processo de reforma são muito sensíveis ao custo do gás natural (ROSTRUP-NIELSEN, 2005).

O custo atualizado de produção do hidrogênio obtido na análise termoeconômica foi comparado com os custos apresentados por Cruz e Oliveira Jr.(2008), onde foi possível estimar o ganho de escala da planta estudada $\left(1.200 .000 \mathrm{Nm}^{3} /\right.$ dia $)$ em relação à planta de menor capacidade $\left(550.000 \mathrm{Nm}^{3} /\right.$ dia). Este ganho de escala foi calculado como sendo igual a $37 \%$.

No entanto, cabe ressaltar que, apesar das diversas correções realizadas para adequar este resultado, dois fatores importantes não foram avaliados. Um deles diz respeito ao critério de partição dos custos exergéticos, que foi diferente entre as plantas. O custo exergético do fluxo de hidrogênio da planta de menor foi obtido pelo critério da igualdade, o que de certa forma minimiza o custo de produção do $\mathrm{H}_{2}$. $\mathrm{O}$ outro é a eficiência dos processos, que deveria ser igual numa análise de ganho de escala. No entanto, já foi visto que a planta menor é 3,5\% menos eficiente que a planta estudada. Assim, o resultado obtido para o ganho de escala não é um resultado absoluto, mas sim um indicativo de ganho provável sujeito a uma análise mais apurada.

Além da comparação com a planta similar de menor porte, os resultados obtidos foram comparados com outros provenientes de tecnologias diferentes de obtenção de hidrogênio. Observou-se que os processos termoquímicos, ainda em fase experimental, necessitam de mais aprimoramento para que sejam economicamente viáveis.

Por outro lado, a comparação dos resultados obtidos com os dados de uma planta de gaseificação que produz hidrogênio, com captura do $\mathrm{CO}_{2}$ emitido no processo (DAVISON et. al., 2009), apresenta uma proximidade muito grande no valor do hidrogênio produzido. Como foi dito na discussão dos resultados, é impossível ser categórico no julgamento da tecnologia mais eficiente sem analisar outros parâmetros como confiabilidade e local de construção. Além disso, foram comparados os custos atualizados, enquanto o mais indicado seria a avaliação pelos custos nivelados. Entretanto, a forte dependência do custo de produção do hidrogênio pelo processo de reforma com o custo do gás natural e a provável pressão exercida pelo aumento da demanda, em especial de energia, sobre este energético, pode abrir a possibilidade da implantação de novas tecnologias de 
geração de hidrogênio dentro de refinarias, como o caso da planta de gaseificação, desde que superados os desafios tecnológicos ligados principalmente à confiabilidade e disponibilidade do sistema.

Os valores nivelados apresentados neste trabalho não foram utilizados para comparação com outras tecnologias pela falta de dados nivelados relativos à produção de hidrogênio. Dados de custo nivelado são encontrados com maior abundância no setor de geração de energia elétrica. Assim, pode ser feita uma análise combinada para utilização do $\mathrm{H}_{2}$ produzido em células a combustível, levando em consideração o custo nivelado de produção do hidrogênio, obtido neste trabalho, e o custo nivelado da célula. Essa análise permitiria calcular se este sistema é competitivo ou não quando comparado com outros sistemas de geração elétrica.

Como recomendação, segere-se a realização de um estudo de otimização da razão vapor-gás natural utilizada no processo de reforma, com o objetivo de maximizar a eficiência exergética do forno reformador.

Finalmente, deve-se destacar que, apesar das simplificações feitas na análise realizada, os resultados obtidos são representativos e que a metodologia desenvolvida pode ser empregada para estudar outros processos de produção de hidrogênio (eletrólise, gaseificação de carvão e reforma de óleo/nafta/etanol) a fim de permitir uma avaliação comparativa de eficiências e custos de produção. 


\section{REFERÊNCIAS}

AITANI A. M.; Process to enhance refinery hydrogen production. . International Journal of Hydrogen Energy. No. 4, pp. 267-271, 1996

ANDERSON, J. Determining manufacturing costs. Chemical Engineering Progress Magazine (CEP Magazine). AIChE - American Institute of Chemical Engineers. Vol.105. n¹. p. 27-31. January, 2009.

ANNEL. Resolução n ${ }^{\circ} 846$, de 30/06/09. Diário Oficial da União de 30/06/09. Tarifas para fornecimento de energia elétrica. Disponível em: <http://www.aeseletropaulo.com.br/portal/interna/?idConteudo=640>. Acesso em: 10 fev. 2010.

AEO - Annual Energy Outlook. Energy Information Administration. U.S. Department of Energy. Estimated levelized cost of new eletricity generating Technologies in 2016. Disponível em: <http://www.instituteforenergyresearch .org/images/LevelizedCosts2010.jpg>. Acesso em: 12 fev. 2010.

ARGONNE NATIONAL LABORATORY. Argonne. U.S. Department of Energy. Consumo global da produção intencional de hidrogênio. Disponível em: <http://www.dis.anl.gov/news/ HydrogenMarkets.html>. Acesso em: 17 mar. 2009.

ARNO A. EVERS FAIR-PR. Hannover. Produção mundial de hidrogênio. Disponível em: <http://www.fair-pr.de/background/worldwide-hydrogen-pro duction-analysis.php>. Acesso em: 12 jan. 2009.

BALL, M.; WIETSCHEL, M. The future of hydrogen - opportunities and challenges. International Journal of Hydrogen Energy. V-34, p. 615-627, 2009.

BANCO Central do Brasil. Taxas de câmbio. Disponível em: <http://www4.bcb.gov.br/pec/taxas/port/ptaxnpesq.asp?id=txcotacao\&id=txcota cao>. Acesso em: 10 jan. 2010.

BEJAN, A.; TSATSARONIS, G.; MORAN, M. Thermal Design and Optimization. Wiley-Interscience Publishing. $1^{\text {st }}$. ed. 1996.

BOLETIM mensal de acompanhamento da indústria do gás natural. Ministério de Minas e Energia - Secretaria de Petróleo, Gás Natural e Combustíveis Renováveis. Departamento de Gás Natural. Ed. n³3. Dezembro, 2009

BP, Statistical Review of World Energy June 2009. Disponível em: <http://www.bp.com/bodycopyarticle.do?categoryld=1\&contentld=7052055>. Acesso em 14 mar. 2009 
BRASIL. Agência Nacional do Petróleo, Gás Natural e Bio-Combustíveis. Resolução ANP n`32 de 16.10.2007. Diário Oficial da União de 17 de outubro de 2007. Disponível em: <http://nxt.anp.gov.br>. Acesso em: 15 jan. 2009.

CETESB. Companhia ambiental do Estado de S. Paulo. São Paulo. Programa de Controle de Poluição do Ar por Veículos Automotores. Disponível em: $<$ http://www.cetesb.sp.gov.br/Ar/emissoes/proconve.asp>. Acesso em: 17 jun. 2009.

CHEMICAL ENGINEERING MAGAZINE. Chemical Engineering Cost Plant Index. Disponível em:<http://www.che.com/pci/>. Acesso em: 18 dez. 2009.

COMPET. Brasília. Índices de dióxido de enxofre. Disponível em: $<$ http://www.conpet.gov.br/poluicao/index.php?segmento=corporativo\#inicio>. Acesso em: 14 mar. 2009.

COMUNICADO 01/10. Fornecimento de água e/ou coleta de esgotos com contrato de demanda firme por ligação. Companhia de Saneamento Básico do Estado de São Paulo - Sabesp. Disponível em: <http://www.sabesp.com.br/sabesp/filesmng.nsf/0DE42376DBC2F3C8832576 C4004BE921/\$File/comunicado_01_2010.pdf>. Acesso em: 12 fev. 2010.

CRUZ, F. E.; OLIVEIRA JR., S., Petroleum Refinery Hydrogen Production Unit: Exergy and Production Cost Evaluation. International Journal of Thermodynamics, Vol. 11 (No. 4), pp. 187-193, December 2008

DAVISON, J. et al. Co-production of hydrogen and electricity with $\mathrm{CO}_{2}$ capture. International Journal of Greenhouse Gas Control. Article in Press, n. 222, 2009

DIAS, V.P.; FERNANDES, E., Fertilizantes: Uma visão global sintética, BNDES Setorial, Rio de Janeiro, n. 24, p. 97-138, set. 2006

DOCEKAL, J. Hydrogen production form hydrocarbons. International Journal of Hydrogen Energy. Vol. 11. pp. 709-714. 1986.

ENERGY INFORMATION ADMINISTRATION. Diagrama simplificado da economia de hidrogênio. Disponível em:<http://www.eia.doe.gov/o iaf/servicerpt/hydro/hydrogen.html>. Acesso em: 12 jun. 2009.

EWAN, B.C.R.; ALLEN, R.W.K. A figure of merit assessment of the routes to hydrogen. International Journal of Hydrogen Energy. V-30, p.809-819, 2005

FARRAR, G.; Nelson-Farrar Quarterly Costimating. Oil \& Gas Journal. Vol.107, Issue 25, p.65-67, 2009

FAO, Food and Agriculture Organization of the United Nations, Current world fertilizer rends and outlook 2008/09. Rome, 2004 
GAGGIOLI, R. A.; WEPFER, W. J. Exergy Economics: I. Cost accounting applications, II. Benefit-cost conservation. Energy, v.5, n.8-9, p.823-837, ago.-set., 1980

HERMANN, W.A. Quantifying global exergy resources. Energy, v-31. P.1685-1702, 2006.

HISTÓRICO de metas para a inflação no Brasil. Banco Central do Brasil. Disponível em: <http://www.bcb.gov.br/Pec/metas/ TabelaMetaseResultados.pdf>. Acesso em: 05 fev. 2010.

IBP - Instituto Brasileiro do Petróleo, Gás e Biocombustíveis. Gás Natural Informações sobre a indústria - Preço médio no Brasil. Disponível em: <http://www.ibp.org.br/main.asp?Team=\{9B9C72A2-0CB2-4D9F-9197A601B881DA4A\}>. Acesso em: 12 fev. 2010.

ICIS HAREN. Uso de amônia e dados de Mercado. Londres. Disponível em: <http://www.icis.com/v2/chemicals/9075154/ammonia/uses.html>. Acesso em: 05 mar. 2009.

IHS-CERA. IHS-CERA Downstream Capital Cost Index (DCCI). Disponível em:<http://www.ihsindexes.com/>. Acesso em: 18 dez. 2009.

INDEX MUNDI. [S.I.]. Produção mundial de amônia distribuída por país. Disponível em: <http://www.indexmundi.com/en/commodities/minerals /nitrogen/nitrogen_t12.html>. Acesso em: 10 fev. 2009.

INSTITUTO ESTADUAL DO AMBIENTE. Rio de Janeiro. Programa de Controle da Poluição do Ar por Veículos Automotores. Disponível em: <http://www.feema.rj.gov.br/proconve-promot.asp\#>. Acesso em: 26 mai. 2009.

KAISER, M. J.; GARY, J. H. Refinery Cost Function in the U.S. Gulf Coast. Petroleum Science and Technology, 27:2, p.168-181, 2009

KRATOCHVIL et al. Innovative Ion Exchange Systems for Cost-Effective Increase in Water Re-Use in Power Plants. In: $70^{\text {th }}$ ANNUAL INTERNATIONAL WATER CONFERENCE, October 4-8, 2009

KOTAS, T.J. The Exergy Method of Thermal Plant. Krieger Publishig Company. $1^{\text {st }}$. ed. 1995.

LAZZARETTO, A.; TSATSARONIS, G. SPECO: A Systematic and General Methodology for Calculating Efficiencies and Costs in Thermal Systems. Energy, v-31, n. 8-9 p.1257 - 1289, jul. 2006.

LEYBROS et al. Plant sizing and evaluation of hydrogen production costs from advanced processes coupled to a nuclear heat source - Part I: Sulphur-iodine cycle; Part II: Hybrid-sulphur cycle. International Journal of Hydrogen Energy, v.35, p.1008 - 1028, 2010. 
LUTZ, A. E. et al. Thermodynamic analysis of hydrogen production by steam reforming. International Journal of Hydrogen Energy. v-28, p.159 - 167, 2003.

MAHLER AGS. Stuttgart. Diagrama lógico do funcionamento do PSA System. Disponível em: <http://www.mahler-ags.com/upload/hydrogen-generationgenerator-plant-hydroswing-flowsheet.jpg >. Acesso em: 13 abr. 2009.

MAPLES, E. M. Hydrogen Manufacture. In: MAPLES, E. M. Petroleum Refinery Process Economics. $2^{\text {nd }}$. ed. Tulsa, Oklahoma, USA. PennWell Corporation. 2000. p.339-340

MEDIDAS e Desvios; Apostila de Física Experimental I. Instituto de Física Armando Dias Tavares. Universidade Estadual do Rio de Janeiro (UERJ). Disponível em: <http://www.dft.if.uerj.br/cursos/FTE1/apostila/lab1.pdf>. Acesso em: 10 jan. 2010

MINISTÉRIO DO MEIO AMBIENTE. Brasília. Resolução Conama no 315, de 29 de outubro de 2002. Disponível em: <http://www.mma.gov.br/port/conama/res/ res02/res31502.html>. Acesso em: 15 mar. 2009.

MOGIANA Especialidades Químicas. São Paulo. Informações sobre mercaptanas. Disponível em: <http://www.mogiana.com/literatura/visualisa_lit.php?catalogo= 20070526_193603.pdf>. Acesso em: 18 fev. 2009.

MOVIMENTO NOSSA SÃO PAULO. São Paulo. Mapa sobre limites de enxofre no diesel. Disponível em: <http://www.nossasaopaulo.org.br/portal/node/2181>. Acesso em: 20 jan. 2009.

NATIONAL HYDROGEN ASSOCIATION. Washington, DC. Produção de hidrogênio. Disponível em: <http://www.hydrogenassociation.org/general/faqs .asp\#howproduced>. Acesso em 20 fev. 2009.

NEEF, H. J. International overview of hydrogen and fuel cell research. Energy. v34. p. 327-333, 2009.

PETERS, M.; TIMMERHAUS, K. Plant Design and Economics for Chemical Engineers. McGraw Hill International Editions. $4^{\text {th }}$. ed. 1991. p. 150-215.

PETRORBRAS DISTRIBUIDORA. Rio de Janeiro. Teor de enxofre do diesel produzido pela Petrobras. Disponível em: <http://www.br.com.br/wps/portal/ PortalDeConteudo>. Acesso em: 18 jun. 2009.

STOLL, R. E.; von LINDE, F. Hydrogen-what are the costs? Hydrocarbon Processing Magazine, p.42-46, Issue of December, 2000

SZKLO, A. S.; CASTELO BRANCO, D. A.; GOMES, G. L. Desafios e oportunidades tecnológicas para o refino de petróleo: o caso de uma refinaria no Brasil. 4 ${ }^{\mathrm{a}}$ PDPETRO, Campinas -SP, 21-24out. 2007 
REGO, E. E. Entendendo a expressiva participação das termelétricas a gás natural no primeiro leilão de energia nova. Revista Brasileira de Energia, Vol.13 (No.2), p.89-92, $2^{\circ}$ Sem. 2007

RIVERO, R.; RENDON, C.; MONROY, L. The Exergy of Crude Oil Mixtures and Petroleum Fractions: Calculation and Application. International Journal of Thermodynamics, Vol.2 (No.3), p.115-123, September-1999

ROSTRUP-NIELSEN, T. Manufacture of hydrogen. Catalysis Today, v.106, p. 293-296, 2005

SCIUBBA, E. Exergo-economics - Thermodynamic foundation for a more rational resource use. International Journal of Energy Research, v.29, p.613-636, 2005

SEROVA, E.N.; BRODIANSKI, V.M. The concept "environment" in exergy analysis Some special cases. Energy. v-29, p.2397-2401, 2004

SHUDO, Y. et al. Exergy analysis of the demonstration plant for co-production of hydrogen and benzene from biogas. International Journal of Hydrogen Energy. v-34, p.4500-4508, 2009.

SRI CONSULTING. Menlo Park, CA. Chemical Economics Handbook. Disponível em: http://www.sriconsulting.com/CEH/Public/Reports/743.5000/. Acesso em: 15 jan. 2009

SZARGUT, J.; MORRIS, D.; FRANK, S. Exergy analysis of thermal, chemical and metallurgical process. Hemisphere Publishing Corporation. $1^{\text {st }}$. ed. 1988.

TAXA de juros de longo prazo. BNDES - Banco Nacional de Desenvolvimento Econômico e Social. Editado em 22/1/2010. Disponível em: <http://www.bndes.gov.br/SiteBNDES/export/sites/default/bndes_pt/Galerias/Ar quivos/produtos/download/tjlp.pdf>. Acesso em: 05 fev. 2010.

TSATSARONIS, G. Thermoeconomic analysis and optimization of energy systems. Progress in Energy and Combustion Science, Volume 19, Issue 3, Pages 227-257, 1993.

UOP LLC. Des Plaines. Processo de funcionamento do PSA System. Disponível em: <http://www.uop.com/objects/psaanimation.html>. Acesso em: 13 abr. 2009.

UPPAL, K. B. Cost estimating made simple. Hydrocarbon Processing, Gulf Publishing Company, Pages 168C-168E, issue: September 1997.

U.S. DEPARTMENT OF ENERGY. Washington, DC. Orçamento do governo Americano para programas de hidrogênio. Disponível em: $<$ http://www1.eere.energy.gov/hydrogenandfuelcells/budget.html>. Acesso em 31 mai. 2009. 
WIKIPEDIA. LZ 127 Graf Zeppelin. Disponível em:<http://pt.wikipedia.org/ wiki/LZ_127_Graf_Zeppelin >. Acesso em: 12 jun. 2009.

WORLD COAL INSTITUTE. Londres. Histórico de produção mundial de aço nos últimos 9 anos. Disponível em:<http://www.worldcoal.org/resources/coalstatistics/coal-steel-statistics/>. Acesso em: 14 mar. 2009.

ZUIDEVELD, P. L. et. al. Initial Operation of the Shell Pernis Residue Gasification Project. Gasification Technologies Conference, October 4-6, 1998.

ZHANG, Y. et. al. Hydrogen amplification of coke oven gas by reforming of methane in a ceramic membrane reactor. International Journal of Hydrogen Energy. V-33, p. 3311-3319, 2008. 
ANEXOS

\title{
Programa desenvolvido no EES
}

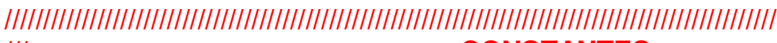 \\ CONSTANTES
}

III

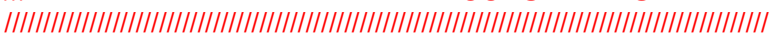

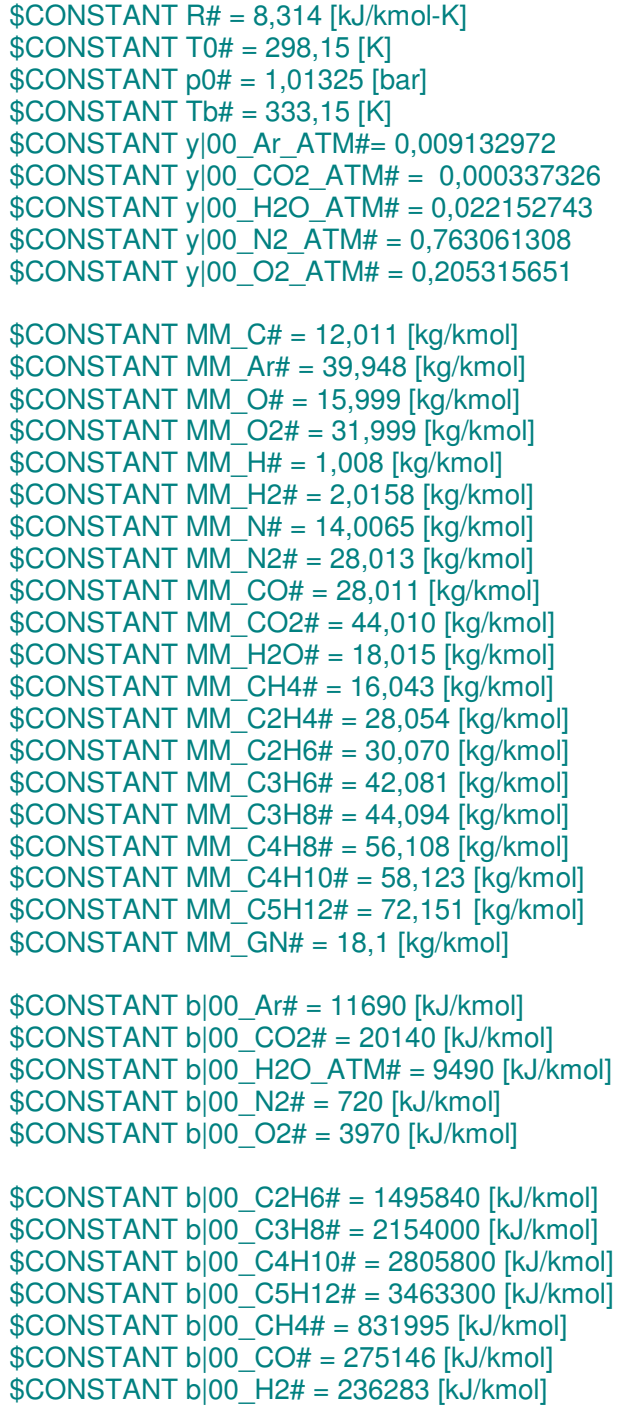

||||||||||||||||||||||||||||||||||||||||||||||||||||||||||||||||||||||||||||||||||||||||||||||||| III $\quad$ PROCEDURES AND FUNCTIONS |||||||||||||||||||||||||||||||||||||||||||||||||||||||||||||||||||||||||||||||||||||

||||||||||||||||||||||||||||||||||||/Função Entalpia//||||||||||||||||||||||||||||||||||||||

"Função que determina entalpia da mistura em determinado ponto do sistema"

Function $\mathrm{H}(\mathrm{x})$

"!1 - Procura a Vazão Molar, Pressão e Temperatura do fluxo 'x' na Tabela 'Process'" 


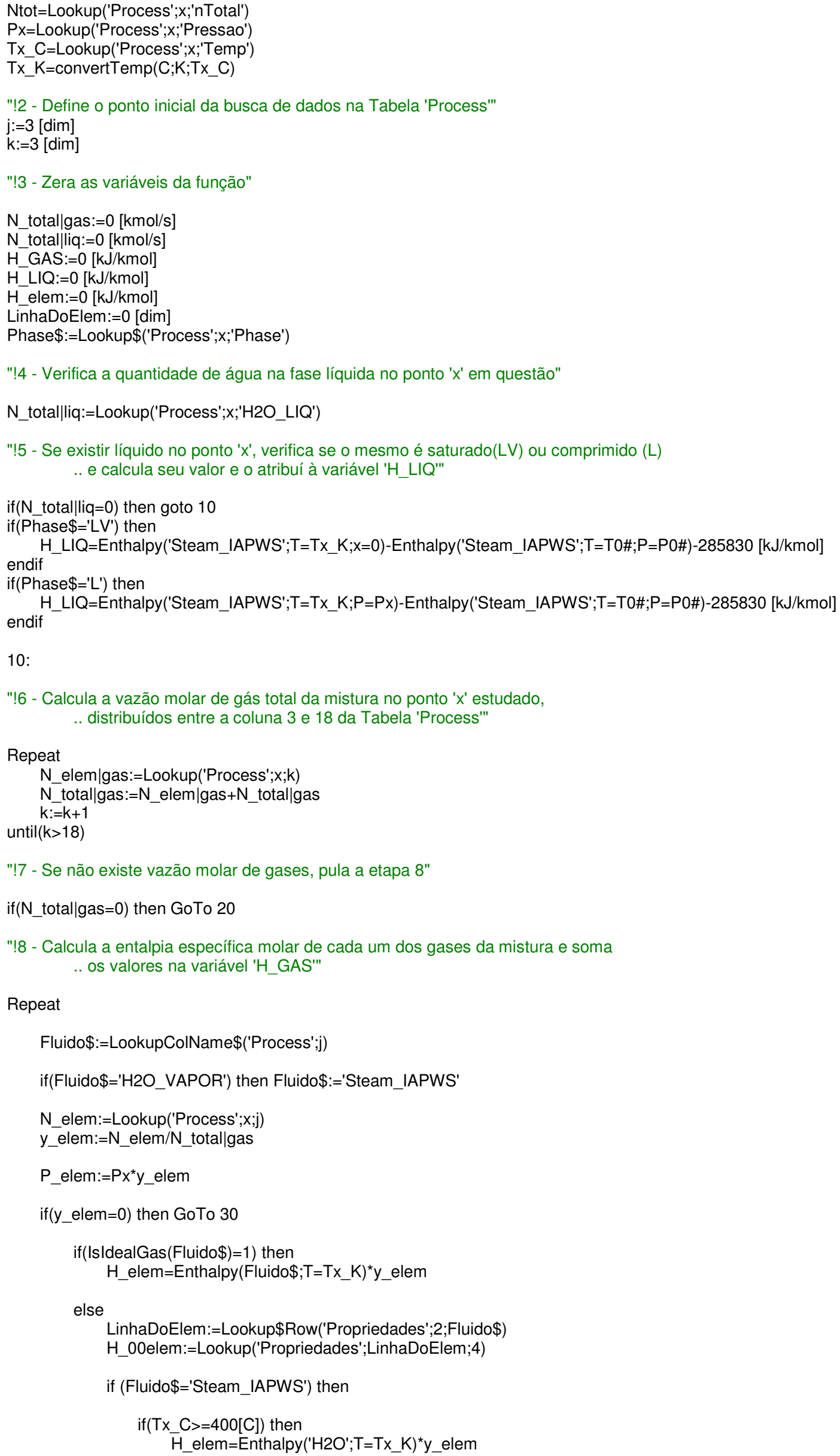


else

if (Phase $\$ \mathbf{y}^{\prime} \mathrm{LV}$ ) then

Hcalc1=Enthalpy(Fluido\$;T=Tx_K;X=1)-Enthalpy(Fluido\$;T=T0\#;P=P0\#)-285830 [kJ/kmol]

$\mathrm{H}$ elem $=$ Hcalc ${ }^{*} \mathrm{y}$ elem endif

if (Phase $\left.\$={ }^{\prime} \mathrm{V}\right)$ ) then

Hcalc2=Enthalpy(Fluido\$;T=Tx_K;P=P_elem)-Enthalpy(Fluido\$;T=T0\#;P=P0\#)-285830 [kJ/kmol]

$\mathrm{H}$ elem $=\mathrm{Hcalc}^{*} \mathrm{y}$ elem endif

endif

else

Hcalc3=Enthalpy(Fluido $\$ ; T=T x \quad K ; P=P$ elem)-Enthalpy(Fluido $\$ ; T=T 0 \# ; P=P 0 \#)+H$ 00elem

H_elem $=$ Hcalc $3^{*} y \_$elem

endif

endif

H_GAS:=H_elem+H_GAS

30:

$\mathrm{j}:=\mathrm{j}+1$

Until(j>18)

20:

"!9 - Calcula a fração de gás e a fração de líquido no fluxo 'x' em questao"

fracao gas $=\mathrm{N}$ total $\mid$ gas $/ \mathrm{N}$ tot

fracao_liq=N_total|liq/Ntot

"!10 - Calcula a entalpia específica molar total $(H)$ no ponto estudado somando as variáveis 'H_GAS'

.. e 'H_LIQ' e ponderando pela respectiva fração de gás e a fração de líquido no fluxo 'x"'

$H:=f r a c a o \_g a s^{*} H \_G A S+f r a c a o \_l i q^{*} H \_L I Q$

END

|||||||||||||||||||||/Função Entalpia nas Condições de Referência//II||||||||||||||||||||||

"Função que determina entalpia da mistura em um ponto específico do processo

.. nas condições definidas para o ambiente de referência $\left(25^{\circ} \mathrm{C}\right.$ e 1,01325 bar)"

Function $\mathrm{H} \_0(x)$

"!1 - Procura a Vazão Molar na Tabela 'Process' e define a Pressão e Temperatura do fluxo 'x'"

Ntot=Lookup('Process';x;'nTotal')

$P x=1,01325$ [bar]

Tx_C=25 [C]

Tx_K=convertTemp(C;K;Tx_C)

"!2 - Define o ponto inicial da busca de dados na Tabela 'Process""

$\mathrm{j}:=3[\mathrm{dim}]$

$\mathrm{k}:=3$ [dim]

"!3 - Zera as variáveis da função"

N_total|gas: $=0[\mathrm{kmol} / \mathrm{s}]$

N_total|liq: $=0[\mathrm{kmol} / \mathrm{s}]$

H O GAS: $=0[\mathrm{~kJ} / \mathrm{kmol}]$

H_O_LIQ:=0 [kJ/kmol]

H_O_elem: $=0[\mathrm{~kJ} / \mathrm{kmol}]$

LinhaDoElem: $=0$ [dim]

Phase \$:=Lookup\$('Process';x;'Phase') 
"!4 - Verifica a quantidade de água na fase líquida no ponto 'x' em questão"

N_total|liq:=Lookup('Process';x;'H2O_LIQ')

"!5 - Se existir líquido no ponto ' $x$ ', verifica se o mesmo é saturado(LV) ou comprimido (L)

.. e calcula seu valor e o atribuí à variável 'H_LIQ'"

if $\left(\mathrm{N} \_\right.$total $\mid$liq $\left.=0\right)$ then goto 10

if $($ Phase $\$=' L V ')$ then endif

H_O_LIQ=Enthalpy('Steam_IAPWS';T=Tx_K;X=0)-Enthalpy('Steam_IAPWS';T=T0\#;P=P0\#)-285830 [kJ/kmol]

if(Phase $\$=' L ')$ then endif

H_O_LIQ=Enthalpy('Steam_IAPWS';T=Tx_K;P=Px)-Enthalpy('Steam_IAPWS';T=T0\#;P=P0\#)-285830 [KJ/kmol]

10:

"!6 - Calcula a vazão molar de gás total da mistura no ponto 'x' estudado,

.. distribuídos entre a coluna 3 e 18 da Tabela 'Process'"

Repeat

N_elem|gas:=Lookup('Process';;;k)

N_total $\mid g a s:=N \_$elem|gas $+\mathrm{N} \_$total $\mid g a s$

$\mathrm{k}:=\mathrm{k}+1$

until $(\mathrm{k}>18)$

"!7 - Se não existe vazão molar de gases, pula a etapa 8"

if $\left(\mathrm{N} \_\right.$total $\left.\mid g a s=0\right)$ then GoTo 20

"!8 - Calcula a entalpia específica molar de cada um dos gases da mistura e soma .. os valores na variável 'H_0_GAS'"

Repeat

Fluido\$:=LookupCoIName $\$($ Process';j)

if(Fluido $\left.\$=' H 2 O \_V A P O R '\right)$ then Fluido $\$:=' S t e a m \_I A P W S '$

N_elem:=Lookup('Process';x;j)

y_elem:=N_elem $/ \mathrm{N} \_$total $\mid g a s$

P_elem:=Px*y_elem

if(y_elem=0) then GoTo 30

if(IsIdealGas(Fluido\$)=1) then

H_0_elem =Enthalpy(Fluido $\left.\$ ; T=T x \_K\right)^{*} y \_e l e m$

else

LinhaDoElem:=Lookup\$Row('Propriedades';2;Fluido\$)

H_00elem:=Lookup('Propriedades';LinhaDoElem;4)

if (Fluido\$='Steam_IAPWS') then

if $\left(\mathrm{Tx}_{\mathrm{C}} \mathrm{C}>=400[\mathrm{C}]\right)$ then

H_0_elem $=$ Enthalpy('H2O';T=Tx_K $)^{*} y \_$elem

else

if (Phase $\$=' L V ')$ then

H_Ocalc1=Enthalpy(Fluido\$;T=Tx_K; $=1$ )-Enthalpy(Fluido\$;T=T0\#;P=P0\#)-285830 [kJ/kmol] endif

H_O_elem $=\mathrm{H} \_0$ calc $1^{*} y \_$elem

if (Phase $\$=' \mathrm{~V}$ ') then

$[\mathrm{kJ} / \mathrm{kmol}]$

H_Ocalc2=Enthalpy(Fluido $\$ ; T=T x \_K ; P=P \_$elem)-Enthalpy(Fluido $\left.\$ ; T=T 0 \# ; P=P 0 \#\right)-285830$

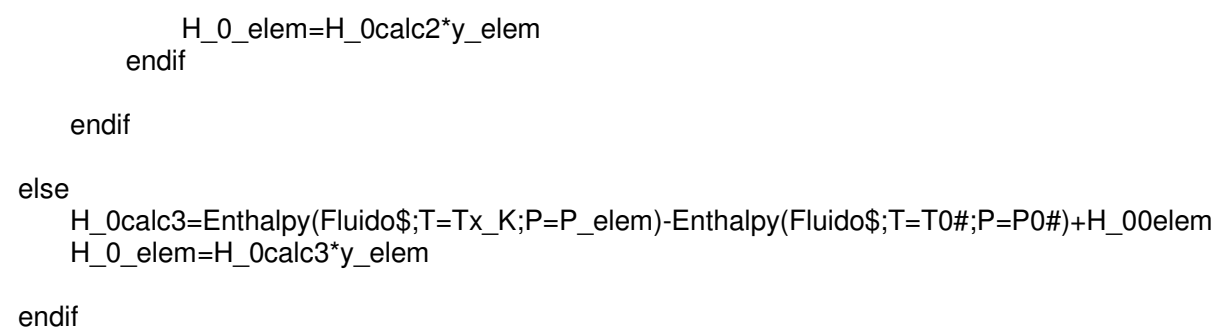


H_0_GAS:=H_0_elem+H_0_GAS

30:

$\mathrm{j}:=\mathrm{j}+1$

Until(j>18)

20:

"!9 - Calcula a fração de gás e a fração de líquido no fluxo 'x' em questao"

fracao_gas=N_total|gas $/$ Ntot

fracao_liq=N_total|liq/Ntot

"!10 - Calcula a entalpia específica molar total (H_0) no ponto estudado somando as variáveis 'H_0_GAS' .. e 'H_O_LIQ' e ponderando pela respectiva fração de gás e a fração de líquido no fluxo 'x'"'

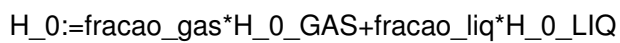

END

|||||||||||||||||||||||||||||||||||||||/|Função Entropia/||||||||||||||||||||||||||||||||||||||||

"Função que determina entropia da mistura em determinado ponto do sistema"

Function $\mathrm{S}(\mathrm{x})$

"!1 - Procura a Vazão Molar, Pressão e Temperatura do fluxo 'x' na Tabela 'Process'"

Ntot=Lookup('Process'; $;$;'nTotal')

Px=Lookup('Process'; ;;'Pressao')

Tx_C=Lookup('Process'; $;$;'Temp')

Tx_K=convertTemp $\left(\mathrm{C} ; \mathrm{K} ; \mathrm{Tx} \_\mathrm{C}\right)$

"!2 - Define o ponto inicial da busca de dados na Tabela 'Process'"

$\mathrm{j}:=3[\mathrm{dim}]$

$\mathrm{k}:=3[\mathrm{dim}]$

"!3 - Zera as variáveis da função"

$\mathrm{N}$ total $\mid$ gas: $=0[\mathrm{kmol} / \mathrm{s}]$

N_total|liq: $=0[\mathrm{kmol} / \mathrm{s}]$

S_GAS: $=0[\mathrm{~kJ} / \mathrm{kmol}-\mathrm{K}]$

S_LIQ:=0 [kJ/kmol-K]

S_elem: $=0[\mathrm{~kJ} / \mathrm{kmol}-\mathrm{K}]$

LinhaDoElem: $=0$ [dim]

Phase \$:=Lookup\$('Process';x;'Phase')

"!4 - Verifica a quantidade de água na fase líquida no ponto 'x' em questão"

N_total|liq:=Lookup('Process'; $;$;'H2O_LIQ')

"!5 - Se existir líquido no ponto 'x', verifica se o mesmo é saturado(LV) ou comprimido (L) .. e calcula seu valor e o atribuí à variável 'S_LIQ"'

if $\left(\mathrm{N} \_\right.$total|liq=0) then goto 10

if $($ Phase $\$=' L V ')$ then endif

S_LIQ=Entropy('Steam_IAPWS';T=Tx_K;X=0)-Entropy('Steam_IAPWS';T=T0\#;P=P0\#)+69,95 [kJ/kmol-C]

if $\left(\right.$ Phase $\left.\$=^{\prime} '{ }^{\prime}\right)$ then

S_LIQ=Entropy('Steam_IAPWS';T=Tx_K;P=Px)-Entropy('Steam_IAPWS';T=T0\#;P=P0\#)+69,95 [kJ/kmol-C] endif

10:

"!6 - Calcula a vazão molar de gás total da mistura no ponto 'x' estudado, .. distribuídos entre a coluna 3 e 18 da Tabela 'Process'"

Repeat

N_elem|gas:=Lookup('Process';x;k) 


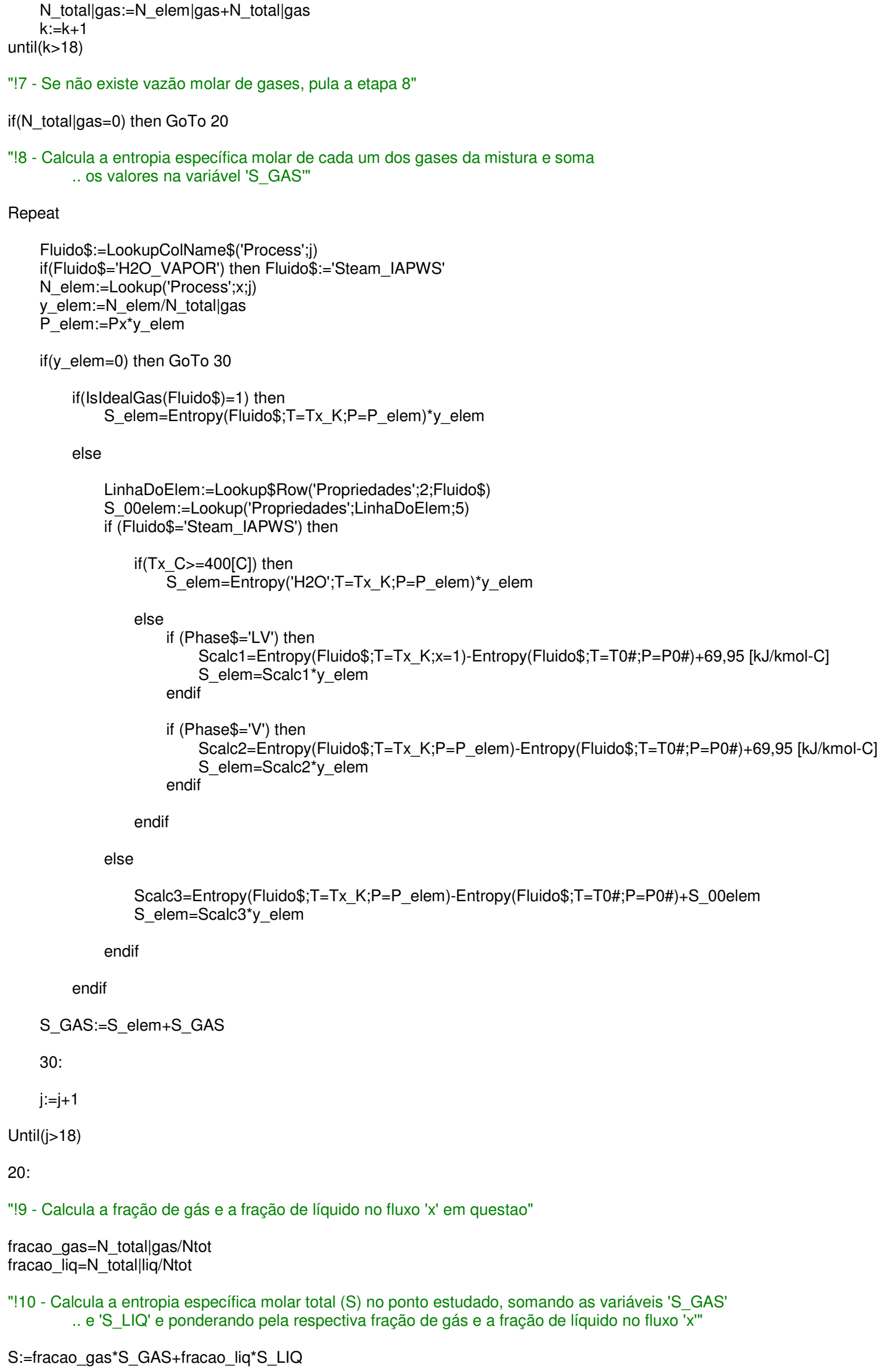


|/IIIIIIIIIIII//Função Entropia nas Condições de Referência//IIIIIIIIIIIIIIIIIIIII

"Função que determina entropia da mistura em um ponto específico do processo

.. nas condições definidas para o ambiente de referência $\left(25^{\circ} \mathrm{C}\right.$ e 1,01325 bar)"

Function S_0(x)

"!1 - Procura a Vazão Molar na Tabela 'Process' e define a Pressão e Temperatura do fluxo 'x'"

Ntot=Lookup('Process'; $;$;'nTotal')

$\mathrm{Px}=1,01325[\mathrm{bar}]$

Tx_C=25[C]

Tx_K=convertTemp (C;K;Tx_C)

"!2 - Define o ponto inicial da busca de dados na Tabela 'Process'"

$\mathrm{j}:=3[\mathrm{dim}]$

$\mathrm{k}:=3[\mathrm{dim}]$

"!3 - Zera as variáveis da função"

N_total $\mid$ gas: $=0[\mathrm{kmol} / \mathrm{s}]$

N_total|liq: $=0[\mathrm{kmol} / \mathrm{s}]$

S_0_GAS: $=0[\mathrm{~kJ} / \mathrm{kmol}-\mathrm{K}]$

S_0_LIQ: $=0[\mathrm{~kJ} / \mathrm{kmol}-\mathrm{K}]$

S 0 elem: $=0[\mathrm{~kJ} / \mathrm{kmol}-\mathrm{K}]$

LinhaDoElem: $=0[\mathrm{dim}]$

Phase\$:=Lookup\$('Process';x;'Phase')

"!4 - Verifica a quantidade de água na fase líquida no ponto 'x' em questão"

N_total|liq:=Lookup('Process';x;'H2O_LIQ')

"!5 - Se existir líquido no ponto 'x', verifica se o mesmo é saturado(LV) ou comprimido (L) .. e calcula seu valor e o atribuí à variável 'S_LIQ'"

if $\left(N \_\right.$total $\mid$liq $\left.=0\right)$ then goto 10

if (Phase $\$=' L V ')$ then

S_0_LIQ=Entropy('Steam_IAPWS';T=Tx_K;X=0)-Entropy('Steam_IAPWS';T=T0\#;P=P0\#)+69,95 [kJ/kmol-C] endif

if(Phase $\left.\$=^{\prime} ' L^{\prime}\right)$ then

S_0_LIQ=Entropy('Steam_IAPWS';T=Tx_K;P=Px)-Entropy('Steam_IAPWS';T=T0\#;P=P0\#)+69,95 [kJ/kmol-C] endif

10:

"!6 - Calcula a vazão molar de gás total da mistura no ponto 'x' estudado, .. distribuídos entre a coluna 3 e 18 da Tabela 'Process'"

Repeat

N_elem|gas:=Lookup('Process';;;k)

$\mathrm{N}$ _total|gas:=N_elem|gas $+\mathrm{N}$ _total|gas

$\mathrm{k}:=\mathrm{k}+1$

until $(k>18)$

"!7 - Se não existe vazão molar de gases, pula a etapa 8"

if $(\mathrm{N}$ _totall|gas $=0)$ then GoTo 20

"!8 - Calcula a entropia específica molar de cada um dos gases da mistura e soma .. os valores na variável 'S_0_GAS'"

Repeat

Fluido\$:=LookupCoIName $\$(' P r o c e s s ' ; j)$

if(Fluido\$='H2O_VAPOR') then Fluido\$:='Steam_IAPWS'

N_elem:=Lookup('Process'; ; ;j)

y_elem:=N_elem $/ \mathrm{N}$ _total|gas

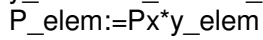

if $\left(y \_\right.$elem $\left.=0\right)$ then GoTo 30

if(IsldealGas(Fluido\$)=1) then 
S_0_elem=Entropy(Fluido $\left.\$ ; T=T x \_K ; P=P \_e l e m\right)^{*} y \_$elem

else

LinhaDoElem:=Lookup\$Row('Propriedades';2;Fluido\$)

S_00elem:=Lookup('Propriedades';LinhaDoElem;5)

if (Fluido\$='Steam_IAPWS') then

if $\left(T x C_{>}=400[C]\right)$ then

S_0_elem=Entropy('H2O';T=Tx_K;P=P_elem $)^{*} y \_$elem

else

if (Phase $\$=' L V ')$ then

S_0calc1=Entropy(Fluido\$;T=Tx_K;X=1)-Entropy(Fluido\$;T=T0\#;P=P0\#)+69,95 [kJ/kmol-C] endif

S_0_elem $=$ S_0calc ${ }^{*} \mathrm{y}$ elem

if (Phase\$='V') then

C]

S_0calc2=Entropy(Fluido\$;T=Tx_K;P=P_elem)-Entropy(Fluido\$;T=T0\#;P=P0\#)+69,95 [kJ/kmolendif

S_0_elem $=$ S_0calc2 ${ }^{*} y \_$elem

endif

else

S_0calc3=Entropy(Fluido $\$ ; T=T x \_K ; P=P \_$elem)-Entropy(Fluido $\left.\$ ; T=T 0 \# ; P=P 0 \#\right)+S \_00 e l e m$ endif

endif

S_0_GAS:=S_0_elem+S_0_GAS

30:

$\mathrm{j}:=\mathrm{j}+1$

Until(j>18)

20:

"!9 - Calcula a fração de gás e a fração de líquido no fluxo 'x' em questao"

fracao_gas=N_total|gas/Ntot

fracao_liq=N_total||liq/Ntot

"!10 - Calcula a entropia específica molar total (S_0) no ponto estudado, somando as variáveis 'S_0_GAS'

.. e 'S_LIQ' e ponderando pela respectiva fração de gás e a fração de líquido no fluxo 'x'"

S_0:=fracao_gas*S_0_GAS+fracao_liq*S_0_LIQ

END

||||||||||||||||||||||/Função Vazão Molar Total (nTotal)//II||||||||||||||||||||||

"Função que determina a vazão molar da mistura em um ponto específico do processo"

Function $\mathrm{n}(\mathrm{x})$

n:=Lookup('Process';x;'nTotal')

END

|||||||||||||||||||||||||||||||/Função Exergia Física |||||||||||||||||||||||||||||||||||

"Função que determina a exergia física da mistura em determinado ponto do sistema"

Function B_ph $(\mathrm{x})$

$B \_p h=H(x)-H \_0(x)-T O \#^{*}\left(S(x)-S \_0(x)\right)$

END 
||||||||||||||||||||||||||||||||Função Exergia Química ||||||||||||||||||||||||||||||||||||

"Função que determina a exergia química da mistura em determinado ponto do sistema"

Function B_ch $(x)$

"!1 - Procura a Vazão Molar na Tabela 'Process' e define a Pressão e Temperatura do fluxo 'x'"

Ntot=Lookup('Process'; $x ;$ 'nTotal')

Px=Lookup('Process'; $x ;$ 'Pressao')

"!2 - Define o ponto inicial da busca de dados na Tabela 'Process"'

$\mathrm{j}:=3[\mathrm{dim}]$

$\mathrm{k}:=3[\mathrm{dim}]$

"!3 - Zera as variáveis da função"

N_total|gas: $=0[\mathrm{kmol} / \mathrm{s}]$

N_total|liq: $=0[\mathrm{kmol} / \mathrm{s}]$

SomaB ch1: $=0[\mathrm{~kJ} / \mathrm{kmol}]$

SomaB_ch2:=0 [dim]

B ch1 elem: $=0[\mathrm{~kJ} / \mathrm{kmol}]$

B_ch2_elem:=0 [dim]

B ch gas: $=0[\mathrm{~kJ} / \mathrm{kmol}]$

LinhaDoElem: $=0$ [dim]

"!4 - Calcula a vazão total molar de gases no ponto estudado"

Repeat

N_elem|gas:=Lookup('Process';;;k)

N_total|gas: $=\mathrm{N} \_$elem $\mid$gas $+\mathrm{N} \_$total $\mid$gas

$\mathrm{k}:=\mathrm{k}+1$

until(k>18)

if $\left(\mathrm{N} \_\right.$total $\left.\mid g a s=0\right)$ then GoTo 10

"!5 - Calcula a exergia quimica molar dos gases da mistura no ponto estudado"

Repeat

Fluido\$:=LookupCoIName $\$(' P r o c e s s ' ; j)$

if(Fluido $\$=$ 'H2O_VAPOR') then Fluido $\$:=' S t e a m \_I A P W S '$

$\mathrm{N}$ elem:=Lookup('Process'; $;$;j)

$y \_$elem:=N_elem/ $N$ _total|gas

if $\left(y \_\right.$elem $\left.=0\right)$ then GoTo 20

LinhaDoElem:=Lookup\$Row('Propriedades';2;Fluido\$)

B 00elem:=Lookup('Propriedades';LinhaDoElem;6)

B_ch1_elem $=y$ _elem ${ }^{*} B \_00$ elem

SomaB_ch1:=B_ch1_elem+SomaB_ch1

B_ch2_elem $=y \_$elem $*$ In(y_elem)

SomaB_ch2:=B_ch2_elem+SomaB_ch2

20:

$\mathrm{j}:=\mathrm{j}+1$

Until(j>18)

B_ch_gas:=SomaB_ch1+R\#*T0\#SomaB_ch2

10:

"!6 - Calcula a exergia quimica molar padrão da água líquida comprimida presente no ponto estudado"

N_total|liq:=Lookup('Process';x;'H2O_LIQ')

B_ch_LIQ:=900[kJ/kmol]

"!7 - Calcula a fração de gás e a fração de líquido no fluxo 'x' em questao"

fracao_gas=N_total|gas/Ntot

fracao_liq=N_total|liq/Ntot 
"!8 - Calcula a exergia quimica específica molar total no ponto estudado"

B_ch:=fracao_gas*B_ch_gas+fracao_liq*B_ch_LIQ

END

||||||||||||||||||||||||||||||||Procedimento CALCULO ||||||||||||||||||||||||||||||||||||

"Calcula a exergia totas específica de cada ponto e outras propriedades"

Procedure CALCULO(X:Ponto\$;N_tot;Temp;Press;H;H_0;S;S_0;B_ph;B_ch;B_tot)

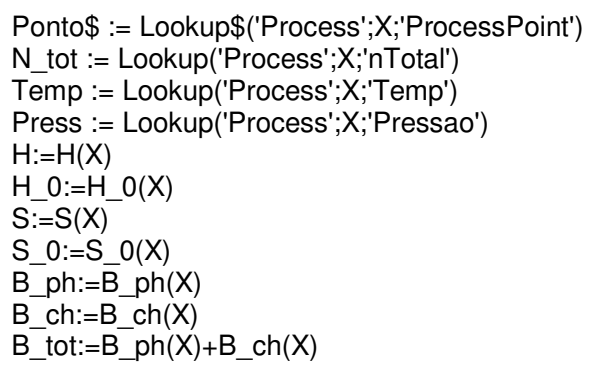

END

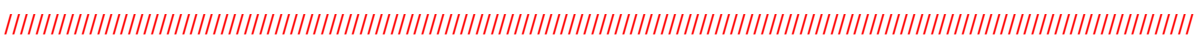

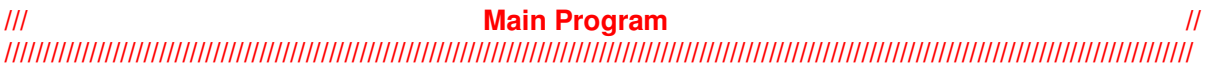

CALL CALCULO(1:Ponto\$[1];N_tot[1];Temp[1];Press[1];H[1];H_0[1];S[1];S_0[1];B_ph[1];B_ch[1];B_tot[1]) CALL CALCULO(2:Ponto\$[2];N_tot[2];Temp[2];Press[2];H[2];H_0[2];S[2];S_0[2];B_ph[2];B_ch[2];B_tot[2]) CALL CALCULO(3:Ponto\$[3];N_tot[3];Temp[3];Press[3];H[3];H_0[3];S[3];S_0[3];B_ph[3];B_ch[3];B_tot[3]) CALL CALCULO(4:Ponto\$[4];N_tot[4];Temp[4];Press[4];H[4];H_0[4];S[4];S_0[4];B_ph[4];B_ch[4];B_tot[4]) CALL CALCULO(5:Ponto\$[5];N_tot[5];Temp[5];Press[5];H[5];H_0[5];S[5];S_0[5];B_ph[5];B_ch[5];B_tot[5]) CALL CALCULO(6:Ponto\$[6];N_tot[6];Temp[6];Press[6];H[6];H_0[6];S[6];S_0[6];B_ph[6];B_ch[6];B_tot[6]) CALL CALCULO(7:Ponto\$[7];N_tot[7];Temp[7];Press[7];H[7];H_0[7];S[7];S_0[7];B_ph[7];B_ch[7];B_tot[7]) CALL CALCULO (8:Ponto\$[8];N tot[8];Temp[8];Press[8];H[8];H 0[8];S[8];S 0[8];B ph[8];B ch[8];B tot[8]) CALL CALCULO(9:Ponto\$[9];N_tot[9];Temp[9];Press[9];H[9];H_0[9];S[9];S_0[9];B_ph[9];B_ch[9];B_tot[9])

CALL CALCULO(10:Ponto\$[10]; $N$ tot[10];Temp[10];Press[10];H[10];H 0[10];S[10];S 0[10];B ph[10];B ch[10];B tot[10]) CALL CALCULO(11:Ponto\$[11];N_tot[11];Temp[11];Press[11];H[11];H_0[11];S[11];S_0[11];B_ph[11];B_ch[11];B_tot[11]) CALL CALCULO(12:Ponto\$[12];N_tot[12];Temp[12];Press[12];H[12];H_O[12];S[12];S_0[12];B_ph[12];B_ch[12];B_tot[12]) CALL CALCULO(13:Ponto\$[13];N_tot[13];Temp[13];Press[13];H[13];H_0[13];S[13];S_O[13];B_ph[13];B_ch[13];B_tot[13]) CALL CALCULO(14:Ponto\$[14];N_tot[14];Temp[14];Press[14];H[14];H_0[14];S[14];S_0[14];B_ph[14];B_ch[14];B_tot[14]) CALL CALCULO(15:Ponto\$[15];N_tot[15];Temp[15];Press[15];H[15];H_0[15];S[15];S_0[15];B_ph[15];B_ch[15];B_tot[15]) CALL CALCULO(16:Ponto\$[16];N_tot[16];Temp[16];Press[16];H[16];H_0[16];S[16];S_0[16];B_ph[16];B_ch[16];B_tot[16]) CALL CALCULO(17:Ponto\$[17];N_tot[17];Temp[17];Press[17];H[17];H_0[17];S[17];S_0[17];B_ph[17];B_ch[17];B_tot[17]) CALL CALCULO(18:Ponto\$[18];N_tot[18];Temp[18];Press[18];H[18];H_0[18];S[18];S_0[18];B_ph[18];B_ch[18];B_tot[18]) CALL CALCULO(19:Ponto\$[19];N_tot[19];Temp[19];Press[19];H[19];H_0[19];S[19];S_0[19];B_ph[19];B_ch[19];B_tot[19])

CALL CALCULO(20:Ponto\$[20];N_tot[20];Temp[20];Press[20];H[20];H_0[20];S[20];S_0[20];B_ph[20];B_ch[20];B_tot[20]) CALL CALCULO(21:Ponto\$[21];N_tot[21];Temp[21];Press[21];H[21];H_0[21];S[21];S_0[21];B_ph[21];B_ch[21];B_tot[21]) CALL CALCULO(22:Ponto\$[22];N_tot[22];Temp[22];Press[22];H[22];H_0[22];S[22];S_0[22];B_ph[22];B_ch[22];B_tot[22]) CALL CALCULO(23:Ponto\$[23];N_tot[23];Temp[23];Press[23];H[23];H_0[23];S[23];S_0[23];B_ph[23];B_ch[23];B_tot[23]) CALL CALCULO(24:Ponto\$[24];N_tot[24];Temp[24];Press[24];H[24];H_0[24];S[24];S_0[24];B_ph[24];B_ch[24];B_tot[24]) CALL CALCULO(25:Ponto\$[25];N_tot[25];Temp[25];Press[25];H[25];H_0[25];S[25];S_0[25];B_ph[25];B_ch[25];B_tot[25]) CALL CALCULO(26:Ponto\$[26];N_tot[26];Temp[26];Press[26];H[26];H_0[26];S[26];S_0[26];B_ph[26];B_ch[26];B_tot[26]) CALL CALCULO(27:Ponto\$[27];N_tot[27];Temp[27];Press[27];H[27];H_0[27];S[27];S_0[27];B_ph[27];B_ch[27];B_tot[27]) CALL CALCULO(28:Ponto\$[28];N_tot[28];Temp[28];Press[28];H[28];H_0[28];S[28];S_0[28];B_ph[28];B_ch[28];B_tot[28]) CALL CALCULO(29:Ponto\$[29];N_tot[29];Temp[29];Press[29];H[29];H_0[29];S[29];S_0[29];B_ph[29];B_ch[29];B_tot[29])

CALL CALCULO(30:Ponto\$[30];N_tot[30];Temp[30];Press[30];H[30];H_0[30];S[30];S_0[30];B_ph[30];B_ch[30];B_tot[30]) CALL CALCULO(31:Ponto\$[31];N_tot[31];Temp[31];Press[31];H[31];H_0[31];S[31];S_0[31];B_ph[31];B_ch[31];B_tot[31]) CALL CALCULO(32:Ponto\$[32];N_tot[32];Temp[32];Press[32];H[32];H_0[32];S[32];S_0[32];B_ph[32];B_ch[32];B_tot[32]) CALL CALCULO(33:Ponto\$[33]; $N$ tot[33];Temp[33];Press[33];H[33];H 0[33];S[33];S O[33];B ph[33];B ch[33];B tot[33]) CALL CALCULO(34:Ponto\$[34];N_tot[34];Temp[34];Press[34];H[34];H_0[34];S[34];S_0[34];B_ph[34];B_ch[34];B_tot[34]) CALL CALCULO(35:Ponto\$[35];N_tot[35];Temp[35];Press[35];H[35];H_0[35];S[35];S_0[35];B_ph[35];B_ch[35];B_tot[35]) CALL CALCULO(36:Ponto\$[36];N_tot[36];Temp[36];Press[36];H[36];H_0[36];S[36];S_0[36];B_ph[36];B_ch[36];B_tot[36]) CALL CALCULO(37:Ponto\$[37];N_tot[37];Temp[37];Press[37];H[37];H_0[37];S[37];S_0[37];B_ph[37];B_ch[37];B_tot[37]) CALL CALCULO(38:Ponto\$[38];N_tot[38];Temp[38];Press[38];H[38];H_0[38];S[38];S_0[38];B_ph[38];B_ch[38];B_tot[38]) CALL CALCULO(39:Ponto\$[39];N_tot[39];Temp[39];Press[39];H[39];H_0[39];S[39];S_0[39];B_ph[39];B_ch[39];B_tot[39]) 
CALL CALCULO(41:Ponto\$[41];N_tot[41];Temp[41];Press[41];H[41];H_0[41];S[41];S_0[41];B_ph[41];B_ch[41];B_tot[41]) CALL CALCULO(42:Ponto\$[42];N_tot[42];Temp[42];Press[42];H[42];H_0[42];S[42];S_0[42];B_ph[42];B_ch[42];B_tot[42]) CALL CALCULO(43:Ponto\$[43]; $N$ tot[43];Temp[43];Press[43];H[43];H 0[43];S[43];S o[43];B ph[43];B ch[43];B tot[43]) CALL CALCULO(44:Ponto\$[44];N_tot[44];Temp[44];Press[44];H[44];H_0[44];S[44];S_0[44];B_ph[44];B_ch[44];B_tot[44]) CALL CALCULO(45:Ponto\$[45];N tot[45];Temp[45];Press[45];H[45];H_0[45];S[45];S_0[45];B ph[45];B ch[45];B tot[45]) CALL CALCULO(46:Ponto\$[46];N_tot[46];Temp[46];Press[46];H[46];H_0[46];S[46];S_0[46];B_ph[46];B_ch[46];B tot[46]) CALL CALCULO(47:Ponto\$[47];N_tot[47];Temp[47];Press[47];H[47];H_0[47];S[47];S_0[47];B_ph[47];B_ch[47];B_tot[47]) CALL CALCULO(48:Ponto\$[48];N tot[48];Temp[48];Press[48];H[48];H_0[48];S[48];S_0[48];B ph[48];B ch[48];B tot[48]) CALL CALCULO(49:Ponto\$[49];N_tot[49];Temp[49];Press[49];H[49];H_0[49];S[49];S_0[49];B_ph[49];B_ch[49];B_tot[49])

CALL CALCULO(50:Ponto\$[50];N_tot[50];Temp[50];Press[50];H[50];H_0[50];S[50];S_0[50];B_ph[50];B_ch[50];B_tot[50]) CALL CALCULO(51:Ponto\$[51];N_tot[51];Temp[51];Press[51];H[51];H_0[51];S[51];S_0[51];B_ph[51];B_ch[51];B_tot[51]) CALL CALCULO(52:Ponto\$[52]; $N$ tot[52];Temp[52];Press[52];H[52];H 0[52];S[52];S 0[52];B ph[52];B $\operatorname{ch}[52] ; B$ tot[52]) CALL CALCULO(53:Ponto\$[53];N_tot[53];Temp[53];Press[53];H[53];H_0[53];S[53];S_0[53];B_ph[53];B_ch[53];B_tot[53]) CALL CALCULO(54:Ponto\$[54];N_tot[54];Temp[54];Press[54];H[54];H_0[54];S[54];S_0[54];B_ph[54];B_ch[54];B_tot[54]) CALL CALCULO(55:Ponto\$[55];N tot[55];Temp[55];Press[55];H[55];H_0[55];S[55];S_0[55];B ph[55];B ch[55];B tot[55]) CALL CALCULO(56:Ponto\$[56];N_tot[56];Temp[56];Press[56];H[56];H_0[56];S[56];S_0[56];B_ph[56];B_ch[56];B_tot[56]) CALL CALCULO(57:Ponto\$[57];N tot[57];Temp[57];Press[57];H[57];H_0[57];S[57];S 0[57];B ph[57];B ch[57];B_tot[57]) CALL CALCULO(58:Ponto\$[58];N_tot[58];Temp[58];Press[58];H[58];H_0[58];S[58];S_0[58];B_ph[58];B_ch[58];B_tot[58]) CALL CALCULO(59:Ponto\$[59];N_tot[59];Temp[59];Press[59];H[59];H_0[59];S[59];S_0[59];B ph[59];B ch[59];B tot[59]) CALL CALCULO(60:Ponto\$[60];N_tot[60];Temp[60];Press[60];H[60];H_0[60];S[60];S_0[60];B_ph[60];B_ch[60];B_tot[60])

|||||||||||||||||||||||||||||||||||||||||||||||||||||||||||||||||||||||||||||||||||||||||||||||

//Os resultados de todos os equipamentos analisados estarão presentes nos vetores 70 e acima// ||||||||||||||||||||||||||||||||||||||||||||||||||||||||||||||||||||||||||||||||||||

\footnotetext{
"-------------- V-01 ----------------"

EQPTO\$[70]='V-01'

"!Balaço Energético >> Q + ne*he = ns*hs + W"
}

$\mathrm{W}[70]=0[\mathrm{~kJ} / \mathrm{s}]$

$\operatorname{Ein}[70]=n(1)^{*} \mathrm{H}[1]$

Eout $[70]=n(2) * H[2]$

$\mathrm{Q}[70]=$ Eout[70]-Ein[70]

Epsilon_E[70]=Eout[70]/Ein[70]

"!Balaço Exergético $>>$ ne* $\mathrm{Be}=\mathrm{ns}{ }^{\star} \mathrm{Bs}+\mathrm{Soma}\left(1-(\mathrm{T} 0 / \mathrm{Tb})^{\star} \mathrm{Qj}\right)+\mathrm{W}+\mathrm{Bd} "$

$\mathrm{Bq}[70]=(1-(\mathrm{TO} \# / \mathrm{Tb} \#))^{\star} \mathrm{Q}[70]$

Bin_ph[70]=n(1)*B_ph[1]

Bout ph $[70]=n(2) \star B$ ph[2]

Bin tot[70] $=n(1)^{*} B$ tot $[1]$

Bout_tot[70] $=\mathrm{n}(2){ }^{\star} \mathrm{B}$.tot[2]

$\mathrm{Bd}[7 \overline{0}]=$ Bin tot[70]-Bout tot[70]--W[70]

Epsilon_Bph[70]=Bout_ph[70]/Bin_ph[70]

Epsilon_Btot[70]=Bout_tot[70]/Bin_tot[70]

"------------------ P-01

EQPTO\$[71]='P-01'

"!Balaço Energético >>> Q + ne*he $=n s^{*} h s+W "$

$\mathrm{W}[71]=0[\mathrm{~kJ} / \mathrm{s}]$

$\operatorname{Ein}[71]=n(2)^{*} H[2]+n(4)^{*} H[4]$

Eout $[71]=n(3) * H[3]+n(5) * H[5]$

$\mathrm{Q}[71]=$ Eout[71]-Ein[71]

Epsilon_E[71] $=\left(n(2)^{*}(H[3]-H[2])\right) /\left(n(4)^{*}(H[4]-H[5])\right)$

"!Balaço Exergético $>>$ ne*Be $=$ ns ${ }^{*} \mathrm{Bs}+\mathrm{Soma}\left(1-(\mathrm{TO} / \mathrm{Tb})^{*} \mathrm{Qj}\right)+\mathrm{W}+\mathrm{Bd}$

$\mathrm{Bq}[71]=(1-(\mathrm{T} 0 \# / \mathrm{Tb} \#))^{\star} \mathrm{Q}[71]$

Bin_ph[71] $=n(2)^{*} B \_p h[2]+n(4)^{*} B \_p h[4]$

Bout ph[71] $=n(3)^{*} \mathrm{~B}$ ph[3]+n(5)*B ph[5]

Bin_tot[71] $=n(2)^{*}$ B_tot[2] $+n(4)^{*}$ B_tot[4]

Bout_tot[71] $=n(3) * \bar{B}$ tot $[3]+n(5) * \bar{B}$ tot $[5]$

$\mathrm{Bd}[71]=$ Bin_tot[71]-Bout_tot[71]-W[71]

Epsilon_Bph[71] $=\left(n(2)^{*}\left(B \_p h[3]-B \_p h[2]\right)\right) /\left(n(4)^{*}\left(B \_p h[4]-B \_p h[5]\right)\right)$

Epsilon_Btot[71] $=\left(n(2)^{*}(B\right.$ _tot[3]-B_tot[2] $\left.)\right) /\left(n(4)^{*}(B\right.$ _tot[4]-B_tot[5] $\left.)\right)$ 
EQPTO\$[72]='MX-01'

"!Balaço Energético >>> Q + ne*he $=n s^{*} h s+W "$

$W[72]=0[\mathrm{~kJ} / \mathrm{s}]$

$\operatorname{Ein}[72]=n(3)^{*} \mathrm{H}[3]+\mathrm{n}(6)^{*} \mathrm{H}[6]$

Eout[72] $=n(7){ }^{*} \mathrm{H}[7]$

Q[72]=Eout[72]-Ein[72]

Epsilon_E[72]=Eout[72]/Ein[72]

"!Balaço Exergético $\gg>>n{ }^{*} \mathrm{Be}=\mathrm{ns}^{*} \mathrm{Bs}+\mathrm{Soma}\left(1-(\mathrm{TO} / \mathrm{Tb})^{*} \mathrm{Q} \mathrm{j}\right)+\mathrm{W}+\mathrm{Bd}$ "

$\mathrm{Bq}[72]=(1-(\mathrm{T} 0 \# / \mathrm{Tb} \#))^{*} \mathrm{Q}[72]$

Bin_ph[72] $=n(3)^{*} B \_p h[3]+n(6)^{\star} B \_p h[6]$

Bout_ph[72] $=n(7)^{*} B \_p h[7]$

Bin tot $[72]=n(3)^{*} B$ tot $[3]+n(6)^{*} B$ _tot $[6]$

Bout_tot[72]=n(7)** ${ }^{*}$ _tot[7]

$\mathrm{Bd}[\overline{72}]=$ Bin tot[72]-Bout tot[72]-W[72]

Epsilon_Bph[72]=Bout_ph[72]/Bin_ph[72]

Epsilon_Btot[72]=Bout_tot[72]/Bin_tot[72]

"----------------- R-01

EQPTO\$[73]='R-01'

"!Balaço Energético > > Q + ne*he $=n s^{*} h s+W "$

$\mathrm{W}[73]=0[\mathrm{~kJ} / \mathrm{s}]$

$\operatorname{Ein}[73]=n(8)^{*} \mathrm{H}[8]$

Eout[73]=n(9)*H[9]

Q[73]=Eout[73]-Ein[73]

Epsilon_E[73]=1-((Eout[73]-Ein[73])/Ein[73])

"! Balaço Exergético >> ne* $\mathrm{Be}=\mathrm{ns}^{*} \mathrm{Bs}+\mathrm{Soma}\left(1-(\mathrm{TO} / \mathrm{Tb})^{*} \mathrm{Qj}\right)+\mathrm{W}+\mathrm{Bd} "$

$\mathrm{Bq}[73]=(1-(\mathrm{TO} \# / \mathrm{Tb} \#))^{*} \mathrm{Q}[73]$

Bin $p h[73]=n(8)^{*} B$ ph[8]

Bout_ph[73] $=n(9)^{*} B \_p h[9]$

Bin_tot[73]=n(8)*B tot $[8]$

Bout tot[73] $=\mathrm{n}(9)^{*} \mathrm{~B}$ tot[9]

$\mathrm{Bd}[7 \overline{3}]=$ Bin_tot[73]-Bout_tot[73]-W[73]

Epsilon Bph[73]=Bout ph[73]/Bin ph[73]

Epsilon_Btot[73]=Bout_tot[73]/Bin_tot[73]

"------------------ MX-02 -------------------"

EQPTO\$[74]='MX-02'

"!Balaço Energético >>> Q + ne*he = ns*hs + W"

$\mathrm{W}[74]=0[\mathrm{~kJ} / \mathrm{s}$

$\operatorname{Ein}[74]=n(9)^{*} \mathrm{H}[9]+\mathrm{n}(39)^{*} \mathrm{H}[39]$

Eout $[74]=n(10)^{*} \mathrm{H}[10]$

Q[74]=Eout[74]-Ein[74

Epsilon_E[74]=1-((Eout[74]-Ein[74])/Ein[74])

"!Balaço Exergético >> ne*Be $=n s^{*} \mathrm{Bs}+\mathrm{Soma}\left(1-(\mathrm{TO} / \mathrm{Tb})^{*} \mathrm{Qj}\right)+\mathrm{W}+\mathrm{Bd} "$

$\mathrm{Bq}[74]=(1-(\mathrm{TO} \# / \mathrm{Tb} \#))^{*} \mathrm{Q}[74]$

Bin_ph[74]=n(9)*B_ph[9]+n(39)*B_ph[39]

Bout $\mathrm{ph}[74]=\mathrm{n}(10)^{*} \mathrm{~B}$ ph[10]

Bin_tot[74] $=n(9)^{*} B \_$tot $[9]+n(39)^{*} B \_$tot [39]

Bout_tot[74]=n(10) ${ }^{\star} B$ tot $[10]$

Bd[74]= Bin tot[74]-Bout tot[74]-W[74]

Epsilon_Bph[74] =Bout_ph[74]/Bin_ph[74]

Epsilon_Btot[74]=Bout_tot[74]/Bin_tot[74] 
$\mathrm{W}[75]=-560[\mathrm{~kJ} / \mathrm{s}]$

$\operatorname{Ein}[75]=n(7)^{*} H[7]+n(10)^{*} H[10]+n(11)^{*} H[11]+n(47)^{*} H[47]+n(53)^{*} H[53]+n(36)^{*} H[36]+n(48)^{*} H[48]+n(43)^{*} H[43]+n(23)^{*} H[23]$ Eout[75] $=n(8)^{*} H[8]+n(11)^{*} H[11]+n(12)^{*} H[12]+n(48)^{*} H[48]+n(54)^{*} H[54]+n(37)^{*} H[37]+n(45)^{*} H[45]$

Q[75]=Eout[75]-Ein[75]+W[75]

Epsilon E[75] $=\left(n(7)^{*}(H[8]-H[7])+n(10)^{*}(H[11]-H[10])+n(47)^{*}(H[48]-H[47])-n(11)^{*} H[11]+n(12)^{*} H[12]+n(53)^{*}(H[54]-\right.$

$\left.H[53])+n(36)^{*}(H[37]-H[36])\right) /\left(n(43)^{*} H[43]+n(23)^{*} H[23]+n(48)^{*} H[48]-n(45)^{*} H[45]\right)$

"!Balaço Exergético >>> ne*Be $=n s^{*} B s+\operatorname{Soma}\left(1-(T 0 / T b)^{*} \mathrm{Qj}\right)+\mathrm{W}+\mathrm{Bd} "$

$\mathrm{Bq}[75]=(1-(\mathrm{TO} \# / \mathrm{Tb} \#))^{*} \mathrm{Q}[75]$

Bin_ph[75]=n(7)*B_ph[7]+n(10)*B_ph[10]+n(11) ${ }^{*} B \_p h[11]+n(47)^{*} B \_p h[47]+n(53)^{*} B \_p h[53]+n(36)^{*} B \_p h[36]+n(48)^{*} B \_p h[48]+n($ 43) $)^{\star} B \_p h[43]+n(23)^{\star} B \_p h[23]$

Bout $p h[75]=n(8)^{*} B \quad p h[8]+n(11)^{*} B \quad p h[11]+n(12)^{*} B \quad p h[12]+n(48)^{*} B \quad p h[48]+n(54)^{*} B \quad p h[54]+n(37)^{*} B \quad p h[37]+n(45)^{*} B$ ph[45] Bin_tot[75] $=n(7)^{*} B \_$tot $[7]+n(10)^{*} B \_$tot $[10]+n(11)^{*} B \_$tot $[11]+n(47)^{*} B \_$tot $[47]+n(53)^{*} B \_$tot $[53]+n(36)^{*} B \_$tot $[36]+n(48)^{*} B \_$tot $[48]+n($ $43)^{\star} B$ tot [43]+n(23)*B_tot[23]

Bout tot[75] $=n(8)^{*} B$ tot $[8]+n(11)^{*} B$ tot $[11]+n(12)^{*} B$ tot $[12]+n(48)^{*} B$ tot[48]+n(54)*B tot[54]+n(37)* $B$ tot[37]+n(45)* $B$ tot[45] $\mathrm{Bd}[\overline{75}]=$ Bin_tot[75]-Bout_tot[75]-W[75]

Epsilon Bph[75] $=0$

Epsilon_Btot[75] $=\left(n(7)^{*}\left(B \_t o t[8]-B \_t o t[7]\right)+n(10)^{*}\left(B \_t o t[11]-B \_t o t[10]\right)+n(47)^{\star}\left(B \_t o t[48]-B \_t o t[47]\right)-\right.$

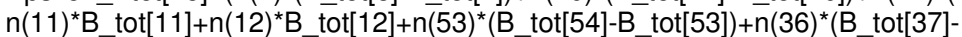

B_tot[36] $) /\left(n(43)^{*} B \_t o t[43]+n(23)^{*} B \_t o t[23]+n(48)^{*} B \_t o t[48]-W[75]-n(45)^{*} B\right.$ _tot [45])

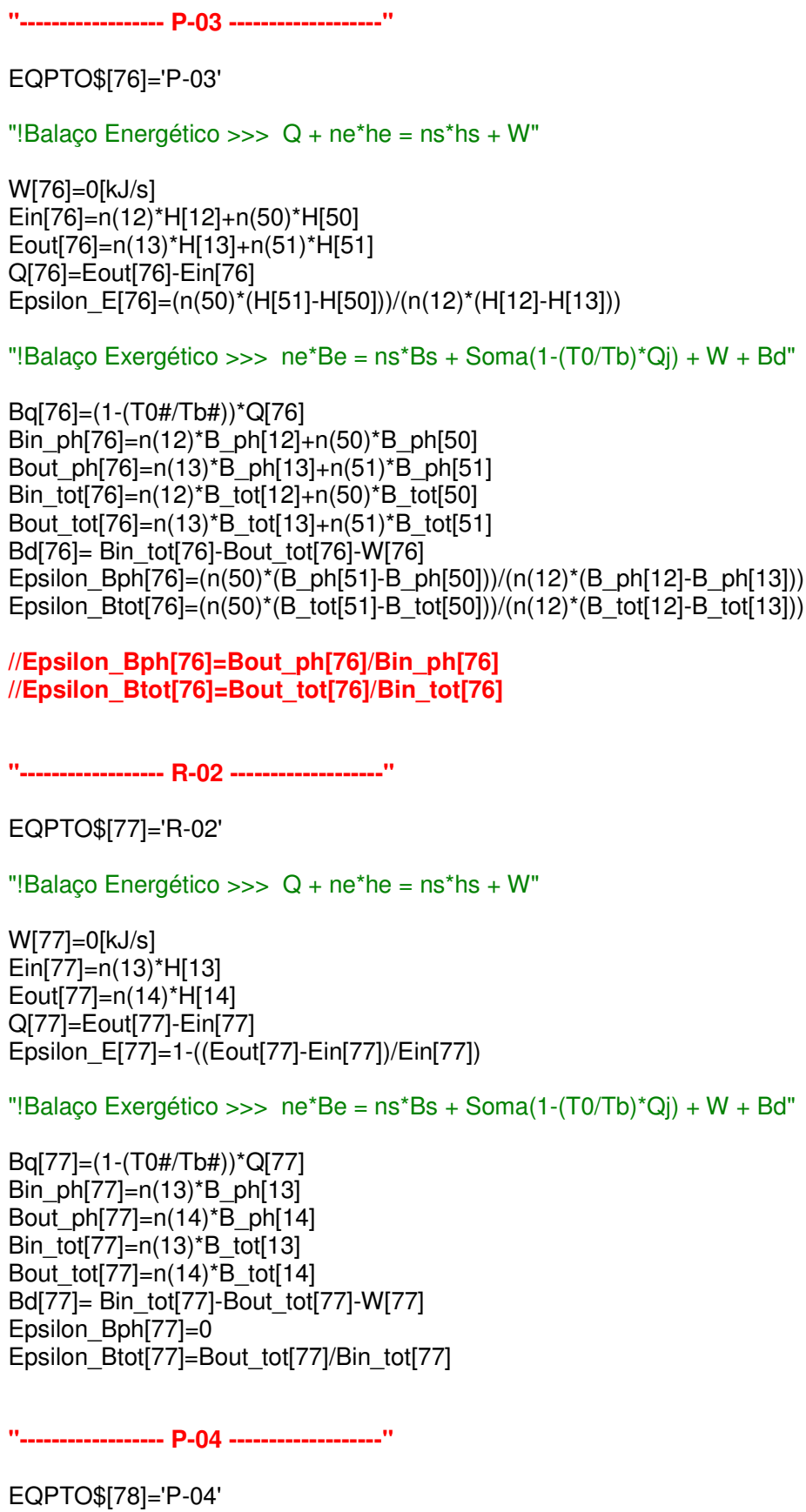


"!Balaço Energético > > Q + ne*he =ns*hs + W"

$\mathrm{W}[78]=0[\mathrm{~kJ} / \mathrm{s}]$

$\operatorname{Ein}[78]=n(14)^{*} H[14]+n(34)^{*} H[34]$

Eout[78] $=n(15)^{*} H[15]+n(35)^{\star} H[35]$

Q[78]=Eout[78]-Ein[78]

Epsilon_E[78] $=\left(n(34)^{*}(H[35]-H[34])\right) /\left(n(14)^{*}(H[14]-H[15])\right)$

"!Balaço Exergético >>> ne*Be $=n s^{*} B s+\operatorname{Soma}\left(1-(T 0 / T b)^{*} \mathrm{Q} j\right)+\mathrm{W}+\mathrm{Bd} "$

$\mathrm{Bq}[78]=(1-(\mathrm{TO} \# / \mathrm{Tb} \#))^{*} \mathrm{Q}[78]$

Bin $p h[78]=n(14)^{*} B$ ph[14]+n(34)*B ph[34]

Bout_ph[78] $=n(15)^{*}$ B_ph[15] $+n(35)^{*} B \_p h[35]$

Bin_tot[78] $=n(14)^{*} B$ tot $[14]+n(34)^{*} B \_$tot [34]

Bout tot[78]=n(15)*B tot $[15]+n(35)^{*} B$ tot [35]

$\mathrm{Bd}[7 \overline{8}]=$ Bin_tot[78]-Bout_tot[78]-W[78]

Epsilon_Bph[78] $=\left(n(35)^{\star}\left(B \_p h[35]-B \_p h[34]\right)\right) /\left(n(15)^{*}(B \quad p h[14]-B \quad p h[15])\right)$

Epsilon_Btot[78] $=\left(\mathrm{n}(35)^{*}\left(\mathrm{~B} \_\right.\right.$tot[35]-B_tot[34] $\left.)\right) /\left(\mathrm{n}(15)^{*}\left(\mathrm{~B} \_\right.\right.$tot[14]-B_tot[15] $\left.)\right)$

"----------------- P-05 ------------------"

EQPTO\$79]='P-05'

"!Balaço Energético $>>>\mathrm{Q}+$ ne*he $=$ ns*hs + W"

$\mathrm{W}[79]=0[\mathrm{~kJ} / \mathrm{s}]$

$\operatorname{Ein}[79]=n(15)^{*} \mathrm{H}[15]+\mathrm{n}(30)^{*} \mathrm{H}[30]$

Eout $[79]=n(16)^{*} \mathrm{H}[16]+n(57)^{*} \mathrm{H}[57]$

Q[79]=Eout[79]-Ein[79]

Epsilon_E[79] $=\left(n(30)^{\star}(H[57]-H[30])\right) /\left(n(15)^{\star}(H[15]-H[16])\right)$

"!Balaço Exergético >>> ne*Be $=n s^{*} \mathrm{Bs}+\operatorname{Soma}\left(1-(\mathrm{TO} / \mathrm{Tb})^{*} \mathrm{Qj}\right)+\mathrm{W}+\mathrm{Bd}$ "

$\mathrm{Bq}[79]=(1-(\mathrm{T} 0 \# / \mathrm{Tb} \#))^{*} \mathrm{Q}[79]$

Bin_ph[79] $=n(15)^{*} B \_p h[15]+n(30)^{*} B \_p h[30]$

Bout ph[79] $=n(16)^{*} B$ ph[16] $+n(57)^{*} B$ ph[57]

Bin_tot[79] $=n(15)^{*} B$ tot $[15]+n(30)^{*} B$ _tot[30]

Bout_tot[79] $=n(16)^{*} \bar{B}$ _tot $[16]+n(57)^{*} \bar{B}$ tot $[57]$

$\mathrm{Bd}[79]=$ Bin tot[79]-Bout_tot[79]-W[79]

Epsilon_Bph[79] $=\left(n(30)^{*}\left(B \_p h[57]-B \_p h[30]\right)\right) /\left(n(15)^{*}\left(B \_p h[15]-B \_p h[16]\right)\right)$

Epsilon_Btot[79] $=\left(\mathrm{n}(30)^{*}\left(\mathrm{~B}\right.\right.$ _tot $[57]-\mathrm{B} \_$tot $\left.\left.[30]\right)\right) /\left(\mathrm{n}(15)^{*}(\mathrm{~B}\right.$ _tot[15]-B_tot[16] $\left.)\right)$

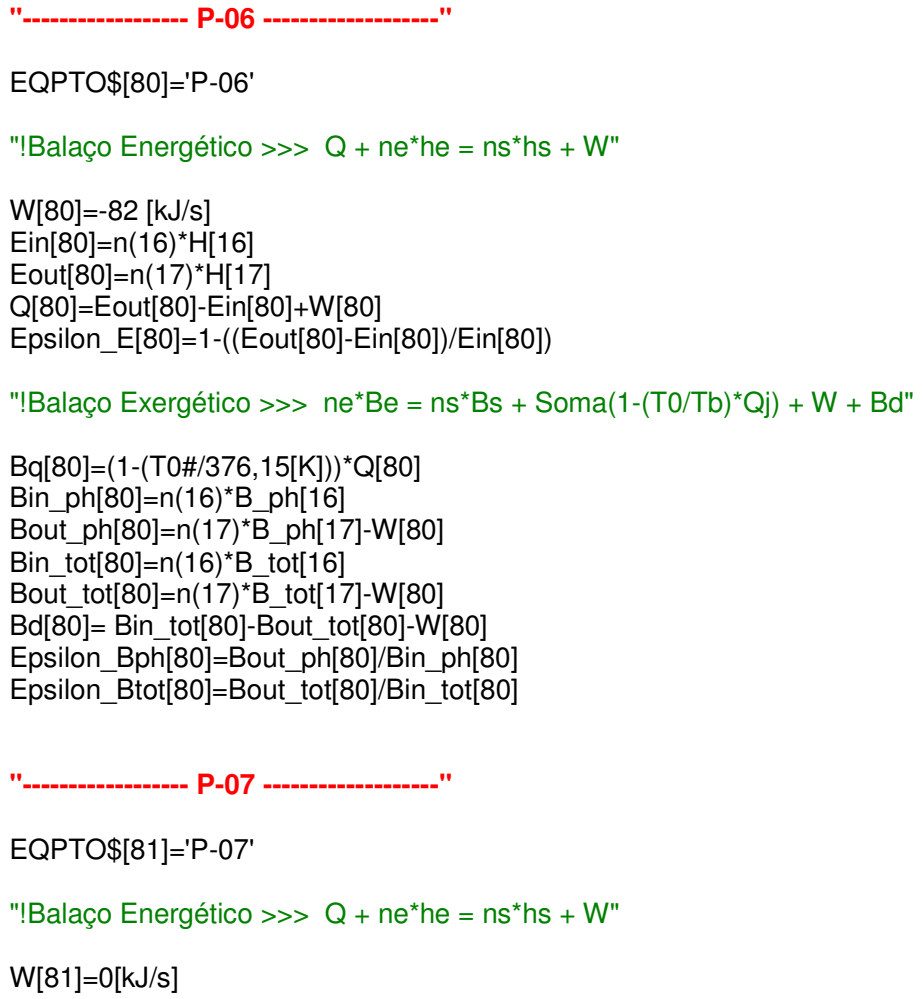

$\mathrm{W}[81]=0[\mathrm{~kJ} / \mathrm{s}]$ 
$\operatorname{Ein}[81]=n(17)^{*} H[17]+n(19)^{*} H[19]$

Eout [81] $=n(18)^{*} H[18]+n(20)^{*} H[20]$

Q[81]=Eout[81]-Ein[81]

Epsilon_E[81] $=\left(n(19)^{*}(H[20]-H[19])\right) /\left(n(17)^{*}(H[17]-H[18])\right)$

"!Balaço Exergético $\gg>>n{ }^{*} \mathrm{Be}=\mathrm{ns}^{*} \mathrm{Bs}+\mathrm{Soma}\left(1-(\mathrm{TO} / \mathrm{Tb})^{*} \mathrm{Q} \mathrm{j}\right)+\mathrm{W}+\mathrm{Bd}$ "

$\mathrm{Bq}[81]=(1-(\mathrm{T} 0 \# / \mathrm{Tb} \#))^{*} \mathrm{Q}[81]$

Bin_ph[81] =n(17)*B_ph[17] $+n(19)^{*} B \_p h[19]$

Bout_ph[81] $=n(18)^{*} \bar{B} \_$ph[18] $+n(20)^{*} B \_p h[20]$

Bin tot [81] $=n(17)^{\star} B$ tot[17] $+n(19)^{*} B$ tot[19]

Bout_tot[81] $=\mathrm{n}(18)^{*} \bar{B} \_$tot $[18]+\mathrm{n}(20)^{*} \bar{B} \_$tot[20]

$\mathrm{Bd}[81]=$ Bin tot[81]-Bout tot[81]-W[81]

Epsilon_Bph[81] $=\left(\mathrm{n}(19)^{*}\left(\mathrm{~B} \_\mathrm{ph}[19]-\mathrm{B} \_p h[20]\right)\right) /\left(\mathrm{n}(18)^{*}\left(\mathrm{~B} \_\mathrm{ph}[18]-\mathrm{B} \_\mathrm{ph}[17]\right)\right)$

Epsilon_Btot[81] $=\left(n(19)^{*}\left(B \_t o t[19]-B \_t o t[20]\right)\right) /\left(n(18)^{*}\left(B \_t o t[18]-B \_t o t[17]\right)\right)$

"---------------- V-05 -------------------"

EQPTO\$[82]='V-05'

"!Balaço Energético >>> Q + ne*he =ns*hs + W"

$\mathrm{W}[82]=0[\mathrm{~kJ} / \mathrm{s}]$

$\operatorname{Ein}[82]=n(18)^{*} \mathrm{H}[18]$

Eout[82] $=n(21)^{*} H[21]+n(24)^{\star} H[24]$

$\mathrm{Q}[82]=$ Eout[82]-Ein[82]+W[82]

Epsilon_E[82]=Eout[82]/Ein[82]

"!Balaço Exergético >>> ne*Be $=n s^{*} \mathrm{Bs}+\mathrm{Soma}\left(1-(\mathrm{TO} / \mathrm{Tb})^{*} \mathrm{Qj}\right)+\mathrm{W}+\mathrm{Bd} "$

$\mathrm{Bq}[82]=(1-(\mathrm{T} 0 \# / \mathrm{Tb} \#))^{*} \mathrm{Q}[82]$

Bin_ph[82]=n(18)*B ph[18]

Bout_ph[82] $=n(21)^{*}$ B_ph[21] $+n(24)^{*} B \_p h[24]$

Bin_tot[82] $=n(18)^{*} B$ tot $[18]$

Bout tot[82] $=n(21)^{*} B$ tot[21] $+n(24)^{*} B$ tot[24]

$\mathrm{Bd}[82]=$ Bin_tot[82]-Bout_tot[82]-Bq[82]-W[82]

Epsilon Bph[82]=Bout ph[82]/Bin ph[82]

Epsilon_Btot[82]=Bout_tot[82]/Bin_tot[82]

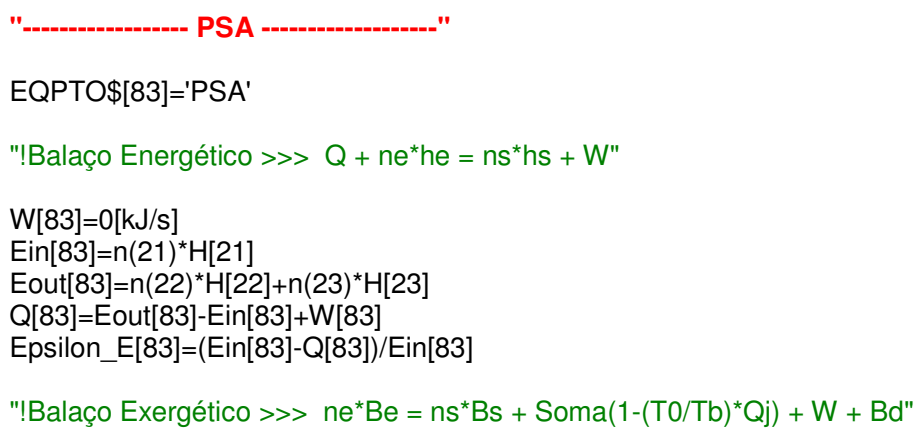

"! Balaço Energético >>> Q + ne*he $=n s^{*} h s+$ W"

$\mathrm{W}[83]=0[\mathrm{~kJ} / \mathrm{s}]$

$\operatorname{Ein}[83]=n(21)^{*} \mathrm{H}[21]$

Eout[83] $=n(22)^{*} H[22]+n(23)^{*} H[23]$

Q[83]=Eout[83]-Ein[83]+W[83]

Epsilon_E[83] $=(\operatorname{Ein}[83]-Q[83]) / E i n[83]$

"!Balaço Exergético >> ne* Be $=n s^{*} \mathrm{Bs}+\mathrm{Soma}\left(1-(\mathrm{TO} / \mathrm{Tb})^{*} \mathrm{Q} \mathrm{j}\right)+\mathrm{W}+\mathrm{Bd}$ "

$\mathrm{Bq}[83]=(1-(\mathrm{T} 0 \# / \mathrm{Tb} \#))^{*} \mathrm{Q}[83]$

Bin ph[83] $=n(21)^{*} B$ ph[21]

Bout_ph[83] $=n(22)^{*} B \_p h[22]+n(23)^{*} B \_p h[23]$

Bin_tot[83] $=n(21)^{*} B$ tot [21]

Bout tot[83] $=n(22)^{*} B$ tot[22] $+n(23)^{*} B$ tot[23]

$\mathrm{Bd}[83]=$ Bin_tot[83]-Bout_tot[83]-W[83]

Epsilon Bph[83]=Bout_ph[83]/Bin_ph[83]

Epsilon_Btot[83]=Bout_tot[83]/Bin_tot[83]

"

$$
\text { VALVE-01 }
$$

EQPTO\$[84]='VALVE-01'

"!Balaço Energético $>>>Q+n e^{*} h e=n s^{*} h s+W "$

$\mathrm{W}[84]=0[\mathrm{~kJ} / \mathrm{s}]$

$\operatorname{Ein}[84]=n(24)^{\star} H[24]$

Eout[84] $=n(25)^{*} \mathrm{H}[25]$

$\mathrm{Q}[84]=$ Eout[84]-Ein[84]+W[84]

Epsilon_E[84] $=(\operatorname{Ein}[84]-Q[84]) / \operatorname{Ein}[84]$ 
"!Balaço Exergético >> ne ${ }^{*} \mathrm{Be}=\mathrm{ns}{ }^{*} \mathrm{Bs}+\mathrm{Soma}\left(1-(\mathrm{TO} / \mathrm{Tb})^{*} \mathrm{Q} \mathrm{j}\right)+\mathrm{W}+\mathrm{Bd} "$

$B q[84]=(1-(T 0 \# / T b \#))^{*} Q[84]$

Bin ph $[84]=n(24)^{*} B$ ph[24]

Bout ph[84] $=n(25)^{\star} B$ ph[25]

Bin_tot[84]=n(24)*B_tot[24]

Bout tot $[84]=n(25)^{*} B$ tot $[25$

$\mathrm{Bd}[84]=$ Bin_tot[84]-Bout_tot[84]-W[84]

Epsilon_Bph[84]=Bout_ph[84]/Bin_ph[84]

Epsilon_Btot[84]=Bout_tot[84]/Bin_tot[84]

"----------------- P-08 ------------------"

EQPTO\$[85]='P-08'

"!Balaço Energético >>> Q + ne*he $=n s^{*} h s+$ W"

$\mathrm{W}[85]=0[\mathrm{~kJ} / \mathrm{s}]$

$\operatorname{Ein}[85]=n(25)^{\star} H[25]+n(27)^{\star} H[27]$

Eout $[85]=n(26)^{*} H[26]+n(28)^{*} H[28]$

$\mathrm{Q}[85]=$ Eout[85]-Ein[85]+W[85]

Epsilon_E[85] $=\left(n(25)^{*}(H[26]-H[25])\right) /\left(n(27)^{\star}(H[27]-H[28])\right)$

"!Balaço Exergético $\gg>>n{ }^{*} \mathrm{Be}=\mathrm{ns}^{*} \mathrm{Bs}+\mathrm{Soma}\left(1-(\mathrm{TO} / \mathrm{Tb})^{*} \mathrm{Q} \mathrm{j}\right)+\mathrm{W}+\mathrm{Bd}$ "

$\mathrm{Bq}[85]=(1-(\mathrm{T} 0 \# / \mathrm{Tb} \#))^{*} \mathrm{Q}[85]$

Bin_ph[85] $=n(25)^{*} B \_p h[25]+n(27)^{*} B \_p h[27]$

Bout_ph[85] $=n(26)^{*}$ B $\_$ph[26] $+n(28)^{*}$ B $\_$ph[28]

Bin tot $[85]=n(25)^{*} B$ tot[25] $+n(27)^{*} B$ tot[27]

Bout_tot[85]=n(26)* $\bar{B}_{\text {_tot }}[26]+\mathrm{n}(28)^{*} \overline{\mathrm{B}}$ _tot[28]

$\mathrm{Bd}[85]=$ Bin tot[85]-Bout tot[85]-W[85]

Epsilon_Bph[85] $=\left(\mathrm{n}(26)^{*}\left(\mathrm{~B} \_p h[26]-B \_p h[25]\right)\right) /\left(\mathrm{n}(27)^{*}\left(\mathrm{~B} \_p h[27]-B \_p h[28]\right)\right)$

Epsilon_Btot[85] $=\left(\mathrm{n}(26)^{*}(\mathrm{~B}\right.$ _tot[26]-B_tot[25]) $) /\left(\mathrm{n}(27)^{*}\left(\mathrm{~B}_{-}\right.\right.$tot[27]-B_tot[28] $\left.)\right)$

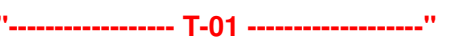

EQPTO\$[86]='T-01'

"!Balaço Energético > > Q + ne*he =ns*hs + W"

$\mathrm{W}[86]=0[\mathrm{~kJ} / \mathrm{s}]$

$\operatorname{Ein}[86]=n(26)^{*} H[26]+n(31)^{*} H[31]$

Eout $[86]=n(27)^{*} H[27]+n(32)^{*} H[32]$

Q[86]=Eout[86]-Ein[86]+W[86]

Epsilon_E[86]=Eout[86]/Ein[86]

"!Balaço Exergético >>> ne*Be $=n s^{*} B s+\operatorname{Soma}\left(1-(T 0 / T b)^{*} \mathrm{Qj}\right)+\mathrm{W}+\mathrm{Bd} "$

$\mathrm{Bq}[86]=(1-(\mathrm{TO} \# / \mathrm{Tb} \#))^{*} \mathrm{Q}[86]$

Bin $p h[86]=n(26)^{*} B$ ph[26] $+n(31)^{*} B$ ph[31]

Bout_ph[86] $=n(27)^{*} B \_p h[27]+n(32)^{*} B \_p h[32]$

Bin_tot $[86]=n(26)^{*} B$ tot $[26]+n(31)^{*} B$ tot [31]

Bout tot[86] $=n(27)^{*} B$ tot[27] $+n(32)^{*} B$ tot[32]

$\mathrm{Bd}[86]=$ Bin_tot[86]-Bout_tot[86]-W[86]

Epsilon_Bph[86]=Bout_ph[86]/Bin_ph[86]

Epsilon_Btot[86]=Bout_tot[86]/Bin_tot[86]

"-------------- V-03 ----------------"

EQPTO\$87]='V-03'

"!Balaço Energético >>> Q + ne*he = ns*hs + W"

$\mathrm{W}[87]=-45[\mathrm{~kJ} / \mathrm{s}]$

$\operatorname{Ein}[87]=n(35)^{\star} H[35]+n(51)^{*} H[51]+n(54)^{*} H[54]$

Eout[87] $=n(36)^{*} H[36]+n(42)^{*} H[42]+n(50)^{*} H[50]+n(53)^{*} H[53]$

$\mathrm{Q}[87]=$ Eout[87]-Ein[87]+W[87]

Epsilon_E[87]=Eout[87]/Ein[87]

"!Balaço Exergético >> ne*Be $=n s^{*} \mathrm{Bs}+\mathrm{Soma}\left(1-(\mathrm{TO} / \mathrm{Tb})^{*} \mathrm{Qj}\right)+\mathrm{W}+\mathrm{Bd} "$

$\mathrm{Bq}[87]=(1-(\mathrm{T} 0 \# / \mathrm{Tb} \#))^{*} \mathrm{Q}[87]$ 
Bin_ph[87] $=n(35)^{*} B \_p h[35]+n(51)^{*} B \_p h[51]+n(54)^{*} B \_p h[54]$

Bout_ph[87] $=n(36)^{*}$ B_ph[36] $+n(42)^{*} B \_p h[42]+n(50)^{*}$ B_ph[50] $+n(53)^{*} B \_p h[53]-W[87]$

Bin tot[87] $=n(35)^{*} B$ tot[35] $+n(51)^{*} B$ tot[51] $+n(54)^{*} B$ tot[54]-W[87]

Bout_tot[87] $=n(36)^{*} \bar{B}$ tot [36] $+n(42)^{*} \bar{B}$ tot [42] $+n(50)^{*} \bar{B}_{-}$tot[50] $+n(53)^{*} B$ _tot[53]

$\mathrm{Bd}[87]=$ Bin_tot[87]-Bout_tot[87]-W[87]

Epsilon_Bph[87]=Bout_ph[87]/Bin ph[87]

Epsilon_Btot[87]=Bout_tot[87]/Bin_tot[87]

"----------------- V-04 -------------------""

EQPTO\$[88]='V-04'

"!Balaço Energético >>> Q + ne*he =ns*hs + W"

$\mathrm{W}[88]=0[\mathrm{~kJ} / \mathrm{s}]$

$\operatorname{Ein}[88]=n(42)^{*} H[42]$

Eout $[88]=n(59)^{*} \mathrm{H}[59]$

Q[88]=Eout[88]-Ein[88]+W[88]

Epsilon_E[88] $=(\operatorname{Ein}[88]-Q[88]) / E i n[88]$

"!Balaço Exergético >> ne* Be $=n s^{*} B s+\operatorname{Soma}\left(1-(T 0 / T b)^{*} \mathrm{Qj}\right)+\mathrm{W}+\mathrm{Bd} "$

$\mathrm{Bq}[88]=(1-(\mathrm{T} 0 \# / \mathrm{Tb} \#))^{*} \mathrm{Q}[88]$

Bin $p h[88]=n(42)^{*} B$ ph[42]

Bout ph[88] $=n(59)^{*} B$ ph[59]

Bin_tot[88]=n(42)*B_tot[42]

Bout tot $[88]=n(59)^{*} \mathrm{~B}$ tot[59]

$\mathrm{Bd}[8 \overline{8}]=$ Bin_tot[88]-Bout_tot[88]-W[88]

Epsilon Bph[88]=Bout ph [88]/Bin ph[88

Epsilon Btot[88]=Bout tot[88]/Bin tot[88]

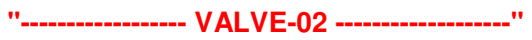

EQPTO\$[89]='VALVE-02'

"!Balaço Energético $>>>Q+n e^{*} h e=n s^{*} h s+$ W"

$W[89]=0[\mathrm{~kJ} / \mathrm{s}]$

$\operatorname{Ein}[89]=n(56)^{*} \mathrm{H}[56]$

Eout[89] $=n(30)^{*} \mathrm{H}[30]$

$\mathrm{Q}[89]=$ Eout[89]-Ein[89]+W[89]

Epsilon_E[89] $=(\operatorname{Ein}[89]-Q[89]) / \operatorname{Ein}[89]$

"!Balaço Exergético > > ne* $\mathrm{Be}=\mathrm{ns}^{*} \mathrm{Bs}+\mathrm{Soma}\left(1-(\mathrm{TO} / \mathrm{Tb})^{*} \mathrm{Q} \mathrm{j}\right)+\mathrm{W}+\mathrm{Bd} "$

$\mathrm{Bq}[89]=(1-(\mathrm{TO} \# / \mathrm{Tb} \#))^{*} \mathrm{Q}[89]$

Bin_ph[89] $=n(56)^{*} B \_p h[56]$

Bout_ph[89]=n(30)*B. $\mathrm{B} \_$ph[30]

Bin tot $[89]=n(56)^{*} B$ tot[56]

Bout_tot $[89]=n(30)^{*} \bar{B} \_$tot $[30]$

$\mathrm{Bd}[89]=$ Bin tot[89]-Bout tot[89]-W[89]

Epsilon_Bph[89]=Bout_ph[89]/Bin_ph[89]

Epsilon_Btot[89]=Bout_tot[89]/Bin_tot[89]

"----------------- UGH

EQPTO\$69]='UGH'

Epsilon Btot[69] $=\left(n(20)^{*} B\right.$ tot [20]+n(22)* $B$ tot[22] $+n(28)^{*} B$ tot[28] $n(32)^{*} B$ tot[32] $n(45)^{*} B$ tot[45]+n(55) ${ }^{*} B$ tot $[55]+n(58)^{*} B$ t ot $\left.[58]+n(59)^{*} B \_t 0 t[59]\right) /\left(n(1)^{*} B \_t o t[1]+n(6)^{*} B \_t o t[6]+n(19)^{*} B \_t o t[19]+n(43)^{*} B \_t o t[43]+n(46)^{*} B \_t o t[46]+n(60)^{*} B \_t o t[60]\right)$

|||||||||||||||||||||||||||||||||||||||||||||||||||||||||||||||||||||||||||||||

"Custos anualizados dos equipamentos"

"!Como não existe unidade monetária no EES, optou-se por deixar os valores

.. financeiros como sendo adimensionais [dim]"

hpyr $=8400[\mathrm{~h}]$

"!Um dos custos abaixo deve estar entre colchetes (comentáio) para que o

. programa funcione. Oscustos de fora dos colchetes serão considerados pelo programa"

"!Custos atualizados" 


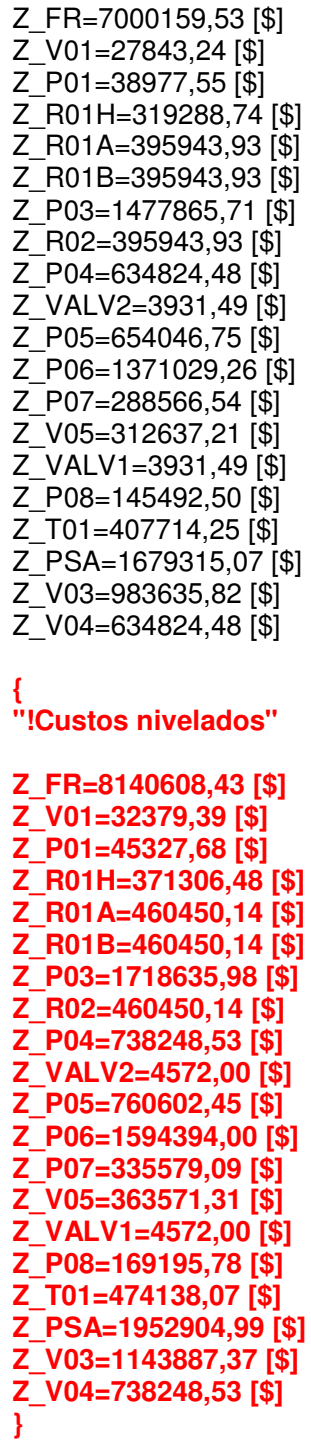

"!FLev é o fator de levelization (nivelamento), com i=4,5\% a.a. (inflação prevista) .. e tempo de amort. de 20 anos. É utilizado para transformar os custos atualizados .. em custos nivelados"

FLev $=1$ [dim] "!* 1,5375228865[dim]"

CustoEletricidade $=4,68611 \mathrm{E}-5[\$ / \mathrm{kJ}]^{*} \mathrm{FLev}$

CustoGasNatual $=9,1136 \mathrm{E}-6[\$ / \mathrm{kJ}]^{*} \mathrm{FLev}$

CustoAguaDesmi $=\left(1,10 \mathrm{E}-3[\$ / \mathrm{kg}]^{*} 18,015[\mathrm{~kg} / \mathrm{kmol}] / \text { B_tot[60] }\right)^{*} \mathrm{FLev}$ CustoAguaResfriam $=\left(0,11 \mathrm{E}-3[\$ / \mathrm{kg}]^{\star} 18,015[\mathrm{~kg} / \mathrm{kmol}] / \mathrm{B}_{\text {_tot}}[19]\right)^{\star} \mathrm{FLev}$

"!Matriz de custo"

W_fan $=560[\mathrm{~kJ} / \mathrm{s}]$

W_P06 $=82[\mathrm{~kJ} / \mathrm{s}]$

W_Compr $=45[\mathrm{~kJ} / \mathrm{s}]$

$\mathrm{Tsph}=3600[\mathrm{~s}] / 1[\mathrm{~h}]$

"!Definindo a Matriz de custo A"

"!1 - Coluna c_el"

$\mathrm{A}[1 ; 1]=\mathrm{W}$ fan ${ }^{\star} T$ sph

$A[2 ; 1]=0$

$A[3 ; 1]=0$

$A[4 ; 1]=0$

$A[5 ; 1]=0$

$A[6 ; 1]=0$ 


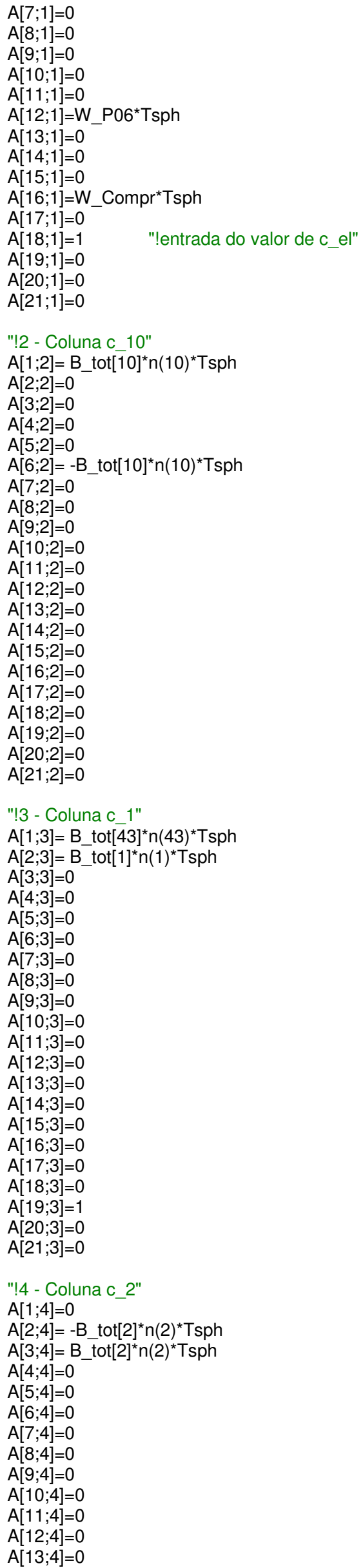




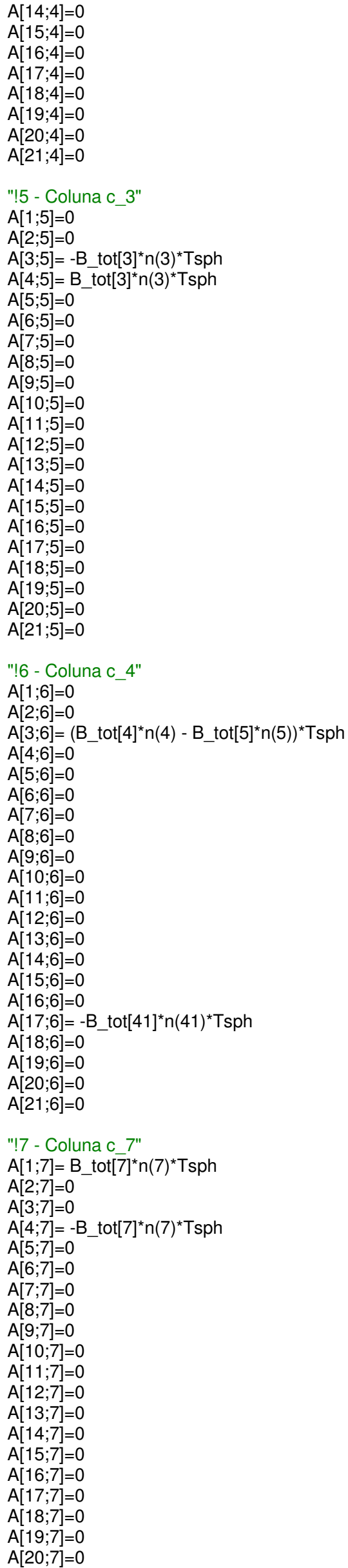


$\mathrm{A}[21 ; 7]=0$

"!8 - Coluna c 9"

$A[1 ; 8]=0$

$A[2 ; 8]=0$

$A[3 ; 8]=0$

$A[4 ; 8]=0$

$A[5 ; 8]=-B$ tot $[9]^{*} n(9)^{\star} T s p h$

$A[6 ; 8]=$ B_tot $[9]^{*} n(9)^{*} T s p h$

$A[7 ; 8]=0$

$A[8 ; 8]=0$

$A[9 ; 8]=0$

$\mathrm{A}[10 ; 8]=0$

$A[11 ; 8]=0$

$\mathrm{A}[12 ; 8]=0$

$\mathrm{A}[13 ; 8]=0$

$A[14 ; 8]=0$

$A[15 ; 8]=0$

$\mathrm{A}[16 ; 8]=0$

$A[17 ; 8]=0$

$\mathrm{A}[18 ; 8]=0$

$A[19 ; 8]=0$

$\mathrm{A}[20 ; 8]=0$

$\mathrm{A}[21 ; 8]=0$

"!9 - Coluna c 37"

$A[1 ; 9]=-\operatorname{sph}^{\bar{*}}\left(B \_t 0 t[8]^{*} n(8)+B \_t o t[12]^{*} n(12)+B \_t o t[37]^{*} n(37)+B \_t o t[54]^{\star} n(54)\right)$

$A[2 ; 9]=0$

$A[3 ; 9]=0$

$A[4 ; 9]=0$

$\mathrm{A}[5 ; 9]=$ B_tot $[8]^{*} \mathrm{n}(8)^{*}$ Tsph

$\mathrm{A}[6 ; 9]=\mathrm{B} \_$tot $[39]^{*} \mathrm{n}(39)^{*} \mathrm{~T}$ sph

$A[7 ; 9]=B$ tot $[12]^{*} n(12)^{\star} T$ sph

$\mathrm{A}[8 ; 9]=0$

$A[9 ; 9]=0$

$\mathrm{A}[10 ; 9]=0$

$A[11 ; 9]=0$

$\mathrm{A}[12 ; 9]=0$

$\mathrm{A}[13 ; 9]=0$

$A[14 ; 9]=0$

$\mathrm{A}[15 ; 9]=0$

A[16;9]= B_tot[54] ${ }^{*} n(54)^{*} T s p h$

$A[17 ; 9]=B$ tot $[38]^{*} n(38)^{\star} T s p h$

$A[18 ; 9]=0$

$A[19 ; 9]=0$

$\mathrm{A}[20 ; 9]=0$

$A[21 ; 9]=0$

"!10 - Coluna c 36"

$A[1 ; 10]=\operatorname{Tsph}^{*}\left(B_{-}\right.$tot $\left.[36]^{*} n(36)+B \_t o t[53]^{*} n(53)\right)$

$\mathrm{A}[2 ; 10]=0$

$\mathrm{A}[3 ; 10]=0$

$\mathrm{A}[4 ; 10]=0$

$\mathrm{A}[5 ; 10]=0$

$A[6 ; 10]=0$

$A[7 ; 10]=B$ tot $[50]^{*} n(50)^{\star} T$ sph

$A[8 ; 10]=0$

$\mathrm{A}[9 ; 10]=0$

$\mathrm{A}[10 ; 10]=0$

$\mathrm{A}[11 ; 10]=0$

$\mathrm{A}[12 ; 10]=0$

$\mathrm{A}[13 ; 10]=0$

$A[14 ; 10]=0$

$\mathrm{A}[15 ; 10]=0$

$A[16 ; 10]=-T \operatorname{sph}^{*}\left(B \_t o t[36]^{*} n(36)+B \_t o t[50]^{*} n(50)+B \_t o t[53]^{*} n(53)\right)$

$\mathrm{A}[17 ; 10]=0$

$\mathrm{A}[18 ; 10]=0$

$A[19 ; 10]=0$

$\mathrm{A}[20 ; 10]=0$

$\mathrm{A}[21 ; 10]=0$

"!11 - Coluna c 13"

$\mathrm{A}[1 ; 11]=0$

$A[2 ; 11]=0$

$A[3 ; 11]=0$

$\mathrm{A}[4 ; 11]=0$ 
$\mathrm{A}[5 ; 11]=0$

$\mathrm{A}[6 ; 11]=0$

$A[7 ; 11]=-T \operatorname{sph}^{*}\left(B \_t o t[13]^{*} n(13)+B\right.$ tot $\left.[51]^{*} n(51)\right)$

$A[8 ; 11]=B \_$tot $[13]^{\star} n(13)^{\star} T$ Tsph

$A[9 ; 11]=0$

$\mathrm{A}[10 ; 11]=0$

$A[11 ; 11]=0$

$A[12 ; 11]=0$

$\mathrm{A}[13 ; 11]=0$

$A[14 ; 11]=0$

$A[15 ; 11]=0$

$\mathrm{A}[16 ; 11]=$ B_tot[51] $]^{*} \mathrm{n}(51)^{\star} \mathrm{Tsph}$

$A[17 ; 11]=0$

$A[18 ; 11]=0$

$A[19 ; 11]=0$

$\mathrm{A}[20 ; 11]=0$

$\mathrm{A}[21 ; 11]=0$

"!12 - Coluna c 14"

$\mathrm{A}[1 ; 12]=0$

$\mathrm{A}[2 ; 12]=0$

$\mathrm{A}[3 ; 12]=0$

$A[4 ; 12]=0$

$\mathrm{A}[5 ; 12]=0$

$A[6 ; 12]=0$

$A[7 ; 12]=0$

$A[8 ; 12]=-B \_t o t[14]^{\star} n(14)^{\star} T s p h$

$A[9 ; 12]=B$ tot $[14]^{*} n(14)^{\star} T s p h$

$\mathrm{A}[10 ; 12]=0$

$\mathrm{A}[11 ; 12]=0$

$\mathrm{A}[12 ; 12]=0$

$\mathrm{A}[13 ; 12]=0$

$A[14 ; 12]=0$

$\mathrm{A}[15 ; 12]=0$

$A[16 ; 12]=0$

$\mathrm{A}[17 ; 12]=0$

$\mathrm{A}[18 ; 12]=0$

$A[19 ; 12]=0$

$\mathrm{A}[20 ; 12]=0$

$\mathrm{A}[21 ; 12]=0$

"!13 - Coluna c_15"

$\mathrm{A}[1 ; 13]=0$

$\mathrm{A}[2 ; 13]=0$

$\mathrm{A}[3 ; 13]=0$

$\mathrm{A}[4 ; 13]=0$

$A[5 ; 13]=0$

$\mathrm{A}[6 ; 13]=0$

$A[7 ; 13]=0$

$A[8 ; 13]=0$

$\left.A[9 ; 13]=-T \operatorname{sph}^{*}\left(B \text { tot }[15]^{*} n(15)+B \text { tot[35] }\right]^{*} n(35)\right)$

$A[10 ; 13]=0$

$A[11 ; 13]=B$ tot $[15]^{*} n(15)^{*} T s p h$

$A[12 ; 13]=0$

$A[13 ; 13]=0$

$\mathrm{A}[14 ; 13]=0$

$A[15 ; 13]=0$

$\mathrm{A}[16 ; 13]=$ B_tot[35] ${ }^{*} \mathrm{n}(35)^{\star} \mathrm{Tsph}$

$A[17 ; 13]=0$

$\mathrm{A}[18 ; 13]=0$

$\mathrm{A}[19 ; 13]=0$

$\mathrm{A}[20 ; 13]=0$

$\mathrm{A}[21 ; 13]=0$

"!14 - Coluna c_60"

$\mathrm{A}[1 ; 14]=0$

$\mathrm{A}[2 ; 14]=0$

$\mathrm{A}[3 ; 14]=0$

$\mathrm{A}[4 ; 14]=0$

$A[5 ; 14]=0$

A $[6 ; 14]=0$

$\mathrm{A}[7 ; 14]=0$

$A[8 ; 14]=0$

$A[9 ; 14]=B$ tot $[34]^{*} n(34)^{*} T s p h$

$A[10 ; 14]=\bar{B}$ _tot $[56]^{*} n(56)^{*} T$ sph

$A[11 ; 14]=0$ 
$A[12 ; 14]=0$

$\mathrm{A}[13 ; 14]=0$

$A[14 ; 14]=0$

$\mathrm{A}[15 ; 14]=0$

$\mathrm{A}[16 ; 14]=0$

$\mathrm{A}[17 ; 14]=\mathrm{B}$ tot $[40]^{*} \mathrm{n}(40)^{*} \mathrm{Tsph}$

$A[18 ; 14]=0$

$A[19 ; 14]=0$

$A[20 ; 14]=1$

$\mathrm{A}[21 ; 14]=0$

"!15 - Coluna c_30"

$\mathrm{A}[1 ; 15]=0$

$A[2 ; 15]=0$

$\mathrm{A}[3 ; 15]=0$

$\mathrm{A}[4 ; 15]=0$

$A[5 ; 15]=0$

$A[6 ; 15]=0$

$A[7 ; 15]=0$

$A[8 ; 15]=0$

$A[9 ; 15]=0$

$\mathrm{A}[10 ; 15]=-B \_$tot $[30]^{*} \mathrm{n}(30)^{*} \mathrm{~T}$ sph $A[11 ; 15]=B$ tot $[30]^{*} n(30)^{\star} T$ sph

$A[12 ; 15]=0$

$A[13 ; 15]=0$

$\mathrm{A}[14 ; 15]=0$

$A[15 ; 15]=0$

$A[16 ; 15]=0$

$A[17 ; 15]=0$

$A[18 ; 15]=0$

$\mathrm{A}[19 ; 15]=0$

$\mathrm{A}[20 ; 15]=0$

$\mathrm{A}[21 ; 15]=0$

"!16 - Coluna c_16"

$\mathrm{A}[1 ; 16]=0$

$\mathrm{A}[2 ; 16]=0$

$\mathrm{A}[3 ; 16]=0$

$\mathrm{A}[4 ; 16]=0$

$A[5 ; 16]=0$

$A[6 ; 16]=0$

$A[7 ; 16]=0$

$\mathrm{A}[8 ; 16]=0$

$\mathrm{A}[9 ; 16]=0$

$\mathrm{A}[10 ; 16]=0$

$A[11 ; 16]=-\operatorname{ssph}^{*}\left(B \_t o t[16]^{*} n(16)+B \_t o t[57]^{*} n(57)\right)$

$A[12 ; 16]=$ B_tot $[16]^{\star} n(16)^{\star}{ }^{\star} T s p h$

$A[13 ; 16]=0$

$\mathrm{A}[14 ; 16]=$ B_tot $[31]^{*} \mathrm{n}(31)^{\star} \mathrm{Tsph}$

$A[15 ; 16]=0$

$\mathrm{A}[16 ; 16]=0$

$A[17 ; 16]=0$

$\mathrm{A}[18 ; 16]=0$

$\mathrm{A}[19 ; 16]=0$

$A[20 ; 16]=0$

$\mathrm{A}[21 ; 16]=0$

"!17 - Coluna c 17"

$\mathrm{A}[1 ; 17]=0$

$A[2 ; 17]=0$

$\mathrm{A}[3 ; 17]=0$

$\mathrm{A}[4 ; 17]=0$

$A[5 ; 17]=0$

$A[6 ; 17]=0$

$\mathrm{A}[7 ; 17]=0$

$\mathrm{A}[8 ; 17]=0$

$\mathrm{A}[9 ; 17]=0$

$\mathrm{A}[10 ; 17]=0$

$A[11 ; 17]=0$

$A[12 ; 17]=-B \_t o t[17]^{\star} n(17)^{\star} T$ sph

$\mathrm{A}[13 ; 17]=\mathrm{B}$ tot$[17]^{*} \mathrm{n}(17)^{\star} \mathrm{Tsph}$

$A[14 ; 17]=0$

$\mathrm{A}[15 ; 17]=0$

$A[16 ; 17]=0$

$\mathrm{A}[17 ; 17]=0$

$\mathrm{A}[18 ; 17]=0$ 
$\mathrm{A}[19 ; 17]=0$

$\mathrm{A}[20 ; 17]=0$

$A[21 ; 17]=0$

"!18 - Coluna c 18"

$\mathrm{A}[1 ; 18]=0$

$\mathrm{A}[2 ; 18]=0$

$A[3 ; 18]=0$

$\mathrm{A}[4 ; 18]=0$

$A[5 ; 18]=0$

$\mathrm{A}[6 ; 18]=0$

$\mathrm{A}[7 ; 18]=0$

$A[8 ; 18]=0$

$\mathrm{A}[9 ; 18]=0$

$\mathrm{A}[10 ; 18]=0$

$A[11 ; 18]=0$

$A[12 ; 18]=0$

$A[13 ; 18]=-B$ tot $[18]^{*} n(18)^{*} T$ sph

$\mathrm{A}[14 ; 18]=B_{\text {_tot }}[18]^{*} \mathrm{n}(18)^{*} \mathrm{Tsph}$

$\mathrm{A}[15 ; 18]=0$

$A[16 ; 18]=0$

$A[17 ; 18]=0$

$A[18 ; 18]=0$

$\mathrm{A}[19 ; 18]=0$

$\mathrm{A}[20 ; 18]=0$

$\mathrm{A}[21 ; 18]=0$

"!19 - Coluna c 19"

$\mathrm{A}[1 ; 19]=0$

$A[2 ; 19]=0$

$\mathrm{A}[3 ; 19]=0$

$\mathrm{A}[4 ; 19]=0$

$A[5 ; 19]=0$

$\mathrm{A}[6 ; 19]=0$

$A[7 ; 19]=0$

$A[8 ; 19]=0$

$\mathrm{A}[9 ; 19]=0$

$A[10 ; 19]=0$

$\mathrm{A}[11 ; 19]=0$

$\mathrm{A}[12 ; 19]=0$

$\mathrm{A}[13 ; 19]=\mathrm{B}$ tot$[19]^{*} \mathrm{n}(19)^{\star} \mathrm{Tsph}$

$A[14 ; 19]=-B \_$tot $[28]^{*} n(28)^{*} T$ sph

$A[15 ; 19]=0$

$A[16 ; 19]=0$

$A[17 ; 19]=0$

$\mathrm{A}[18 ; 19]=0$

$\mathrm{A}[19 ; 19]=0$

$\mathrm{A}[20 ; 19]=0$

$\mathrm{A}[21 ; 19]=1$

"!20 - Coluna c 21"

$\mathrm{A}[1 ; 20]=0$

$\mathrm{A}[2 ; 20]=0$

$\mathrm{A}[3 ; 20]=0$

$\mathrm{A}[4 ; 20]=0$

$\mathrm{A}[5 ; 20]=0$

$\mathrm{A}[6 ; 20]=0$

$A[7 ; 20]=0$

$\mathrm{A}[8 ; 20]=0$

$A[9 ; 20]=0$

$\mathrm{A}[10 ; 20]=0$

$\mathrm{A}[11 ; 20]=0$

$\mathrm{A}[12 ; 20]=0$

$\mathrm{A}[13 ; 20]=0$

$A[14 ; 20]=-B \_$tot $[21]^{*} n(21)^{*} T$ sph

$\mathrm{A}[15 ; 20]=\mathrm{B}$ tot$[21]^{*} \mathrm{n}(21)^{\star} \mathrm{Tsph}$

$A[16 ; 20]=0$

$A[17 ; 20]=0$

$\mathrm{A}[18 ; 20]=0$

$A[19 ; 20]=0$

$\mathrm{A}[20 ; 20]=0$

$A[21 ; 20]=0$

"!21 - Coluna c 22"

$\mathrm{A}[1 ; 21]=$ B_tot[23] ${ }^{*} \mathrm{n}(23)^{\star} \mathrm{Tsph}$ $A[2 ; 21]=0$ 
$A[3 ; 21]=0$

$A[4 ; 21]=B \_t o t[6]^{*} n(6)^{\star} T s p h$

$A[5 ; 21]=0$

$\mathrm{A}[6 ; 21]=0$

$A[7 ; 21]=0$

$A[8 ; 21]=0$

$A[9 ; 21]=0$

$A[10 ; 21]=0$

$\mathrm{A}[11 ; 21]=0$

$\mathrm{A}[12 ; 21]=0$

$A[13 ; 21]=0$

$A[14 ; 21]=0$

$A[15 ; 21]=-T \operatorname{sph}^{*}\left(B \operatorname{tot}[22]^{*} n(22)+B \operatorname{tot}[23]^{*} n(23)\right)$

$\mathrm{A}[16 ; 21]=0$

$A[17 ; 21]=0$

$A[18 ; 21]=0$

$A[19 ; 21]=0$

$A[20 ; 21]=0$

$A[21 ; 21]=0$

"!1 - Vetor B - sistema"

$\mathrm{B}[1]=-Z$ Z FR/hpyr

$\mathrm{B}[2]=-\mathrm{Z} \_\mathrm{V} 01 / \mathrm{hpyr}$

$B[3]=-Z$ Z P01/hpyr

$\mathrm{B}[4]=0$

$B[5]=-\left(Z \_R 01 H+Z \_R 01 A+Z \_R 01 B\right) / h p y r$

$\mathrm{B}[6]=0$

$\mathrm{B}[7]=-Z \quad \mathrm{P03} / \mathrm{hpyr}$

$\mathrm{B}[8]=-Z_{-} \mathrm{R} 02 / \mathrm{hpyr}$

$\mathrm{B}[9]=-Z$ P04/hpyr

$\mathrm{B}[10]=-\bar{Z} \_\mathrm{VALV} 2 / \mathrm{hpyr}$

$\mathrm{B}[11]=-Z$ PO5 $/$ hpyr

$B[12]=-Z$ P06/hpyr

$B[13]=-Z-P 07 / h p y r$

$\mathrm{B}[14]=-(\mathrm{Z}$ V05 + Z VALV1 + Z P08 + Z T01)/hpyr

$\mathrm{B}[15]=-Z$ PSA $/$ hpyr

$\mathrm{B}[16]=-\left(\bar{Z} \_\right.$V03+Z_V04)/hpyr

$\mathrm{B}[17]=0$

$\mathrm{B}[18]=$ CustoEletricidade

$\mathrm{B}[19]=$ CustoGasNatual

$\mathrm{B}[20]=$ CustoAguaDesm

$\mathrm{B}[21]=$ CustoAguaResfriam

"!Fazendo $\left.B=A^{*} C E x\right] "$

DUPLICATE $\mathrm{i}=1 ; 21$

END

$B[i]=\operatorname{sum}\left(A[i ; k]^{*} \operatorname{CEx}[k] ; k=1 ; 21\right)$

"!Custo de produção total"

"!Custo dos fluxos de saída da planta"

Produto\$[1]='Hidrogênio (pto 22)'

CustoExergetico[1]=CEx[21]

CustoTot[1] =CEx[21]*B tot[22] ${ }^{*} n$ tot[22] ${ }^{\star} T$ sph

CustoMolar[1]=CustoTot[1]/(n_tot[22] ${ }^{*}$ Tsph)

CustoTon[1] =1000[dim] ${ }^{*}$ CustoMolar[1]/MM_H2\#

Produto\$[2]='Condensado exportado (pto 28)'

CustoExergetico[2]=CEx[19]

CustoTot[2]=CEx[19] ${ }^{*} B$ tot[28] ${ }^{*}$ _tot[28 ${ }^{*}$ Tsph

CustoMolar[2]=CustoTot[2]/(n_tot[28 ${ }^{*}$ Tsph)

CustoTon[2]=1000[dim] ${ }^{*}$ CustoMolar[2]/MM_H2O\#

Produto $\$[3]='$ Vapor de baixa (pto 58)'

CustoExergetico[3]=CEx[16]

CustoTot[3] $=$ CEx[16] ${ }^{*} B$ _tot[58 $]^{*}$ _ttot[58 $]^{*} T$ sph

CustoMolar[3]=CustoTot[3]/(n tot[58 ${ }^{*}$ Tsph)

CustoTon[3] =1000[dim] ${ }^{*}$ CustoMolar[3]/MM_H2O\#

Produto\$[4]='Condensado exportado (pto 5)'

CustoExergetico[4]=CEx[6]

CustoTot[4]=CEx[6] ${ }^{*}$ B_tot[5] ${ }^{*}$ _tot[5] ${ }^{*}$ Tsph 
CustoMolar[4]=CustoTot[4]/(n_tot[5] $]^{\star}$ Tsph)

CustoTon[4] $=1000[\mathrm{dim}]^{*}$ CustoMolar[4]/MM_H2O\#

Produto\$[5]='Vapor a 15 bar (pto 55)'

CustoExergetico[5]=CEx[6]

CustoTot[5]=CEx[6] $]^{*} B$ tot $[55]^{*} n$ tot[55 $]^{*} T$ sph

CustoMolar[5]=CustoTot[5]/(n_tot[55]*Tsph)

CustoTon[5]=1000[dim $]^{*}$ CustoMolar[5]/MM H2O\#

"!Custo do fluxo com potencial para melhoria de aproveitamento (vapor superaquecido)"

Produto $\$[17]='$ Vapor a superaquecido (pto 38)'

CustoExergetico[17]=CEx[9]

CustoTot[17]=CEx[9]*B_tot[38] $]^{*} n \_t o t[38]^{*} T$ sph

CustoMolar[17] =CustoTot[17]/(n ${ }^{-}$tot[38 $]^{\star}$ Tsph $)$

CustoTon[17] $=1000[\mathrm{dim}]^{*}$ CustoMolar[17]/MM H2O\#

"!Custo dos fluxos de entrada da planta"

Produto\$[9]='Gás Natural (pto 1)'

CustoExergetico[9]=CEx[3]

CustoTot[9]=CEx[3] $]^{*}$ _tot[1] $]^{*}$ _tot $[1]^{*}$ Tsph

CustoMolar[9]=CustoTot[9]/(n_tot[1] $]^{*}$ Tsph)

CustoTon[9]=1000[dim] ${ }^{*}$ CustoMolar[9]/MM_GN\#

Produto\$[10]='Água de caldeira (pto 60)'

CustoExergetico[10]=CEx[14]

CustoTot[10]=CEx[14] ${ }^{\star} B \_$tot $[60]^{*} n \_$tot $[60]^{*} T$ sph

CustoMolar[10]=CustoTot[10]/(n tot[60 $]^{\star}$ Tsph)

CustoTon[10] $=1000[\mathrm{dim}]^{*}$ CustoMolar[10]/MM_H2O\#

Produto\$[11]='Gás combustível (pto 43)'

CustoExergetico[11]=CEx[3]

CustoTot[11] $=$ CEx[3] $]^{*} B$ tot[43] $]^{*} n$ tot[ $[43]^{*} T$ sph

CustoMolar[11]=CustoTot[11]/(n_tot[43] $]^{\star}$ Tsph)

CustoTon[11]=1000[dim] ${ }^{*}$ CustoMolar[11]/MM GN\#

Produto\$[12]='Água de resfriamento (pto 19)'

CustoExergetico[12]=CEx[19]

CustoTot[12]=CEx[19] ${ }^{*} B$ _tot[19] ${ }^{*}$ _tot[19] ${ }^{*}$ Tsph

CustoMolar[12]=CustoTot[12]/(n tot[19] ${ }^{\star} T$ sph $)$

CustoTon[12]=1000[dim] ${ }^{*}$ CustoMolar[12]/MM_H2O\#

Produto\$[13]='Hidrogênio de reciclo (pto 6)'

CustoExergetico[13]=CEx[21]

CustoTot[13]=CEx[21] $]^{*}$ B tot $[6]^{*} n \_$tot[6] $]^{*}$ Tsph

CustoMolar[13]=CustoTot[13]/(n_tot[6] $]^{*}$ Tsph)

CustoTon[13]=1000[dim] ${ }^{*}$ CustoMolar[13]/MM_H2\#

Produto $\$[14]=$ 'Custo de amortização total por hora'

CustoExergetico[14] $=0$

CustoTot[14] $=(Z \quad F R+Z \quad V 01+Z \quad P 01+Z R 01 H+Z \quad R 01 A+Z \quad R 01 B+Z \quad P 03+Z \quad R 02+Z \quad P 04+Z \quad V A L V 2+Z \quad P 05+Z \quad P 06+Z \quad P 07+Z$

V05+Z_VALV1+Z_P08+Z_T01+Z_PSA $+Z$ _ $03+Z$ _ V04)/hpyr

CustoMolar[14]=0

CustoTon[14] $=0$

Produto\$[15]='Custo de energia elétrica total por hora'

CustoExergetico[15]=CEx[1]

CustoTot[15]=(W_fan+W_P06+W_Compr $)^{\star}$ Tsph $^{*}$ CustoEletricidade

CustoMolar[15] $=0$

CustoTon[15]=0 